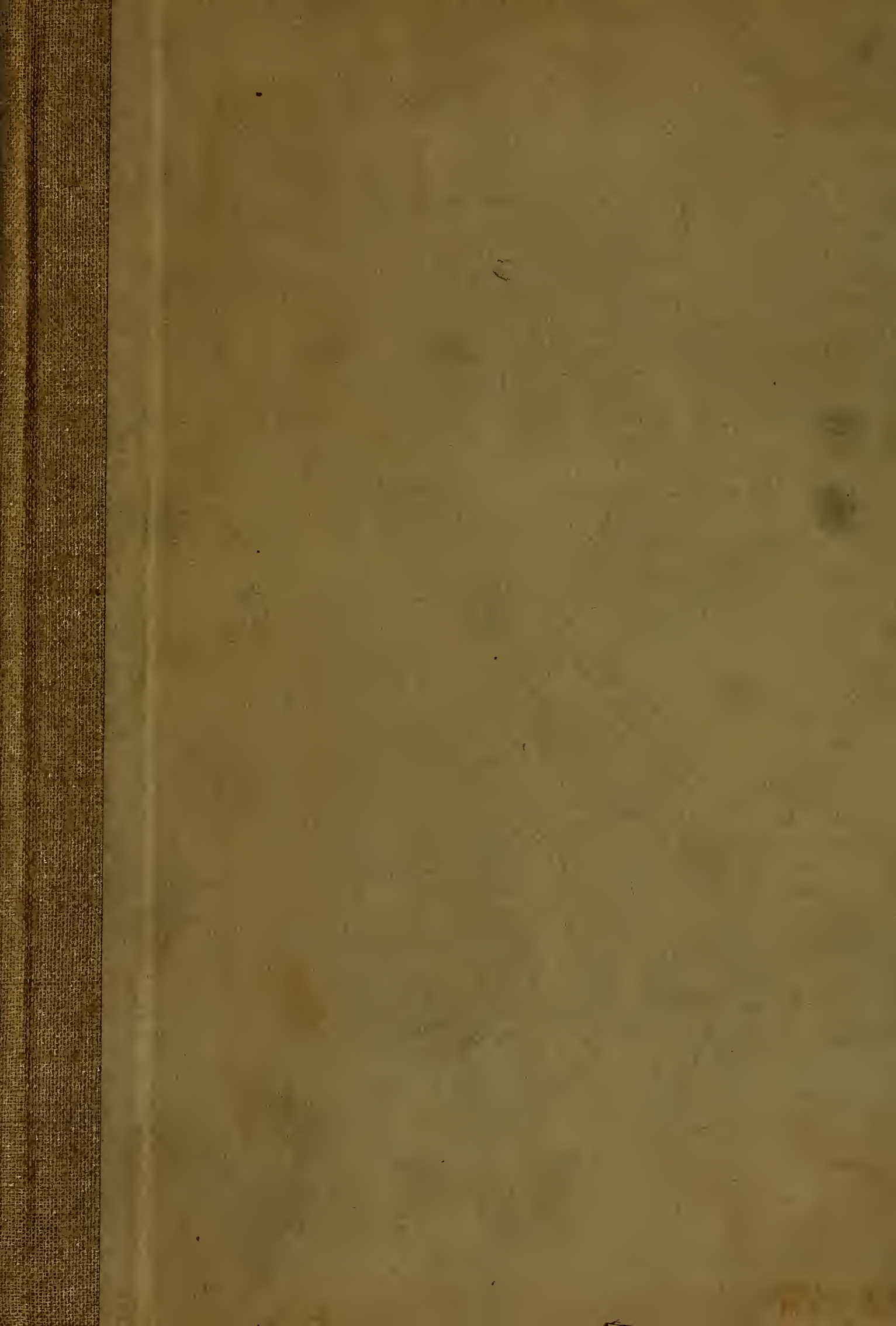




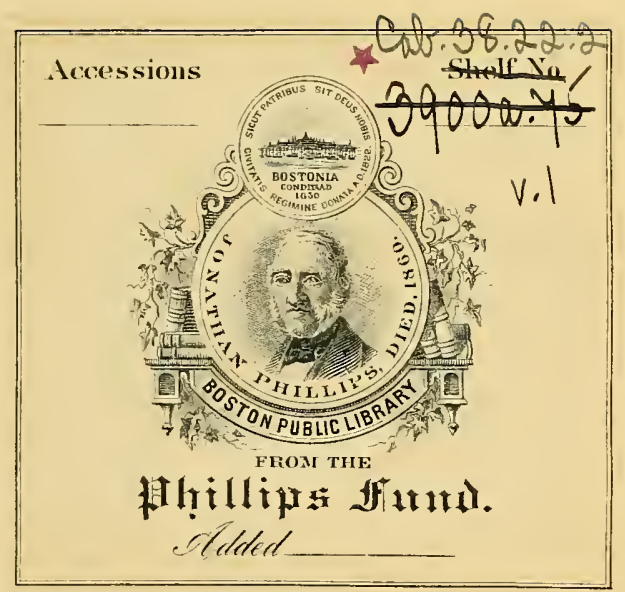





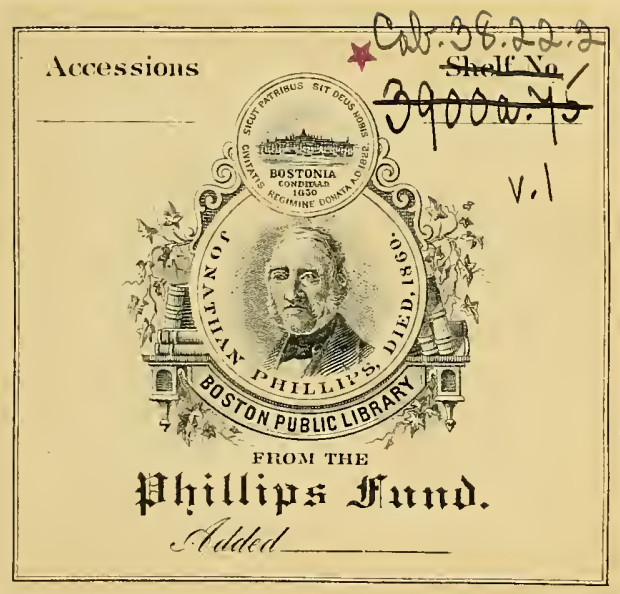



Digitized by the Internet Archive in 2011 with funding from

Boston Public Library

http://www.archive.org/details/naturalhistoryof01phil 


\section{A NATURAL HISTORY OF THE DUCKS}

IN FOUR VOLUMES

VOLUME I 
. 



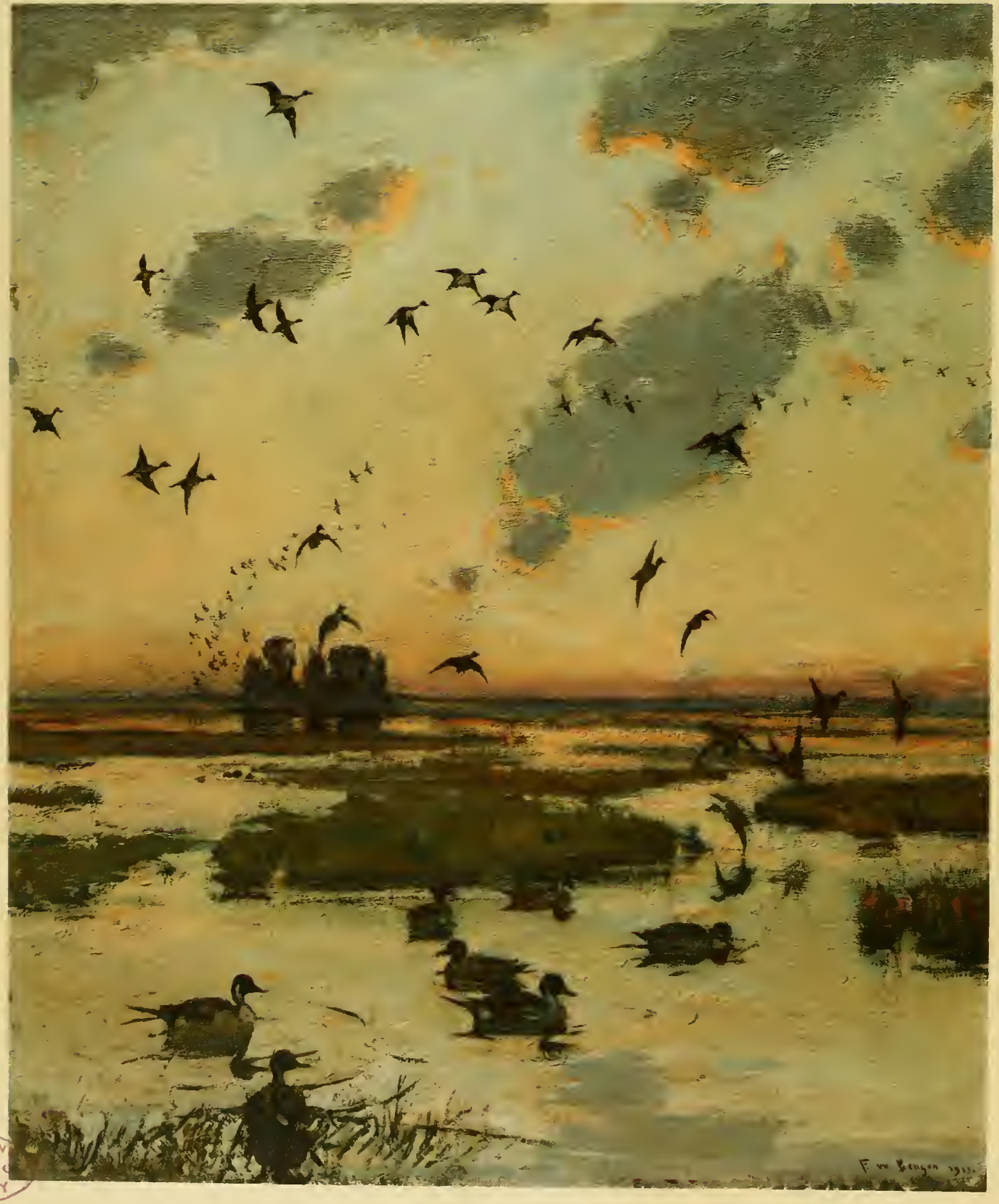






\title{
A NATURAL HISTORY OF THE DUCKS
}

\author{
BY \\ JOHN C. PHILLIPS \\ ASSOCIATE CURATOR OF BIRDS IN THE MUSEUM \\ OF COMPARATIVE ZOÖLOGY AT HARVARD COLLEGE
}

WITH PLATES IN COLOR AND IN BLACK AND WHITE FROM DRAWINGS BY

FRANK W. BENSON, ALLAN BROOKS

AND

LOUIS AGASSIZ FUERTES

VOLUME I

PLECTROPTERINEE, DENDROCYGNINE, ANATINE (IN PART)
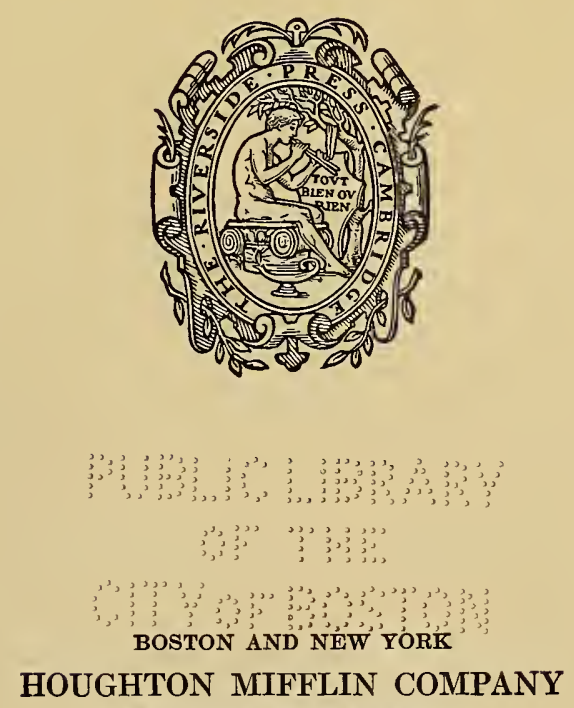

Ube Rimerøiðe press Cambriðge

1922 


\section{COPYRIGHT, I922, BY JOHN C. PHILIIPS}

ALI RIGHTS RESERVED

$$
+\operatorname{tat}, 3 i+152
$$




\section{ACKNOWLEDGMENT}

To Mr. William L. Langer, whose knowledge of languages and bibliography has been indispensable, I owe a lasting debt for many summers of faithful work. Major Allan Brooks and Louis Agassiz Fuertes have given much time and thought to their drawings and have helped me with their general knowledge of the Duck Tribe. Dr. Glover M. Allen has devoted valuable time to checking references, and his advice has served to smooth out many wrinkles. To Frank W. Benson, who has done so much in teaching us the decorative value of water-fowl, I owe the frontispiece of this first volume. Lastly I must say a word for the patient and painstaking manner in which many naturalists and sportsmen have answered hundreds of long and tedious letters.

John C. Phillips

Wenham, Massachusetts

November, 1922 
COPYRIGHT, 1922, BY JOHN C. PHILLIPS

ALL RIGHTS RESERVED

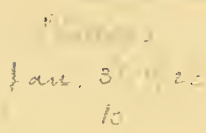




\section{ACKNOWLEDGMENT}

To Mr. William L. Langer, whose knowledge of languages and bibliography has been indispensable, I owe a lasting debt for many summers of faithful work. Major Allan Brooks and Louis Agassiz Fuertes have given much time and thought to their drawings and have helped me with their general knowledge of the Duck Tribe. Dr. Glover M. Allen has devoted valuable time to checking references, and his advice has served to smooth out many wrinkles. To Frank W. Benson, who has done so much in teaching us the decorative value of water-fowl, I owe the frontispiece of this first volume. Lastly I must say a word for the patient and painstaking manner in which many naturalists and sportsmen have answered hundreds of long and tedious letters.

John C. Phillips

Wenham, Massachusetts

November, 1922 



\section{CONTENTS}

WILD-FOWL, By PAI TA-SHUN 2

INTRODUCTION 3

ORDER CHENOMORPHÆ, SUBORDER ANSERES, FAMILY ANATIDE 41

SUBFAMIIY PLECTROPTERINE

Spur-winged Goose, Plectropterus gambensis (Brisson) 49

Black Spur-Winged Goose, Plectropterus gambensis niger Sclater $\quad 56$

Muscovx Duck, Cairina moschata (Linné) $\quad 57$

Comb or KNoв-BILled DucK, Sarcidiornis melanota (Pennant) 68

South American Comb Dбck, Sarcidiornis carunculata (Lichtenstein) $\quad 77$

White-winged Wood DбCK, Asarcornis scutulata (S. Müller) 80

Hartlaub's Teal, Pteronetta hartlaubi (Cassin) 85

PinK-headed DரcK, Rhodonessa caryophyllacea (Latham) 90

African Pygmy Goose, Nettapus auritus (Boddaert) 94

Green Prgmy Goose, Nettapus pulchellus (Gould) 98

Indian Pygmy Goose or Cotton Teat, Nettapus coromandelianus (Gmelin) 102

SUBFAMILY DENDROCYGNINE 113

White-Faced Tree Duck, Dendrocygna viduata (Linné) 117

Fulvous Tree Duck, Dendrocygna bicolor (Vieillot) 128

Wandering Tree Duck, Dendrocygna arcuata (Horsfield) 140

Lesser Whistling Teal, Dendrocygna javanica (Horsfield) 148

Black-bellied Tree Duck, Dendrocygna autumnalis (Linné) 157

Gray-Breasted Tree Duck, Dendrocygna discolor Sclater and Salvin 163

Black-Billed Tree DUCK, Dendrocygna arborea (Linné) 168

Spotted Tree Deck, Dendrocygna guttulata Wallace 174

Eyton's Tree Duck, Dendrocygna eytoni (Eyton) 177 
SUBFAMILY ANATINE 183

Egyptian Goose, Alopochen agyptiacus (Brisson) $\quad 187$

Orinoco Goose, Alopochen jubatus (Spix) 200

Common SHeldrake, Tadorna tadorna (Linné) 204

RADJAH Sheldrake, Tadorna radjah (Garnot) 224

Tadorna radjah rufitergum Hartert $\quad 227$

Crested Sheldrake, Pseudotadorna cristata Kuroda 228

Ruddy Sheldrake, Casarca ferruginea (Pallas) 230

South African Sheldrake, Casarca cana (Gmelin) 247

New Zealand or Paradise Sheldrake, Casarca variegata (Gmelin) 250

Australlan Sheldrake, Casarca tadornoides (Jardine and Selby) $\quad 259$ 


\section{LIST OF PLATES}

Plate 1. The Duck Marsh

Frontispiece

By Frank W. Benson

Plate 2. SpUR-Winged Goose, Plectropterus gambensis (Brisson). Adult male By Louis Agassiz Fuertes facing page 50

Plate 3. Muscovr Dock, Cairina moschata (Linné). Adult male and female

By Louis Agassiz Fuertes facing page 58

Plate 4. Coмb or KNob-BILled Duck, Sarcidiornis melanota (Pennant). Adult male and female facing page 68

By Louis Agassiz Fuertes

Plate 5. South American Coмв Duck, Sarcidiornis carunculata (Lichtenstein) Adult male and female By Louis Agassiz Fuertes facing page 78

Plate 6. White-WINGed Wood DucK, Asarcornis scutulata (S. Müller). Adult male and female By Louis Agassiz Fuertes

Plate 7. Hartlaub's Teal, Pteronetta hartlaubi (Cassin). Adult male, female, and downy young By Louis Agassiz Fuertes facing page 86

Plate 8. Pink-Headed Duck, Rhodonessa caryophyllacea (Latham). Adult male and female By Louis Agassiz Fuertes

Plate 9. African Pygmy Goose, Nettapus auritus (Boddaert). Adult male and female By Louis Agassiz Fuertes

Plate 10. Green Pygmy Goose, Nettapus pulchellus (Gould). Adult male Indian Pygmy Goose oR Cotton Teal, Nettapus coromandelianus (Gmelin) Adult male and female By Louis Agassiz Fuertes

Plate 11. White-Faced Tree Duck, Dendrocygna viduata (Linné). Adult Black-Bellied Tree Duck, Dendrocygna autumnalis (Linné). Adult Gray-breasted Tree Duck, Dendrocygna discolor Sclater and Salvin Adult

By Louis Agassiz Fuertes

Plate 12. Fulvous Tree Duck, Dendrocygna bicolor (Vieillot). Aduit

Lesser Whistling Teal, Dendrocygna javanica (Horsfield) Adult Wandering Tree Duck, Dendrocygna arcuata (Horsfield) Adult

By Louis Agassiz Fuertes 
Plate 13. Downy Young of Tree Ducks

Black-Beldied Tree Duck, Dendrocygna autumnalis (Linné)

Fulvous Tree Duck, Dendrocygna bicolor (Vieillot)

Lesser Whistling Teal, Dendrocygna javanica (Horsfield) facing page 148 By Allan Brooks

Plate 14. Spotted Tree Duck, Dendrocygna guttulata Wallace. Adult

Eyton's Tree Duck, Dendrocygna eytoni (Eyton). Adult

Black-Billed Tree Duck, Dendrocygna arborea (Linné). Adult By Louis Agassiz Fuertes

Plate 15. Egyptian Goose, Alopochen agyptiacus (Brisson). Adult

Orinoco Goose, Alopochen jubatus (Spix). Adult

facing page 188

By Louis Agassiz Fuertes

Plate 16. Common Sheldrake, Tadorna tadorna (Linné). Adult male and female

RAdJAh Sheldrake, Tadorna radjah (Garnot). Adult male facing page 204 By Louis Agassiz Fuertes

Plate 17. Ruddy Sheldrake, Casarca ferruginea (Pallas). Adult male and female South African Sheldrake, Casarca cana (Gmelin). Adult male and female

facing page 230

By Louis Agassiz Fuertes

Plate 18. New Zealand or Paradise Sheldrake, Casarca variegata (Gmelin) Adult male and female

Australian Sheldrake, Casarca tadornoides (Jardine and Selby). Adult male and female

By Louis Agassiz Fuertes 


\section{LIST OF MAPS}

MaP 1. Distribution of Spur-winged Goose (Plectropterus gambensis) facing page 52

MAP 2. Distribution of Muscovy Duck (Cairina moschata) facing page 60

MAP 3. Distribution of Comb Duck (Sarcidiornis melanota) facing page 70

Map 4. Distribution of South American Comb Duck (Sarcidiornis carunculata) facing page 79

MAP 5. Distribution of White-winged Wood Duck (Asarcornis scutulata) facing page 82

MAP 6. Distribution of Hartlaub's Teal (Pteronetta hartlaubi) facing page 88

MaP 7. Distribution of Pink-headed Duck (Rhodonessa caryophyllacea) facing page 92

MAP 8. Distribution of African Pygmy Goose (Nettapus auritus) $\quad$ facing page 96

MaP 9. Distribution of Green Pygmy Goose (Nettapus pulchellus) facing page 98

MaP 10. Distribution of Indian Pygmy Goose (Nettapus coromandelianus) facing page 104

MAP 11. Distribution of White-faced Tree Duck (Dendrocygna viduata) facing page 120

MAP 12. Distribution of Fulvous Tree Duck (Dendrocygna bicolor) facing page 132

MAP 13. Distribution of Wandering Tree Duck (Dendrocygna arcuata) facing page 142

MaP 14. Distribution of Lesser Whistling Teal (Dendrocygna javanica) facing page $\mathbf{1 5 0}$

MAP 15. Distribution of Black-bellied Tree Duck (Dendrocygna autumnalis)

facing page 158

MaP 16. Distribution of Gray-breasted Tree Duck (Dendrocygna discolor)

MAP 17. Distribution of Black-billed Tree Duck (Dendrocygna arborea)

facing page 164

Map 18. Distribution of Spotted Tree Duck (Dendrocygna guttulata)

facing page $\mathbf{1 7 0}$

MaP 19. Distribution of Eyton's Tree Duck (Dendrocygna eytoni)

facing page 174

MAP 20. Distribution of Egyptian Goose (Alopochen rgyptiacus)

facing page 178

MAP 21. Distribution of Orinoco Goose (Alopochen jubatus)

MAP 22. Distribution of Common Sheldrake (Tadorna tadorna)

facing page 190

MAP 23. Distribution of Radjah Sheldrake (Tadorna radjah)

facing page 200

facing page 208

MAP 24. Distribution of Ruddy Sheldrake (Casarca ferruginea)

facing page 224

Map 25. Distribution of South African Sheldrake (Casarca cana)

facing page 234

MAP 26. Distribution of New Zealand Sheldrake (Casarca variegata)

facing page 248

MaP 27. Distribution of Australian Sheldrake (Casarca tadornoides)

facing page 252

facing page 260 
Plate 13. Downy Young of Tree Ducks

Black-Bellied Tree Duck, Dendrocygna autumnalis (Linné)

Fulvous Tree Duck, Dendrocygna bicolor (Vieillot)

Lesser Whistling Teat, Dendrocygna javanica (Horsfield) facing page 148 By Allan Brooks

Plate 14. Spotted Tree Duck, Dendrocygna guttulata Wallace. Adult

Eyton's Tree Duck, Dendrocygna eytoni (Eyton). Adult

Black-BILled Tree Duck, Dendrocygna arborea (Linné). Adult

By Louis Agassiz Fuertes

facing page 168

Plate 15. Egrptian Goose, Alopochen agyptiacus (Brisson). Adult

Orinoco Goose, Alopochen jubatus (Spix). Adult

By Louis Agassiz Fuertes

facing page 188

Plate 16. Common Sheldrake, Tadorna tadorna (Linné). Adult male and female Radjah Sheldrake, Tadorna radjah (Garnot). Adult male facing page 204 By Louis Agassiz Fuertes

Plate 17. Ruddy Sheldrake, Casarca ferruginea (Pallas). Adult male and female South African Sheldrake, Casarca cana (Gmelin). Adult male and female

By Louis Agassiz Fuertes

facing page 230

Plate 18. New Zealand or Paradise Sheldrake, Casarca variegata (Gmelin) Adult male and female

Australian Sheldrake, Casarca tadornoides (Jardine and Selby). Adult male and female

By Louis Agassiz Fuertes

facing page 250 


\section{LIST OF MAPS}

MaP 1. Distribution of Spur-winged Goose (Plectropterus gambensis) facing page 52

MaP 2. Distribution of Muscovy Duck (Cairina moschata) facing page 60

MAP 3. Distribution of Comb Duck (Sarcidiornis melanota) facing page $\mathbf{7 0}$

MaP 4. Distribution of South American Comb Duck (Sarcidiornis carunculata)

facing page 79

MaP 5. Distribution of White-winged Wood Duck (Asarcornis scutulata) facing page 82

MaP 6. Distribution of Hartlaub's Teal (Pteronetta hartlaubi) facing page 88

MaP 7. Distribution of Pink-headed Duck (Rhodonessa caryophyllacea) facing page 92

MaP 8. Distribution of African Pygmy Goose (Nettapus auritus) $\quad$ facing page 96

MaP 9. Distribution of Green Pygmy Goose (Nettapus pulchellus) facing page 98

Map 10. Distribution of Indian Pygmy Goose (Nettapus coromandelianus) facing page 104

Map 11. Distribution of White-faced Tree Duck (Dendrocygna viduata) facing page 120

Map 12. Distribution of Fulvous Tree Duck (Dendrocygna bicolor) facing page 132

MaP 13. Distribution of Wandering Tree Duck (Dendrocygna arcuata) facing page 142

Map 14. Distribution of Lesser Whistling Teal (Dendrocygna javanica) facing page 150

MAP 15. Distribution of Black-bellied Tree Duck (Dendrocygna autumnalis)

facing page 158

MaP 16. Distribution of Gray-breasted Tree Duck (Dendrocygna discolor)

facing page 164

MAP 17. Distribution of Black-billed Tree Duck (Dendrocygna arborea) facing page 170

Map 18. Distribution of Spotted Tree Duck (Dendrocygna guttulata) facing page 174

MaP 19. Distribution of Eyton's Tree Duck (Dendrocygna eytoni) facing page 178

MaP 20. Distribution of Egyptian Goose (Alopochen agyptiacus) $\quad$ facing page 190

MaP 21. Distribution of Orinoco Goose (Alopochen jubatus) facing page 200

MAP 22. Distribution of Common Sheldrake (Tadorna tadorna) facing page 208

MAP 23. Distribution of Radjah Sheldrake (Tadorna radjah) facing page 224

MAP 24. Distribution of Ruddy Sheldrake (Casarca ferruginea) facing page 234

Map 25. Distribution of South African Sheldrake (Casarca cana) facing page 248

MaP 26. Distribution of New Zealand Sheldrake (Casarca variegata) facing page 252

MaP 27. Distribution of Australian Sheldrake (Casarca tadornoides) facing page 260 




\section{WILD-FOWL}

How oft against the sunset sky or moon

I watched that moving zig-zag of spread wings

In unforgotten autumns gone too soon,

In unforgotten springs!

Creatures of desolation! Far they fly

Above all lands bound by the curling foam.

In misty fens, wild moors, and trackless sky

These wild things have their home.

They know the tundra of Siberian coasts

And tropic marshes by the Indian seas.

They know the clouds and nights, and starry hosts

From Crux to Pleiades.

Dark flying rune against the western glow,

It tells the sweep and loneliness of things,

Symbol of autumns vanished long ago,

Symbol of coming springs. 


\section{INTRODUCTION}

SiNCE the dawn of history wild-fowl have occupied the attention of man. The Egyptians well knew their value as an article of diet, and one can still see many different kinds faithfully reproduced on the bas-reliefs of the earlier dynasties, together with the nets and boats used in catching them. At least one species they held sacred; but domestication of ducks does not appear to have been perfected until the Roman times.

Long before the Egyptians, we can imagine that the great hosts of water-fowl which peopled the earth must have been not only a source of nourishment, but an inspiration to primitive man. Indeed, in southern Spain neolithic cave drawings of swans, geese, and ducks have been discovered which must be six thousand or eight thousand years old. We can picture the Eskimos on ice-bound coasts casting longing glances to the south as the sun rose higher and open water began to form in the snowcovered bays. And we know how our own Amerinds hunted ducks and geese with bow and arrow and with primitive traps. Eggs, especially of the sea ducks, were highly valued then, just as they are now, while the skins and down supplied warm clothing, and numerous ornaments as well. Even in Central Asia Prjewalsky found the degraded inhabitants of the Lob-Nor depending largely on ducks for their foodsupply. So important were wild ducks to these people that they appeared as a regular part of the purchase money supplied to the parents of a bride.

It is not difficult to understand that creatures which come and go almost with the regularity of the sun and moon must have impressed themselves strongly upon the mind of primitive man, especially in Northern regions. Even as the migrating quail are supposed to have saved the Israelites from starvation in the wilderness, so wildfowl must have tided over periods of distress in the life of our ancestors.

In our own times civilized peoples have learned more and more to appreciate the ducks, geese, and swans. Many beautiful poems have been inspired by pictures of sharp-winged squadrons seen against crisp autumn skies, and few and slothful indeed are those individuals whose pulses do not quicken and whose eyes do not brighten as our great gray geese plough through the depths of space, seeming to make the dome of the sky ever higher and more mysterious.

Lovers of the smaller water-fowl are found in increasing numbers, and when the means are at hand, this love is expressed in ornamental pools stocked with scores of the most beautiful varieties, or zoological gardens containing rare species, from dainty Teal to huge and vicious Spur-wings. There are no more beautiful birds in the world than Mandarins and Carolina Ducks, especially if they can be maintained in a free-flying state, and no others are so well suited to the requirements of the amateur enthusiast. 
Many epicures consider the flesh of prime wild ducks superior to that of all other game, and ducks are still sold literally by the carload in most of the large markets of the world. European and English markets had even begun to draw upon Russia and China before the war. Fortunately we in America have stopped the trade in ducks, and hope to preserve for future generations at least a taste of the thrilling sport we have enjoyed, and an occasional dish of the delicate birds as well. Upon the lordly Canvas-back of the Chesapeake, which made old Frank Forester's mouth fairly run with water, whole volumes of praise have been lavished. But of our American Widgeon and Ruddy Ducks almost as much might be written.

\section{RELATIONSHIP}

Although the present work is not especially concerned with classification, it is fitting that the relationships of the order be briefly sketched. First of all we want to know how to diagnose the Anseres (lamellirostral swimmers), and where to place them among other birds. Second, we naturally ask about the records of fossil ducks and geese in geological time. Third, we ought to know something about the great groups, or subfamilies into which these toothed-billed swimming birds are divided, and what their characteristics are; the lesser groups, or genera, may well be left to the text of the book. And, fourth, one ought with considerable trepidation to venture an opinion as to which group or family seems to be the most primitive, and which the most specialized. Finally, something should be said explaining the reasons for arranging the ducks in the order in which they will appear; although it must be recognized that any arrangement is purely arbitrary, and tells very little of the actual relationship.

The Anseres form a large and rather diverse order including the swans, geese, and ducks. They have the bill moderately long or short, covered with soft skin, and on the front or anterior end a nail-like, horny plate, which sometimes curves over the end of the bill like a hook. The bill is usually flattened and the edges are supplied with horny teeth, or lamella. The tarsus is short, usually shorter than the middle toe, and the front toes are webbed. The wings may be short, or moderately long, and the young are precocial. The most important external characteristics are the short legs, webbed feet, and laminated bill.

Anatomically this order agrees with the storks in having the bridge or band form of palate (desmognathous), but differs from them in having basipterygoid processes, two pairs of a certain muscle attached to the windpipe (tracheosternal); and welldeveloped, functional caca.

A group of birds called the screamers (Palamedece) from South America is often included as a suborder coördinate with the swans, geese, and ducks. These birds are structurally very gooselike, although they do not look so. They are wading birds, about the size of a small turkey, with a short decurved bill, and enormous feet with- 
out webs to the toes. They should probably be elevated to the rank of an order by themselves.

The flamingoes, or Phønicopteri, are intermediate between anserine birds on the one hand and the storks and herons on the other. Sometimes they appear as a suborder next to the swans, geese, and ducks, but according to the American Ornithologists' Union's classification they are placed in a special order of their own.

Speaking very generally, therefore, more or less successful investigations connect the duck tribe with the flamingoes, through the geese, and so rather definitely with the storks and herons. Through the screamers our group may be distantly connected with the rails and cranes.

On the other end of our series of anserine birds, where as a rule the Mergansers and Torrent Ducks are placed, we have to admit the presence of a gap extremely difficult to bridge. In fact some authorities do not attempt to bridge this gap at all, but start afresh with the birds of prey, the pigeons, or the tinamus. However, there is some evidence that through the mergansers, especially the Smew, the duck tribe is connected with the diving birds: cormorants, loons, and grebes. Forbes associated the ducks with the grebes and the divers, while Eimer and Fickert, basing their conclusions upon the phylogeny of color and color-pattern, connect the Smew with the loons, and the Torrent Ducks with the grebes; but these findings may simply mean parallel development without close relationship.

Gadow regarded the ducks and their allies as the rather slightly modified descendants of the same group of which the penguins, the pelicans, the divers, and the grebes are highly specialized forms.

Huxley, working from the arrangement of the palatal bones, placed this order at the head of his desmognathous, or bridged-palate series, followed by the flamingoes, the herons and their allies, and the pelicans and their allies. The rest of the desmognathous birds, including the birds of prey, the owls, the parrots, and most of the picarian birds (puff-birds, barbets, toucans, and woodpeckers), appear to belong to a different series.

Mitchell has studied our group carefully from the standpoint of the intestinal tract, and thinks that the gooselike birds should be separated from the screamers. He finds the Smew very peculiar and different from all other geese and ducks.

Fürbringer, Newton, Shufeldt, Beddard, Sclater, and Stejneger have all contributed to our knowledge of this subject.

A few years ago a distinguished palæontologist was quoted as saying that from the tertiary deposits some fifteen thousand mammals and six thousand reptiles have been described, but only fifteen birds! Bird bones are more easily destroyed by time, and the creatures themselves are far less likely to meet their end in caves, quicksands, and other such places, where so many mammals, fortunately for us, have been preserved. Altogether, we have every reason to believe that many intermediate 
forms which combined the characters of the goose and duck tribe, the flamingoes, the pelicans, cormorants, and their allies, the storks and herons, and the hawks, once existed. The extinction of these primitive forms leaves us very much in the dark as to their inter-relationships, but a few points have been brought out by the discovery of fossils.

In the Pleistocene and Recent deposits in Oregon are found many species which still exist, besides a huge extinct goose, Anser condoni, and a gigantic swan. Fossil swans have also been found in other parts of the world. The Pleistocene of New Zealand has yielded a huge flightless, gooselike bird, Cnemiornis calcitrans, which has several characters in common with the present-day Cape Barren Goose, and has been placed in the same subfamily. It seems to have been exterminated quite recently, perhaps at the same time as the Moa.

Fossil geese belonging to the existing genus Anser have been found in the upper Miocene and Pliocene strata in various parts of Europe. Chenornis, in the midMiocene, is a fossil duck which is said to have affinities with other groups, possibly the petrel, pelican, and tropic-bird families. There are many other fossil ducks of existing or allied genera from Europe and the United States in Miocene and Pleistocene, but curiously enough no fossil mergansers have been brought to light, which may point to a recent origin for these fish-eaters.

An entirely distinct family of anserine birds, the Gastornithido, have been discovered in the Eocene of France and England. Gastornis, one of the genera in this family, was a huge gooselike fowl as large as an ostrich, and even considered by some as allied to the ostriches. One very peculiar thing about these huge birds was that the sutures of the skull did not close with age, but remained open throughout life.

In other strata there are fossils which show some affinity to anserine birds, but the relationship is very vague.

Considering the Anseres as a suborder, containing one family, Anatida, the swans, geese, and ducks, we must now ask how we are to divide them further, not only for our own convenience, but in order to show as much as possible the closer relationships. Almost any child can tell a swan, and few mistakes are possible either with the true geese or the true ducks, but we have to consider subfamilies and genera which merge into one another so gradually that a hard-and-fast line between geese and ducks is impossible to draw. The skeletal characters are by no means as marked as one would suppose, and so great an authority as Shufeldt has shown that the skull of the Whistling Swan, apart from size, has no characters to distinguish it from that of the Canada Goose. Indeed this goose is so much like a Mallard in the skull form that osteologically no fixed line can be drawn. We have to take into account the number of vertebræ, the general appearance and proportions, and even the habits.

The first subfamily of the Anatidce comprises the swans, or Cygnina, easily dis- 
tinguished by their long necks, which actually have more vertebræ than the necks of geese, and by other characters of less importance. Some swans show most remarkable convolutions of the trachea. The Semipalmated Goose, Anseranas semipalmata, is usually placed next to the swans in a subfamily of its own (Anseranatina).

The third subfamily consists of the Spur-wings, Plectropterino, a very heterogeneous group, which is usually placed next to the swans. Its members are included in this work because it contains various species, such as the Muscovy, the Comb Ducks and the Groose Teal (Nettapus), which ordinarily come under the category of ducks. The constitution of this group is open to much speculation. There is no doubt that some of its genera, as arranged by Salvadori, should be removed and placed nearer the true ducks. I have considered it as composed of the same genera as Salvadori in his Catalogue of Birds, except that I have taken out the Mandarin and Carolina Ducks and placed them at the end of the true ducks, as they now appear in the Check-List of the American Ornithologists' Union.

The Spur-wing subfamily are birds with rather long tails, the feathers of which are broad and rounded at the tips. The upper parts are mostly glossy and the hind toe is long. These ducks inhabit the tropics of both the Old and the New Worlds and have arboreal habits.

The subfamily Cereopsince, represented by only one living species, the Cape Barren Goose of Australia, also includes the great extinct New Zealand Goose, Cnemiornis calcitrans, mentioned above.

We may place the true geese, Anserino, next in order, and among them should perhaps be included the Swan Goose (Coscoroba), although its exact position is still doubtful, and it may be nothing more than a huge duck related to the Sheldrakes, and possibly to the Tree Ducks. These Anserina differ from the swans in having the neck always shorter than the body, and in having the front of the tarsus covered with small hexagonal, instead of narrow, scales. They differ from the last subfamily by the absence of a cere.

The Chenonettince are another subfamily typified by the brant geese of the pampas of South America. This subfamily has not been considered among the ducks and is probably nearer to the Brant than to the true ducks. It has received various positions in schemes of classification.

The Tree Ducks, Dendrocygnina, are often placed among the true ducks, but I believe they well deserve to rank as a subfamily by themselves, a position which Shufeldt assigned to them in his anatomy of the group. They are defined by that authority as arboricole ducks, with very long legs, the tibio-tarsi more or less denuded, the middle toe considerably more than one third the length of the tarsus, and the thecæ of the leg and tarso-metatarsus reticulated. The orbits of the cranium are completely surrounded by bone, and there are but seventeen cervical vertebræ. Morphologically they are nearer to the ducks than to the swans and geese, and they 
form a very compact and sharply differentiated group which has been included in this work.

We now come to the ducks themselves, the Anatina, about which there can be little confusion. They are headed by the Sheldrakes of the Old World, birds which show very distinct gooselike characteristics, especially in their habits; and it is possible that at some future time they may be relegated to a subfamily by themselves. The true surface-feeding, or river ducks, of the genus Anas, are the more typical members of the Anatince.

The diving, bay, or sea ducks, subfamily Fuligulina, typified by the Pochards and Scaups, form a more or less natural group, whose members are distinguished not only by different habits and a less elegant form, but by having the hind toe broadly lobed or webbed. The legs are placed somewhat farther back, and the gait is waddling. The curious Black-headed Duck (Heteronetta) of South America forms a connecting link between the surface-feeding and the diving ducks.

The spiny-tailed ducks, subfamily Erismaturina, include the Ruddy Duck group, and the Musk Duck of Australia. These stiff-tailed diving ducks are characterized not only by their cormorant-like tails, but by their thick-appearing necks, which in the male sex contain curious tracheal air-sacs.

The Torrent, or Mountain Ducks, Merganettince, are very peculiar, grebelike divers, mostly confined to high Andean streams, having long stiff tails, and a bill like that of a Merganser, but lacking the serrations.

The Mergince, the last subfamily of the swan, goose, and duck tribe, contains the familiar fish-eating ducks (Mergansers) with their characteristic toothed bills, slender bodies, and fish-eating habits.

The classification of the great suborder Anseres or lamellirostral swimmers may be summed up in the following scheme, which conforms very closely to the one suggested by Shufeldt in 1914.

\begin{tabular}{|c|c|c|}
\hline \multirow[t]{6}{*}{ Suborder } & Families & Subfamilies \\
\hline & & 1. Cygnince - Swans \\
\hline & & 2. Anseranatina - Semipalmated goose \\
\hline & & 3. Plectropterince - Spur-wing family \\
\hline & & 4. Cereopsince - Cape Barren Goose \\
\hline & & 5. Anserince - True geese \\
\hline \multirow{7}{*}{$\begin{array}{l}\text { Anseres } \\
\text { (Lamellirostres) }\end{array}$} & Anatido. & 6. Chenonettince - Australian Maned Goose \\
\hline & & 7. Dendrocygnina - Tree Ducks \\
\hline & & 8. Anatina - Fresh-water, or river, ducks \\
\hline & & 9. Fuligulin $x-$ Diving ducks \\
\hline & & 10. Erismaturina - Spiny-tailed ducks \\
\hline & & 11. Merganettina - Torrent, or Mountain, Ducks \\
\hline & $\begin{array}{l}\text { Gastornithidae } \\
\text { (extinct) }\end{array}$ & 12. Mergana - Mergansers, or sawbils \\
\hline
\end{tabular}


We have seen how meager are the findings in geological strata, and it follows that any opinion as to the relative age of the different groups of Anseres becomes little more than a guess. The evidence points to a greater geological age for the geese and swans than for the ducks; but all we can say is that geese and swans earlier than the Miocene and Pleistocene ages were different from the geese of to-day. The Tree Ducks may represent, and indeed they suggest, older and less specialized forms, as do the Spur-wings, but there is really no evidence upon which to base such a statement. We can say, however, that the true surface-feeding ducks have not been found except in very recent geological strata, while it is quite remarkable that no fossil Merganser, save those belonging to present species, has been brought to light. The Mergansers and possibly the Torrent Ducks may be thought of as more recently specialized than the swans and geese.

Any linear scheme of arrangement is unsatisfactory, for it cannot in the least represent the phylogeny of a group. The order in which the ducks are placed is, after all, almost purely arbitrary. We begin with the Spur-wing family, which many writers will regard as not ducks at all, and work through the more or less anserine ducks to ducks of the Mallard type. The Mallard usually heads the list of surfacefeeding or river ducks, for no particular reason, except that it is a well-known species. It might be just as well to start with the Carolina and Mandarin Ducks. The river ducks do, however, form a very compact series, and most of them probably produce fertile hybrids in crosses. They may be considered in one or two genera or split into fifteen or twenty genera, according to the taste of the systematist.

The diving ducks are more diverse than the fresh-water ducks, but the two subfamilies merge into each other through certain aberrant types like Heteronetta, and anatomically there are almost no important characters to separate them.

Those groups which we consider last among the ducks and geese are placed at the end merely as a matter of convenience, and they leave a gap into which it is difficult to fit any other order of birds.

\section{SCOPE OF THE WORK}

IT has been my purpose to bring together from many scattered sources of information as complete an account of the life-histories of the various ducks and ducklike birds as could be utilized in convenient form. The true geese and the swans have not been included. I have tried always to give correct references for all statements made, and it is the intention to publish a bibliography at the end of the last volume. Where scattered notes are quoted, a complete reference is usually given in the text, but when the reference is to a larger work, the writer's last name and the date are given, which makes it necessary to consult the bibliography.

My own experiences have been used in great part to check up the observation of 
others, but I lay no claim to much original material. With certain species, however, I am very familiar, both in the wild state and in confinement.

It is almost impossible to realize the enormous amount of literature which has accumulated around this group of birds. Practically there is no end to it, for it fills the pages of hundreds of local sportsmen's journals all over the world, besides the hundreds of scientific and popular periodicals devoted to natural history. The information of any one person can, therefore, never be complete. Very often, too, extremely interesting accounts can barely be referred to for lack of space. A volume might easily be written upon each of the common palæarctic or nearctic ducks, while on the other hand there is almost no information about many sedentary and island species. Among the little-known birds may be mentioned the Guam Island Duck, Salvadori's Duck from New Guinea, and the Brazilian and Auckland Island Mergansers.

Since Volume 27 of the Catalogue of Birds in the British Museum was published (Salvadori, 1895), the number of species of ducks belonging to the five great subfamilies Plectropterino, Anatina, Fuligulino, Erismaturino, and Mergince has scarcely changed at all. Latin names have come and gone with such amazing frequency that only the specialist can attempt to follow them. Genera almost too numerous to mention have been suggested, but the tendency is now to make almost all the true surface-feeding ducks congeneric. This appears to me the wisest course, for members of the whole genus Anas, as here considered, are probably not only potentially fertile inter se, but would produce fertile hybrids, could the proper conditions be brought about. The Green-winged Teals, for instance, are just as typically surface-feeding ducks as are the larger Mallard-like ducks, both in anatomy and in habits. The Widgeons form a very obvious and sharply defined little group, and yet it would be easy enough to make a different genus out of each of the three species on anatomical characters alone (trachea, for instance). Indeed, Mr. Alexander Wetmore, who has paid particular attention to skull characters in ducks, has shown me rather wellmarked differences in the skulls of closely related species of ducks, so that when all is said and done we get back very nearly where we started from and acknowledge that present classification, no matter what it is based on, is largely a matter of convenience, and subject to varying opinion.

A large number of races (subspecies) of ducks have been described in recent years, mostly based upon size characters, and these will be considered at the end of the account of the several species. The species will first be taken up as a unit; its description, its distribution, and its habits.

\section{GENERAL DISTRIBUTION}

Ducks are found throughout the world, wherever fresh- or salt-water feeding grounds are available, but certain regions are far richer than others, both in species 
and in numbers of individuals. In a general way it may be said that those parts of the temperate and subarctic regions embracing huge tracts of poorly drained plains and steppes are the true home of the duck tribe. The great inland breeding grounds of western North America support some twenty-three species, whereas the rocky barrens that lie east of Hudson Bay support regularly only three or four. In the same way the huge wild-fowl reservoir extending from eastern Germany through Finland, Russia, and Siberia supports great hordes of water-fowl that winter as far south as the White Nile, Abyssinia, and East Africa on the west, and northern India and China on the east. The North American ducks may be said to winter from the northern States as far south as the Great Central Valley of Mexico, but the bulk of them remain along the South Atlantic and Gulf Coasts and the central valleys of California.

The tropical rain forests, all over the world, are poor in the number of duck species. The Congo and the Amazon basins are noteworthy in that respect, for they support no true surface-feeding ducks and only a few species belonging to gooselike genera that have mostly arboreal habits. Polynesia and Melanesia are likewise remarkable for the extreme poverty of their duck fauna; for throughout all the Pacific Islands we have only one true, wide-ranging species, the Australian Black Duck, while a few straggling migrants are attracted from Alaska and the Chinese mainland. On one or two oceanic islands are found isolated species, such as the Hawaiian Duck, the Laysan Teal, the Coues' Gadwall, and the Guam Island Duck.

In India and Burma are found a goodly variety of ducks, part migrants and part isolated and local species, such as the curious Pink-headed Duck and the little-known White-winged Wood Duck.

Coming now to the southern continents, we find the ducks very richly represented in southern South America, south of the rain forests, as well as in South Africa, Australia, and New Zealand. In all this Southern Hemisphere, of less rigorous winters, but with well-defined wet and dry seasons, migrations are not so marked, nor so clearly understood as in the north; the breeding season extends over a longer period, and all species tend to become dependent on local water conditions and therefore more erratic in their movements. They may even breed over their whole range, a condition very seldom seen among the northern ducks.

Southern South America supports twenty-eight species of ducks, and is noteworthy for its richness in teal. Those species which extend into the lakes of the high Andean plateau have tended to become local, to increase in size, and to form new but not very different species. In South America also we find the wholly unique semi-flightless Steamer Duck, the largest of all the ducks, while high up amid the snows on the western slopes of the Andean range, the very interesting little Merganser-like Torrent Ducks, perhaps related to the grebes, which in scattered pairs occupy the streams, and are to this day little known. 
South Africa, Australia, and New Zealand are remarkable for the magnificent sheldrakes of the genera Tadorna and Casarca, and, true to its reputation for ancient or specialized types, Australia supports the most peculiar and aberrant members of the duck tribe - the flightless duck of Auckland Island, the Musk Duck, the Blue Mountain Duck, and the Pink-eared and Freckled Ducks. South Africa, on the other hand, contains no very peculiar types.

Looking at the duck family from the standpoint of far northern ranges, we find the Eiders and their near relatives characteristic of the arctic regions the world around. The Old-squaw and the King Eider are the two species which extend the farthest north, and the whole family of Eiders are all far northern breeders, while even their winter distribution is chiefly arctic, or at least well beyond that of most other species. The holarctic Ducks and Teal of the Northern Hemisphere once bred in larger numbers over the southern part of their present ranges, but settlement and drainage has greatly affected them in both western Europe and the United States. They naturally tend, however, to breed well south of the arctic salt-water ducks, while some of them - the Spoonbills, Blue-winged Teals, Ruddy Ducks, etc. - can breed even in the south temperate or tropical regions. The true diving ducks, the Pochards and Scaups, occupy an intermediate breeding range, and are not characteristic of arctic areas.

True sea ducks, like the Scoters and Eiders, are not found in the Southern Hemisphere and range only about as far south in winter as latitude $35^{\circ}$ in North America and $42^{\circ}$ in Europe.

The typical ducks of the tropics are the Tree Ducks, which are found all around the world. Two species, the White-faced and the Fulvous, are remarkable for their distribution, which includes both Africa and South America, and in the case of the latter even India and Burma. The members of this genus are typically sedentary, but real migrations do occur at the limits of their ranges, while the coming of the rains gives rise to many local movements which are too intricate to be easily followed.

Wide-ranging Specres. Such cosmopolitan species as the Pintail, Mallard, Shoveller, and Gadwall extend around the world in the Northern Hemisphere, and vary either not at all or in a very minor degree, giving rise to races such as the Greenland Mallard and the American Pintail. Among the sea ducks, the Long-tailed (Harelda glacialis) is the most abundant, and is another good example of a holarctic bird.

Confined, or Insular, Species. The best example is the Laysan Teal, whose sole habitat is a small pond on Laysan Isle in the mid-Pacific Ocean. After the Japanese bird raids in 1909, this species was reduced to twelve or thirteen individuals. An- 
other island race, the Coues' Gadwall, is confined to two small islands of the Fanning group. Ten other species are confined to islands.

Distributions are taken up in detail under the account of each species, and maps are used to give a graphic picture of the range. These maps should be considered as giving only a general picture, for many large areas have to be included which are not favorable to water-birds for various reasons. Some of these features are deserts or mountain ranges, or regions of deep lakes with steep rocky shores.

Migration. We understand only a few facts in regard to migration. We know that certain species arrive in certain regions at certain times, but we do not know the extent of territory over which the individual passes in a given year. We know that there are summer movements, males collecting in definite areas after leaving the females, and banded birds have recently brought out the fact that there are summer dispersals, often in a northerly direction, about which we know almost nothing. We commonly think of the ducks migrating south in autumn, and this of course is true, but Allan Brooks has told me of extensive movements of male Scoters on the fourth of July, along the Pacific Coast.

Ducks banded at Bear River, Utah, have been taken all over the West, from California to the Mississippi Valley, and north to the Canadian line. There are no simple north and south migration routes, but as far as we can see an endless complexity of movement.

It is best in studying this subject to admit at the start that our picture of it is only the crudest beginning, nor do we know anything of the "sixth sense" that keeps the bird oriented, "lone wandering but not lost," as Bryant has so beautifully expressed it. The subject is complicated in so many ways that the species, the sex, and perhaps even the exact age, must be taken into account, and the direction of movement is not necessarily the same for the same species in different localities. For instance, many western-bred Canadian ducks bear east and south to reach the Atlantic seaboard, but they do not necessarily return by the same road, nor do all individuals in a given breeding locality occupy the same winter quarters. Western-bred ducks banded at Lake Erie on migration do not all go to the Atlantic seaboard; some continue south to the Gulf Coast. Then again we know that the White-winged Scoter, whose breeding area is restricted to a rather small section west of James and Hudson Bays, migrates both to the east and to the west, and although it does not breed on either coast, enormous numbers of non-breeders spend the summer on the Atlantic and Pacific shores.

In Europe records from banded Mallards show a tendency for those nesting in Sweden, East Prussia, and Kurland, to migrate southwest in autumn, and with Pintails there is a definite interchange between the west coast of Denmark and Fin- 
land. Teal banded in Denmark spread out later to southwestern England, Ireland, the west coast of France, Holland, southern Spain, and northern Italy. A European Widgeon banded in England in 1915 was taken on the north coast of the Caspian Sea in 1918, which shows a very remarkable east and west dispersal.

Most interesting, too, is the distribution of the sexes in migration. The true geese migrate in pairs and families. Not so with the ducks, for it is quite certain that among most of our common ducks the females and young start first and go farther, while the males come later, and these males may even stay in a more northerly winter area. This applies also to the Mergansers. On the other hand, the old males of the Scoters migrate very early, even in July and August, although they do not necessarily go farther south. In some cases, at least, with birds of this genus (Oidemia), the females and young, who come later, pass the males and winter south of them. With the Barrow's Golden-eye, the males disappear entirely as soon as the females lay their eggs, and leave the mountain streams of British Columbia for regions unknown. In a great many of the surface-feeding ducks the males assemble at certain points and begin to moult as soon as incubation has begun.

Then there is another phase of this most interesting subject. In a given locality there may be individuals of a certain species that are sedentary, and others that arrive from distant breeding-grounds in the winter to swell the ranks. Or it may be that locally bred ducks depart before their northern-bred brothers arrive, as we see in the case of our own Black Ducks. We may even picture to ourselves cases in which breeding groups from different localities are continually overlapping each other on migration, no one group moving very far in a southerly or northerly direction, although the movement of the species as a whole may be considerable. Again, it is by no means sure that a northern-bred group within a species will move only a short distance to the south. I am quite certain that our northern- and western-bred Black Ducks, the so-called Red-legs, actually are found farther to the south in winter than the ducks bred along the coast of New England and the Gulf of St. Lawrence.

Certain well-favored spots, which are cool enough for nesting, and yet have open water in winter, harbor small sedentary groups within a species. Thus Mallards, and apparently the same individuals, remain throughout the year in certain parts of Alaska and our Rocky Mountains. In North America many ducks are forced to travel two or three thousand miles, from the Athabasca Delta to North Carolina, let us say; but in western Europe, on account of a more uniform climate, warmer winters and cooler summers, there is no necessity for so extended a journey, and we find a tendency to shorter migrations, and more sedentary groups within the species. The Mallard is as good an example as any. As we move farther east, however, we reach countries where there are very cold winters and hot summers and conditions are more like those in North America.

Young Mallards bred in England have been extensively banded there; many of 
them have been shot and the bands recovered. The results show that this group of birds is almost sedentary, but the interesting point is that it is not absolutely so, for one or two per cent of them have turned up, and apparently as breeding birds, in places as far off as East Prussia. So we see another reason why local breeding groups do not become differentiated into subspecies, for they are not absolutely local and a certain leakage or interchange with other groups appears to take place regularly.

I have said that migration back to the breeding area is not always over the same course by which the birds departed. Most of our North American ducks breed in the great area from the Dakotas, through Manitoba, Saskatchewan, and Alberta, to the Athabasca and Mackenzie Valleys. From here they radiate in many directions. One great group of Mallards, Teal, Widgeon, and diving ducks strikes east, and, part of them collecting at certain spots in the Great Lakes region, eventually arrive on the Atlantic Coast, mostly south and west of New England. Some of these birds, particularly the Mallard, gradually withdraw from the sounds of North Carolina during the winter, so that after the middle of January they are almost absent, and these birds undoubtedly go north by a more inland route. In the Mississippi Valley there is a greater movement north in the spring than south in the autumn, while on the North Atlantic coast certain species are practically absent in the spring in the same places where they are common in the early autumn. We must picture, therefore, a great circular journey, which no doubt was first developed through necessity, for the States of the Mississippi Valley are often so dry in October that only a limited number of ducks can stop there, while in March and April the great rivers are in full flood and provide optimum conditions for all water-loving birds. These circular journeys are not confined to ducks. They are well seen in the Golden Plover and in the Eskimo Curlew, although of course these waders continue much farther south than do our ducks. Certain warblers also have a different route in the spring.

It is true in a general way that the Anatido are less bound by a hard-and-fast timesense during migration than many of the passerine birds, and yet they are more accurate in their dates of arrival than is commonly supposed, for the mere fact of their non-appearance at a given point does not mean that the species is tardy. It is quite as likely that they failed to stop because water conditions were not suitable, or because meteorological conditions were so favorable that the flight kept to sea, or made the journey without breaks. Arrival of the Lesser Scaup in eastern Massachusetts is very regular. In my own records October 6th was earliest, and October 19th the latest, in twenty years. The average is October 12th, and as a matter of fact, in spite of small numbers, these ducks arrived on that date for six of the twenty years.

The latitude at which a species winters is, of course, dependent to a great extent upon the severity of the weather. On our Atlantic Coast, the great sounds where diving ducks commonly winter may be completely closed with ice, and when this happens there is a secondary flight, perhaps for only a short distance, but possibly 
as far as Florida or even Cuba. The winter dispersal of diving ducks, Scaup, Canvasback, and Red-head, is markedly irregular, and apparently delicately adjusted to crops of various water-plants, which vary greatly in luxuriance from year to year.

In any famous ducking locality the proportion of the different species varies, suggesting factors of which we are in complete ignorance. Shooting-records will show great Teal, Mallard, or Widgeon years; still, as a rule, very big years show an abundance of several species.

In my own region, which is just east of the usual range of western-bred migrants, there occasionally comes a season when Mallards, Red-heads, or Ruddies are much more numerous than usual. This points to the fact that routes are not absolutely fixed. Stray birds taken at points distant from the usual range are nearly always the young of the year.

The height at which the duck tribe travels and the speed of migration are subjects often discussed, but it is impossible to lay down any hard-and-fast laws. It seems to be generally agreed that older observers exaggerated the height at which birds usually migrate. Meinertzhagen concludes that migrants are seldom found at over five thousand feet altitude, and that the bulk of bird movement is conducted below three thousand feet. Almost any sportsman knows that geese and ducks make their diurnal as well as their migratory flights much higher in fine than in foul weather. Wild-fowl are seen migrating at their greatest height on clear frosty mornings with light north or northwest winds. At these times such large birds as Canada Geese may travel so far above the earth as to be difficult to see, probably over four thousand feet, and it is possible that many ducks pass across the zenith at such a height as to be invisible, say above thirty-five hundred feet. But any sort of bad weather changes all this, and low clouds, heavy head winds, sleet, or snow will bring the migration close to the earth. Under really adverse conditions geese and ducks may be seen struggling along at scarce a gunshot above the ground.

The time of the day probably makes little difference to most ducks, and in this they differ widely from our passerine birds. Active migration takes place on favorable nights as well as by day, but I have often thought that the first part of the night was a period of more activity than the last part, to be followed by renewed movement just before morning and during the first hour after dawn.

It is very remarkable that enormous numbers of one species often arrive at a favorite stopping-place almost at the same time. Mr. Frank Benson tells me that on the 25th of October, 1920, he witnessed in broad daylight between the hours of eight and ten in the morning the arrival of thousands upon thousands of Red-heads and Canvas-backs which before that day were entirely absent. This was at Long Point, Lake Erie. They first appeared in long wavering lines, flock after flock in rapid succession at a height of perhaps twenty-five hundred to three thousand feet. When directly over the marsh, they "let go" and came down at terrific speed, so that in a very 
short time the marsh was swarming with them. Few sportsmen have been lucky enough to see one of these great arrivals from the North.

Some species, like the Ruddy, absolutely refuse to travel by day, and a migrating flock which arrives during the night will not leave until after dark the next night. I have seen migrating Ruddies come into a pond just at the first streak of dawn, but never later.

Scoters perform leisurely journeys along the coast during morning and evening hours, and sometimes all day, but they very seldom cross over land except at night, or extremely early in the morning, sharing the same fear of land as the Ruddy.

It is impossible to get an accurate idea of the distance which may be traveled by the individual flock without rest. If the Canada Goose be any criterion, it seems to me very likely that many ducks may travel a thousand miles without a stop, if the conditions are suitable, but I know of no observation that would throw much light on this point. It remains purely a speculation. We know that geese will not stop at New England points during very favorable weather, and presumably perform their entire flight from New Brunswick or Nova Scotia to Virginia at one journey. Swans probably make even longer journeys, and it is doubtful whether the bulk of the Red-heads and Canvas-backs that tarry on the north shore of Lake Erie make another stop until they reach Virginia and North Carolina.

It would be interesting to know more about feeding habits during migration. I think it will be found that ducks while under the active impulse to move care very little about filling their crops. Many flocks that I have noticed merely rest and wash up for an hour or two, and show no desire to feed. The Pintails that winter on the Hawaiian Isles come probably from the Alaskan Peninsula or the Aleutian Islands and cover a distance of twenty-two hundred miles without food, although of course they can rest if the sea is not too rough.

\section{PLUMAGE}

Althougr the patterns of ducks are various, and the colors run through the whole gamut of the rainbow, yet most species, even those not at all closely related, show a ducklike general plan - that is, a head and neck color, a breast color, and a wing speculum. However, some, as the Scoters, are plain or self-colored all over, while others, as the extraordinary Freckled Duck of Australia, have an entirely unducklike coloring and no wing speculum. The plumage is usually more varied in the male, but in at least fifty-three cases the sexes are alike, or differ only in size or in slightly duller coloration. In some, as in the Torrent Ducks, the female is brilliantly but differently colored from the male, and the same thing may be seen in the Sheldrakes of Australia and New Zealand. In the Paradise Sheldrake, the first young plumage is much more like that of the male than that of the female, so that females actually pass through a sort of male phase before they reach maturity. 
It is fitting here to say something about color-patterns in the group as a whole. Dr. G. M. Allen has shown that in Teal Ducks we find six of what he calls primary color patches. These are a median crown patch, two ear patches, two neck patches, two shoulder patches, two side patches, and two rump patches. A reduction in the color strength of one of these patches, either by partial albinism, or during the evolution of a new species, has in many cases demonstrated the breaks between these color areas. The interesting thing about this arrangement of epidermal colors is the fact that very likely it is of a fundamental nature, and applies not only to birds but to mammals.

MouLts. In all the typical arctic and Northern-Hemisphere ducks, of both the New and the Old World, the adults of both sexes have two annual moults. Pairs arrive at the breeding area in full plumage. Soon after the females commence to incubate, the males retire and begin to change to the "eclipse" plumage. During the eclipse, which is a much plainer and less-differentiated dress that remains in its full development for only about three or four weeks, the primary wing-feathers as well as the tail-feathers are moulted, and the bird becomes flightless. These feathers are shed only once during the year, and always earlier in the male than in the female. The female does not moult until the young are more or less able to care for themselves, and thus she is some four or five weeks behind the male in this respect, an adaptation obviously of great value.

In assuming the winter dress again, the old males are the first to change, and in some species, as, for instance, the Mallard, the specimens in full dress may be found by early October. In most of the northern ducks, however, the winter plumage is hardly perfect before November, and, in birds of the year, not before December or later. In the Shoveller and the Blue-winged Teal perfect plumage does not come before early spring.

The typical diving ducks, Pochards and Scaups, have their moults a good deal like those of the surface-feeders, but the eclipse is not so perfect, and young birds do not reach maturity until their second winter. Some of them do not breed the first year.

The Ruddy Duck is an exception to the above, as his true red breeding-plumage is not assumed until March or April, and lasts only a short time, through the summer instead of the winter. Thus he retains his eclipse plumage from August (for males stay with the females and young and moult late) all through the later summer, autumn, and winter.

The species in which the sexes have similar and dull coloring do not, of course, have an eclipse, but they do have a double moult. None of the males of South American or Australian ducks have an eclipse, the significance of which is not clear at present. 
It is interesting, but perhaps not very productive, to inquire the reasons why $\mathrm{Na}$ ture has deprived the male of his gorgeous feathers during midsummer, for the eclipse of ducks is almost unique in the avian world, most bird families carrying a brilliant plumage throughout the whole summer and not acquiring it again until spring. It is commonly said that the eclipse is a wise provision of Nature to render the male less conspicuous at the time when he is rendered helpless during moult. It is perhaps just as easy to say that the eclipse is merely a periodic repetition of an earlier type of plumage, and the male becomes helpless, shedding his quills, because he gets along very well at this season of profusion without flying about in search of food. However, it seems to me that an entirely different view might be taken, based on the recent castration work of Goodale, Pearl, Boring, and others. We now know that male plumage in birds is not affected by removal of the sex organs, while female plumage is more or less changed to male when ovaries are removed or cease to function through embryonic conditions, old age, or disease. But the power to acquire an eclipse is dependent upon the male sex organs as Goodale showed. Other sex characters - spurs, wattles, voice, and behavior - are not so clearly dependent on the secretion of sex glands. It is apparent, then, that the power to produce male plumage is carried by the female, and that the female sex glands secrete a substance which inhibits or modifies "maleless." Now, we do not have to assume that sex plumage in the male duck is a recent development. On the contrary, it is quite as likely that it is a primitive character and antedates the somber female plumage, and birds like the Florida Duck and the Hawaiian Duck may have arisen from a Mallard-like type through suppression of the male plumage. This throws a very different light on the whole subject. The eclipse may be a recent plumage developed through necessity for protection, while the brilliant winter dress persists at a time of year when it is of little disadvantage, and the birds are well able to look after themselves. In the same way the so-called protective coloring of the female may be recent, in an evolutionary sense, and due to some sort of natural selection, as Wallace long ago pointed out. The eclipse, therefore, may not be a return to a primitive condition at all, but may represent a highly specialized dress. And in this connection we must notice that by nature it is not a return to a female plumage so much as it is to a modified male plumage. I once kept a male Mallard in a cold room all summer, and in this way delayed his moult. When he was brought out into normal surroundings in September, he immediately moulted, but went directly into his full dress, omitting his eclipse. We have then the same anomaly that occurs in castrated ducks - a failure to assume the eclipse. It seems, therefore, that this latter plumage is dependent, not only on the presence of the male sex organs, but on their function during the period of breeding activity. A curious anomaly, which $I$ have seen in the Carolina Duck is the retention of a perfect eclipse plumage in the male throughout the entire year. 
Most ornithologists would admit, I think, that the little Hawaiian Duck is nothing more than a degenerate Mallard, the males having lost most of their gay coloring. It has, however, kept certain male characters, and some specimens look a good deal like a Mallard in summer, or eclipse, dress.

We now come to a large category of ducks that do not assume full dress until more than one year old. The Harlequin male does not attain maturity for fourteen months, and the Eiders not until their fourth year. The curious Steamer Duck does not reach maturity until at least over two years of age, and possibly not until much later. Many of the Pochards and Scaups are not really in perfect feather until eighteen or twenty months of age - and their first eclipse is somewhat different from later ones.

It may be worth while to make some general remarks on the sequence of moults in ducks, because this subject will not be freely considered under the different species. In the seventeenth century Willoughby and Ray offered their quaint theory of the causes of moult in birds and perhaps, after all, we have not pushed the knowledge of this subject so far that we can afford to laugh overmuch. They supposed "that there is the same cause of the casting the feathers in birds, that there is of the falling off of the hair in men and other animals upon recovery from a fever or other disease, or upon refection after long abstinence. For in cock-birds the heat and turgency of lust, is, as it were, a kind of fever, and so in the spring time their bodies being exhausted by the frequent use of venery, they become lean; but in the hens the time of sitting and bringing up their young answers to a disease or long abstinence, for at that time they moderate themselves by hunger and continual labor, etc., etc."

The first true feathers appear on the scapulars and tail, the last parts to retain down being the head and neck and under side. The first plumage, usually called the juvenile plumage, is attained at the age of eight or ten weeks, and resembles in a marked degree that of the adult female, although it may be distinguished by various minor differences. The sexes of young ducks can usually be separated when they have reached this stage (first or juvenile plumage), but they resemble each other closely. The first tail-feathers are blunt at the tips.

First let us follow the male of what we may call a typical palearctic duck (Mallard, Teal, Widgeon, and others). During the first winter the male may or may not attain full adult plumage; at any rate, there is a nearly complete moult of body feathers, usually the whole tail (sometimes only the central feathers), between September and April. Note here that the juvenile flight-feathers are always retained, and rather frequently the feathers of the back and rump and, perhaps, some wingcoverts. In some species feathers of the lower breast and abdomen are not renewed during the first winter.

The first eclipse plumage, which is assumed in June or July, may or may not resemble the adult eclipse, but in the typical cases it is the same, and the year-old 
male cannot be told from the two- or three-year-old bird. The eclipse is acquired by a nearly complete body and tail moult, usually followed at varying intervals by the single annual moult of the primaries (flight-feathers), the outer secondaries, and some or all of the wing-coverts. The male is then flightless for a time. In certain species the pre-eclipse moult is not nearly so complete as this, and may not involve the back, rump, abdomen, or tail. Sometimes the central tail-feathers are shed before the outer ones, as in the Mallard.

Usually there is no period of actual stasis in the moulting process throughout the entire summer, for the pre- and post-eclipse moults merge into one another. In some species, however (Ruddy Duck, Blue-winged Teal), eclipse plumage is retained for several months. With the assumption of the new flight-feathers the eclipse may be said to be perfect, although it is often practically so before these flight-feathers are shed.

The adult male winter plumage is assumed during the second autumn by another (post-eclipse) moult which affects the body-feathers, tail and innermost secondaries, and is often completed by November or December. After this there are two annual moults one of which includes the flight-feathers.

To return now to the female. Her down plumage is the exact counterpart of that of the males and her first or juvenile plumage is assumed in the same manner. Usually a sexual difference appears in the first plumage which may be appreciated by any one who has handled many specimens, but in some species no differences between male and female can be detected at this time. During the first autumn and winter the young female goes through a moult of the body-feathers, and sooner or later of the tail-feathers, becoming by spring (sometimes by early winter) difficult to tell from a fully adult female, although the juvenile wing is still present. Now comes the difference in the moulting periods of the sexes. The female prepares herself for the breeding season by a nearly complete body moult, which may take place at any time between autumn and late spring, but occurs typically from February to May. This is a rather slow and easily overlooked moult, which affects most bodyfeathers, the down, some or all of the tail-feathers, the inner secondaries, perhaps some wing-coverts, but never the primaries or outer secondaries. This moult leads to what may be termed the breeding or summer plumage of the female, a plumage slightly, sometimes strikingly different from the autumn-winter (eclipse of Annie Jackson) plumage. As we shall see, this breeding plumage is retained, although often in a very ragged and faded condition, until the maternal duties are accomplished, when it is followed by a complete moult in late summer or early autumn affecting the whole body and the wings. Apparently the female does not always become flightless, as does the male, but on this point more information is needed. The typical cycle for the female is now completed, and we see that the two moults in this sex, although they are chronologically delayed in comparison with those of the 
male, are not so different as appears at first sight. Because they extend over a long period and are easily overlooked, they have been misunderstood.

These general remarks on the subject of moult can be interpreted only as applying to the common northern migrant ducks. We shall see that moult in the tropical and southern hemisphere species is very irregular and ill-defined. In all those species where maturity is not reached the first year (Eiders and Scoters), the plumage changes and moults are still more complex. Then, too, it must not be forgotten that there is a very remarkable amount of variation in the time at which different stages of plumage are reached, even in the same species in similar localities. It is often possible to find forward young of the year in nearly complete maturity by early winter, while others, for reasons little understood, may not reach such a stage until late winter or early spring.

The whole subject of the sequence of plumage and moults in the duck tribe almost deserves a monograph to do it justice. The main facts have been well worked out by Annie Jackson (Meinertzhagen) and E. L. Schiöler.

\section{FLIGHT}

WHо can describe the flight of wild-fowl to one who has never seen it - those great flocks driving through space with perfect order and precision, conveying an idea of power and volition which the scattered, irregular, and rather aimless-looking flights of most of the smaller land birds utterly fail to give us?

Nearly all ducks are rapid flyers, and there is so much diversity of opinion as to which are the fastest that it is hardly worth while, in the light of our present knowledge, to attempt to analyze very deeply. It is safe to say that fifty-five or sixty miles an hour can be attained by many species, and forty to fifty miles is a common speed during migration. Some of the diving ducks certainly fly faster when near the ground than the Mallard-like species. Teals seem to go by at a greater rate than Mallards, but their small size and erratic behavior make this more apparent than real. The great ease with which aëroplanes traveling at not more than seventy-five miles an hour have managed to pick up and kill ducks over the rice-fields of California makes it look as if we should have to revise our earlier conceptions of the velocity of ducks' flight. Recent observations place the speed of ducks while migrating at from fortyfour to fifty-nine miles per hour. (Meinertzhagen, Ibis, 1921.) Migrating Canada Geese travel at forty-five miles per hour.

The river ducks and Teals are far more active and skillful on the wing than the shorter-winged diving ducks, Scoters, and Eiders. But speed and activity on the wing are not confined to the true ducks, for both are well developed in Nettapus (the Goose Teals), the Carolina and Mandarin Ducks, the Hooded Merganser, and others. The great Steamer Duck of antarctic America, that weighs eight or nine pounds, is apparently on the border-line in losing completely the power of flight. 
Individuals differ in their ability to raise the body from the ground or water, and old specimens actually have slightly shorter wings than the young ones, and become even more helpless. Various attempts to separate this species into two kinds, a volant and a non-volant form, have thus far ended in failure. There is only one wholly flightless species, namely, the Auckland Island Duck.

Domestication almost immediately affects the wing-muscles of wild Mallards. In two or three generations they become too lazy or too heavy to care about any long flights. Under the same conditions the male Muscovy grows so heavy that he is practically flightless, although the female remains fairly active. Most tropical and sedentary species are slower on the wing than their northern relatives.

Ducks do not assume the arrow type of flock as regularly as geese. Migrating Mallards, Black Ducks, and many diving ducks fall into long wavering lines or very blunt arrows, with scattering individuals stringing along inside the arc. There is very little flock formation in wild-fowl when moving only short distances, and some species, such as the Carolina Duck, seem always to fly in irregular, compact groups.

\section{DIURNAL MOVEMENTS}

DucKs as a whole are naturally very active in the early morning, and again in the evening, while much feeding is done on clear moonlight nights. Persecution has greatly affected the habits of wild-fowl the world over, and it is rare now to find ducks, except in far northern breeding grounds, carrying on their daily routine without modification. Of course in well-protected areas before the shooting season opens, one can gain a very good idea of natural habits. The daily movements of the flock are again greatly altered during active migration.

Surface-feeding ducks manage when necessary to find their food entirely by night, except under great stress of storm and frost. Diving ducks must have some period of daylight to feed, else they will eventually be driven from their wintering ground to some more favorable location. With this end in view various communities and many sportsmen's clubs have limited shooting to two, three, or four days each week. It appears that Pochards and Scaups will under certain conditions feed at night, and just how common this habit is remains to be found out. Golden-eyes, Scoters, and Eiders are species which appear to feed entirely by day.

\section{WARINESS}

AlL ducks that have survived in shot-over countries are more or less wild. Even the ridiculously tame Ruddy is susceptible of some education, especially when he keeps in large flocks. Originally all ducks must have been perfectly fearless in the presence of man, and their confidence can even now be restored, for such a species as our very highly educated Black Duck has in certain protected spots become so tame as to allow himself to be caught by the hand. All our true fresh-water ducks become 
very shy under persecution; the Teals less so. But certain species show not only timidity, but perfect adaptation to a harassed existence. Of course, no matter how wild the bird, if its diurnal habits are uniform, and it flies over, or arrives at, similar points each day, it will surely eventually be killed; our Black Ducks have not only learned a great deal about man and his weapons, but have acquired the habit of taking different routes from day to day, so that they may completely baffle the shooter.

All young ducks are fairly tame until shot at. I have decoyed Black Ducks successfully by simply waving a hat above the grass and giving a few quacks, but on our New England coast the same species becomes so shy as to defy almost all efforts for its capture, except when stress of weather closes part of its feeding grounds. All ducks become more "gentle" during strong winds or freezing weather. As a rule flocks on active migration are far more confiding than after they have become localized in some definite place for a few weeks. Thus in our New England ponds one can tell almost at a glance a flock of local, wintering ducks, that has come in from the coast for shelter during a storm, from a flock of migrants that stops here and there only for a few hours.

Some island species, as the Laysan and the Georgian Teals, are still fearless in the presence of man, and in certain parts of India, where it is left alone through religious tolerance, the Ruddy Sheldrake, usually a very shy bird, becomes perfectly oblivious to human activities.

Speaking broadly, the Spur-winged group are mostly wary, the Goose Teals and the Tree Ducks less so, and the Egyptian Geese and Casarcas extremely observant and very intelligent. All the Mallard-like ducks, except a few isolated species, are wild and capable of great adaptation. The diving ducks are not individually so intelligent as the fresh-water ducks, but here again there are many differences, and the Golden-eyes are extremely wary and also unsociable with other species. None of the Scoters and Eiders can be called susceptible of much education, while all the Spiny-tailed, or Ruddy Duck, family are distinctly stupid.

One cannot estimate wariness by the ease with which the birds come to decoys. Some rather tame ducks do not decoy, because they lack the instincts of sociability.

\section{SPECIAL SENSES}

THAт hearing and sight and the sense of touch are highly developed in most anatine birds is recognized by every one. On the sense of smell there is such widely conflicting evidence that $\mathbf{I}$ am inclined to dismiss the subject without comment, for I certainly have nothing of interest to add, except the fact that Mallard Ducks can easily detect the presence of various essential oils when placed on their food. That there is in some geese and ducks a power to detect enemies down wind under certain conditions must be acknowledged. No one who has talked to the old decoy-men of Hol- 
land and England feels confident in ruling out the possibility of a sense of smell. Nevertheless, I have hundreds of times decoyed ducks and geese directly up wind where they had plenty of time to detect my presence, without their showing any suspicion, so that one becomes very skeptical that what has been described as a sense of smell in birds is really analogous to what we see in mammals. It has been suggested with reason that birds are provided with some more or less "occult" power of finding food; and the extraordinary ease with which diving ducks discover hidden waterplants seems to rule out a mere happy-go-lucky trial-and-error search.

Some evidence for and against a sense of smell in birds has been summed up by Mr. J. H. Gurney in the Ibis for 1922.

\section{VOICE}

THE various call-notes of water-fowl are among the most interesting of all sounds. A few, as the "south south southerly" song of the Long-tailed Duck, or Old-squaw, the whistle of the Widgeon, and some of the notes of Teal, are really musical, but for the most part they form a great variety of sound with little musical merit. A large raft of Mallards, Teals, Pintails, and Widgeons, especially when feeding at night, gives off a confused volume of sounds, mostly rapid chatterings, jabberings, coarse low, and squeaky high-pitched quacks, with now and then sharp whistles. In the spring, male ducks have special courtship notes, and these are very curious and entirely unducklike in character, such as the catlike "meeow" of the male Redhead, and the rarely heard dovelike coo of the Greater Scaup, audible only a few yards away. These notes are very often intimately associated with display attitudes.

Diving ducks of almost all kinds are much quieter than the surface-feeders, and most ducks are rather quiet while flying. The Tree Ducks, which are obviously nocturnal, are exactly opposite, for they continually keep up the most amazing whistles while on the wing, and they are very silent on the ground or water.

On the whole, the remarkable boxlike bony pouch situated near the bifurcation of the trachea in the males of most ducks seems to act as a voice-stopper and tones down the quack to a reedlike note or whistle. The differentiation of the voice is one of the earliest signs of sex in Mallard Ducks, and the "quack" when once heard invariably means a female. There is, however, a period at which the voice is half male and half female, when it is extremely puzzling to make out the sex. Young ducks in down make a variety of small peeping sounds.

Embryo Mallards show a swelling of the windpipe in both sexes, which gradually disappears in females, so that some time after hatching it is not noticeable in that sex.

Those species which do not have a tracheal box have some other curious secondary sex character, like the tracheal air-sac of the Ruddy, the subgular pouch of the Musk Duck, or the osophageal dilatation in the Black-headed Duck (Heteronetta). 
Among the Tree Ducks we find less difference in the tracheæ of the sexes, and there is no tracheal box in the male. We do, however, find the trachea widened into a simple spacious chamber in this sex, but the voice does not seem to be affected.

\section{ASSOCIATION OF SPECIES}

ONE of the most striking characteristics of this group of birds is their sociability. Among northern migrants, the Mallards, Teals, Widgeons, and Pintails mix together on their winter feeding grounds almost indiscriminately, while companies of Canvas-backs, Red-heads, and Scaups, with a sprinkling of Widgeons, are a common sight. But even the smaller ducks are often seen feeding side by side with geese and swans. The fancier may safely confine almost all ducks in the same pond, and will have no real difficulty except with Casarcas, Spur-winged Geese, Comb Ducks, and allied species.

There is some parasitism among ducks. The case of the Widgeon feeding on plants brought up by Pochards and Scaups is often cited, but this is not true parasitism. It is less well known that certain diving ducks, notably Canvas-backs, Ruddies, and Red-heads, lay quite indiscriminately in each other's nests, and the Black-headed Duck (Heteronetta) is apparently about as parasitic as the cuckoo. Duck nests have been described in which four species have laid eggs.

Association may, of course, be merely accidental, as when it is brought about by similar food habits. There are some kinds of water-fowl that are quite averse to mixing with kindred species, or even with others of their own kind, but such habits are found mostly among the gooselike, not among the true ducks. It is this mixing of so many different sorts of birds, showing off their various and characteristic flights and swimming postures, that makes sitting in a duck-blind so fascinating. It is not at all uncommon to bring home ten or twelve species of ducks in one day's shooting in localities like Currituck Sound, North Carolina.

Sociability almost ceases when the breeding grounds are reached, and ducks seldom breed in colonies, like gulls and terns. Eiders, some Tree Ducks and perhaps some diving ducks are exceptions. Many species do place their nests in fairly close proximity to each other, but others, as Casarcas and Egyptian Geese, isolate themselves and have a strictly limited "beat" from which they chase away all intruders.

The European Sheldrake appears to have a real understanding with foxes and other mammals that could very easily destroy its nests, were they so inclined. Other ducks nest on cliffs among birds of prey, and yet are apparently free from harm.

\section{FOOD}

IT is hardly necessary to enumerate plants and animals upon which ducks are dependent. Under each species will be found such details as I have been able to gather. The more adaptable ducks of the Mallard type are practically omnivorous, and their 
choice seems to be controlled only by the size of their gullets and the capacity of their crops. Most diving ducks are, however, much less independent, and their distribution is from time to time deeply affected by slight changes in freshness or saltness of lagoons and the consequent luxuriance of various crops of water-plants and mollusks.

It follows, of course, that most of the fresh-water ducks are easy to maintain in confinement on ordinary grains, while such species as Scaups, Golden-eyes, Scoters, Eiders, and the fish-eating Mergansers are only kept alive with infinite care and trouble. Among the surface-feeders, Shovellers do not live well, because their natural food consists of a large proportion of very minute animal and plant life.

There is a greatly increased proportion of animal matter in the summer food of ducks, and the young for the first few weeks depend upon animal food, chiefly the larvæ of insects, for sixty to ninety per cent of their entire diet.

\section{COURTSHIP AND NESTING}

As I shall notice under the Mallard, and may repeat here, the term "courtship" will be used to cover the whole series of events resulting from the "mating hunger," all activities, in fact, which lead up to the building of the nest. The term "display" will be used merely to describe those social plays which result finally in the choice of a mate, and where display is well developed it is probable that the female does actually select her own mate, although we still lack experimental evidence on this point.

Under courtship we should consider the search for the mate, the fighting, or rivalry of males, etc., but "courtship" must not be used in an anthropomorphic sense. We must always bear in mind that the birds' activities are exercised mostly in an unconscious manner, and without real understanding, although their general behavior may remind us very greatly of our own.

Display antics have occupied the attention of field observers a great deal of late years. They are well worthy of study because they are extremely complex, and very characteristic of the species. There is no doubt that these postures hark back a long way in the relationship of the various subfamilies of Anatida. I do not think they were described before Naumann's great work on the birds of middle Europe about a hundred years ago. Besides being interesting in themselves, they are often very beautiful, and tend to exhibit the grace or agility of the performer in its highest degree, and to show off the striking parts of his plumage.

It would be interesting to inquire into the origin of display, but this would draw us into a general discussion of the evolution of sex, and the origin of secondary sex characters, a subject that would lead us far afield. We must admit that in some way these sex postures are closely associated with the choice of mates, for they are very elaborately developed in many different families of birds, are almost as pronounced in reptiles, and are highly organized in insects. It is hard to understand whether 
they appeared before or after sex differentiation, and whether they were not at first common to both sexes, as they are in some cases now. There is a splendid field for inquiry into the question of the choice of mates in birds.

Display is seen at almost any time of year except when ducks are in full moult, and it has no necessary relation to the pairing act. Ducks that are definitely paired practically cease to display, and it follows that these actions are best seen, not on the breeding grounds, but in early spring. Mallards and Black Ducks begin to pair in late winter or very early spring, the older ones doubtless before the birds of the year. At the same time, or a very little later, the reproductive organs of both sexes begin to enlarge. Other species, Teals, Pintails, Widgeons, and Gadwalls, do not generally pair until a little later. Flocks of diving ducks, Scaups, Red-heads, Ring-necks, and Scoters, break up into pairs later than the surface-feeders.

On the nesting grounds we see various pursuit flights, single males chasing a pair of mated birds or perhaps many males chasing one female; and these flights, though interpreted in various ways, cannot be considered, in my opinion, as part of a display. Francis Harper, who spent the whole spring season among the ducks on the Athabasca Delta, seems to think that a mad scramble among all near-by males occurs whenever a female who is ready for pairing appears. In order to join in these pursuit flights a male will temporarily abandon his own mate who may be beside him. I had always thought of the pursuit flight as having to do more with rivalry for nesting sites than anything else, in other words a question of territory, but these observations of Harper's put a different light on the matter.

The time for nesting varies in holarctic species with the latitude at which the individual stops for breeding. As we approach the warm countries, the nesting time is not only much earlier in the spring, but it extends over a longer season. In all those tropical countries dominated by a definite rainy season, ducks breed directly after the floods begin, when it becomes possible for them to disperse over the interior. This may mean irregular flights from coast to interior, but such movements are not true migration.

It would take altogether too much space to go into an enumeration of the nesting sites of ducks. Most of the true fresh-water and diving ducks nest on the ground, or over the water, whereas nearly all the tropical species nest in trees, not necessarily in hollow limbs, but quite as often in deserted nests of other species. It is certainly rare for ducks to build stick nests of their own, but there are such instances among Tree Ducks.

The adaptable Mallard chooses tree nesting sites much more often than is generally known, and probably, should elevated positions become necessary, this sagacious bird would soon learn to discard ground-nesting entirely.

Many diving ducks build nests that are almost floating, while it is not rare for surface-feeders to lay their eggs a long distance from the water. The Tree Ducks 
nest both on the ground and in trees, depending upon the kind of country. The same species may have entirely different habits in different parts of its range. The Goose Teals (Nettapus) are mostly tree-nesters. The Casarcas always choose a covered nesting place, and the common European Sheldrake occupies the burrows of rodents.

Eggs of the more typical ducks are rather uniform in appearance, unspotted, and white, greenish blue, or brownish in color. There is nothing particularly noteworthy about the eggs of this group. They are without any suggestion of protective (?) markings, but this is more than made up by the general habit of covering the clutch with down plucked from the female's breast. All groups except the Tree Ducks line the nest with down. The egg of a certain species, the curious Pink-headed Duck of India, is almost as round as a billiard ball and polished like ivory.

The number of eggs in a clutch varies greatly even among individuals of the same species, and birds of the year as a rule lay a smaller number. Nevertheless, there is probably a typical number for each kind. Practically all the holarctic ducks and also those of southern South America lay a large clutch of from eight to fourteen eggs. A few tropical ducks lay from four to six eggs, and several Australian species and those living on islands lay small clutches. The Torrent Ducks seem to lay only two eggs, being in this respect more like the loons and grebes.

The incubation period varies from twenty-three or twenty-four days in the Teal, to thirty days in the Tree Ducks and thirty-four or thirty-five days in the Muscovy. The typical period is twenty-eight days.

There are many interesting differences connected with the habits of the male during and after incubation, and these are not well known in the rarer ducks. In some Tree Ducks, and probably at times in the Sheldrakes, the males assist in incubation. This never occurs among the typical fresh-water or the diving ducks.

In most of our northern ducks the male leaves the female after the young are hatched, and often as soon as incubation commences. Probably in most cases he never sees his family again, for these males assemble at certain favorite places and in the strictest retirement proceed to moult. There may even be considerable movements of males at this time, as in the Scoters, Eiders, Barrow's Golden-eyes, and others, and it is rather a common observation that no old males are seen at a given breeding ground after June. For instance, flocks of male Pintails numbering more than a thousand suddenly appear about the middle of June in the Bear River marshes of Utah, and moult there. On the other hand the male Ruddy Duck is a very dutiful father, and stays with his growing family at least until they are safely on the road to maturity. Nearly all those species in which the female and the male have similar plumage, like the Tree Ducks, the Casarcas, and the gooselike Spur-wing group, behave in an entirely different manner, and the males are very pugnacious and active guardians of the family. Exceptional cases have been noted in which individual 
males of our northern ducks stay with the female and young brood; such instances have been recorded among Mallards, Gadwalls, and Shovellers.

There seems to be some rather important relation between the early desertion of the females by the males and the presence of an eclipse plumage, and there is a great temptation to hazard some sort of explanation to account for this. Data on the movements of the sexes in those South American species where the male and female plumage is the same ought to shed light on this point. We now know that males of the South American Pintail, in which there is very little sex difference of plumage, leave the females just as do the common ducks of the Northern Hemisphere.

\section{FOOD VALUE}

IN the first half of the nineteenth century the epicures of Baltimore and Philadelphia made the Canvas-back of the Gunpowder and adjacent rivers famous everywhere. But the Ruddy Duck, perhaps second to the Canvas-back, scarcely became known as a table bird until the late nineties. Before the sale of ducks was stopped in our eastern markets, Ruddies were selling at from $\$ 2.50$ to $\$ 3.00$ per pair, and Canvasbacks at from $\$ 6.00$ to $\$ 8.00$, so that the Ruddy in proportion to its weight was the more expensive. This was probably the highest price ever paid for ducks. In the fourteenth century in England Gurney tells us that Teals sold for as little as two pence each and Mallards at from three pence to five pence.

From the epicurean viewpoint I should place our American Widgeon when shot on good feeding grounds as at least third in order of merit. Indeed, Frank Forester placed it as second only to the Canvas-back. The Red-head would be classed by many as second to the Canvas-back, but much depends upon the food, for Redheads at times feed in salt water, along with Greater Scaup.

With European ducks I am less familiar, but I do not understand that there is any species there comparable to our best, although this statement would no doubt be violently contested by our brother sportsmen across the water.

When we come to the whole group of surface-feeding ducks there is really very little choice among species, and a great many of the supposed preferences are wholly imaginary. Under similar feeding conditions, few, if any, could make intelligent discrimination between Mallard, Black Duck, Pintail, Gadwall, and Teal.

Eiders, Scoters, Mergansers, the true Sheldrakes or Casarcas, and most of the Spur-wing family are practically unfit for food. Young Scoters, before they have reached salt water, are not "fishy," but dry and tasteless.

Golden-eyes, Buffle-heads, and Hooded Mergansers are fairly palatable when fresh from interior breeding grounds.

A great deal of nonsense has crept into literature regarding the palatability of the flesh of wild-fowl, and some species have received undue praise merely because they were eaten by some meat-hungry traveler in remote regions. I myself have eaten 
Eider Ducks, young Burgomaster Gulls, and even herons, and found them delicious, but the same birds at home would probably have driven the cook out of the kitchen. New England "coot" stew (made from Scoter Ducks) is still popular in this region, but it is good in direct proportion to the thoroughness of its disguise in cooking, and loons, herons, and grebes might serve about as well if a sufficiency of the culinary art were lavished upon them.

There has been no chemical analysis of the flesh of wild ducks so far as I have discovered, but it is not likely that it differs much from what is found in tame varieties. According to a United States Government Bulletin, ducks as purchased contain less refuse than do chickens, and in the actual meat there is about the same amount of water. The proteid content is about the same, but the fat is twice as much, so that the actual caloric value of the edible portion is considerably greater, in fact the difference amounts to nearly sixty per cent. Wild ducks' meat is a hearty food, and it should appear on the table as the pièce de résistance, not, as it so often does, following a substantial meat course.

I do not think wild-fowl in good condition need be hung more than two or three days. This does not hold with pheasants, grouse, snipe, and woodcock, but I never could see that the flavor of a really prime duck was improved with age. After roasting in a very hot oven, the carcass should be well singed in a flame, or seared with a red-hot iron.

In considering the qualities of ducks' flesh the age of the bird, the place at which it was shot, the flavor, the texture, and the delicacy should be considered. Sometimes birds of fair flavor are coarse and dry, as with Scaups and Golden-eyes; others that are juicy and delicate may have too strong a flavor from feeding on marine mollusks.

The best physicians of Rome, according to Aldrovandi, were against the use of tame ducks' meat as apt to "agree not with the stomach," but the flesh of wild ducks was considered savory and wholesome. There are many allusions to the medicinal virtues of ducks' flesh in older writings.

\section{HUNTING}

Tris subject is far too lengthy a one to consider, and it is covered so well by many books in this country, and particularly in England, that it would be of little interest here. Under each species some mention will be made of hunting methods, but nearly every part of a country has its characteristic boats, decoys, dogs, and blinds, so that a full consideration is not possible. The more primitive native methods of shooting or netting will here and there be referred to. This subject has been carefully studied by MacPherson in his History of Fowling.

Many keen duck-shooters find themselves getting more and more sentimental as they grow older, and these are the men who originate all our worth-while reforms, not the type that has been brought up to look with holy horror upon guns and shoot- 
ing-men. I remember the late Wilton Lockwood used to say that a man ought to be hanged for shooting a Teal, yet he was as keen as any one in the pursuit of Black Ducks and Golden-eyes. Lockwood was an artist and a very successful breeder of water-fowl, but toward the last of his life his earlier hobby was dropped, and he became a lover of flowers, which shows again how sentiment may change with age. In my own case I must say that I am more and more inclined to agree with Frank Forester, who held ordinary duck-shooting from a blind in very low esteem. After all, real sport is measured by its demand upon skill, patience, and woodcraft, and shooting baited ducks over a large flock of decoys, while seated in a comfortable box, to say nothing of a punter and a dog to chase the cripples, does not call for a very large measure of any of these qualities.

The English science of punting for ducks with a big gun is commonly considered in this country as entirely beyond the pale, but as a matter of fact any method by which ducks are stalked is far more sportsmanlike than where the birds are brought to the shooter. I have often thought that sculling after Black Ducks in a whitecovered float among the ice-cakes and snow-fields of our New England marshes was the most difficult, exciting, and perhaps dangerous way of getting fowl which I have ever engaged in. So again the ethics of sport are more or less comparative, and not absolute. In places where ducks are very shy and scarce, one does not hesitate to use live decoys, but where they are plentiful, these aids are not necessary and really detract from the pleasure.

So much for the great science of duck-shooting. Every one has his favorite methods, his pet memories; but as for me, regardless of ethics, let me hark back to before the days when night shooting was a misdemeanor, and let me watch the fading daylight on the wintry, wind-swept marsh, where some strip of sand dunes stands out a glowing rose-color in the darkening east, and with a few crude bunches of seaweed decoys for company, let me strain my ears during that magic half-hour of twilight for the regular "swish-swish-swish" of incoming ducks and then suddenly see those marvelous black silhouettes, as a troop of "duskies" cuts in, and with down-curved wings and lowered necks crosses the still rosy band of western sky.

\section{ENEMIES}

Wттн enemies, again, it is not necessary to deal just here, but they may as well be briefly classified. First and foremost, of course, comes man, but his work will be considered under the head of "Status," for his damage is mostly recent. Among mammals nearly all the small carnivores are destructive at times, and more particularly the mongoose, rat, stoat, and fox when introduced into new environments. Even the domestic cat has taken to feeding upon water-fowl in Australia and in our own West, and hogs at times interfere with breeding grounds. The otter is sometimes very destructive to pinioned ducks on enclosed ponds. 
Among birds are eagles, hawks, especially the peregrine type, owls, ravens, crows, magpies, and gulls. Among reptiles crocodiles and certain snakes are the most important, while turtles, where the larger kinds occur on breeding waters, take a heavy toll of young birds. The huge monitor lizards of the genus Varanus eat both eggs and young and are destructive to certain tropical ducks. Fish of the pike family are dangerous to young ducks. Sea ducks have even been caught by large clams, when diving for food.

Many parasitic worms have been found in the intestines of ducks, some encysted in the muscles of the breast. There are also various feather-mites which are common. Ducks have been known to be killed by leeches.

We might include under enemies the lead-poisoning from eating shot, which is found rather commonly in ducks, and also the alkali poisoning, or "duck sickness," seen recently in our own West.

\section{STATUS}

This is a subject which ought to interest us above all others. We are living at a time when the whole world is being overrun and desolated by civilized man, and we of this generation will be held responsible by those who follow us. To us comes the task, hopeless as it seems at times, of saving those remnants of birds and mammals that are found to be compatible with life on an ever more crowded and greedy globe. With many rare and beautiful species we can collect only a few skins for preservation, and chronicle in our journals the date of the taking of the last wild specimen. But fortunately with our group there is much that can be done, and many of our most valuable kinds of ducks breed so far from agricultural latitudes that the creation of suitable winter refuges and of certain sanctuaries to ensure them food and protection during migration is all that is necessary at present.

There is, I think, no group of birds that will respond so readily to encouragement as the Anatidoe, but they are faced throughout the interior with grave dangers, because of the constant drainage of lakes and swamps, while on the coast they are threatened with a constantly increasing amount of pollution by oil. Nevertheless, there is a brighter side to this picture, for great storage-basins for the irrigation of vast desert tracts are being created in many heretofore nearly waterless regions, and it seems as if the benefit from these might offset the damage from the other. The oil nuisance may be stopped in time, as sportsmen are already thoroughly aroused, and oil kills fish as well as birds.

The status of a species is most difficult to estimate, and until some sort of a status bureau is created which shall have for its object the sole duty of checking up State game and fish, sportsmen's-club, warden, and individual reports, we shall really know little about the subject. A bureau such as this would in a few years well repay its cost, and it would gather very valuable data on the shifting of bird populations, 
good and bad breeding years, and destructive industries, as well as irruptions of bird enemies. We need more studies like that conducted by Wetmore in the Bear River marshes of Utah, where an estimate of the exact number of breeding pairs was arrived at. Our own Biological Survey is doing as much of this sort of work as it can.

Now, there are reasons why the status of a given species is hard to get at, and most of these reasons are not considered by the average sportsman. A census of particularly attractive areas, where duck population gathers to the full limit of food resources, is obviously misleading, for less favorable stopping-places will be drained before the great resorts become affected. It might be likened to the depopulation of some of our Western States, which does not in the least affect the city of New York. Besides, migration routes are not hard and fast, and we are at a loss to explain the irruptions of certain species at certain places, or their dearth at others. And then there are droughts and floods, bad breeding years, destruction of great brackishwater lagoons by breaking of beaches, introduction of carp or pike, and perhaps catastrophes from storm and frost that we cannot possibly take into consideration. The great northern periodic cycles of mice and rabbits with their attendant increase of predaceous lynxes, hawks, and owls may even affect the breeding grounds of ducks. And last, but not least, we want to know the approximate numbers destroyed by man from the Arctic Ocean to the Gulf of Mexico, the decrease of breeding area from time to time, and the effect of industries which may pollute the waters by chemicals or scatter oils on the surface.

Mr. E. W. Nelson, the present Chief of the United States Biological Survey, writes me that he considers the molestation of wild-fowl by aëroplanes one of the most serious dangers for the future. They certainly have the effect of driving ducks entirely away from regions over which they patrol, but duck are very adaptable, and I have noticed that the Scaup Ducks on Lake Worth in Florida no longer pay any attention to them.

During the ornithological history of this country only one species of North American duck has disappeared, namely, the Labrador Duck. Whether this was due to complete destruction upon some restricted breeding ground, or whether changes in the molluscan fauna of our bays or harbors interfered with a delicately adjusted dietary, which the specialized bill suggests, or whether it was from some entirely unthought-of reason, we can only speculate.

We must record the fact that Dresser's Eider is in great danger, unless the depredations of the Newfoundland and Labrador fishermen can be stopped, but no other species is in immediate danger here.

Among factors which are of local importance in destroying ducks, we ought to mention the accidental taking of large numbers of several species of diving ducks in fish-nets. This has assumed some importance on Lake Erie.

Nearly all species were on the down grade in America before spring shooting was 
finally closed in 1913. The process is now temporarily arrested, but it is very doubtful whether any increase is more than temporary. We must look ahead to the time when our population will be at least two hundred million, and our waste places practically eliminated outside parks and sanctuaries. It is fair to presume that the number of guns in the field when that time comes will be at least three times what it is at present, and more likely five or six times.

Among vanishing species we may record the Hawaiian Duck, Laysan Teal, Brazilian and Auckland Island Mergansers, and several Australian ducks. Our own Carolina Duck was placed in the vanishing class a few years ago, but now its safety seems assured. Among the diving ducks of North America both the Red-head and the Ruddy ought to receive careful consideration, on account of their southern breeding range. That group of Ruddies that wintered on the Atlantic Coast has been reduced to a small fraction of its former numbers since $\mathbf{1 8 9 5 .}$

Before we consider the destruction of ducks in our own time we ought to realize that wild-fowl have always been destroyed by man in large numbers. There is reason to think that nets discovered in the lake dwellings of Switzerland - a culture which existed at least as far back as 10,000 B.c. - were used to take Teals or ducks. Primitive people everywhere seem to have used the net with good effect, and it is probable that most of the catching was done during the season of moult, or before the young could fly. In New Zealand the natives carefully guard certain lakes and engage in great duck-drives in which trained dogs are used. In the season of 1867 seven thousand are said to have been caught in one lake in three days. Accounts of the great duck-drives carried out by Indians in the Bay of Fundy appear in Audubon's "Ornithological Biography," and similar methods were used on the coast of Maine by the early settlers in taking ducks, probably mostly Scoters, as far back as the late eighteenth century. This art was almost certainly learned from the Indians. When Penhallow visited the Kennebec River in Maine in August, 1717, to treat with the Indians, he described a great duck-hunt, during which four thousand and six hundred ducks were killed without the use of guns, and afterwards sold to the English for a penny a dozen! Ducks, therefore, have always been subjected to heavy toll, and have withstood persecution well on account of the large annual increase in their numbers; but primitive man did not drain marshes, introduce foreign pests, or scatter oil about.

It is interesting, also, in considering status, to give an idea of the enormous destruction to which ducks have been subjected in recent times, and these figures will give us a clue to the millions which must once have made up, and still do in many cases, the total population of a given species. In Europe, Naumann, Payne-Gallwey, and others have collected records from some of the older decoys, which institutions date back to 1730 in the East Friesian Islands, to the middle of the seventeenth century in England, to 1582 in Holland, and apparently much earlier in Germany. More primi- 
tive decoys, not the perfected kind with pipes, were common in England in the reign of King John, 1199-1216, and were looked upon as an adjunct of the King's Forest.

In the old times a good day at a Friesian Island decoy would yield 600 to 800 birds, but now not more than 100 to 150. On the Island of Föhr they used to capture on exceptional days 2000 to 2200 ducks. In the year 1789 one decoy took 66,000 . In the year 1841 one decoy on the Island of Sylt took 25,244. In 1887 this same decoy captured only 6260. One decoy in the Island of Föhr took in 1841 as many as 52,334 birds, but in 1887 six decoys on this same island got only 33,000. On the three East Friesian Islands in 1887 eleven decoys took 56,000 ducks. In an old Dutch book, called "Letters from the Isle of Texel," written by Pieter Cuyck in 1783, I find a reference to the five decoys which were worked there at that time. Cuyck says that he has seen 600 or 700 Widgeons caught there in one day. From the Kattenpolder decoy he had seen "so many ducks taken to the barge in order to be conveyed to Amsterdam, that carts with two horses, which were again followed by a small cart with two wheels, were loaded with them." There are still about one hundred and sixty decoys operating in Holland and at one time there must have been twice as many at least, so it is easy to see what great numbers of ducks must have been taken in one small area. In general, it seems that no great diminution of ducks took place in that region between 1830 and 1860, but after that the decrease was rapid, doubtless going hand in hand with the diking off and drainage of huge areas.

A decoy built by George I of Hesse, in Friesland, yielded 29,665 ducks between 1575 and 1584. Gurney mentions a great banquet in the year 1465 in which 400 swans and 4000 Mallards and Teals appeared on the bill of fare!

A remarkable statement was made by Meinertzhagen (1920) that 600,000 ducks were taken annually in the vicinity of Port Saïd for Egyptian markets. I must say that this number seemed scarcely credible to me until I began to investigate further. In America the numbers regularly taken were enormous. Cooke tells of one gunner at Big Lake, Arkansas, who sold 8000 Mallards during the winter of 1893-94, while from this one place the total number sent to market was 120,000. In the winter of 1913-14, as many as 117,843 Mallards were received in the markets of New Orleans, 27,955 Pintails, 850 Carolina Ducks, 13,632 Ring-necks (?), 15,620 Gadwalls, 1037 Canvas-backs, 789 Red-heads, 36,864 Shovellers, 30,276 Teals, and 38,560 Blue-bills, or a total of over 283,000. The markets of San Francisco received 47,565 Mallards during the winter of 1895-96, and the California Commissioner writes me that from 800,000 to $1,000,000$ ducks are still taken annually in that State. Forbush reported that at Georgetown, South Carolina, the rail-head for a famous ducking country, 5000 Mallards and Black Ducks were received in a single day.

At Currituck Sound, North Carolina, there are some twelve or fifteen clubs which formerly took an annual toll of between 2000 and 6000 ducks each, besides many others which took less. One club at Currituck has a score of 74,942 ducks shot in 
twenty-two years. Another had 49,000 to its credit in twenty years. Then take the Canvas-backs, Red-heads, Ruddies, and other ducks shot by batteries and bush blinds in the open Sound, and we must conclude that from this one region, not over forty miles long, with its clubs and its market shooters, between 100,000 and 125,000 ducks were taken each season, and in exceptional years probably 150,000.

The first attempt at anything like an analysis of the total game shot in a season was made by the Minnesota Commissioner in 1919. Each holder of a shootinglicense was asked to report all the game taken during the season, and this resulted in a very interesting set of figures. Granted a large error in the recording of the birds shot - for many sportsmen did not report - besides errors in computation of the totals, we must admit their value as a starting-point. Even if we halve them, the results are quite beyond preconceived notions of actual numbers of ducks in any one place. The Minnesota list gives the number of ducks taken in 1919 as 1,804,000, and in 1920 as $1,180,000$, these figures being still subject to revision. If we take one million as a basis for an average for this State, and sit down with a map of the United States before us, using such figures as I have already outlined for famous ducking grounds, and taking the country State by State, we arrive at a total which is almost staggering. I cannot place it at less than 6,000,000 and I doubt if it is under 10,000,000. For the present, the closing of markets, the shortening of the season, and the bag-limit have perhaps reduced the annual toll by one half; but we must feel quite certain that all the factors which have helped to save the situation will be more than made up for in the future by the increase in hunters' licenses, the growth of industries, and drainage.

To sum up, these estimates, and many more which might be produced, serve to show us what enormous numbers of wild-fowl actually exist, and can continue to do so provided they have the proper places to live and breed in and are given reasonable protection. We must remember that they withstood the most persistent and destructive methods of hunting, such as the decoy systems of England and Holland, so long as their feeding grounds remained intact, but just as soon as these were reduced beyond a certain point, the numbers which were annually taken fell away rapidly.

\section{DAMAGE}

Certainly ducks do some damage to crops where they arrive in large numbers before the grain is harvested, but it is usually an easy matter to carry on a campaign of "frightfulness" which will keep them out of the crops. The only serious complaints in the United States have been from the rice-growers of California and Arkansas. Rice ripens late in the season, so that migrants arrive in enormous numbers and special means have to be adopted to keep them out. Aëroplanes have been useful, although harmful to the ducks, and a certain amount of shooting has been permitted 
under special permits from the United States Biological Survey. This matter has been discussed from time to time in reports of the Chief of the Bureau of Biological Survey and in United States Department of Agriculture bulletins.

In taking up the different species, mention will be made of grain-feeding habits wherever this seems to be of economic importance. We must hope that methods only mildly destructive will be worked out to prevent economic loss, and these, of course, will differ according to the nature of the crop and the kinds of wild-fowl that feed upon it. A certain type of bomb exploded during the night has already proved quite successful in California.

\section{BEHAVIOR IN CAPTIVITY}

THeRE is a general impression in this country that almost any species of wild duck can be bred under fence, and that large numbers are being so reared on farms and preserves and in municipal gardens. A certain game-breeders' journal has fostered this idea. Now, if we get down to cold, hard, and disagreeable facts, we shall find that only a half-dozen species can be classed as among those that lay readily in confinement, and the great proportion of ducks can either not be reared at all, or only with great difficulty, as a sort of avicultural "stunt." In other words, they are in the same category as our Ruffed Grouse and Prairie Chickens. I do not include in the above generalization those places where ducks are kept on large ponds in almost natural conditions, many of them with full wings, and particularly those ponds located where there is no bad winter freeze-up. With such fortunate conditions many kinds can be tempted to lay that would rarely or never build nests in artificial enclosures or small crowded pools, where all natural food, both plant and animal, is soon exhausted. Then there is a large class of ducks that simply do not keep healthy in captivity, and are short-lived when deprived of wild food. Such are Shovellers, Scaups, Canvasbacks, Golden-eyes, Eiders, and the fish-eaters. Ruddy Ducks only live a week or two. Some of the rarer tropical and Australian ducks have received so little attention from aviculturalists that we hardly know what they might do. But the mere fact that a species apparently flourishes does not mean that it is easily bred. Thus the Tree Ducks live to a green old age, without as a rule any sexual instincts showing themselves. The two easiest ducks to breed are Mallard and Muscovy, but even Mallards will often refuse to lay the first spring after they have been trapped and pinioned. Carolina Ducks are next in order. Egyptian Geese are readily bred, when one has the space; as are Ruddy Sheldrakes, and Paradise Sheldrakes. Most of the Mallard-like ducks are seldom kept, because they are not particularly ornamental, but the Indian Spot-bill responds readily in confinement, and so does the Australian Duck.

The Pintail must be classed as fairly easy to rear, and the Blue-winged Teal, if one can winter it successfully, is not a rare breeder. For the rest, it must be said that 
they fall into a very different class, and although there are some successful fanciers who rear many in England, Holland, and Germany, the breeding of them save by an expert is certainly exceptional. In this group which reproduce with difficulty we might place the Gadwall, the three Widgeons, the Green-winged and Formosan Teals, and the Brazilian and Ring-necked Teals. The Bahama or Red-billed Ducks reproduce somewhat more easily. It should be added that when a hand-reared stock of any species has once been established, the problem of getting ducks to breed is very much reduced.

Among the diving ducks the European Pochard has been most frequently bred, but our Red-head only a few times. The Canvas-back has reproduced only two or three times, although no especial difficulty has been experienced in rearing them from eggs gathered in the wild. The Scaups have never laid eggs in artificial surroundings.

The Eiders and Golden-eyes have laid eggs very rarely under conditions of expert care, and the Scoters and Mergansers not at all. The Spiny-tailed, or Ruddy Duck family do not bear captivity.

Many interesting observations have been made upon pinioned ducks in enclosed ponds, but birds under these conditions do not by any means act as they would in the wild. For instance, the diving ducks do not moult so promptly or completely, and seldom go into a perfect eclipse. Display, also, may not be carried out so actively, and there is a tendency for perverted traits to appear, which result in an indiscriminate crossing of widely different species. In fact, so common is crossing in captive ducks that it is sometimes easier to get hybrids from the mixed population of a pond than to get the pure strains. Hybrids in the wild state are, however, very rare, and it is extremely doubtful whether any new species have arisen in this way. The only really common mixtures are between Mallards and Black Ducks, and I believe that most of these may be the result of wild Black Ducks mating with semiwild "call" Mallards, or "puddle-ducks" of various types.

During the period when the French Société d'Acclimatation was most active - that is, some fifty years ago - tremendous efforts were made to naturalize, and if possible domesticate, new birds, both for their use and their beauty, but the practical results were negative. After great expenditure of time and money no species of anatine bird except the Gray Goose, Mallard, and Muscovy has been shown in any way susceptible of true domestication, with the possible exception of the Egyptian Goose and the Canada Goose.

It is always interesting, I think, to record the experience of an individual, where, as in aviculture, one gets such different and conflicting results. Before listing those species which have reproduced on my farm at Wenham, Massachusetts, I should say that I have never had adequate ponds for my birds, and seldom any natural flow of water after the first of July, so that conditions have not been favorable. Particular 
attention has never been given to any save the Carolina Duck, and this bird has been reared by the hundred.

The following species have laid eggs, and young have been reared to maturity from them, usually under hens as foster mothers: Mallard, Indian Spot-bill, Australian Duck, Pintail, European Green-winged Teal, American Blue-winged Teal, Mandarin, and Carolina Duck.

The other kinds that have been represented on my ponds, often by only a pair or two, and have never bred, are as follows: Ruddy Sheldrake, European Sheldrake, White-faced Tree Duck, Fulvous Tree Duck, South American Pintail, American, European, and Chilian Widgeon, Gadwall, Falcated Teal, American Green-winged Teal, Baikal Teal, Ringed Teal, Garganey Teal, Shoveller, Bahama Duck, Canvasback, Pochard, Red-head, Red-crested Pochard, Rosy-billed Duck, Greater Scaup, Lesser Scaup, and Ring-necked Scaup. 


\section{ORDER CHENOMORPHÆ}

SUBORDER ANSERES

FAMUI ANATIDE 



\title{
ORDER CHENOMORPHA
}

\author{
SuborDer Anseres (Ducks, Geese, and Swans)
}

Family Anatid $\pi$

Ducks are typically shorter-necked than geese and swans, with fewer neck vertebræ. In common with other members of the suborder, they are adapted for a more or less aquatic life, with webbed feet for swimming (except in Anseranas) and a broad more or less flattened bill provided with horny lamellæ about the edge, for sifting out food from muddy water. They agree in having a tufted oil-gland (presumably a derived rather than a primitive character); the feathers are provided with a small after-shaft, which, however, is sometimes absent. In the arrangement of the feathers, the dorsal tract divides about halfway down the neck, enclosing a long narrow median space, and the pectoral tract likewise divides at about the same level, giving off an outer band on each side. The wing has the diastataxic interval.

The muscular anatomy is remarkably uniform throughout the group. One peculiar duck character, but found also in the loon, tinamus, and some fowls, is the meeting of the two great breast muscles over the keel of the sternum. Another marked peculiarity of the group is that the biceps femoris muscle gives off a tendinous slip attaching it to the gastrocnemius muscle, a condition found elsewhere, curiously, in the ostrich. In all members of the group, the muscle formula of the hind leg is ABX+, which means that of the five muscles important in classification, the femoro-caudal and its accessory head are present, as well as the ambiens, while the semitendinosus, though present, lacks the accessory portion that is often found arising from the distal end of the femur. Characteristic of the group and of the related screamers (Palamedeida) is the possession of two pairs of extrinsic tracheal muscles (i.e., muscles having one attachment only to the trachea) and one pair of intrinsic muscles (both origin and insertion on the trachea) attached in ducks to the third or fourth tracheal ring in front of the syrinx. In most ducks, at least in the males, the trachea at its junction with the two bronchi becomes dilated to form an asymmetrical bulbus or chamber of varying size. In the geese this enlargement is not found, but its place is taken by a bony tube formed by fusion of the tracheal rings.

In the possession of from sixteen to nineteen vertebræ in front of those bearing ribs, the ducks and geese differ from the swans in which there are from twenty-three to twenty-five. In most ducks the number is sixteen or seventeen; in geese, nineteen. The following osteological characters of the Anseres are drawn up by Seebohm (1889): (1) the dorsal vertebræ are heterocœlous (i.e., the articulating surface is 
convex at one end and concave at the other end of the vertebra); (2) in the bifurcation of the nasals, they are holorhinal (i.e., the nasal opening is rounded posteriorly instead of being continued as a narrow slit on to the frontal part of the skull); (3) the sternum has but one xiphoid process on each side of the median process; (4) the basipterygoid processes of the basisphenoid bone articulate with the pterygoids far forward and as close to the palatines as possible; (5) the lateral occipital vacuities may or may not be present; (6) the angle of the mandible is much produced behind the articulation and recurved. The maxillo-palatines are thin plates fused with each other across the palate for their entire length (i.e., the skull is desmognathous). The combination of the third and fourth characters is diagnostic of the suborder, and within the suborder the combination of the second, fourth, and sixth is equally so. 
SUBFAMILY PLECTROPTERINAE 



\section{SUBFAMILY PLECTROPTERINAE}

This group is characterized by Salvadori as follows: hind toe rather long, not lobed; feet palmated; neck moderately long; tail feathers rather long, broad, rounded at the tip; upper parts mostly glossy.

Seven genera are here included. The Carolina and Mandarin Ducks, though placed in this subfamily by Salvadori, are generally included among the more typical ducks of the subfamily Anatinæ. The same author supplies the following key to the external generic characters.

A. Lores naked; forehead and base of bill furnished with caruncles.

$\mathbf{a}^{1}$. A long spur at the bend of the wing $\ldots \ldots \ldots \ldots \ldots \ldots \ldots \ldots \ldots \ldots$ Plectropterus

$b^{1}$. Wings without spurs . . . . . . . . . . . . . . . . . . . . . . . . . . . . . .

B. Lores densely feathered.

$c^{1}$. A large fleshy comb on the base of the culmen in the male............. Sarcidiornis $\mathrm{d}^{1}$. No comb at the base of the culmen.

$\mathrm{e}^{1}$. Bill equaling or exceeding double the depth at its base.

$f^{1}$. Bill about the length of the head.

$\mathrm{g}^{1}$. Outline of the loreal feathering at the base of bill convex anteriorly.....Asarcornis

$\mathrm{g}^{2}$. Outline of loreal feathering straight and inclined backward......... Rhodonessa

$\mathbf{f}^{2}$. Bill shorter than head; outline of loreal feathering inclined anteriorly......Pteronetta $\mathrm{e}^{2}$. Bill shorter than twice its depth at base; size very small............... Nettapus 



\section{SPUR-WINGED GOOSE \\ PLECTROPTERUS GAMBENSIS (BRISSON)}

(Plate 2)

\section{SYNONYMY}

Anser gambensis Brisson, Ornithologie, vol. 6, p. 283, 1760.

Anas gambensis Linné, Systema Naturæ, ed. 12, vol. 1, p. 195, 1766.

Plectropterus gambensis Stephens, General Zoölogy, vol. 12, pt. 2, p. 7, pl. 36, 1824. Plectropterus rüppelli Sclater, Proc. Zool. Soc. London, 1859, p. 132, pl. 153, fig. 1. Plectropterus scioanus Salvadori, Ann. Mus. Civ. Storia Nat. Genova, ser. 2, vol. 1, p. 239, 1884.

\section{Vernacular Names}

English:

Spur-winged Goose

Gambo Goose

French:

Plectroptère de Gambie

German:

Sporengans

Dutch:

$\left.\begin{array}{l}\text { Wilde Macaauw } \\ \text { Maccoa }\end{array}\right\}$ South Africa

Spanish:

Pato ferrao.

Bechuana:

Peele peele
Kaffir:

Esikwi

Basuto:

Letsikhin

Angola:

Janda

East Africa:

Bata mkuba.

Arabic:

Abu qadum

Wuz abu qaru

Hitt

\section{DESCRIPTION}

AddLt MaLe: General color black with coppery red and green reflections; sides of head, throat, lower part of the neck, breast and abdomen, thighs and under tail-coverts, some of the lesser wingcoverts and edge and angle of the wing, white; a stout, sharp, pointed carpal spur at the bend of the wing.

Iris hazel; bill, including the bare skin at the top of the head and the frontal knob, red; nail of the bill whitish; bare skin around the eye and on the sides of the face gray; feet flesh-colored.

Length about 800 to $1000 \mathrm{~mm}$.; wing 410 to 540 ; tail 170 to 210 ; bill 60 to 80 ; tarsus 90 to 120 .

Weight about 12 pounds (5.4 kilograms); has been obtained up to 15 pounds (6.8 kilograms) (Stark and Sclater, 1906; A. Chapman, 1921). 
Adult FEMALE: Like the male, but smaller, weighing from 6.5 to 7.5 pounds (2.9 to 3.4 kilograms) (Hollister in litt.).

Young BIRDs have the face entirely feathered and no frontal knob.

Young IN Down: Very pale yellow-brown all over, almost buff on the lower side (some specimens which I saw at Tring were darker above). There is no distinct face pattern, but light patches on wing rudiments, scapular region, and sides of rump are well developed, besides a white area along the sides which may almost merge with the rump patches. Thus the pattern approaches that seen in the young of the sheldrakes (Tadorna). Carpal spur well developed. Iris brownish gray, feet gray, bill gray except along the lamellæ where it is red.

\section{DISTRIBUTION}

THE range of this species includes the entire area south of the Sahara, exclusive of Madagascar. There is apparently no migration proper, so that summer and winter range will be considered at the Range: same time. Like many other African birds it does, however, show seasonal changes in general distribution, depending upon the dry and the wet seasons; but our knowledge of these flights is of course very limited.

In the West it has been recorded for Senegal (Lichtenstein, 1854) and Gambia, having occurred at Bathurst (Rendall, 1892). It is said to be not rare and to breed in domesticity (?) in the SenegamGambia bian region and Casamance (Rochebrune, 1883-85). Sousa has reported it for Bissao, Portuguese Guinea, and though there are no records for either French Guinea or Sierra Leone, I think very likely that it occurs there, for it has been found breeding on Gulf of the Marfa River, western Liberia (Büttikofer, 1885). There is no evidence of its ocGuinea currence on the Ivory Coast, though it may be found there. In general the species appears to be rare on the Guinea Coast and in western Africa. J. Smith (fide Reichenow, 1900) has reported it from Accra on the Gold Coast, and there are records for both Mangu and Kratschi in Togoland (Reichenow, 1899b; 1897). I have been unable to discover any information of its occurNigeria rence in Dahomey. In Nigeria it is found in Sokoto (Hartert, 1886), and on the Niger (Baikie, fide Reichenow, 1900), while on the Benue it is common and a few are found also at Yo (B. Alexander, 1907). From Lake Chad it has been recorded also by Denham and Clapperton (1826). So far as I know, it has not yet been recorded from Camerun or the French Congo, and Mr. J. P. Chapin, of the American Museum Expedition (in litt., 1914) found it very rare, as were all other water-fowl, in the Upper Congo forests.

Eastward, however, the Spur-wing is common in the Sudan. It appears to migrate locally as the season varies, but is in most months fairly common everywhere south of Khartum (Butler, 1905), Sudan though apparently not of frequent occurrence in the Southwest (Butler, 1908). It has been recorded for the White Nile a number of times (Witherby, 1901; Ogilvie-Grant,

1902; Antinori, 1864; Sassi, 1906; Jägerskiöld, 1904). Antinori, however, states that it is more common on the Blue than on the White Nile, but I found it almost absent there in the winter season. A. E. Brehm (1857) and Kotschy (fide Reichenow, 1900) both met with it at Senaar. Von Heuglin (1873) took young birds in Kordofan, so it presumably breeds in that region. He saw the birds south even in Bahr-el-Ghazal, and Antinori states that they are not rare in that section. It has also been noted in Abyssinia where von Heuglin found it on Lake Tana. Rüppell (1845) and Salvadori $(1884 ; 1888)$ have recorded it from Shoa, and Reid (Ogilvie-Grant and Reid, 1901) saw the birds in pairs on Lake Ailan near Addis-Ababa, and states that there were large flocks at the junction of the Moggoi and Hauash Rivers. Von Erlanger in 1905 also found it on the lower Hauash. Whether or not it occurs in eastern Abyssinia or in Somaliland, I am unable to say, but it would scarcely be more than a rare bird in this desert region. 



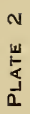

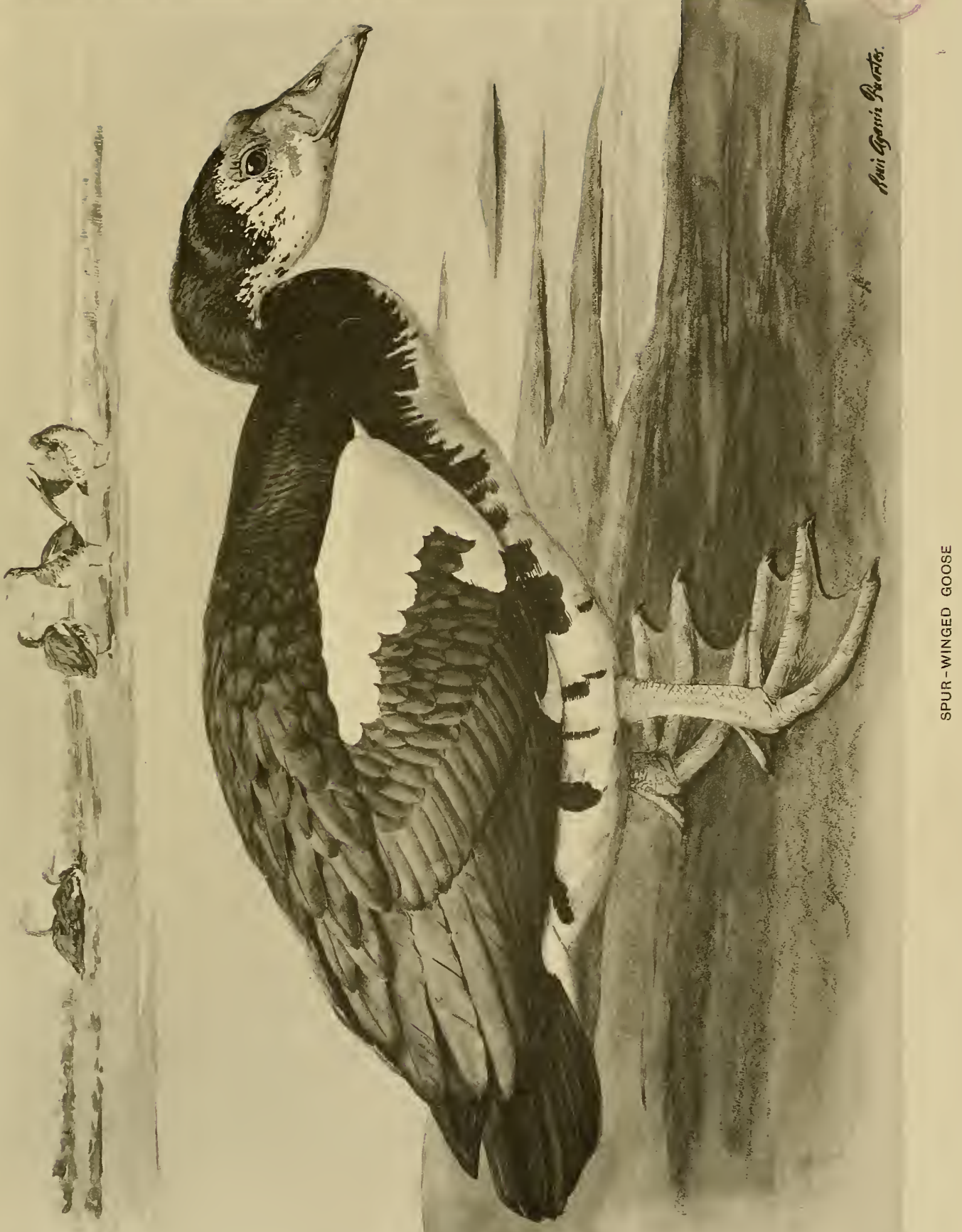



In British East Africa the species occurs almost exclusively in the lake region of the southern central part. Lönnberg (1912) says it is not found in the dry season, but that it is pretty common in the wet weather, at Kagio, Fort Hall, Punda Melia, and that it may breed on the British Rovin River. G. H. Gurney (1909) states that it is common on Lake Naivasha and East Africa the Athi River, while Fischer (1884) has recorded it for Kageji and Lake Naivasha. According to Ogilvie-Grant (1901) it has been taken at Buffa Lake. Van Someren (1916) states that it is common, and breeds on Lake Nakuru. Another record for the Athi River is that of Dearborn (1909). In Uganda it has, as far as I know, been found only by van Someren (1916) who has reported it for Kasaka and Jinja.

It seems that in Tanganyika Province (German East Africa) the species is much more abundant. Schillings (1905) found it on the Pangani River and common on the Rufu River, and on the Lafitti Hills, as well as south of Kilimandjaro. He states also that the species is abundant on Lake Njiri. According to Sjöstedt (1910), it occurs on the Natron Lakes, and in the Kilimandjaro-Meru region, "not rarely" in the dry season. In the wet season he met it at altitudes up to 1400 meters. Further records are those for Lake Jipi (Volkens, 1897) for Newala (Tristram, 1888), for Pangani, Kingani, Ronga and Engatana (Fischer, 1885), for Bagamojo, Ugalla, Wualaba, where it breeds, Tanganyika, Kakomo, Bogo Katani, Lualaba, Luwule, Itambe Lake, Lugoma, Lufira and Likulwe (Böhm, 1882), for Kibaja Massai (Neumann, 1898), for Tareba in Massai (Shelley, 1889), for Uniamuesi (P. L. Sclater, 1864), and for the extreme southeastern shore at Muasi (Grote, 1912).

From the western side of Tanganyika the species has been recorded as occurring in the Congo Free State. Both Neave (1910) and Mouritz (1914) state that it is not uncommon in Katanga, while Böhm (1882) met with it in the Upemba Lake region and von Trotha (fide Reichenow, $1900)$ in the vicinity of Lake Tanganyika. Neave (1910) also reports that it is frequently Tanganyika found in northern Rhodesia, and it has been taken near Lake Banguelo (Salvadori, 1914). We may assume that it inhabits also the western section of the Colony, for it has been recorded from the upper Zambesi, where it is rather abundant (Livingstone, 1857; J. Chapman, 1868; Holub and von Pelzeln, 1882), and lower Zambesi (W. L. Sclater, 1912); and it has been found in Zambesi various sections of southern Portuguese West Africa, namely, in Benguela, at Huilla, and at Humbe, on the Kuene River, and at Quindumbo (Barboza du Bocage, 1877-81). South Africa Andersson (1872) however, did not meet with the species in German Southwest Africa, and if it occurs at all, it must be rare there. On the other hand, it is quite common in the lake region of the Bechuana Protectorate (Horsbrugh, 1912), on the Okawango River (Andersson, 1872), on Lake Ngami (Andersson, 1872; Fleck, 1894; Bryden, 1893; J. Chapman, 1868), on the Tonka River (Andersson, 1872; Bryden, 1893; J. Chapman, 1868), at Nocana (Fleck, 1894), on the Botletli River (Bryden, 1893; J. Chapman, 1868) and on the Limpopo River (Holub and von Pelzeln, 1882). It is recorded also from Matabeleland (E. C. Chubb, 1908; Buckley, 1874) and has been reported as not uncommon in Mashonaland (G. Marshall, 1900). On the coast, in Portuguese East Africa, it seems to be fairly abundant, having been found on Lake Shirwa (Shelley, 1893) and commonly on the Shiré River (Kirk, 1864; Sperling, 1868; Percival, 1902) as well as on the Lower Zambesi, where it breeds (J. Chapman, 1868; Kirk, 1864; B. Alexander, 1900).

In the Cape Region the Spur-wing is, however, rare. The records for the Transvaal are all for the southern and western borders, in parts of which it is common according to Horsbrugh (1912). W. Ayres (1887) met with it at Potschefstroom. Gilfillan met with it on the Vaal Cape near Heidelberg (Stark and Sclater, 1906) and from the Bechuana frontier it has been Colony recorded as found at Taungs (Stark and Sclater, 1906), on the Harts River (Holub and von Pelzeln, 1882), and near Mafeking (Nicolls and Eglington, 1892). It has been seen a few times in Natal, at Newcastle (Butler, Feilden and Reid, 1882) and at Howick, Maritzburg, and the Conzella flats (Woodward, 1899). It is not uncommon and apparently breeds in Zululand (W. L. Sclater, 1912). In Basutoland it was found breeding near Maseru on the Caledon River (Bowker, fide Stark and 
Sclater, 1906), and is said to be common on the vleis of the Orange River, where it breeds (Horsbrugh, 1912; Holub and von Pelzeln, 1882; Haagner and Ivy, 1908). It is extremely rare in Cape Colony, excepting on parts of the Orange River, though it was found rather frequently at Matatiele and East Griqualand (Davies, 1908). It was once met with at Aliwal North (C. H. T. Whitehead, 1903) and is said to be not uncommon in the Lady Grey Division (Lawrence, fide Stark and Sclater, 1906). On the coast it occurs rarely at Port St. John (Shortridge, 1904) and at King William's Town. So far as I know it has never been reported from any of the western regions of the Colony, and it is unknown from (former) German Southwest Africa.

It must be added here that the present species has been taken a few times in Europe, and though it is more than probable that these were escaped specimens, there are still writers who have their Europe doubts. One was taken on June 20, 1821, near St. Germans, Cornwall, England, and Europe another in February, 1855, near Banff, Scotland; while the third record for the British Isles is one for Pewsey, Wilts, England, September 3, 1869 (F. O. Morris, 1903). One was taken in Berkshire, England, 1858-59 (B. O. U. Check-list). It has been taken on the continent but once, to my knowledge, namely, at Alfeite, Portugal (Seabra, 1910).

\section{GENERAL HABITS}

Aцtнолgr the literature on this species is considerable, it must be confessed that very little is known of its intimate life-history. Von Heuglin (1873) has given us the most detailed account, and one which is well worth summarizing. He says in part, that in Northeast Africa this duck lives in pairs or families, and during the winter dry season is sometimes found in large flocks on waters and swamps. In the daytime they like to lie in the lowlands where wild rice is abundant, and also on moist meadows or new grain-fields. Mornings and evenings they alight amidst "hellish uproar" on open waters and sandbanks. They do not seem to migrate in Northeast Africa, but when the dry season begins they leave some of their favorite haunts, especially the extensive swamps which lie on the banks of both Blue and White Niles and their tributaries. In these districts they inhabit both the swampy woods and the treeless morasses. On land their attitude resembles that of the swans, the neck being sometimes erect, but more frequently S-shaped. In spite of their short legs and large webbed feet, their gait is certain and quick; the flight, however, is somewhat clumsy, prolonged, and occasionally gliding, and when rising or alighting the bird is very noisy. The breeding period, he thinks, must fall in the summer rainy season, for at that time single pairs break away from the flocks. He himself never found a nest, but had young birds brought to him from Kordofan in September. The moult takes place in December.

Abel Chapman (1921), speaking of their habits on the White Nile, says that they prefer to roost on drier islands and on firmer ground than those selected by the Egyptian Geese.

Daily Movements. Böhm (1882) states that partly before sunrise and partly after, they arrive from their roosting-places on the swamps and ponds to spend the 


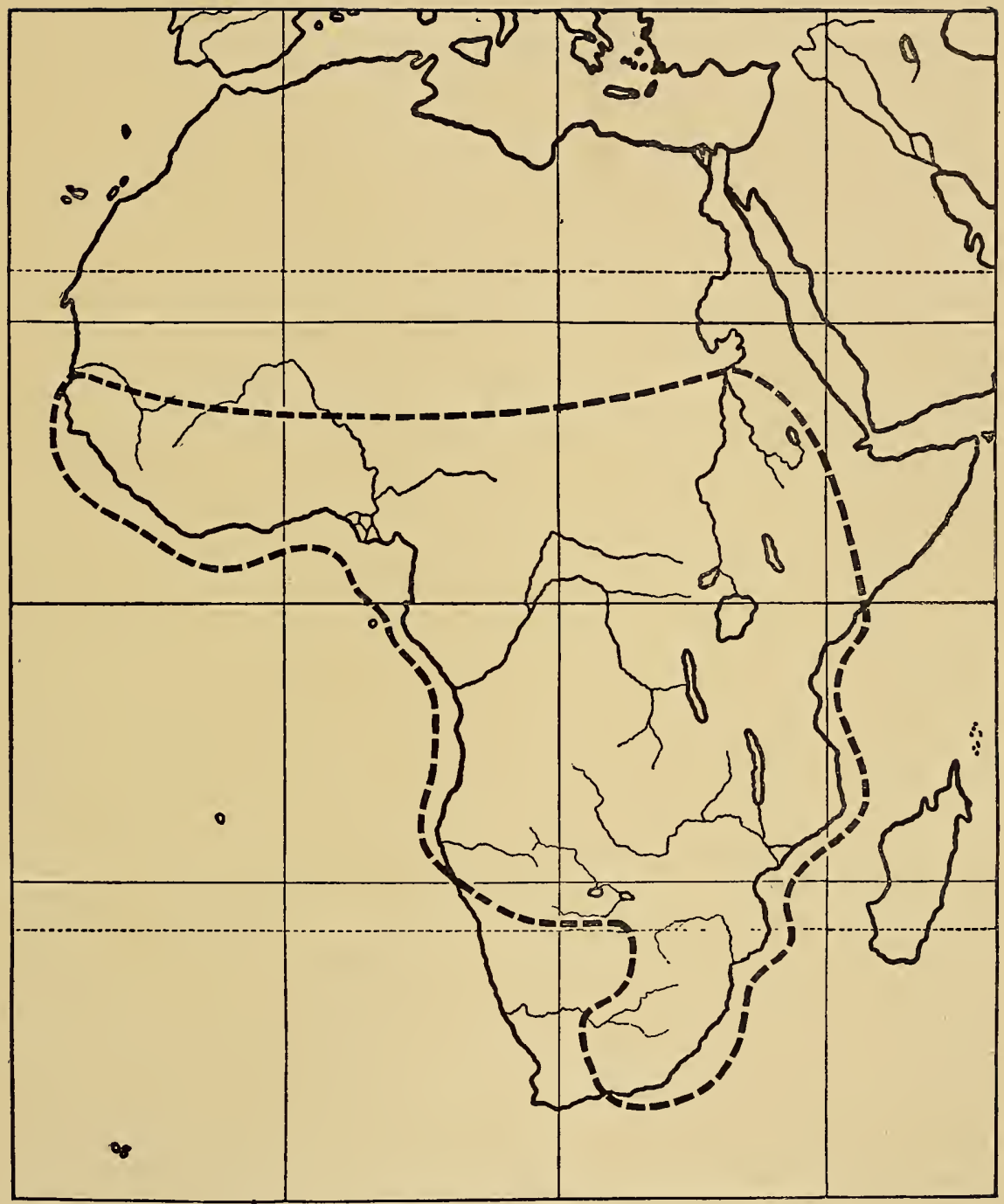

MaP 1. Distribution of Spur-winged Goose (Plectropterus gambensis) 

days in feeding, and that before alighting, they usually circle a few times. Sometimes they perch on a solitary dead tree in some swamp. In landing on the ground they take care not to alight heavily. The neck and feet are stretched out, and the beating of the large wings makes a loud noise. This writer thinks that they occasionally spend the night on the branches of trees. At least three other observers found birds perching or roosting on trees. In the marshes their feeding-places are easily discoverable on account of the paths which they make through the grass. Exceptionally, Abel Chapman (1921) found them flying far afield on moonlight nights. In the daytime he frequently saw them squatting on sandbanks where they had a very untidy and unsightly appearance in contrast to the trim and smart appearance of northern wild-fowl.

WARINESS. Nearly all observers are in agreement as to their extreme shyness, but T. Ayres (1880) says that in the Transvaal they would almost invariably creep away instead of taking wing, so that unless the hunter has a dog it is no easy matter to find them. At times also they seem to be very inquisitive, and when on the wing will occasionally approach a hunter near enough to be within easy range. None of the so-called African Geese seems to post sentries, and whole flocks of this species may be seen apparently fast asleep (A. Chapman, 1921).

Fuight. Witherby (1901) did not find them in large flocks on the White Nile, and usually they were seen in company with larger numbers of Egyptian Geese. On the whole the consensus of opinion is that these birds are seldom found in large numbers, the flocks usually averaging from five to a dozen, though as many as thirty or forty have been seen together. In the Kilimandjaro region, Sjöstedt (1910) found them in February and March in small flocks. When disturbed they stretched their long necks, the head motionless, then slowly arose with heavy wing strokes and flew away high over the steppe. He also found them rather high up on the mountains, and during the rainy season, on April 14, several specimens were seen at an altitude of 1400 meters, in company with the Black Duck (Anas sparsa).

VoICE. Heinroth (1911) describes the voice as a series of short, abrupt, though sometimes prolonged, whistling sounds, like the squeak of a rubber doll, very insignificant for so large a bird. Usually the note is accompanied by jerky movements of the head and body. In spite of his wide experience in zoölogical matters, Heinroth is not sure whether or not the note of both sexes is the same. Other observers have described the voice in various ways, but nearly all remark its extreme weakness, considering the size of the birds. In the young the note seems to be a hissing noise. In older birds it has been described as a hoarse quack, or even as a trumpet-like sound. According to Horsbrugh (1912) it is a curiously weak sort of whistle which 
sounds like cow-whit, sometimes clear, sometimes rather harsh. He never heard any trumpet-like or loud, clanging notes. Mr. Crandall, of the New York Zoölogical Park, tells me that he has never heard the female call, and describes the male's note as a "whistling quack," often repeated.

Food. These birds appear to be omnivorous. Kirk (1864) speaks of their eating the "nyka," the tuberous enlargement of the Nymphæa bud. Von Heuglin (1873) describes their diet as consisting of grain and grass sprouts, worms, crustaceans, fishes, and snails. Many other observers have noted their habit of feeding in grainfields. Holub and von Pelzeln (1882) found them living on fish, insects, worms, mollusks, seeds and fresh grass.

Courtship and Nesting. There is no information about display attitudes in this species. Heinroth noted no peculiar postures when a male Spur-wing mated with a female Muscovy in the Berlin Zoölogical Garden.

In spite of the fact that this bird is common over the greater part of Africa, very few nests appear to have been found by travelers. In the Sudan it seems quite certain that they breed in the spring during the rainy season, but in other localities it is probable that the breeding season is much more irregular, for in western Liberia Buittikofer (1885) found young in the middle of November and in Zululand Grant (W. L. Sclater, 1912) took eggs in April. The commonest situation for the nest seems to be among long grass, often some distance from the water, but on the Zambesi, Kirk (1864) and Livingstone (1857) say that they nest on ant-hills. Bowker (Stark and Sclater, 1906) took a clutch of eight eggs from an old heron's (Scopus umbretta) nest on an overhanging rock on the banks of the Caledon River, Natal. Hartert (1886) thought that they nested in trees, but admitted never having found a nest. Observers are not in agreement regarding the number of eggs in a clutch, the figures given varying from three or six, up to ten or twelve. There appear to be no observations as to the nest itself, which is probably no more than a hollow lined with grass. The eggs are smooth, shining, and ivory white, with numerous fine pores, and measure $71 \times 53 \mathrm{~mm}$.

Status of Species. A general idea of the wide distribution and abundance of this species has been given under the heading "Distribution." Shortridge (1904) notes that it is now rare where it used to be plentiful in eastern Cape Colony. Butler (1905) found it not as common as the Egyptian Goose on the White Nile. He noted, however, "enormous numbers" during April in eastern Senaar. There are only one or two observations as to their natural enemies, namely, that of Holub and von Pelzeln (1882) who say they are fed upon by crocodiles and otters in South Africa. Kothe (1911) shot one in Tanganyika Province (German East Africa) which had evidently lost a leg from the attack of a crocodile. 
It seems probable that this fine bird will remain plentiful, both on account of its ability to look after itself and because of its small food value. Where it is much persecuted by man, it may undoubtedly become nocturnal in its feeding habits all over its range, and so continue abundant in thickly settled localities. Just how much damage the species does to agriculture it is impossible to say. Horsbrugh (1912) in writing of South Africa says that these geese do an "immense amount of damage, treading down the standing corn with their huge feet, and spoiling much more than they eat." An informant wrote him that the birds also alight on the corn when it is stacked, and completely ruin it by stripping the grain off the top sheaves. In these localities they apparently already feed by night.

Food VALUE. Every traveler agrees as to the coarse character of the flesh, and the unpleasant flavor of the Spur-wing's meat. Such expressions as "coarse, rank, fishy, and tasteless" are used in describing its culinary value. The only two exceptions to this verdict are from Stark and Sclater (1906), who found the young birds "delicate and good," and from Horsbrugh (1912), who says that while young the birds are "not bad eating," though when old they are "quite impossible."

Behavior In Captivity. The Spur-wing is a common species in zoölogical gardens, but I can find only two records of its ever having bred in captivity. Flower (1915) reported its having twice bred in the Zoölogical Gardens at Cairo. Haagner and Ivy (1908) saw these birds in Cape Colony living on farms in a semi-domesticated condition, and they were informed that the birds had been reared from the eggs. Presumably these eggs had been taken from the nests of wild birds. On the Zambesi River it was also found in a semi-domesticated condition (Tiesler, 1905), but there is no information that would lead me to suppose that the species has been truly domesticated, in spite of what Rochebrune (1883-85) says about seeing it domesticated among the negroes of Senegambia. They are very easily kept in confinement, and will eat all ordinary grains and even raw meat. At times they become very pugnacious, and cannot be kept together with smaller or more delicate species. Heinroth (1911) in his excellent paper on the psychology of Anatida, tells of a Muscovy male which was actually "perforated" by the spurs of one of these geese, and of a female Black Swan that had her back torn in tatters and her head almost scalped by the same weapons. He furthermore states that sometimes certain individuals become dangerous even to human beings. In Cairo it was found to be perfectly safe to leave these birds out at night where, in spite of the presence of jackals and wildcats, they came to no harm. Spur-wings and the larger cranes were the only species which could stand such exposure (Finn, 1919). Mr. Blaauw, of Hilversum, Holland, tells me that he kept this species only once and got rid of it on account of its pugnacious habits. 
These birds become tame very quickly, and at times live to advanced age. In the Cairo Gardens the length of life was only four years and ten months, but at Frankfort-on-the-Main, Schmidt (1878) gave the age to which they attain as from eight years nine months to nine years nine months. The eighth edition of the "List of Animals Living in London Gardens" (P. L. Sclater, 1883) records one specimen twenty-six years old at that time, and others twenty-five years, sixteen years, etc.

The market value of live specimens before the World War varied from $\$ 20.00$ to $\$ 50.00$ the pair.

Hyвrids. In the Berlin Gardens hybrids were produced with the Muscovy Duck (Cairina). These were all males. About half of them died during early embryonic stages and many more in down stages, few living to maturity (Heinroth, 1911 ; Poll, 1906). This same cross was also made in the New York Zoölogical Gardens in 1911, so Mr. Lee S. Crandall tells me, and there the young lived only a few days, refusing to eat.

Leverkühn (1890) records a cross between a male of this species and a female Egyptian Goose (Alopochen agyptiaca).

\section{GEOGRAPHICAL RACES}

\section{BLACK SPUR-WINGED GOOSE \\ PLECTROPTERUS GAMBENSIS NIGER SCLATER}

\section{SYNONYMY}

Plectropterus niger Sclater, Proc. Zool. Soc. London, 1877, p. 47, pl. 7.

Plectropterus gambensis niger Reichenow, Die Vögel Afrikas, vol. 1, p. 136, 1900.

$$
\begin{array}{ccc}
\multicolumn{2}{c}{\text { Vernacular Names }} \\
\text { English: } & \text { French: } & \text { German: } \\
\text { Black Spur-winged Goose } & \text { Plectroptère noir. } & \text { Schwarze Sporengans. }
\end{array}
$$

THIs geographical race inhabits southern and southeastern Africa and probably intergrades with the true $P$. gambensis. In size it is the same as $P$. gambensis, but the frontal knob is not so prominent, and there appear to be no bare spaces on the sides of the neck. There is said never to be any white on the throat, and the white on the front of the body is much less extensive. P. L. Sclater $(1860$, p. 38) has pointed out differences in the skeleton.

Horsbrugh (1912) says that on the Orange River, South Africa, he saw large flocks of the Black Spur-wing, among which were three or four birds answering to the description of $P$. gambensis, and he does not consider that the theory that the increase in the white of the plumage is due to age, will account for so few specimens of gambensis-like birds among these large flocks. In other words, he considers $P$. niger a valid species, intergrading to the north with birds showing more and more white on the throat and underpart.

Gunning and Haagner (1910) state that some score of Spur-wings in a Transvaal zoölogical garden represent all stages of plumage from $\boldsymbol{P}$. gambensis gambensis to $P$.gambensis niger. They discard the latter form entirely. 


\section{MUSCOVY DUCK \\ CAIRINA MOSCHATA (LINNÉ)}

(Plate 3)

\section{SYNONYMY}

Anas moschata Linné, Systema Naturæ, ed. 10, vol. 1, p. 124, 1758.

Cairina moschata Fleming, Philosophy of Zoöl., vol. 2, p. 260, 1822.

Hyonetta moschata Sundevall, Meth. Nat. Av. Tentamen, p. 146, 1872.

English:

Muscovy Duck

Musky or Musk Duck

French:

Canard musqué

Canard de Barbarie

\section{German:}

Moschusente

Bisamente

Türkische Ente

\section{Dutch:}

Muskuseend

Bizameend

Spanish:

\section{Vernacular Names}

Pato criollo

Pato almizclado

Pato perulero

Portuguese:

Pato bravo

Pato do matto

Pato almizcarado

Indian:

Cotua - (Peru)

Quayaiz - (Colombia)

Mairua

Oumeh $\}$ - British Guiana

Arabic:

Khonkhel

Pato real

\section{DESCRIPTION}

ADULT MaLe: Head, crest and neck brown, except a patch of bare black skin, surrounded by pinkishred caruncles, which extends from back of the eye to the bill. Mantle dark greenish brown. Scapulars and tertials, upper tail-coverts, and tail metallic green or purplish. Whole lower surface brown. Upper and under wing-coverts white like the axillars. Secondaries metallic purple, primaries blackish. Bill varied with blackish and pinkish-white; irides brown-yellow. Legs and feet black (Salvadori). Note: The iris is sometimes described as dirty straw-color, sometimes as seal-brown, the bill black, spotted with light ashy blue. Skin of lores and base of bill black (M.C.Z. specimens).

Length $900 \mathrm{~mm}$.; wing 400 ; tarsus 65 ; bill 75 . Weight 8.8 to 11.0 pounds (4 to 5 kilograms).

Addut Female: Similar to the male, but much smaller and with no naked skin or caruncles on the head.

Irides brown. Bill, blackish, with a pale bluish band. Legs and feet black.

Weight 5.5 pounds (2.5 kilograms). 
Immature Specimens: Less glossy on the back and wing-coverts without white, or with only a few white feathers.

Young IN Down: Not particularly characteristic. Bill very heavy and somewhat hooked at the tip. General coloration somewhat similar to that of a young Mallard but the orbit streak does not extend forward of the eye, only back of it. The superciliary light streaks are very prominent, meeting in front so as to form a nearly white forehead thus differing somewhat from the pattern seen in the Mallard.

\section{DISTRIBUTION}

THE Muscovy, which is found in almost all parts of the world in the domesticated state, is a distinctly tropical species confined to the New World. Its chief habitat is Central America and northern South Mexico America. It is not considered a migrant and breeds in all suitable localities. The range
extends northward to perhaps the Tropic of Cancer in Mexico, it having been found a common resident and breeding bird at Mazatlan, Grayson (Lawrence, 1874) and Forrer ( $f$ ide Salvin and Godman, 1897-1904) having met with it at Presidio. The northern limit is apparently Rio Cruz, central Tamaulipas (Phillips, 1911). De Armas (1893) states that it is common all over Mexico, and Sumichrast (1881) has recorded it for both coasts. Cooke (1906), however, is probably right in fixing the northwestern limit at Mazatlan, nor do I believe the species in the wild state is common north of central Mexico. Xantus (Lawrence, 1874) found the birds on the Zacatula River and Sumichrast (1881) has recorded it from Tapana and Santa Efigenia. Off the coast of Yucatan it has been met with on Cozumel Island (Salvin, 1889).

Throughout Central America this species is abundant. It has been recorded from Belize, British Honduras (Sclater and Salvin, 1859) and from Peten Lake (Leyland, 1859), in Guatemala from Central Yaxha Lake and Rio Polochic on the Atlantic side, and from Santana Mixtan, Chiapam, America and Huamachal on the Pacific side (Sclater and Salvin, 1859, 1865). Leyland (Moore, British 1859) met with it in Honduras on the Chamalacon and Aloor Rivers and G. C. Taylor Honduras (1860) reported it from Lake Yojoa in the same State. It is extremely abundant in westGuatemala ern Nicaragua at Sucuya and has been found breeding about Lake Nicaragua (March, Nicaragua 1864). Richmond (1893) met with it on the Rio Escondido. According to various obCosta Rica servers it is extremely common also in Costa Rica, whence it has been recorded for the Gulf of Nicoya and La Palma (Nutting, 1882) for Miravalles (Underwood, 1896) and for Guanacaste (von Frantzius, 1869). Carriker (1910) states that it is commonest on the Pacific side (which seems to apply to all of Central America) and especially in Guanacaste. He records it also from Bebedero, Bagaces, Miravalles, Rio Grande de Terraba, Buenos Aires and from Guacimo River (on the Atlantic side), where it was very rare, though it is presumably to be found on the lower San Juan River. M'Leannan (Sclater and Salvin, 1864) states that it occurs in Panama, and it has been Panama recorded from there for Laguna de Pita (Salvadori and Festa, 1899) for Colon (de Armas, 1893) and also for the Canal Zone (Stone, 1918).

In South America this species seems to inhabit chiefly the northern areas. On the Magdalena, Colombia, it is common from the mouth up as far as Yeguas (W. Robinson, 1895) and the same is true South for the Cauca Valley (F. M. Chapman, 1917). Pomeroy (1918) has recorded it also for America the lower Magdalena and the Rio Frio. In Ecuador it has been found on the Pastaza Colombia River (Goeldi and Hagmann, 1902). Ernst (1877) met with it in Venezuela and Beebe Ecuador (1909) states that in the northeast it is quite common at the mouth of the San Juan. Venezuela It is abundant also on the Caura and on the Orinoco at Altagracia and Quiribana de

West Indies Caicara (von Berlepsch and Hartert, 1902). Its occurrence in the West Indies is still questionable. Gosse (1847) and Newton (1881) are doubtful about its presence in Jamaica, and though Ballet (1895) has recorded it from Guadeloupe I am inclined not to lend the 




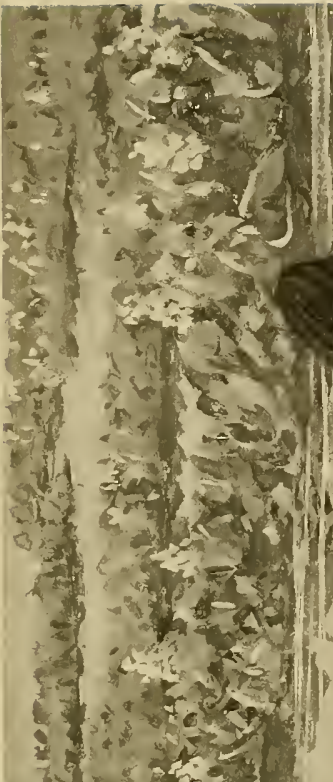

(1) resis ifs 302

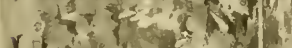
(I)

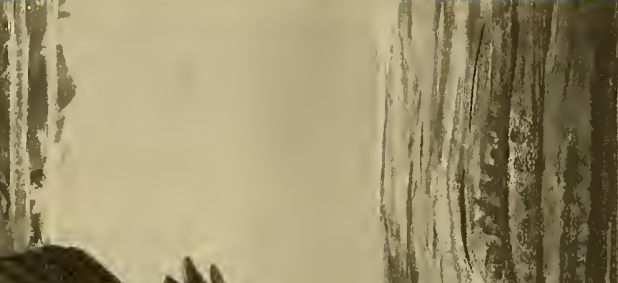
हैं

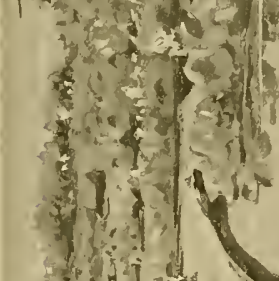
3 a d w Sil $r$ s 10) a

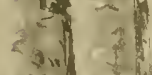
में

क्षेत (n) $x-5$ (i) -1 f
2)
2

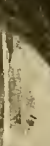
(1) ,
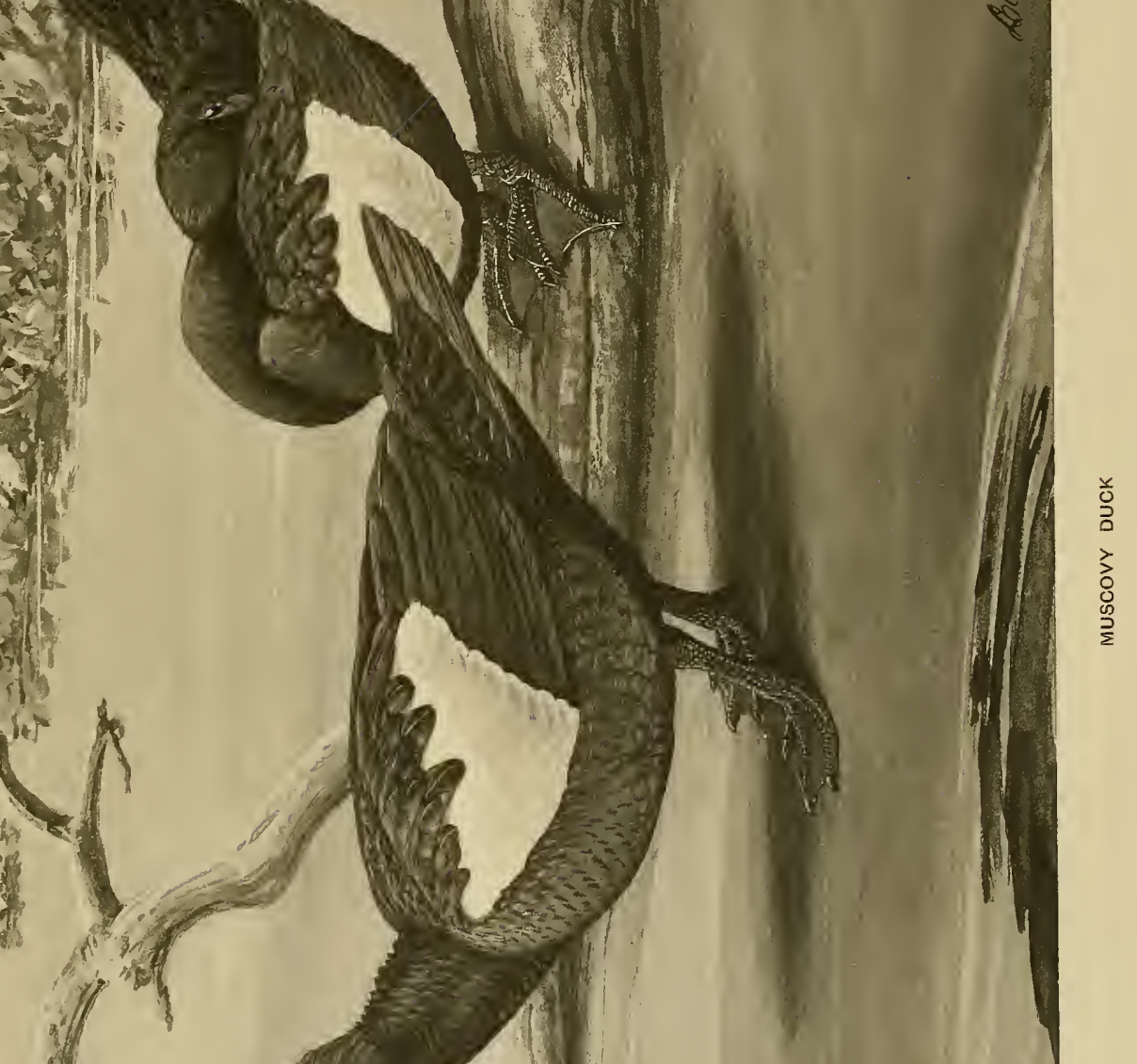

statement much credence. It does, however, inhabit the island of Trinidad (F. M. Chapman, 1894; Leotaud, 1866). Many years ago R. Schomburgk (1848) spoke of it as abundant in British Guiana, and in recent years it has been found there by Whitely (Salvin, 1886) (alt. $2700 \mathrm{ft}$.) and by Dawson (1916). It is also abundant in Dutch Guiana, on the coast as well as inland

Guianas (F. P. and A. P. Penard, 1908-10) and, though there are no records, we may assume that it inhabits also French Guiana.

Throughout the greater part of Brazil the Muscovy is commonly met with. It is abundant on Mexiana Island, in the mouth of the Amazons, and breeds there (Hagmann, 1907) and has been reported as abundant also in Para, Marajo Island, Arary and Amapa (Goeldi, 18941900). According to H. and R. von Thering (1907) it is found in Bahia, Minas Geraes Brazil and Rio de Janeiro, while von Pelzeln has recorded it from the whole central region of Matto Grosso and Rio Madeira. It occurs in Bolivia (D’Orbigny, 1835-44) and in the region of the Brazilian-Peruvian frontier, at Pebas in eastern Peru (Sclater and Salvin, 1867) and Bolivia on the upper Ucayali (Sclater and Salvin, 1866). The species has recently been taken at Charuplaya, Bolivia (C. Chubb, 1919). Von Tschudi (1845-46) met with it even on the coast of Peru, between Lurin and Chorillos, as well as on the lagoons of the high plateaux; and Peru Farabee, collecting for the Museum of Comparative Zoölogy, took two specimens in May, 1909, on the Rio Tambapata, eastern Peru. De Armas (1893) claims that it was exceedingly abundant there in years gone by.

South of the Tropic of Capricorn the species becomes rarer. H. and R. von Ihering (1907) state that it is found in southeastern Brazil in São Paulo and Rio Grande do Sul, while both Burmeister (1872) and von Pelzeln (1868-71) have recorded it from the Rio Parana. Berlepsch Southeastand von Thering (1885) reported a specimen from Taquara, Rio Grande do Sul. In Para- ern Brazil guay the species was found common by Azara (1805) and C. H. B. Grant (1911) states Paraguay that it is still common in the northern parts, especially at Puerto Maira. It occurs quite frequently also in the Argentine, whence it has been recorded from Oran and Salta (Bruch, 1904; E. W. White, 1882). It is known to have bred in the Chaco (Hartert and Venturi, 1909).

Argentina It is known also from Tucuman (Burmeister, 1872; H. and R. von Ihering, 1907; Lillo, 1902) and La Ramada (Lillo, 1902), from Santa Fé (Burmeister, 1872) and from Buenos Aires (Venturi, fide Dabbene, 1910; Sclater and Hudson, 1889). It occurs occasionally in Uruguay (Tremoleras, 1920), though the mouth of the La Plata is far south for the species. A remarkable Uruguay record is that of Oustalet (1901), who tells of the species having been found breeding and occurring in some numbers near Rocca, five miles south of the Rio Negro; that is, about $40^{\circ}$ south latitude.

Pallas (1831), and later on, among others, Keyserling and Blasius (1840), held that this species originally came from the Caspian, and that it is still to be found there in the wild state. This view is, of course, no longer supported by modern ornithologists, and so eminent an authority as Radde (1884), while admitting that wild birds were found in that region, states that they were undoubtedly descendants of escaped birds. In like manner are to be regarded the specimens that from time to time are taken in Europe, though in years gone by Schlegel (1866) as well as Degland (1849) firmly believed some of the specimens from western France were wild birds. Occasionally examples are taken on the east coast of North America. These also are unquestionably escaped birds or descendants of such. M. J. Nicoll, in his "Three Voyages of a Naturalist" (1908, p. 224), says the natives of Tautira in the Tahiti Group brought many of these birds aboard. It has long been domesticated in the Pacific Isles generally.

The species has been domesticated not only in Europe and America, but even in Liberia (Johnston, 1906) and East Africa (G. A. Fischer, 1885), so that we may expect to find it almost anywhere. 


\section{GENERAL HABITS}

The best account of the Muscovy in the wild state is given by F. P. and A. P. Penard, "De Vogels van Guyana" (1908-10), and is in part as follows: They are met with on the seacoast as well as on inland waters. In the dry seasons the species is found in the mangrove regions in flocks of fifty and more, though usually in much smaller numbers. In the low regions along the coast flocks are much larger than at higher altitudes, where more than eight or ten are rare, and where they are often found alone or in pairs. The flock follows a leader when walking, but at the approach of danger the individuals scatter in all directions. During the noonday heat they retire into the thick rushes along the shores. They spend the night on high trees. If approached, they fly to the ground and wait with outstretched necks till the danger is past, but if the danger continues they fly off with a powerful, flapping flight. During the breeding season the males fight violently, trying to abduct each other's mates. Many birds are shot by tying a female to a peg and then scaring up the ducks from the surrounding country. The males are noticeably more numerous than the females, and fight with one another for the decoy female; and sometimes fifty drakes can be killed in one day by this device. At times a dozen decoy birds are used in localities where the species is numerous.

Muscovies, these authors continue, are extremely shy before the breeding season, but are taken by good gunners partly because they always fly low. They have rapidly diminished in numbers in recent years. On the plantations, they say, interbreeding must take place, because in the wild state one finds specimens showing partial albinism. In places where there are no tame birds albinism is not found.

Pomeroy (London Field, July 6, 1918) in writing of Colombia speaks of them as being much persecuted there by the natives and of resorting to high trees both at night and during the heat of the day.

The favorite habitat of the Muscovy is the region of forested swamps along the banks of streams and large rivers, where they lead a rather secluded life in small companies.

Wariness; Daily Movements. Apparently the species is rarely met with far from wooded country except in the wet season when open savannas are flooded. As the dry season advances, they are driven more and more to the wooded banks of streams (Cherrie, 1916). They seem to be well able to take care of themselves, as nearly all writers mention their wary disposition and the inaccessibility of their haunts. Nutting (1882) speaks of them as the shyest and most difficult to approach of all Costa Rican birds. They pass the night in high trees often resorting to the same tree night after night; sometimes, according to Hagmann (1907), dozens roost together in the same tree. A favorite roost in Brazil is the smooth horizontal branch 


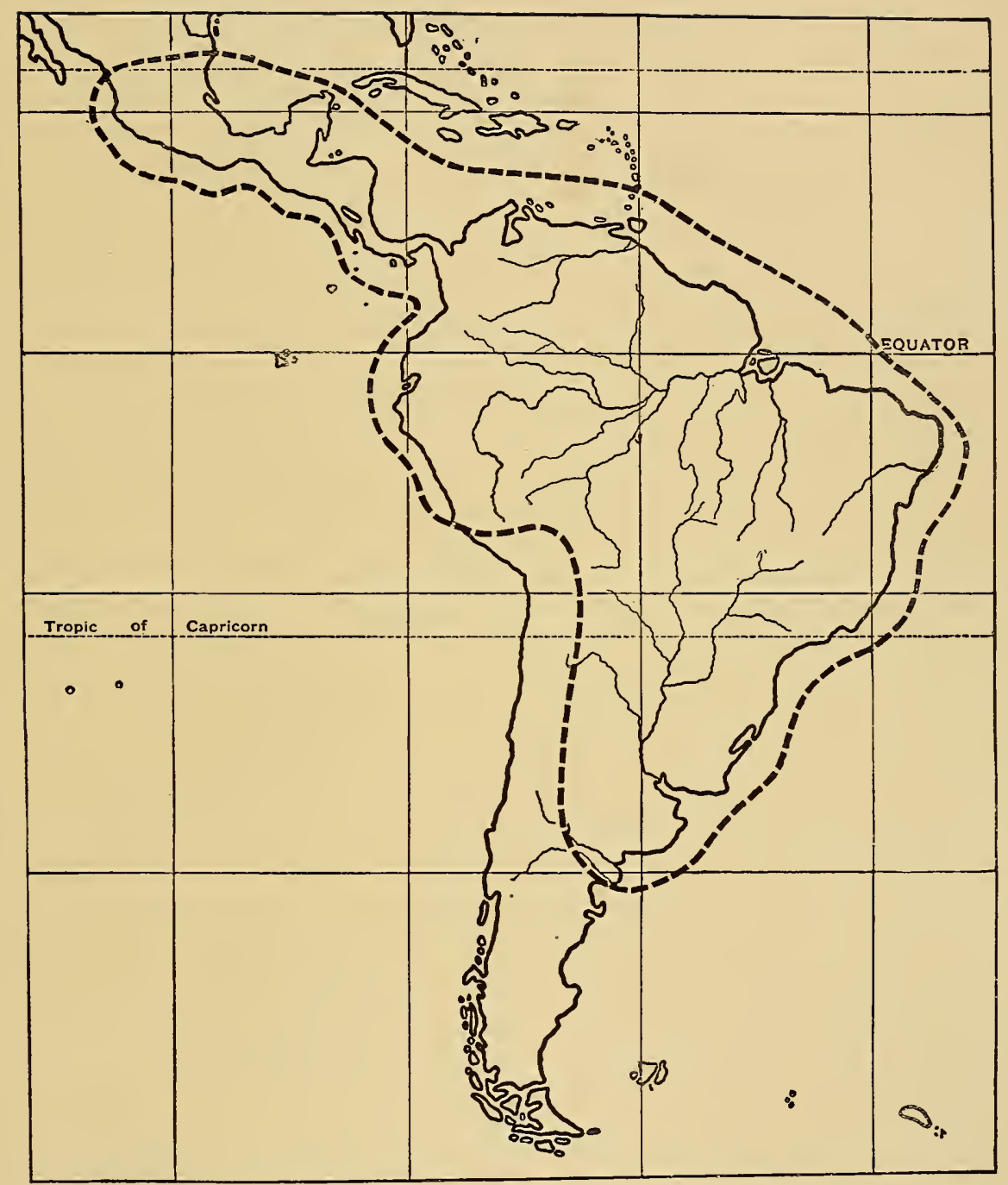

MaP 2. Distribution of Muscovy Duck (Cairina moschata) 

of the Cecropia (Wied, 1832). During the daytime they remain in the forests for the most part, in the evening resorting to their feeding-grounds, or flighting up and down the streams. When alarmed the members of a flock immediately disperse.

Flight; Vorce. Again according to Wied, the flight is extremely fast and causes a whistling sound. The voice is very weak, and, so Heinroth (1911) affirms, "as good as absent." During great excitement males in confinement emit a soft, blowing hiss, accompanied by a drawing back and thrusting forward of the head. In the female Heinroth noted a similar but somewhat higher-pitched blowing sound, and during a period of very great fear a high, frequently repeated quack. The downy young peep like other related Anatida, but not very loudly. I cannot recall any sound made by the few Muscovies that I have kept myself.

The trachea, a plate of which may be found in Eyton's monograph of the Anatide (1838), carries a bony pouch at its lower end, in the male sex only. This is left-sided, irregular in shape, and about an inch in longest diameter.

Food. The Penards (1908-10) state that the Muscovy feeds on small fish, insects, small reptiles, and water-plants. They seem to like termites (white ants) particularly, and to obtain these the birds have to break open the termite nests with their bills. There are a number of other notes on the food of the species in various parts of Central and South America, but I am aware of few careful analyses of stomach contents. Beebe (1909) saw them sifting mud for organic material, and running awkwardly after the small mangrove crabs in brackish or salt-water coves, in northeastern Venezuela. Another writer includes seeds, water-insects, mollusks, snails, worms, and water-plants in their diet, while there is an old note by Gurney and Fisher (1847) relating the stealing and swallowing of live fish from a tub of water by a domestic bird. Not much importance can be attached to this, however, as many species when deprived of their proper food in captivity will greedily catch and eat live minnows. Muscovies do not, however, confine themselves to wild food, but resort, especially at night, to grain-fields. Sclater and Salvin (1876) speak of their plucking up the roots of the Mandioca. Lord William Percy told me that those he collected near Panama were feeding on the seeds of a water-lily. Two stomachs collected by him, on March 14, 1920, in the Canal Zone, were examined by Mr. W. L. McAtee, and found to contain a trace of animal matter (insects), ground-up seeds of a Pontederiad, a seed of Fimbristylus, and other seeds unidentified.

Courtship and Nesting. The Penards (1908-10) found the males fighting violently during the breeding season in an endeavor to abduct one another's mates. It is interesting to note from these observations and from those of Heinroth (1911) that Muscovies are very distinctly polygamous. The former observers found the males 
controlling quite a harem, but it often happened that the weaker birds waited patiently until the stronger ones had almost killed each other, after which they appropriated the females themselves! While fighting, the birds seized each other by the head and struck powerfully with their wings, plucking out each other's feathers. The struggle is accompanied by loud cries, but the character of these the authors do not specify. Why these violent fights did not occur in Heinroth's semi-domestic birds is not evident. During these fights the females swim about quite unconcernedly. They show no interest in their lords and often quietly take flight during the struggle. Where these birds are numerous the water along the shores is often covered with a thick layer of feathers, a fact noted also by the earlier travelers.

There is very little information as to the time of year when the species nests. Sclater and Salvin (1859) were informed that in Central America the Muscovy breeds in December, but at the mouth of the Amazons the month of February is given (Hagmann, 1907). A young brood was taken by Cherrie in Venezuela, May 30th. No doubt the date of nesting is very irregular, but the month of December for Central America certainly does not conform with the breeding season of other species.

There are no observations on the courtship of this species in the wild state, but Heinroth (1911) has given an excellent account of the behavior of individuals threefourths wild in the Berlin Zoölogical Gardens. The sexes do not associate closely together, and there appears to be no family life comparable to that seen in most ducks and geese. Suppose, he continues, that there are on a pond a few Muscovy males and a number of females, we should then see one of the males, wholly in contrast to his otherwise easygoing manner, suddenly rush at one of the females. She flies away and a mad pursuit begins, as a result of which the obstinate female is quite regularly overtaken, ordinarily on the water, but sometimes also on land. As soon as the male seizes the feathers of the head or back she ordinarily lies as though hypnotized, with head and neck outstretched in the well-known mating position. The male usually does not immediately complete the act, but lets her go and swims around her, executing his peculiar head movement in its most extreme expression, now and again picking at the back feathers of the female with his bill. Then suddenly he throws himself upon the female, but usually only to fall over on the other side, repeating these violent tactics several times. Finally, however, he proceeds to the pairing act which is executed in a very awkward manner, so that one might think that the female after its completion would be about half-dead. Nevertheless, the two separate peacefully and paddle toward the shore, bathing themselves energetically.

If there are more males than females at a time just before the laying period, when the females are eager to mate, the pursuit by the male is ordinarily omitted. As soon as the female sees the male rushing at her, she then usually lies down quietly 
and resigns herself to the inconsiderate treatment of the male with "nothing short of masochistic delight." Frequently it happened that sympathetic onlookers would go running to the keepers to plead for the life and health of the poor, and, in their opinion, much-abused female.

Often a female who lacked a mate would, at every attack made upon her by any other duck, quietly lie on the water without resistance and accept, apparently with pleasure, a belaboring by its angry comrade of the pond.

Among the males of a pond there is a very strict order of rank. The birds continually watch each other and the strongest one never permits a weaker one to pair. As soon as he sees a male and a female together, he rushes at the pair in question. The weaker male immediately takes flight when the tyrant approaches, a thing wholly in contrast to the attitude seen among males of the true ducks, who will only permit themselves to be torn from the females after the application of real force. So with the Muscovies, on account of this extreme jealousy, the males in a pond remain together, the strongest one staying in their vicinity. In the laying season all these males have their attention fixed on particular females, who, as a matter of fact, are the ones that are shortly to begin laying, or have already begun their clutch. That the males are able to determine the stage of egg development in the female by the red wattles on the face is, Heinroth thinks, quite possible. After the mating act there was no especial behavior noted except the well-known head movements.

From the above it is quite evident that Muscovies are wholly polygamous in a semi-domestic state, and it is further noted that the males do not in any way concern themselves with the offspring nor follow the females when they are seeking hollows for their nests, as the drakes of the Carolina and Mandarin species always do. Heinroth adds also some very interesting observations on the mating of the Muscovy with an Egyptian Goose.

The nest seems always to be placed from three to twenty meters high in the hollows of trees and commonly, too, between the leaves of palms. Hartert and Venturi (1909) mention their nesting in the dry branches of quebrachas coloradas in the Chaco region. In one instance, however, at the extreme southern portion of its range, south of the Rio Negro, Argentina, it was found nesting on the ground amidst rushes (Oustalet, 1901). The nest appears to consist only of down plucked from the female and the number of eggs is given as eight or nine, often more; ten to fifteen or twenty, according to the Penards. The eggs measure 64-71 x 46-47 mm., are oval, and in color shiny white with a green sheen. According to Heinroth (1908) the incubation period is thirty-five days, but the Penards give only four weeks as the length of the period, which is certainly too short.

So many excellent ornithologists seem inclined to credit the various stories of the mother bird bringing the young to the ground in her bill or upon her back, that these 
picturesque tales can hardly be dismissed until more intimate observations have been made. The young swim well and even dive with ease. The mother has a peculiar danger-call upon hearing which the young scatter in all directions (F. P. and A. P. Penard, 1908-10).

There is something about half-grown Muscovy Ducks that reminds one strongly of young Carolina Ducks, not so much in the color as in the general shape and posture while walking.

Status of Species. In Dutch Guiana the species has rapidly decreased in numbers in recent years (F. P. and A. P. Penard, 1908-10). W. Robinson (1895) reports enormous flocks on the Magdalena River, Colombia. There is apparently no danger of extermination or serious reduction in the numbers of this species as long as large areas remain covered with jungle. Cherrie thought that in Venezuela, in spite of active persecution, not many were brought to bag, and Mr. Crandall tells me that in British Guiana they are probably holding their own.

Food Value. In spite of the disagreeable associations of its name this bird has no odor of musk about it and the young birds are fairly good eating. The old birds are tough and have a strong odor. Heinroth (1911) tells us that they cease to be palatable after they have acquired their red wattles.

Hunt. The birds are taken as they flight to and from their feeding grounds and sometimes over decoy ducks as mentioned under "General Habits." They are also watched for at favorite roosting trees.

Behavion in Captivity. The Muscovy was brought to Europe in the middle of the sixteenth century and has been kept in various parts of the world ever since. It is still very popular in Africa and the Pacific Islands, but seems to have lost favor as a general-utility bird in England and America where of course it cannot compete with the common domestic duck. I have never seen it in either Europe or North America in large numbers, but it is usual to see a pair or two kept, more as an ornament and curiosity than for any economic reason. As generally seen they are greatly mottled with white, and often they lose all traces of their former dark coloration. The tame birds breed when one year old, although it is a question whether they do so in the wild state (Heinroth, 1913). These domestic birds fly freely, but naturally grow less active as they become older and heavier. As to longevity in confinement, it may be said that they reach a considerable age, like most large swimming birds, but exact information is wanting. Flower (1910) notes one that lived over eleven years in the Giza Gardens and it would not surprise me to learn that they reach at times a much greater age. 
Heinroth (1911) has noted a very peculiar and interesting point of behavior in his semi-wild birds in the Berlin Zoölogical Gardens, which he had never seen in any other water-fowl except a certain hybrid. (It is quite possible that this is a display phenomenon.) He says his Muscovies, regardless of age and sex, often stand together, holding their heads and bills in an almost vertical position, while they carry out snapping movements with their bills. Those who have not seen it suppose that the birds are trying to catch insects out of the air, and this remarkable "play" is frequently long continued. They are really feeling around in the air above them with half-opened bills; some observers have received the impression that they were actually trying to swallow their tongues. There seems to be no explanation for this remarkable performance except as I have suggested above. Again, Heinroth, in continuing his account of the behavior of this species, says that angry males thrust their heads and necks under water before starting to attack an adversary. But in this case the conduct expresses great excitement and it is not a prelude to the mating performance as seen in other swimming birds.

When the birds are about to take wing they make aiming motions with their bills (a habit seen also in doves, Carolina Ducks and other birds), at the same time moving the head slowly up and down.

Concerning its relationship to other water-birds, it may be said that Muscovies lord it over nearly all others and copulate freely with any other species of Anatida, producing various sterile hybrids. Males have even been known to attempt mating with a domestic hen, and they have crossed with the Spur-winged Goose in the New York Zoölogical Gardens producing young that lived only a few days. Heinroth (1911) discovered that they fought not only with their bills and wings, but also with their strong claws. He found the old males quite dangerous to handle, and says it is rarely possible to get away without a few bloody scratches. Others, however, do not find Muscovies particularly combative.

Domestic birds like to nest in burrows or sheltered places. There is one instance of a pair building in the steeple of a church in Sussex, England, ninety feet from the ground among the bells. Here the female laid eight eggs (Hussey, 1858).

H. W. Robinson (1914) watched a female push her newly hatched young off a beam in a barn forty feet from the floor, and says they landed uninjured.

Thomas Bell (1850) relates an interesting performance of a domestic Muscovy. One day, after feeding and bathing, and before she returned to her nest, this female carefully passed the point of her bill over every egg. Then she singled one of them out, removed it in her bill to a distance of about three yards, broke it by a stroke of the bill and then returned to her duties of incubation, perfectly contented. The egg proved to be addled. There are a few instances of similar behavior in other ducks.

Under domestication the old males reach a great weight, up to about twelve pounds, and become gradually unable to fly. This is rather curious, because in the 
wild state the males are about double the size of the females and of course remain active on the wing. Domestic life appears to have brought about more retrogression in the males than in the females, for the latter usually fly well.

Hybridization. This species crosses readily with domestic Mallards and the offspring are of enormous size and weight, but sterile. They differ according to which species is the male parent. Those hybrids having the Mallard as the male parent do lay a few small eggs, incapable of development and there are interesting structural differences of the trachea (Heinroth, 1911; Poll, 1906). I reared a number of these crosses and found them excellent for the table.

This duck has also been crossed with the Spur-winged Goose (Plectropterus) as mentioned under that species; and with the Egyptian Goose (Leverkühn, 1890; Lécaillon, 1922), and even with the Shoveller (Leverkuihn, 1890).

History of Domestication. As already noted under "Distribution" the old theory that this species originally came from southern Russia or Turkey has been definitely dismissed. There are, however, various theories as to the locality from which the first specimens were taken to Europe. De Armas (1893, p. 319) offers what seems to me the most plausible explanation. His argument briefly is as follows: The Muscovy was first met with at Cartagena, the capital of the State of Bolivar, Colombia, in 1514, where according to Oviedo the Indians kept it in domestication and called it "Quayaiz." He describes the warts about the head and makes the identity clear, showing also that the color had already been affected by domestication. It was extremely abundant in Peru, whence the Spaniards exported it under the name of "Pato perulero" to Central America, Mexico, and Europe. Garcilasso says it was the only domestic bird of the Peruvians. After death the natives dried the birds in the sun, pulverized them, and used the powder as a perfume! Pizarro even gave some of this perfume to the King of Spain. They were domesticated also in Paraguay, where, as Cabeza de Vaca says, they were of great utility in combating a plague of crickets. At the beginning of the past century, Noceda, the friend of Azara, wrote that the white ducks domesticated on the banks of the Plata were specifically different from the wild ones, but Azara argued that they were one and the same species. Azara perceived no musky odor and contradicted Buffon on this point. Belon mentioned the bird as coming from the New Worid. Cardanus and Rondelet also knew its origin and sent descriptions and drawings to Gesner, who reproduced these in his De Avibus (1555). It was mentioned by Dr. John Kay or Caius (De Rariorum, 1570) as present in England at that time. Nevertheless, some supposed it to have come from Turkey, some from Egypt, some from Barbary, and some from Russia. This last mistaken origin began with a translator from the Latin, who, reading Anas Moschata, translated it into French Oie de Muscovie. Prince 
Maximilian von Wied persisted in considering the European birds as having come from Turkey. The ornithologist John Ray (1678) seems to have been the first to attempt to straighten out all the confusion.

A curious explanation of the name Musk Duck is given by Hill (1864). They were, he says, originally procured from the Mosquito Coast, Nicaragua, the country of the Muysca Indians (see Humboldt's Researches), whence was derived the name Musco Duck, corrupted later into Muscovy Duck.

The West Indian islanders had early domesticated this species, for on the arrival of Columbus his men found "ducks as large as geese" among the Indians. Brézol (1889) quotes Nehring to the effect that the species was imported to Europe in 1550 and spread rapidly to France. 


\title{
COMB or KNOB-BILLED DUCK
}

\author{
SARCidiornis melanota (Pennant)
}

(Plate 4)

\section{SYNONYMY}

Anser melanotus Pennant, Indian Zoölogy, p. 12, pl. 11, 1769.

Sarkidiornis melanonotus Layard, Ann. Mag. Nat. Hist., ser. 1, vol. 14, p. 268, 1854. Sarcidiornis melanonotus Blyth, Ibis, ser. 2, vol. 3, p. 175, 1867.

Sarcidiornis melanonota Sclater, Proc. Zool. Soc. London, 1876, p. 694, pl. 67.

Sarkidiornis africana G. R. Gray, Genera Birds, vol. 3, p. 605, no. 2, 1845.

Sarcidiornis africana Strickland, Ann. Mag. Nat. Hist., ser. 2, vol. 9, p. 349, 1852.

Sarcidiornis melanonotus Lichtenstein, Nomenclator Avium, p. 101, 1854.

\section{Vernacular Names}

English:

Comb Duck

Knob-billed Duck

Black-backed Duck

African Humped Duck

French:

Canard à bosse

Oie cabouc

Oie bronzée

German:

Höckergans

Glanzgans

Bronzerückige Gans

Schwarzrückige Gans

India:

Nukta - Hindu

Nakwa - Chota Nagpur

Naki hansa - Uriya

Jutu chilluwa - Telegu
Do'd sarle haki - Canarese

Neer-koli - Coimbatore

Tan-bay - Burmese

Bowkbang - Karen

Madagascar:

Arosy

Ara

Angongo

Sivongo

Kaboka

Rasana

Angola:

Vioto or Ecubo

Gazaland:

Isekwi

Arabic:

Wuz el tin

Wuz abu qadum

Berkejh

Teukimbub - Tuareg

\section{DESCRIPTION}

Adult Male: Head and neck white, spotted with metallic black feathers that coalesce more or less upon the crown, nape and hind neck; lower neck and whole lower plumage white, tinged sometimes 




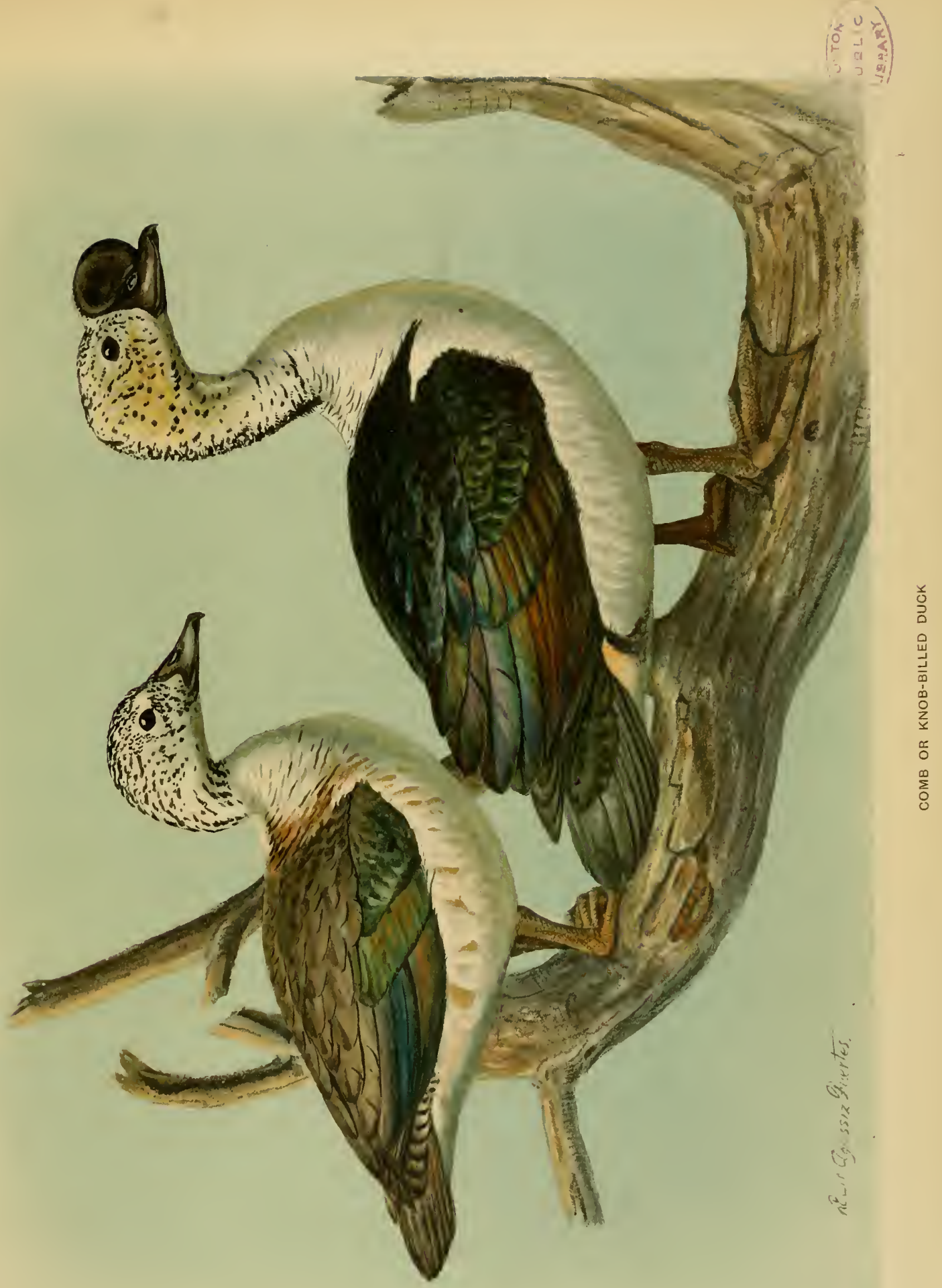



with rufous gray; rest of upper plumage and wings black, glossed with green and blue, except on the secondaries, which are glossed with bronze, and the scapulars, on which the gloss is purple; tail brown. A black mark, almost a collar, on sides of neck, and another black band on the front of the under tail-coverts. Lower back gray (Baker, 1908).

Iris dark brown to yellowish brown; bill black, and at breeding season surmounted by a comb-like protuberance at the base, which is black with white spots (white spots do not occur regularly); feet dark leadish gray.

Bill paler on the lower mandible, and fleshy toward its base (Hume and Marshall, 1879). The fleshy protuberance on the bill becomes greatly enlarged during the breeding season, frequently measuring 55 by $61 \mathrm{~mm}$. (A. Anderson, 1874).

According to Böhm (1882), Finn (1909), and Horsbrugh (1912) the male during the breeding season carries a small bunch of orange feathers at the sides of the lower abdomen. Writing of a male of the closely related $S$. carunculata, which was recently received in the London Zoological Gardens, Seth Smith in the London Field of May 29, 1915, mentions the bright yellow feathers at the base of the tail, and also a patch on either side of the head. Since then $I$ have seen these curious feather tracts in a live bird in New York. This yellow coloring is assumed only in the breeding season and fades immediately in dried specimens.

Length 620 to $750 \mathrm{~mm}$.; wing 350 to 380 ; tail 135 to 150 ; bill 57 to 60 ; tarsus 55 to 75 (Reichenow, 1900).

Adult Female: Like male, but smaller and duller; head and neck more spotted with black, but the black less glossy in character, and the gloss on the upper parts also much less developed; lower back, rump and upper tail-coverts all gray (Baker, 1908). Length about 550 to $580 \mathrm{~mm}$.; wing 280 to 290; tail 125; bill 50; tarsus 45 to 47 (Reichenow, 1900).

Young: Like female, but more spotted about the head and browner all over the upper parts.

Young IN Down (specimens, British Museum): Very characteristic and having a distinct resemblance in head pattern to the young of Tree Ducks. Occiput black or dark brown, superciliary stripe white. Transocular streak, which extends back and merges with the occipital patch, dark brown. Behind the occipital patch is a white band which runs around the back of the head and merges with the white of the face on each side. Back of this from ear to ear is a narrow black line. Down the back of the neck runs a black streak which merges with the dark brown of the mantle and whole upper side. The upper surface carries very marked white patches on the wing rudiments, scapular areas, flanks and sides of rump. The lower surface is grayish.

\section{DISTRIBUTION}

THE Comb Duck is a species resident in Africa and in India, though in both regions it moves about locally to a considerable extent, according to the change of season and the supply of water. In Africa its distribution is practically the same as that of Dendrocygna viduata or of Plectropterus gambensis; for like those species it is found south of the fifteenth parallel of north latitude, and like them it is rare in South Africa. In the west it has been recorded from many localities in Senegambia by Rochebrune (1883-85), whose work, however, has been called into question by Reichenow in his book on the birds of Africa. It occurs in Gambia (British Museum) and presumably in French Guinea and Sierra Leone. Buittikofer (1885) has recorded it from western Liberia, Sugary River, and Pel (Hartlaub, 1855) found it on the Gold Coast. It is

Senegambia Liberia Nigeria reasonable to suppose that it occurs along the entire Guinea coast, though it seems to be rare west of Nigeria. Hartmann (1863) found it common about Loko, in Nigeria, while according to Hartert 
(1886) it is abundant, and apparently breeds in Hausaland, about Zaria and in Sokoto. Boyd Alexander (1907) states that it visits the vicinity of Lake Chad from time to time.

Due to the paucity of information we can only conjecture that it occurs in Camerun and the French Congo. Both Marche and Compiègne (Bouvier, 1878) reported it from Diatakunda, and Camerun Dybowski (Taczanowski, 1874) discovered it in Ubangi, northwestern Belgian Congo. Congo It is a common bird in the Sudan occurring northward even to Kordofan (Strickland, 1850) and Khartum (von Heuglin, 1873). According to Butler (1905) it occurs in increasing numbers on the upper White Nile above El Dueim. Ogilvie-Grant (1902) and von Heuglin (1869) White also state that it is common on the White Nile. The latter saw it also on the Blue Nile Nile, and A. E. Brehm (1857) found it about Senaar. I saw it in good-sized flocks on the big meres near the Dinder River, eastern Sudan, in February, 1913. In the southern Sudan, on the Bahr-el-Ghazal and the Jur it is abundant (Butler, 1905). Farther east it is found frequently in Abyssinia Abyssinia, from Lake Tana in the north (von Heuglin, 1873), southward in Shoa, Angolalla, Gazelle River, Lake Cialalaka and Lake Haddo (Rüppell, 1845; W. C. Harris, 1844; Antinori and Salvadori, 1873; Salvadori, 1888). According to von Erlanger (1905) it was abundant on the Haŭash River. It probably does not extend eastward to the lowlands of Ogaden, nor into Somaliland.

There are few records for eastern British East Africa, though G. A. Fischer (1885) found it at Engatana, and Lamu. Hunter has reported it for the east side of Kilimandjaro (Shelley, 1889), British Kirk (Shelley, 1881) for Malindi, F. G. Jackson (1899) for Ukamba, Ogilvie-Grant East Africa for Lake Naivasha (6700 ft.), Horsbrugh for Uasin Gishu Plateau, Sharpe (1902) for Uvuma Island, Victoria Nyanza, and G. A. Fischer (1885) for Kageji, Victoria Nyanza, while Johnston (1902) met with it in Uganda, and Emin Pasha (1891) has recorded it for Tarangole in the same Protectorate. Ogilvie-Grant (1910) reports a flock seen near Fort Portal, Ruwenzori region. It has been found also in Lado, at Bussisi (Emin, 1891) and in the Nyam-Nyam district between the Sudan and the Congo (Piaggio, fide Reichenow, 1900). There is no information by which we can fix its status in most of the Congo Free State, but it is found in the southeast, in the Katanga district Tanganyika (Neave, 1910), about Lake Tanganyika (Dubois, 1886a), and occasionally on the upper Congo (Chapin, in litt.). In Tanganyika Province (German East Africa) it appears to be not uncommon, especially in the north and the west. Speke (Grant, 1872) and von Trotha (fide Reichenow, 1900) have recorded it from Unyamuesi and Mori Bay, and Schillings (1905) also saw it on Victoria Nyanza. It has been found on Lake Djipe (Volkens, 1897) and breeding on the Natron Lakes and Kilimandjaro (Sjöstedt, 1910), while it is known also from Kibaja Massai and Manjara (Neumann, 1898), from Irangi (Reichenow, 1893), from Wiedhafen (Fülleborn fide Reichenow, 1900) and from Kakoma, Igonda, Marungu, Luwule and Lufuri (Böhm, 1882). Salvadori (1914) recorded it from the Mbusi River, Mozambique.

In northern Rhodesia the Comb Duck is not common, though it is known to breed on Lake Bangweolo (Neave, 1910; Salvadori, 1914) and has been recorded from the Kafue River (Boyd Alexander, Rhodesia 1900). It is abundant, however, on the Upper Zambesi (Bradshaw, fide Stark and Sclater, 1906; Holub and von Pelzeln, 1882) and in northwestern Bechuana Protectorate on the Botletli River (Bryden, 1893), on Lake Ngami where it is resident and presumably breeds (Andersson, 1872), at Kanye (Nicolls and Eglington, 1892). It is fairly abundant also in Portuguese West Southwest Africa, south of the Cuanza River, where it was found at Kakondo, on the Kunene, Africa at Huilla, Gambos and Humbe (Barboza de Bocage, 1877-81). According to Fleck (1894) it occurs in former German Southwest Africa near Rehoboth, Fish River, and Andersson (1872) describes it as common in the rainy season in Damaraland and Great Namaqualand, and breeding in Ovampoland.

South of the Orange River the present species occurs only as a rare straggler. It has been taken on the Kleinmont River, Bathurst Division (Layard, 1875-84), and once in Pondoland, Cape Colony 


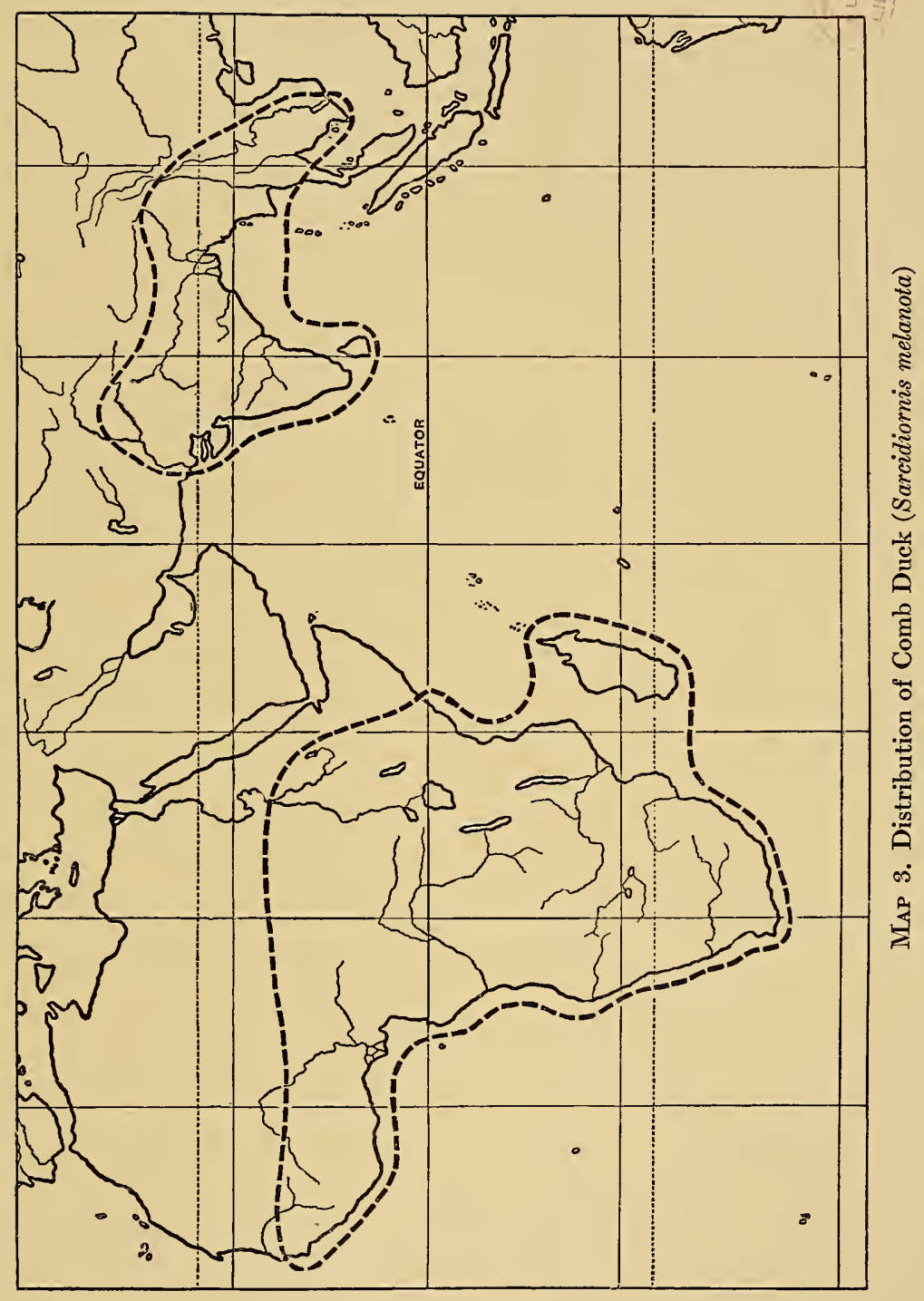



(Horsbrugh, 1912). A specimen had apparently been taken also in Natal some time before 1862 (Sclater, Ibis, ser. 1, vol. 4, p. 284, 1862). There is no record of its occurrence in the Orange South AfRiver Colony, but it has been taken on the Molopo River near Mafeking, southwestern rica; Orange Transvaal (W. Ayres, 1887; Shelley, 1882) at Potchefstroom (Barratt, 1876; W. Ayres, River 1887) and at Rustenburg (W. Ayres, 1887). According to C. H. Taylor (1907), it is resident and breeds in southeastern Transvaal in the Amersfoort District, and Haagner (1914) recently discovered it breeding on the Crocodile River in the same general region, this beTransvaal ing the southernmost breeding record.

Between the Limpopo and the Zambesi, that is in southern Rhodesia, the species has been frequently found. There are specimens from the Tati River in the South African Museum, and F. Oates (1881) found it on the Ramaquaban River. It is common during the rains on the Que Que River, and in Matabeleland in general (C. H. Taylor, 1907; Holub and von Pelzeln, 1882). According to Mouritz (1914) it is not infrequently seen on the Matopo River, and in Mangwe, and it apparently breeds farther north on the Shangani (E. C. Chubb, 1908). In Mashonaland, however, it seems to be very rare, for G. A. K. Marshall (1900) only saw one bird there in upper Mazoe.

The Comb Duck is known also from Portuguese East Africa. Bradshaw (fide Stark and Sclater, 1906) and Kirk (1864) both saw it on the Zambesi, and Manning (fide Reichenow, 1900) has recorded it from Luchinde. Percival (1902) saw only one specimen on the Shiré River, but it has Portuguese been recorded also from Lake Shirwa (Shelley, 1898). In the south it was found by East Africa Swynnerton (1908) near Chibabava, Gazaland. In Madagascar this species, though apparently not particularly common, is found generally distributed in suitable localities (Milne-Edwards and Grandidier, 1876-81; Hartlaub, 1877; Pollen and Dam. 1868; Sibree, 1892; and others).

In Asia the Comb Duck, more generally known as Nukta, is ordinarily found only in India and in the Burmese Countries, where it is resident; though, as in Africa, it moves about as the weather requires. Its northwestern limit was long a subject of dispute, but it is now known to India visit the Punjab rarely, and it is said to breed there (Hume and Marshall, 1879); and Burma along the Lower Indus it is known to occur certainly in Sind, for eight were seen and two shot there in December, 1911 (Webb, Journ. Bombay Nat. Hist. Soc., vol. 21, p. 685, 1912). It does not occur in the Himalayas, however, though the British Museum possesses a specimen from Sikkim Terai. Elsewhere it is generally distributed throughout the peninsula from Rajputana (ex- Sikkim cepting the northwestern part), and Gujerat, Cutch and Kathiawar, south to Ceylon Ceylon and east to Burma. It is, however, rather rare along the entire west coast, in South Konkan, Malabar, and Travancore, as also in the region south of Mysore (Hume and Marshall, 1879; Baker, 1908). Still, in Ceylon, it is not as uncommon as one would suppose, and it is even known to breed there (Legge, 1880; Wait, 1917).

On the east the species is not so rare in Cachar and in Sylhet, where it breeds (Baker, 1908), and it extends up the valley of the Brahmaputra as far as Sadiya (Hume and Marshall, 1879). For a long time its status in Arakan was uncertain, but it is now known to be not uncommon there (Baker, 1908) and it is said to be common also in Upper Burma (Blyth, 1875). It has been recorded Burma as plentiful in Upper Pegu (E. W. Oates, 1883), and the British Museum has a speci- Pegu men from Lower Pegu. Rippon (1901) found the species rather common in the South Shan States. Williamson (1918) has reported a specimen taken thirty miles east of Bangkok, Siam, and Gyldenstolpe (1913) saw in a garden captive birds that were said to have been taken in Siam northeastern Siam.

A very remarkable record for this species is its recent appearance in Fokien, southeastern China, where, at Foochow, a male was shot April 18, and another in June, 1914 (La Touche, 1917). It appears that a flock occurred in that vicinity that year, and the late date, June, may Fohkien indicate breeding. 


\section{GENERAL HABITS}

Haunts. The best accounts of the life-history of this species are to be found in Hume and Marshall (1879) and Baker (1908), from which authors I must of necessity quote freely. This bird is a tree-loving species, and prefers forested swamp areas, not dense forest like the White-winged Wood Duck, but well-wooded, level, and well-cultivated country. It does not like bare-edged sheets of water, and is rarely seen on the larger rivers of India. It is seldom met in hilly ground, although it has been found breeding at an elevation of two thousand feet, and probably nests at even greater altitudes (Baker, 1908). It favors large mango trees. Tickell (quoted by Hume and Marshall, 1879), however, found these birds in very different localities. In the Chota Nagpur region, it inhabited open, uncultivated, bushy country, where it preferred clear water with gravelly or stone bottom, and not shallow muddy jheels or marshes.

WARINEss. As a general thing this species is not exceptionally wary, and Hume says they are not difficult to approach in a punt. According to Stark and Sclater (1906) the birds are easy to approach in South Africa, especially when they have perched. But in India, when in company with a pair or two of Ruddy Sheldrakes, they are much more wild than usual (Hume and Marshall, 1879). Böhm (1885) noted that in German East Africa the females were more shy and cautious than the males, and states also that the males like to associate with Spur-winged Geese.

Daily Movements. Observers differ as to whether they are diurnal or nocturnal in their habits. In East Africa, Böhm (1885) found them much more active in the morning and evening, but Baker (1908), speaking of India, asserts that they are not nocturnal or even crepuscular. Hume and Marshall (1879) also found them feeding much more in the daytime than other ducks or geese. The birds are strictly tree-loving and probably always roost on trees.

Flight; Diving; Perching. With the exception of Legge (1880), who thought them awkward and clumsy on the wing, they are considered powerful and rapid in flight, rising faster and in general swimming and diving more actively than true geese, such as the Bar-heads. But it is doubtful whether they really fly very fast compared to northern water-fowl. On the water the bird sits high like a goose, with stern raised, and the neck is carried in a curve, not straight like that of a swan (Finn, 1915). Heinroth (1911) describes the flight as not very rapid, but steady and regular, the tips of the wings being held very low. The gait, according to Legge (1880), is ungainly, the bird, with its heavy-looking head and broad tail, lifting its feet high and taking rather long strides, cutting anything but a graceful appearance. 
Association. The best observers almost all assert that the Comb Ducks travel about in pairs or families, and only very rarely unite to form flocks. Larger companies have, however, been seen in Nigeria (Hartert, 1886) and in Burma (E. W. Oates, 1883), as well as in the Sudan (von Heuglin, 1873). E. H. Young (1899) tells us that even when in flocks, the various pairs keep together, and when one bird has been shot, its mate will often remain behind. This species does not associate commonly with other water-fowl, but sometimes they are found in company with Spurwings or White-faced Tree Ducks (von Heuglin, 1873; Böhm, 1885), or in India with Ruddy Sheldrakes, the only fowl with which, says Hume, they ever closely associate.

Vorce. In wild birds, and also in those kept in captivity, the voice is almost wholly absent, Heinroth (1911) even maintaining that he never heard them utter any sort of note. By most observers they are described as very silent birds. Von Heuglin (1873) speaks of a tender, whispering note, uttered while on the wing. According to Böhm (1885) the voice is very fine and thin. The testimony of two well-known naturalists, however, is considerably at variance with the above. Legge (1880) describes the note as a low, guttural, quack-like sound, between the voice of a duck and a goose; and Baker (1908) heard them "uttering loud cries" which seemed to him more like the notes of a goose than of a duck. A pair, whose nest he found, used to herald his approach with "loud trumpeting calls" from perches high in a tree. It is possible that the birds call only during the nesting season.

In the male there is a very small left-sided diverticulum at the lower end of the trachea which may affect the voice of this sex (Garrod, 1875). The trachea of the female is simple.

Foon. The food of the Comb Ducks seems to be chiefly of a vegetable character including both wild and cultivated rice. According to Hume and Marshall (1879) they also swallow worms, larvæ of water insects, small shells, fresh-water crustaceans, and occasionally a tiny fish or two. The vegetable part of their diet consists of grass, water weeds, and various kinds of seeds; in India, sometimes, a remarkably hard quadrangular variety of water-grass seed.

Courtship AND Nesting: When the rains commence in India, the Comb Ducks become active throughout the day and move about in pairs. The male, now rendered conspicuous by his much enlarged nasal protuberance, and usually flying in front, is distinguishable at a great distance (Hume and Marshall, 1879). From the Berlin Gardens (Heinroth, 1911) comes the only available account of the courtship of this species. The males in a very erect position approach the females with the same continual dipping movement of the head and neck into the water that is com- 
monly seen in other water-fowl, but which is in marked contrast to the violent behavior of male Muscovies. Finn (1915) found the courting male arching his reck and bending down his head, slightly expanding his wings after the fashion of a swan, only much less. The female does not reciprocate, so far as has been observed, but always takes to flight, is soon overtaken, and forced to yield. The females in the Gardens never produced mature eggs, and apparently had no desire to pair.

In the wild state, in districts characterized by monsoon rains, the pairing season begins with the rains, while the nesting period is somewhat later, varying in India from June to early September; while in Ceylon the breeding season is in February and March. In South Africa the birds nest in November and December, or even earlier, for half-grown young were found by E. C. Chubb (1908) in late November (25th) in southern Rhodesia. In India some of the young are seen on the wing by early October, but many more are unable to fly before November.

The Comb Duck selects for a nesting-site the hollows of old deciduous trees, or the depressions between large branches, where they divide a short distance from the ground. Only very rarely do the birds select a ground site; occasionally, as mentioned by A. Anderson (1874), they appropriate the nest of another species. Both sexes join in the search for a suitable locality, and Anderson saw both birds flying into the nest-tree together, the male uttering a "harsh grating noise." The same writer mentions their nesting in the holes of old ruined forts in the United Provinces of India. In Africa very few observations on the nidification have been made, but C. H. Taylor (1907) found that in southeast Transvaal they nest in long grass at the side of a vlei or pan, and once he discovered a nest among the stones of a lowlying hill. When nesting in the trees, they select hollows and branches not far from the ground, often from six to ten feet. In India the mango tree seems to be a favorite choice. Anderson mentions a nest-hole in a banyan tree thirty feet above the ground. Baker speaks of a nest located in a perpendicular bank.

Materials other than down are used in the formation of the nest, for sticks, dead leaves, grass, and even snake skins have been found. So little has been recorded concerning the size of the clutch that it is difficult to decide on the correct average number. Nine or ten would seem to be a normal complement, though fifteen to twenty, probably the product of two females, have been recorded from one nest. Anderson (1874) speaks of the capture of an emaciated nesting female who had apparently laid the extraordinary number of forty eggs, and he had received other clutches of fifteen to twenty. A still more remarkable nest was described and figured in the London Field of November 27, 1920, p. 772, by T. R. Liveskey. This was situated in a hollow tree twenty-five feet from the ground and contained fortyseven eggs. The writer thought that two or more ducks had laid in this nest, which was certainly the case. They were in different stages of incubation. The eggs measure 60 to $61.5 \mathrm{~mm}$. by 45 to $46 \mathrm{~mm}$., but are rather variable in size. The color 
is yellowish white, or grayish yellow, of fine texture, smooth and fairly glossy (Reichenow, 1900).

Status of Species. I can find no recent account of the status of this species. Baker (1908) is of the opinion that it needs protection during the breeding season, from June first to December first. As already remarked under Distribution, it has always been rare in South Africa, except on the Upper Zambesi, and Taylor states that, having been too much disturbed, it no longer breeds in the Transvaal. In northern Nigeria, Hartert (1915) records it as occurring in "very great numbers"; while on the upper White Nile, and on the Bahr-el-Ghazal, Butler recently found it "very abundant." Several writers speak of this species as being detrimental to freshly sown fields, and it may therefore come more and more into conflict with agricultural interests. Rice-fields seem to suffer particularly from its raids, and in South Africa, Horsbrugh (1912) speaks of its being very destructive to lands sown with "mealies and oats."

Food VALUe. Although this species cannot be considered a very popular bird for the table, nearly all writers are in accord as to its flesh being fairly good eating; at least it usually is better than the Spur-wing or the Egyptian Goose. The young birds are said to be excellent as food. Horsbrugh (1912) found it "not particularly good" in East Africa, while A. L. Butler (1905) considers its flesh more palatable in Africa than in India. Hume and Marshall (1879) and Jerdon (1864) have formed a somewhat lower estimate of its edible qualities in India, and the former write that even the young in early winter, when they are fat and tender, are apt to have a marshy flavor which it is necessary to conceal. Bryden (1893), speaking of South Africa, thought that, of the three so-called African geese, the Spur-wing was best, and the Egyptian Goose the poorest. Of course none of these is to be compared with the true or northern geese.

Hunt. Pollen and Dam (1868) mention that in Madagascar the Comb Ducks are taken during the rainy season in nets. They are said to afford some very good shooting at the commencement of the rains in India. Horsbrugh (1912) speaks of some being taken in traps in cultivated areas in South Africa.

Behavior in Captivity. Although this bird has been commonly kept in parks and in zoölogical gardens for many years, there is only one recorded instance of its nesting in confinement. One of Mr. Blaauw's pinioned female birds in 1902 began to search for a nesting-site. She climbed over a wire fence and nested under a hedge, where she scraped a round depression in the soil and laid her eggs, all of which unfortunately proved to be sterile. The bird did not sit (Blaauw in litt.). 
These birds evidently live to a great age, as Hubbard (1907) mentions specimens as still living in the London Zoological Gardens, which were received in 1876; which would make them over thirty years of age. They are hardy and live out of doors, as is evidenced by the fact that they are able to endure the winter climate of New York, for example.

According to Hume and Marshall (1879) and others, the Comb Ducks are easily tamed and are often captured and kept by natives in both India and Africa. Pollen (1866) says that in Madagascar they were often taken at the moulting period, and mated very readily with Muscovies, particularly when tamed early in life. He noted that they did not get along well with domestic ducks. There are no recorded instances of hybrids produced by matings with domestic Mallards.

In the Berlin Zoölogical Gardens, Heinroth (1911) was able to make some interesting observations on a Comb Duck whose wings had been allowed to grow. This fullwinged bird always flew without previous warning signs, and was gone for half a day at a time. When returning, it did not circle about like most other water-fowl, but shot directly down into the pond.

Their manner of fighting, according to Heinroth, is somewhat different from that of the Spur-wing or the Muscovy. They approach their adversaries with head and neck somewhat laid back, coming up from the side in a peculiar manner, at the same time lifting the wings, particularly the secondaries, before jumping at the opponent. This combatant attitude would usually put to flight the Black Sheldrakes who are as a rule very quarrelsome birds.

The price of these birds has averaged about $\$ 30.00$ a pair in Europe, but since the War it would certainly be far more than this. 


\section{SOUTH AMERICAN COMB DUCK}

SARCIDIORNIS CARUNCULATA (LiChtenstein)

(Plate 5)

SYNONYMY

Anas carunculata Lichtenstein, Abhandl. Akad. Berlin, 1816-17, p. 176.

Sarkidiornis regia G. R. Gray, List Birds in Brit. Mus., vol. 3, p. 126, 1844.

Sarcidiornis regia Bonaparte, Compt. Rend. Acad. Sci. Paris, vol. 43, p. 649, 1856.

Sarcidiornis melanonota Sclater and Salvin, Nomenclator Avium Neotrop., p. 129,

1873.

Sarcidiornis carunculata Sclater and Salvin, Proc. Zool. Soc. London, 1876, p. 377.

\section{Vernacular Names}

English:

South American Comb Duck

South American Black-backed Duck

Crested Duck

American Wattle Duck

French:

Sarcidiornis caronculée

German:

Spanish:

Pato de crista

Pato cristado

Portuguese:

Pato do matto

Pato castelhano

Pato do Cayenna

Pato do crista

Südamerikanische Höckergans

\section{DESCRIPTION}

Adult Male: Differs from the Comb Duck of the Old World (S. melanota) only in having the sides and flanks brownish black instead of white, the rump black, glossed with green instead of gray, while the crescent-like band on the sides of the breast is not so conspicuous.

In a specimen which I examined in the United States National Museum in Washington, the head and neck appear whiter than in the Old World species, while the upper mandible is more hooked at the tip.

In the London Field of May 29, 1915, attention was called to the yellow coloring on the sides of the head. As a matter of fact this is very marked, and even by mid-January a specimen in the New York Zoölogical Gardens had the region back of the eye and the sides of the upper neck a distinct canary yellow, which increased in intensity toward spring; orange feathers also appeared on the sides of the rump during the same period.

Bill dull lead color; iris black or very dark brown; legs and feet dirty yellowish green (live specimen in New York Zoölogical Gardens, 1920).

Female: Same as S. melanota, but having the sides and flanks brownish black as in the male.

Young: Nothing recorded. 
REMARKs: Mr. Crandall informs me that the three young specimens which he received in January, 1919 , all reached maturity by June of the same year, and at that time one of the two males killed the other one.

\section{DISTRIBUTION}

THE northern and western limit of the range of this species has recently been extended by the capVenezuela ture of three live individuals, now in the New York Zoölogical Gardens, near Barcelona, Venezuela (Crandall, Auk, vol. 36, p. 419, 1919).

Mr. T. E. Penard informs me that from July 12 until November, 1918, this species appeared on the British east coast of British Guiana, apparently in some numbers, numerous specimens havGuiana ing been taken (see also Penard, Auk, vol. 36, p. 564, 1919).

Like its African relative it is seldom found in great numbers, and comparatively little is known of its status, because it chiefly frequents the more inaccessible regions. It was reported from Cayenne by Eyton (1838), but, so far as I know, there is no other reference to its occurrence in any of the GuiBrazil and anas until the very recent records mentioned above. At the mouth of the Amazons, it is Amazons found on Marajo Island (Goeldi, 1894-1900) and in the interior in Amazonia, at Barro do Rio Negro (von Pelzeln, 1868-71). It unquestionably inhabits all of central Brazil and has been recorded from Maranhão (Goeldi and Hagmann, 1902), from Pernambuco (Forbes, 1881), from Bahia (Wied, 1832), and from Rio Janeiro (H. and R. von Ihering, 1907). Very likely it occurs Argentina in Minas Geraes and in São Paulo, as well as in Goyaz, for it was found by Natterer in Goyaz Matto Grosso, at Sapitiba and at Caiçara (von Pelzeln, 1868-71). There is one speciBuenos men in the British Museum from Ajó, Buenos Aires Province, collected by E. Gibson Aires in 1898.

The present species must also occur in eastern Bolivia, though it has never been recorded from that Paraguay country. But it is common in Gran Chaco, Paraguay (Kerr, 1901), and has been found Salta and on the Pilcomayo (Dabbene, 1910). It is occasionally found even in northern ArgenTucuman tina, whence it is known from Salta (Holmberg, fide Dabbene, 1910) and from Tucuman (Burmeister, 1872).

\section{GENERAL HABITS}

Almost nothing is known about this species in its forest haunts. Azara (1805) has given as good an account as more recent writers. He says it is the shyest of all the birds of Paraguay. Noseda informed him that there were many more females than males, and that the latter sex was seen in considerable flocks, associated with other ducks along fields and overflowed districts. The males went about alone or in very small bands, and the natives insisted that the sexes represented entirely distinct species. He found it difficult to convince them that such was not the case. Wied (1832), speaking of Brazil, says that they resort to large swamps, surrounded by reeds and grasses, and, in contradiction to the first writer, found them "not particularly shy." Goeldi (1894-1900) agrees with Azara that this species is exceedingly shy, and he found them always one of the first to take wing. Kerr (1901) speaks of them as extremely shy in the Gran Chaco district of Paraguay, and living singly or in pairs.

I am unable to say whether this species is really as rare as the paucity of our knowl- 



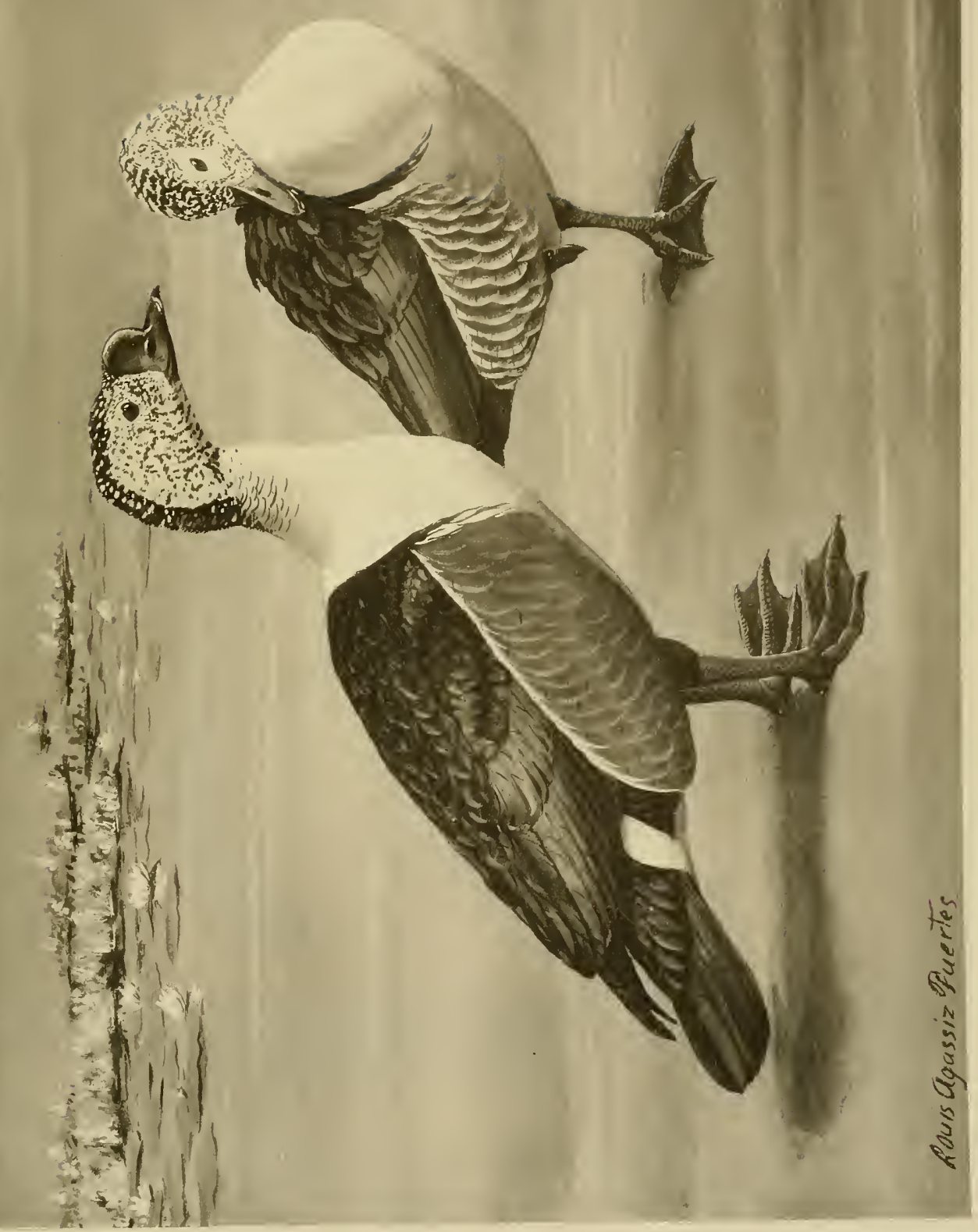

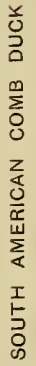





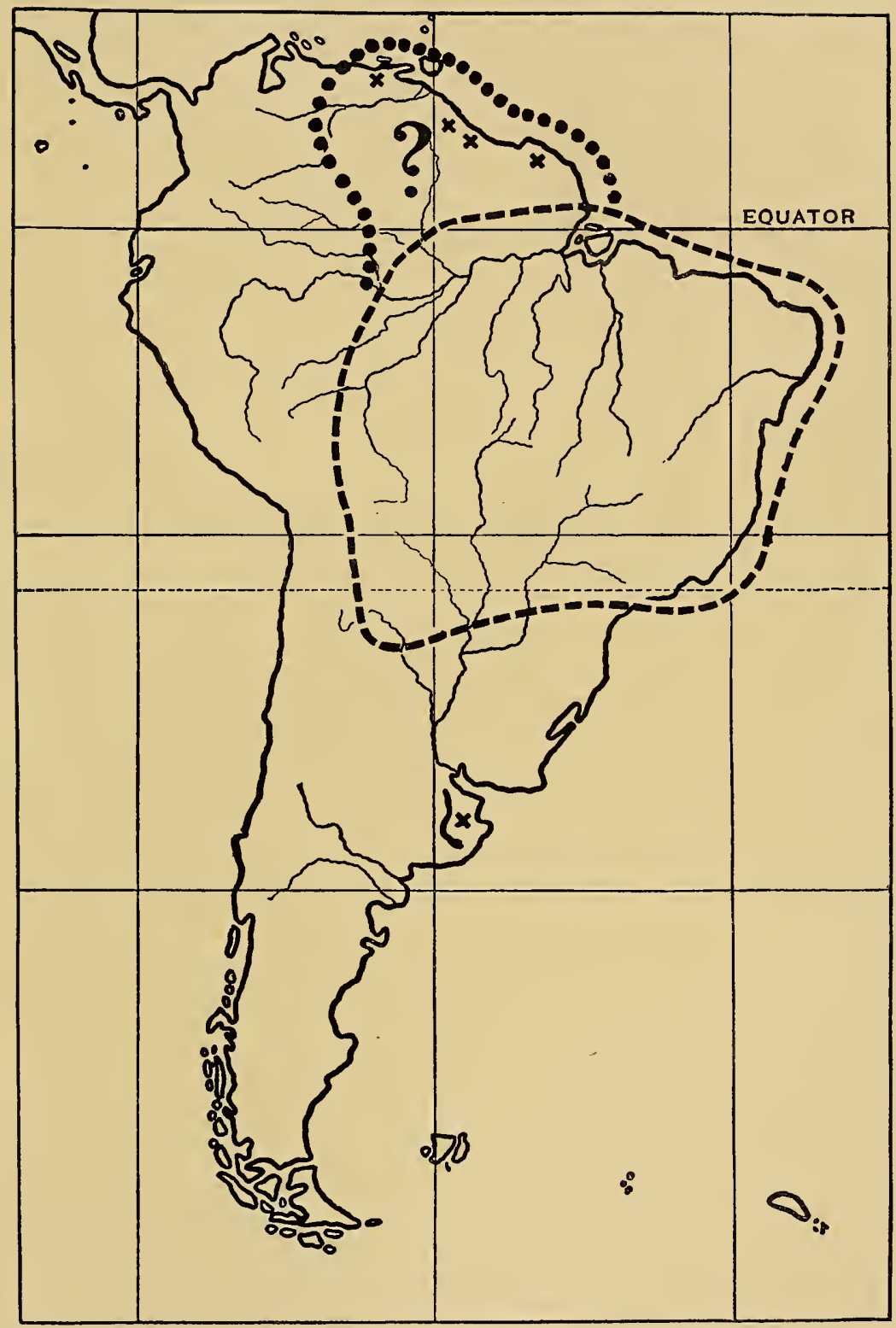

Map 4. Distribution of South American Comb Duck (Sarcidiornis carunculata) The portion enclosed by dotted line indicates apparent recent extension of range. 

edge would suggest. It will probably be found commonly distributed in places that are particularly suited to it.

Food. Nothing recorded.

Courtship And Nesting. No courtship, and no tendency to mate or nest have been observed in captive birds in the New York Zoölogical Gardens.

Status. The apparent recent extension of its range to the north (British Guiana) is of interest.

Food Value. No information.

Behavior in Captrvity. The species was first received at the London Zoological Gardens in 1876. It has never bred, but was still living in 1883 (Sclater, 1883). It has also been kept in Berlin, and in the Buenos Aires Gardens.

The New York Zoölogical Gardens received two males and one female, all immature when taken in November, 1918, near Barcelona, Venezuela (Crandall, Auk, vol. 36, p. 419, 1919). In June, 1919, one of the males killed the other one. The remaining male which I observed in January, 1920, had the reputation of being one of the most pugnacious birds in the Gardens, and was kept in a pen by himself all winter. 


\title{
WHITE-WINGED WOOD DUCK
}

\author{
ASARCORNIS SCUTULATA (S. MÜLLER)
}

(Plate 6)

\section{SYNONYMY}

Anas scutulata S. Müller, Verhand. Land- en Volkenk., p. 159, 1839-44.

Sarcidiornis leucopterus Blyth, Journ. Asiatic Soc. Bengal, vol. 18, p. 820, 1849.

Casarca leucoptera Blyth in Jardine, Contrib. Ornith., p. 141, pl. 64, 1850.

Anas leucoptera Hume and Marshall, Game-birds of India, vol. 3, pp. 147, 172, pl. $20,1880$.

Tadorna scutulata Sclater, Proc. Zool. Soc. London, 1880, p. 512.

Vernacular Names

English:

White-winged Wood Duck
Assam:

Deo-hans

\section{DESCRIPTION}

Adult Male: Head and upper part of neck white, thickly spotted and mottled with black; black spots almost confluent on the dorsal aspect; lower part of neck glossy black, merging into the chestnut brown of the lower parts; mantle black with greenish and purple reflections; breast and abdomen chestnut brown; under tail-coverts blackish brown; back, rump, and upper tail-coverts blackish glossed with green; upper wing-coverts white; median wing-coverts lead color tipped with black so as to form a black band; quills olive brown to blackish, but secondaries having the outer web bluish lead color; tertials brown, the outer one being white with black margin on its outer web; under wingcoverts and axillaries white, the former mixed with some brown feathers; tail dark olive brown.

Old males evidently become more metallic-colored on the mantle and more white about the head and neck, especially the throat and eye regions. Wing having a pronounced carpal knob.

Bill dark yellow to orange, mottled with dusky spots, the nail being light horn color; legs and feet yellow or orange yellow, claws pale horny; iris yellow or orange yellow (collectors differ on this point). Baker (1908) noted that during the breeding season the base of the upper mandible becomes considerably swollen and the orange color deepens to a deep orange or orange red. According to him the iris is brown to blood-red in old birds.

Wing $363 \mathrm{~mm}$. to 401 ; tarsus 56 to 61 ; culmen 58.4 to 66 .

Weight 7.5 to 9.5 pounds (3.8 to 4.3 kilograms); a very fat bird in captivity 9.75 pounds (4.87 kilograms).

Adult Female: Practically the same plumage as in male, but never becomes quite so highly glossed and colored. Bill pale dull lemon, rarely with orange tinge; black mottlings same as in male; base of upper mandible never swollen or red in color; iris brown, never red brown or blood-red (Baker 1908). Weight 4.75 to 6.75 pounds (2.1 to 3.6 kilograms). Wing $305 \mathrm{~mm}$. to 355 ; tarsus 53 to 61 ; culmen 56 to 61 .

Young: Very little recorded on immature plumages. Immature birds are much more brown on the lower parts, but with the black collar on the fore neck. 




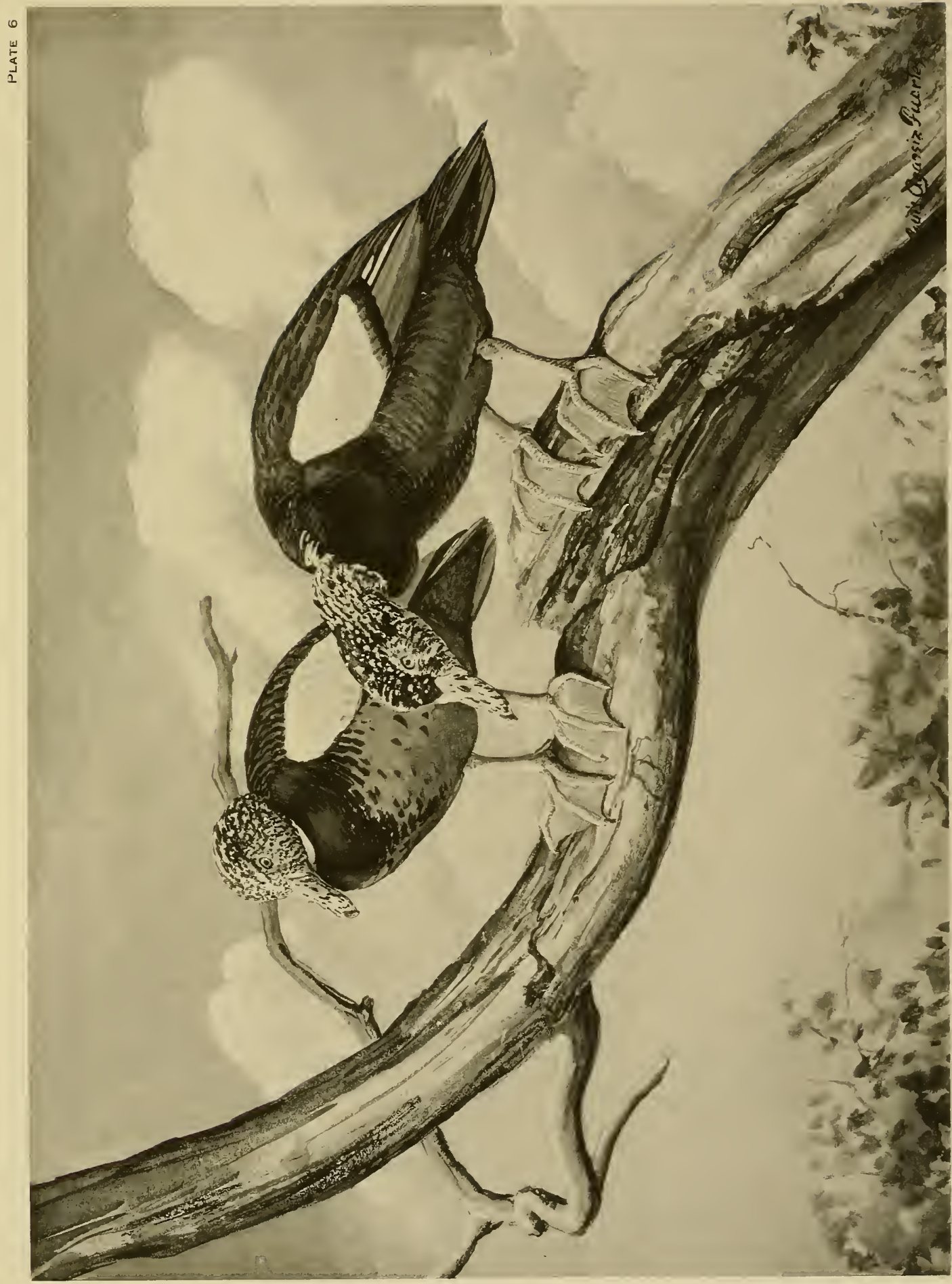



Young IN Down: Not seen.

REMARKS: Salvadori (1895) notices that this bird is kept in confinement in the East and then becomes partially albinistic, white feathers appearing on neck, breast, and abdomen. Stone (1903) mentions two specimens collected in Sumatra which had the head, rump, and breast white. Blyth (1875) called attention to specimens in the Leyden Museum (from Java?) which were parti-colored. I have seen one very albinistic specimen in the British Museum from the Moluccas and also one in the Leyden Museum. There are no specific accounts of the domestication of this duck that I can find.

Moult: Baker (1908) found this species moulting in September or October. The flight feathers were shed very rapidly and the birds were then unable to rise from the ground for ahout a fortnight. After that they were able to flutter from one perch to another or to take short flights. The new plumage is extremely rich and glossy, and gives the birds an entirely different appearance.

\section{DISTRIBUTION}

Av inhabitant of dense and inaccessible forest areas, this species is little known and its status is still uncertain. The only record of its occurrence west of the Ganges is that given by Baker (1908) who speaks of four having been seen in the Singbhoom District, Chutia Nagpur. Jerdon (1864) claimed to have seen many specimens at Dacca on the Lower Brahmaputra, but India most authorities are agreed that he was in error. Northward, however, a specimen was taken in the Garo Hills, another at Tezpur, and a third on the Dhansiri River, Assam, while farther up the Brahmaputra it was found rare in Darrang, but common in Lakhimpur (Hume and Marshall, 1879). Baker's personal observations have done much to support these statements. He describes the species as very rare in Bengal, but becoming increasingly common as one follows the Brahmaputra upstream through Kamrup, Darrang, the Namba Forest, etc., to Lakhimpur, where the species is as well known, apparently, as anywhere, and where it nests (Baker, 1908). Its status southward through Burma is very uncertain, but Blyth (1875) is certainly mistaken when he described it as occurring throughout the country. It is a fairly common bird in Cachar and Naogang (Baker, 1908) and several were seen in Manipur (Huggins, 1913), while it is occasionally seen also in northern Arakan (Hopwood, 1912). Eastward it has been taken at Bhamo, but is very rare in Burma (Evans, Journ. Bombay Nat. Hist. Soc., vol. 13, p. 532, 1901). Rippon (1901) did not meet with it in the South Shan States, nor did Hume's collectors even see it in Upper Burma. It appears to be rare in Tenasserim, though there are some specimens from Tavoy and Mergui (Hume and Marshall, 1879). The species has recently been taken in western Siam, in Siam the Raheng District (Barton, 1914).

In the northern section of the Malay Peninsula it appears to be very abundant, though Gyldenstolpe (1916) says he met with it only once in the northernmost parts $\left(11^{\circ} 50^{\prime}\right.$ north latitude). Hume got specimens from Poonga, Kussoom, and Kopah in this region, while Robinson and Malay Kloss (1911) state that it is very common about Trang and fairly so farther south at Peninsula Chong. Recently the same writers (1919) have recorded it for Nong Kok and Ghirbi in the Puket District. Bonhote (1901) has recorded it from Patelung. At best it seems to be rare in the southern parts of the Peninsula. Vorderman (1890) recorded it from Sumatra and Hartert (1902) says that it was frequently shot in Deli District, northwest Sumatra, by Hagen. The only specific locality I could find is Lampong, extreme southeast, where Harrison and Sumatra Miller shot two specimens in autumn (Stone, 1902). According to Schlegel (1866) the species was found by Müller also in Java, on Lake Gorong and at Buitenzorg, though this may have been a domesticated form. G. R. Gray (1871) was unquestionably wrong in Java giving the Moluccas as its habitat. 


\section{GENERAL HABITS}

BAKER (1908) gives the only really satisfactory account of this rare and handsome duck. In Burma the White-winged Wood Duck inhabits a large area of virgin forest along the foothills of the Himalayas, which is devoid of cultivation, but broken up by many swamps or lakes of all sizes. Among the smaller sheets of water the ducks are found in pairs or singly, and never in companies of more than five or six. They seem always to be wary, and Baker thinks that they do not dive when wounded, but swim to the nearest shore and scramble into the woods. They also inhabit smaller patches of jungle where suitable pools are to be found, but are never to be met on clear waters of swift streams.

At Trang, in the northern part of the Malay Peninsula, Robinson and Kloss (1911) found them flying down to the partially flooded rice-fields to feed in the early morning or late afternoon. In the evening after feeding they went to roost in the patches of jungle growing on small steep hills rising from the general level of the rice-fields. According to Baker (1908) the flight is gooselike. A flock of seven, the largest he ever saw, flew in a line like geese and at a distance would probably have been mistaken for geese.

This Wood Duck apparently does not associate with other species. At least the literature gives no information on this point.

Both Baker and Graham (vide Hume and Marshall, 1879) have heard this species calling. The former describes the note as loud and gooselike. In addition to the "ringing trumpet call" of this bird, both sexes indulge in a very low quacking note, sounding very much as though a Mallard were trying to quack under its breath. While uttering this note the head is always held low and the bill wide open. They also make a hissing noise when angry. Another writer (Gyldenstolpe, 1916) speaks of a faint quacking sound.

FooD. Nothing is known of its diet beyond the note of Robinson and Kloss (1911) that it feeds in rice-fields, and that the specimens examined had been feeding on very large snails, apparently a species of "Ampullaria." In captivity they were omnivorous and proved to be very fond of small fishes, and expert at catching them. They preferred animal food to grain, green food, and water-plants (Baker, 1908).

Courtship and Nesting. Almost nothing is known of the nesting habits of the White-wing. One nest, described by Baker, was taken from a deep hollow caused by a decay at the first bifurcation of the trunk of a tree standing on the banks of a stream. The nest was said by the native who found it to be a mass of grass and other rubbish with a lining of feathers and down. Baker was told also that the birds did not always nest in holes of trees, but sometimes made rough nests on masses of 


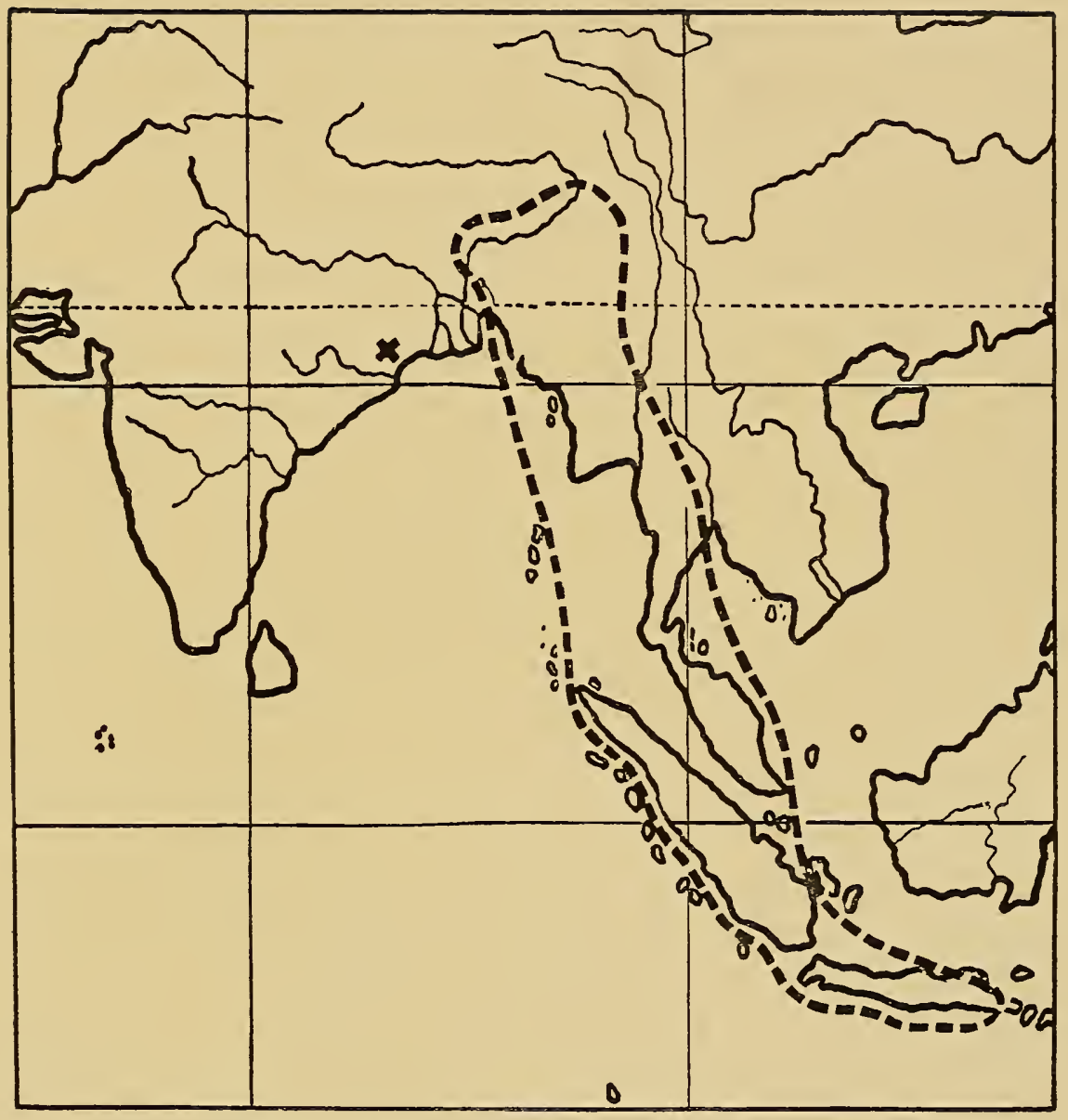

MaP 5. Distribution of White-winged Wood Duck (Asarcornis scutulata) Unusual locality shown by a cross $(X)$ 

branches (nests of other species?), and at other times actually nested on the ground. No description of the eggs is available, but they are probably white or nearly so.

Status of Species. I have no means of estimating the present status of this species, beyond what has been said under Distribution.

Food VALUE. Nothing is recorded, but it is said to be eaten regularly by some planters in Assam. More than three or four birds can rarely be obtained in a day's hunt, and this only after a walk of twenty miles or more. Baker mentions that his live birds were all obtained by setting many nooses about the edges of waters frequented by them where they were easy to catch owing to their habit of resorting to the same stretch of ground when entering or leaving the water.

BeHavior in Captivity. Baker kept many of these birds in confinement. They tamed very readily and did not attempt to fly off except at the approach of the breeding season. In fact, after having been thus tamed, they never made use of their wings, but walked long distances to and from the water, as much as half a mile in one case. Their gait, and their style of swimming according to Finn (1915) are different from those of the Comb Ducks and Sheldrakes, and resemble rather those of the true ducks. The swelling of the drake's bill in the spring is similar to what takes place in the Common Sheldrake. Baker's birds died very quickly when sent to the Calcutta Zoological Gardens and in his aviaries always kept out of the sun from 10 A.M. to 2 P.M. even in the cool weather. He found them very well behaved and never quarrelsome. Probably if Baker's birds had nested in confinement, they would have become more pugnacious. Some Lesser Whistling Teal (Dendrocygna javanica) shared the same yard and never came to any harm. When not feeding, the Whitewinged Wood Ducks almost invariably sat on perches, but they kept their position chiefly by balance of the body, never by grasping of the feet. These caged birds very seldom called, except occasionally in April and May. One female which died in June contained eggs larger than those of a hen. The birds paired regularly in May, the base of the drake's bill becoming swollen and red, but the ducks never laid any eggs.

Finn (1915) remarks that a single female in the London Zoological Gardens often made a spiteful grab at some smaller water-fowl. In 1851 the London Gardens received two specimens from Mr. Blyth, but there was none living in the Gardens in 1883 (Sclater, 1883). In 1905, five specimens arrived in England and were sold for twenty pounds the couple (Hubbard, 1907). So far as I know, no living specimens have ever been received in America.

Mr. Blaauw tells me that he saw living specimens of this duck some years ago on the Duke of Bedford's estate in England, and that they did not live many years. He was much struck with the Muscovy-like appearance of the species. 
Domestication. There are various references to mottled or piebald specimens from Sumatra and Java, and these have been explained on the assumption that the birds were breeding in domestication. This, however, seems to me very improbable because the species has given no evidence of easy domestication. There are instances of considerable changes of plumage after many years in captivity which may account for these freak plumages. The possibility of a distinct southern race (leucoptera) of this species as suggested by Hume and Marshall (1879) still exists. 


\section{HARTLAUB'S TEAL \\ PTERONETTA HARTLAUBI (CASSIN)}

(Plate 7)

\section{SYNONYMY}

Anas cyanoptera Temminck (nec Vieillot), Mus. Lugdunensis.

Pterocyanea cyanoptera Bonaparte, Compt. Rend. Acad. Sci. Paris, vol. 43, p. 659, 1856.

Querquedula hartlaubi Cassin, Proc. Acad. Nat. Sci. Phila., 1859, p. 175.

Anas cuprea Schlegel, Mus. Pays-Bas, Anseres, p. 62, 1866.

Pteronetta hartlaubi Salvadori, Cat. Birds British Mus., vol. 27, p. 63, 1895.

Pteronetta hartlaubi albifrons Neumann, Bull. British Ornith. Club, vol. 21, p. 42, 1908.

\section{Vernacular Names}

\section{English:}

Hartlaub's Teal

German:

Hartlaubs Krickente

\section{Camerun:}

Alot

Aloteke

Arabic:

Boro

\section{DESCRIPTION}

AdULt MALE: Head and upper part of neck black, a white square patch on the frontal edge; rest of plumage bright chestnut, changing into chocolate olive-brown on the rump; upper wing-coverts blue; primaries brown; secondaries olive brown, with a slight bluish tinge near the edge of the outer web; tertiaries olive brown, edged with black on outer web; under wing-coverts brown, washed with dull lead blue; tail brown (Salvadori, 1895).

Bill black with pale gray band near the tip and pale yellow spot below the nostril. Feet dark brown with some yellowish on shanks and toes; webs blackish (Amer. Mus. Nat. Hist.). Iris yellowish brown (Emin Pasha).

Total length $559 \mathrm{~mm}$; wing 270 ; tail 127; culmen 47 . Old males have sometimes a slight swelling at the base of the culmen which disappears in the dried skin (Chapin).

Adult Female: Similar to male.

ImMature Birds: In the Chapin series in the American Museum of Natural History these are lighter on under parts, with edges of feathers lighter in color.

Young IN Down: One specimen in the Museum of Comparative Zoölogy at Cambridge shows upper parts nearly black, lower parts yellowish, chin, neck and breast orange yellow; well-marked black ciliary stripe with superciliary yellow patch, this superciliary patch being almost divided into a front and a back area by the black of the pileum, which at one point touches the eye. Yellowish patch at base of wings, one on sides of back and another on sides of rump; some black feathers around vent; iris 
dark brown; feet black; bill black above, black and whitish beneath (specimen collected by G. L. Bates, Nov. 16, 1910, River Ja, Camerun). Compared with the young of the Mallard this is much blacker on the upper side, with the orbital stripe very broad and black, especially between the bill and the eye. There are no golden, hair-like feathers on the mantle and back. The lower surface is about the same as in the Mallard.

REMarKs: In the Bulletin of the British Ornithologists' Club, vol. 21, p. 42 (1908), Neumann describes as distinct, birds from the Upper Congo, Uelle, and Ituri Rivers in northeastern Congo Free State under the name Pteronetta hartlaubi albifrons. The characters given are: "large white patch on the forehead extending to the middle of the vertex," and also "a ring of white feathers around the eye." In the American Museum of Natural History in New York there is a fine series of eighteen specimens taken by Mr. James P. Chapin in the same region, and only one, a male, has the whole top of the head and periocular region white. In this case the white area extends along the sides of the bill to the chin and is not nearly symmetrical on the two sides of the head. Another specimen has numerous white feathers on the chin and throat, and the white forehead patch very irregular. This patch is usually square and about $85 \mathrm{~mm}$. deep, but sometimes there is no patch at all, and at other times white spots occur up to the pileum. It is therefore apparent that the characters given for the new race are extremely variable, and as partial albinism appears to be quite common about the head in closely allied species (Spur-winged Goose, White-winged Wood Duck, Comb Duck) the characters cannot be considered of much significance, unless supported by large series from different localities. Bates (Ibis, ser. 9, vol. 5, p. 482, 1911), in describing specimens from the Camerun, says that all his examples (six in number) have either no white, or a very faint ticking of white on the forehead, excepting two males which have a white spot on the forehead. He considers the white spot characteristic of the male, but also acquired by old females. All the specimens in the British Museum from the Camerun, Sierra Leone, and West Africa generally are black-headed, so that it is evident that if we consider Pteronetta hartlaubi albifrons a valid race it will have to be restricted to the Ituri and Aruwimi (lower Ituri) Rivers, for no really white-headed birds occur on the Uelle River. Males are found there with white foreheads only.

To sum up, the white head is a variable character, more or less dependent upon age and sex as well as upon locality. It is a matter of opinion whether it should be made the basis of a distinct race.

\section{DISTRIBUTION}

OuR knowledge of the range of this species is still very fragmentary. It is a distinctly non-migratory West African species, found chiefly north of the Equator and perhaps never occurring north of $10^{\circ}$ N. lat. It has been found as far west as western Liberia, on the Junk River (Büttikofer, 1886), where it seems to be not uncommon. Johnston (1906) met it in eastern Liberia and there is a single record for Sierra Leone (Ibis, ser. 10, vol. 2, p. 224, 1914), but there are no records of its occurrence on the Ivory Coast. It is known, however, from the Rio Boutry, Gold Coast (Hartlaub, 1885); but then again, has never been recorded from Togo, Dahomey, or Nigeria. In Camerun it is a well-known bird, especially on the Ja River, where it breeds (Bates, 1909). The same explorer found it at Efulen, Benito, and Como, while Zenker, the first to discover this species in Camerun, found it near Jaunde (Reichenow, 1900). Reichenow (1911) states that it was found on the Decha River and in four places between there and the coast. There are as yet no records from north Camerun. According to Rochebrune (1883-85) it is rare, but resident in Gambia and Senegal, a statement difficult to accept.

On two different occasions the species was found in Spanish Guinea, while in French Equatorial Africa it was found abundant in Gabun, on the Kamma and on the Ogowe Rivers, by Du Chaillu (Cassin, 1859). Recently it has also been taken in the Rio Benito region, at Alen, Uelleburg, and Bebai (Reichenow, 1910). Marche (Barboza de Bocage, 1880) has obtained it from Doumé. The 




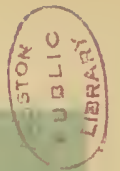
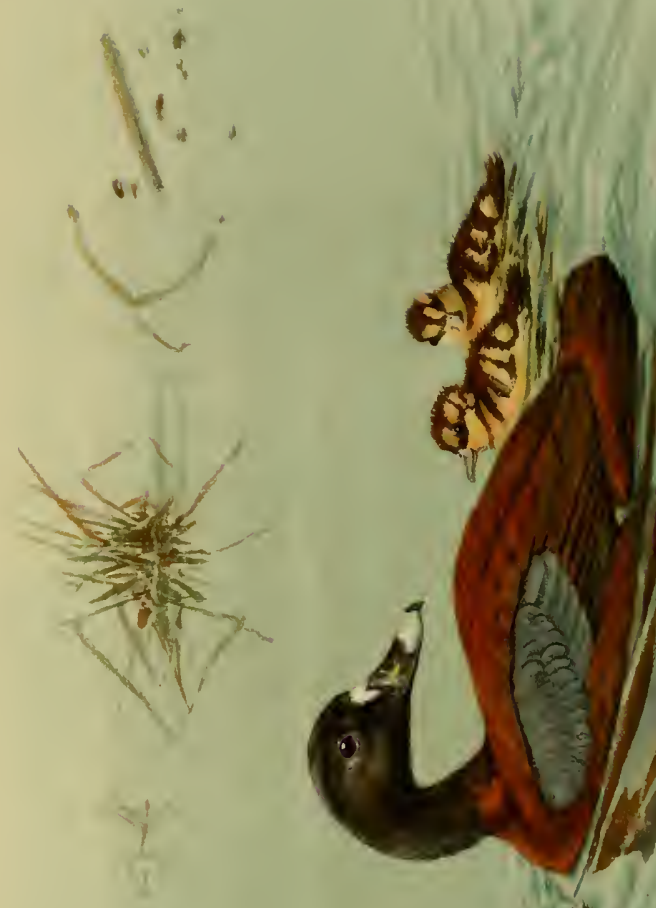

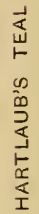
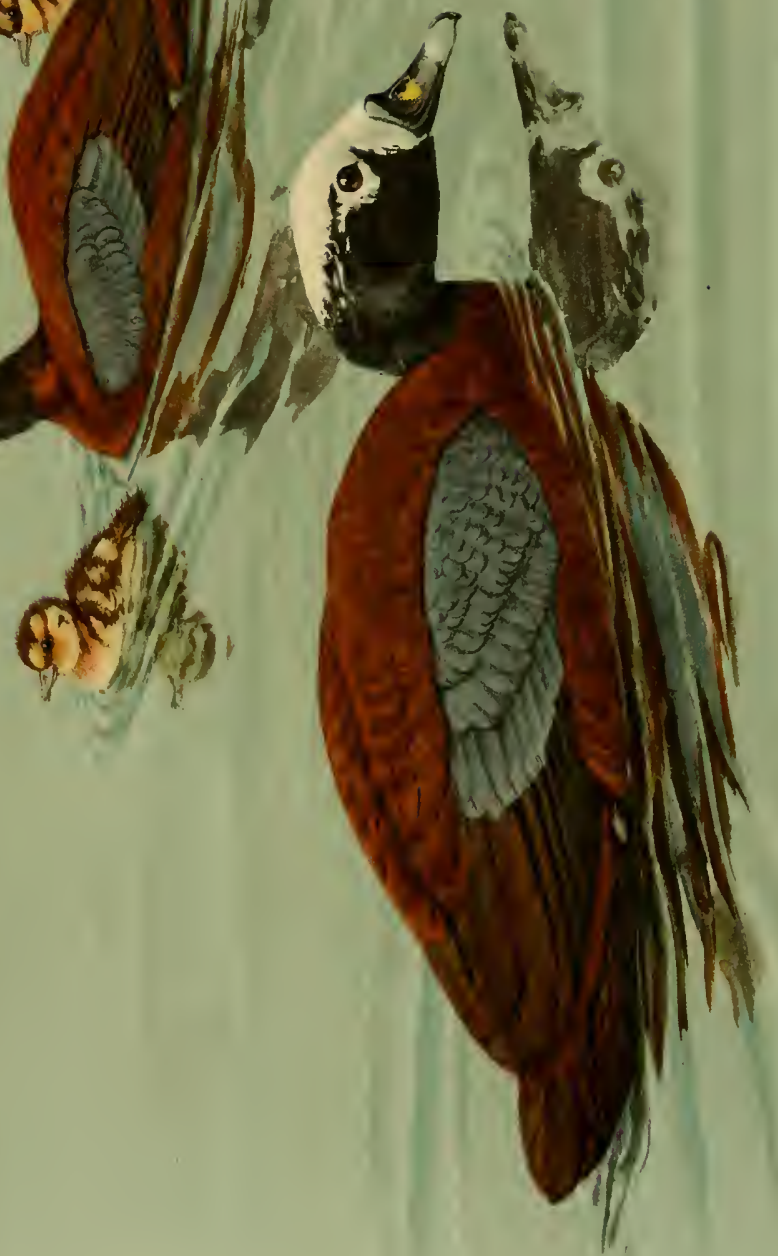

southern limit seems to be the Congo Delta. Just north of there it was found at Luemba and Chissambo on the Loango coast, by Lucan and Petit (Sharpe and Bouvier, 1876). There is also a specimen in the Paris Museum from the interior, namely, from the Alima River.

The chief habitat of this species seems to be the strip from the Atlantic, east to about $29^{\circ} \mathrm{E}$. long., lying between the Equator and $5^{\circ} \mathrm{N}$. lat.; that is, southern Camerun, north-central French Congo, and northern Congo Free State. Mr. Chapin, in a valuable letter, has sent me details as to its status in the northeastern Congo, where it was previously discovered by Camburn (Neumann, Bull. British Ornith. Club, vol. 21, p. 42, 1908). The observations cover the districts of the Upper Uelle and of the Ituri, in both of which areas Camburn also met with this species. Chapin observed and took specimens in the region between Niangara on the Uelle, south to Avakubi on the Aruwimi, and he supposes it occurs east to about $30^{\circ} \mathrm{E}$. long. on the Bomokandi and Ituri. In the region covered by him it was the most abundant duck, though in so poor a duck country it was of course not common. It is most common in the north about Niangara, and on the Bomokandi, and certainly does not extend farther east than Dungu, for in two years it was not seen at Faradje. Emin Pasha found it at Tingasi (Reichenow, 1900). By Mr. Chapin's records for Niangara and Rungu on the Bomokandi the range is extended somewhat to the east. On the Ituri the species is less common than farther north in the Uelle region, though Mr. Chapin believes it occurs in the area southeast of Avakubi.

\section{GENERAL HABITS}

CHAPIN (in litt.) speaks of its habitat as being small brooks entirely hidden in the forest, and he says the birds are very rarely seen on larger rivers. Sharpe (1907) states that it is seldom seen, but often heard, along streams in the Camerun where the foliage is extremely dense. According to this writer, the birds are bold on the Ja River and come to eat cassava roots that are put to soak by the village women. By taking advantage of this habit, people often snare them. Chapin, on the other hand, considers them fairly shy, and says they never allow a man within gunshot if he is in plain view.

Nothing has been recorded concerning the daily movements or the feeding habits of this "Teal," nor have any notes been made as to its flight or gait. Buittikofer in Liberia observed them in a forest of high mangroves on the Junk River where they perched on overhanging branches when startled. Chapin, too, notes that they sometimes fly up and alight on the larger boughs of trees.

In southern Camerun, these ducks are generally seen in pairs, but occasionally a trio is met with, a pair with a third individual "tagging after." Once in August four were seen perching on the limbs of a cotton tree (Bates, 1909). Chapin says that he has seen as many as six together on a pond on the Uelle River, though more often they are in pairs or singles. His observations were made in the northeastern Congo, where ducks are almost unknown, a few Black Ducks (Anas sparsa), an occasional Comb Duck (Sarcidiornis melanotus), and rarely a White-faced Tree Duck (Dendrocygna viduata), or Spur-winged Goose (Plectropterus gambensis), being the only Anatida seen besides the present species. On the occasion of finding six of these Teal together, they were with a Spur-wing; beyond this nothing has been noted as to association with other species. 
Bates (1909) mentions "a raucous noise" made by some of these birds when mating. Sharpe (1907) describes the alarm call as a rapid $k o-k o-k o$ often heard along the streams. Mr. Chapin writes me that the voice is unlike that of any other duck he knows, being heard as they fly over at dawn or dusk and sounding like a loud, hoarse $k^{\prime} h a-k k^{\prime} h a-k^{\prime} h a-k ' h a$ repeated again and again. He thinks the males are probably the noisy ones, for they have a rounded "labyrinth" on the left side of the syrinx. However, this is far from certain, as the bony labyrinth seems usually to decrease the voice, so that one would expect the noisy sex to be females.

Food. All the information I have been able to obtain concerning the food of this species comes from Mr. Chapin. He writes: "The stomachs of Pteronetta usually contain sand or pebbles, sometimes small hard seeds as well, but seldom anything else. Only three of ours showed any other food; this consisted of aquatic insect larvæ (mainly dragon-flies), snails, two small lamellibranch mollusks, a shrimp and a spider."

Courtship and Nesting. Bates was fortunate enough to observe two pairs perched on the large limbs of a cotton tree performing some queer antics. This was in August, and it is reasonable to suppose that the birds were about to nest, for the nesting season seems to be in September and October, judging from the fact that young of all ages have been taken in November. In each of the mating pairs observed by Bates the male faced the female, both bowed their heads and rubbed each other's bills and heads, all the while keeping up a "raucous noise"; after a few minutes they flew away.

This Teal probably selects hollow trees for its nest, but no direct observations have ever been made. In two years Mr. Chapin never found or even heard of a nest, and merely noted that a few old females shot in November still had the ovaries slightly enlarged. He feels certain that they do not breed throughout the whole year. Bates found a female with nine young in late November in the southern Camerun (wet season). Five of these were caught and placed in a pen of wire netting where they were kept alive for several weeks. At first, however, they were placed in a keg, but they soon climbed out, using their claws on the rough wood. They also went up the wire netting, partly by jumping several inches at a time, but the power or inclination to climb ceased after a day or two. Bates suggested that this ability to climb was a special endowment indicating a tree-nesting habit for the species. The egg has never been taken and hence remains undescribed.

Status of Species. Hartlaub's Teal is usually considered a rare bird. Nevertheless, it is common far in the interior, as well as in the Gabun region and in the Camerun, while in Liberia it is apparently not very rare. I cannot say whether it has diminished to any extent in recent years. 


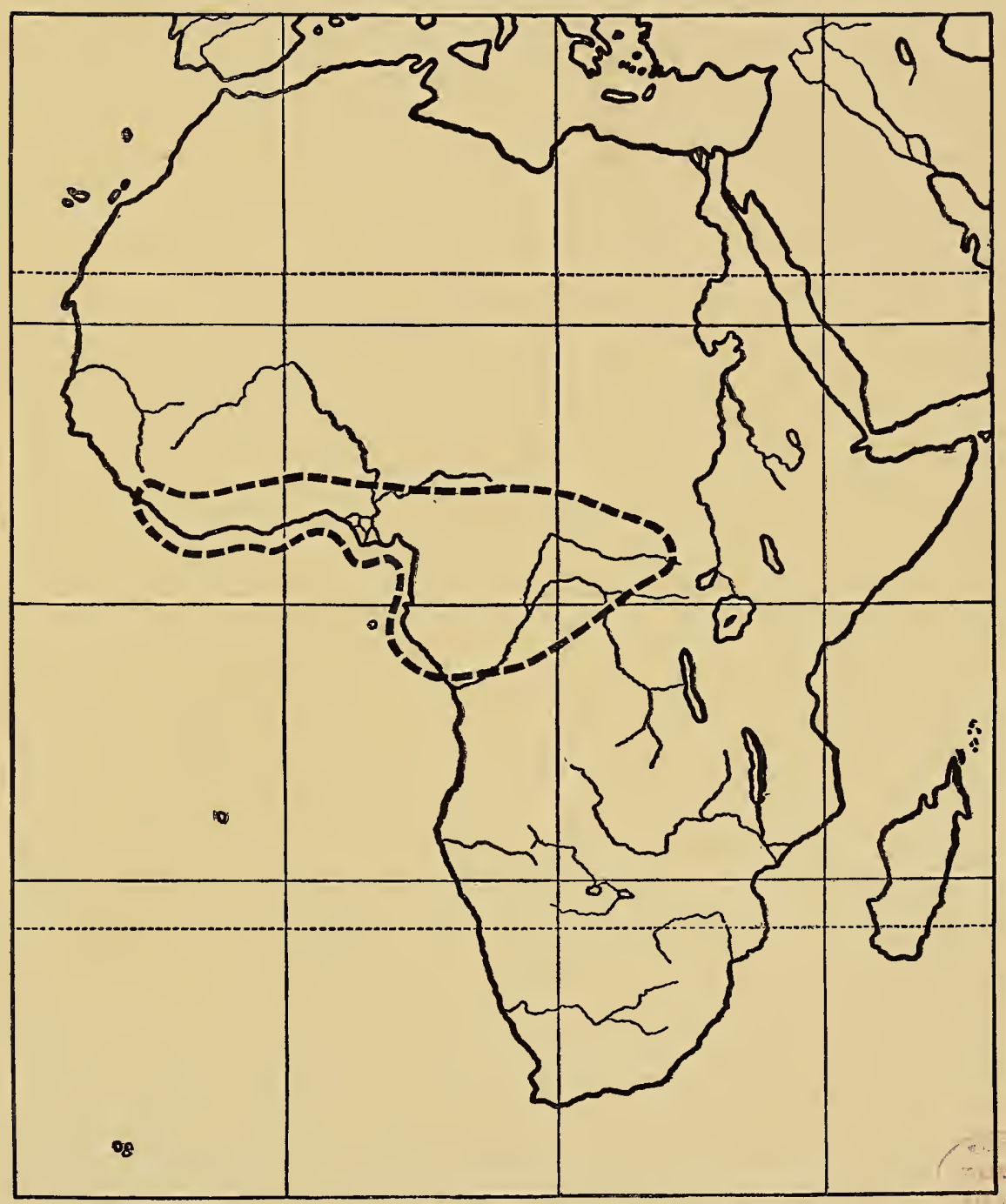

MaP 6. Distribution of Hartlaub's Teal (Pteronetta hartlaubi) 

Food Value. No information is available. Sharpe (1907) mentions the fact that they are sometimes snared by the natives in the Camerun.

Behavior in Captivity. The young birds which Bates mentions as being kept in a pen ate cassava and maize meal, put into water, and they also greedily picked up termites placed on the floor of their pen. It has never been imported into Europe or America. 


\title{
PINK-HEADED DUCK \\ RHODONESSA CARYOPHYLLACEA (LATHAM)
}

(Plate 8)

\author{
SYNONYMY
}

Anas caryophyllacea Latham, Indian Ornith., vol. 2, p. 866, 1790.

Rhodonessa caryophyllacea Reichenbach, Av. Syst. Nat., p. ix, 1852.

\begin{tabular}{cc}
\multicolumn{2}{c}{ Vernacular Names } \\
English: & India: \\
Pink-headed Duck & Saknal - (Bengali) \\
French: & Lal-sira \\
Milouin à cou rose & Golab-lal-sir \\
German: & Dumrar - (Nepal) \\
Rosenkopf-ente & Umar - (Tirhoot)
\end{tabular}

\section{DESCRIPTION}

Adult MaLE: Head, sides of neck, and hind neck beautiful pale rosy pink (which, however, fades somewhat in dried specimens) with a tuft of still brighter feathers on the top of the head in the breeding season. Throat dark brown; rest of plumage fine glossy, dark chocolate-brown, paler and less glossed beneath, but under tail-coverts very dark. Mantle, scapulars, breast and sides with very fine, rosy-whitish vermiculations or points; edge of the wing whitish, speculum reddish fawn or dull salmon color, with a white band at the tip of the secondaries, outer web and tip of the outer primaries brown, the inner web and inner primaries buff. Tertials glossy chocolate-brown, narrowly edged with black on the outer web. Under wing-coverts and quills beneath, pale pink color, with a salmon luster; tail chocolate-brown (Salvadori, 1895).

The shade of brown in the plumage varies a good deal, very old birds being nearly black. The brown in old or worn plumage is much duller and paler (Baker, 1908). Finn says that the male gets darker on the crown during the summer moult.

Bill dull reddish pink, deeper on mandible and darker still on gonys; the base of both mandibles, more especially the maxilla, near the forehead, purer and brighter pink. Irides "fine orange red to deep orange red "; legs and feet blackish, with a tinge of red (Jerdon), or reddish slate (Shillingford).

Length $609 \mathrm{~mm}$.; wing 267; tail 108; culmen 53; tarsus 40 (Salvadori).

Weight about 2 pounds (0.9 kilograms); maximum 2 pounds, 3 ounces (1.0 kilogram).

Adult Female: Similar to male, but duller and paler and more smoky brown. The head is not so pink but the pink area runs all over the chin and throat. The colors of the soft parts all seem to be duller than in the male, and Shillingford gives the bill as pinkish brown, with the base dull white; irides dull orange; tarsus, toes, webs and nails purplish slate. Size as in the male.

Young: Head and neck pale rose-white, with the top of the head, nape, and hind neck brown, the whole plumage lighter brown, the under parts pale dull brown with a streaked appearance and the edges of the feathers lighter than in the center. There may be little or no pink tinge on the head.

Young IN Down: Undescribed. 


$\infty$
$\frac{\omega}{5}$
$\frac{5}{1}$

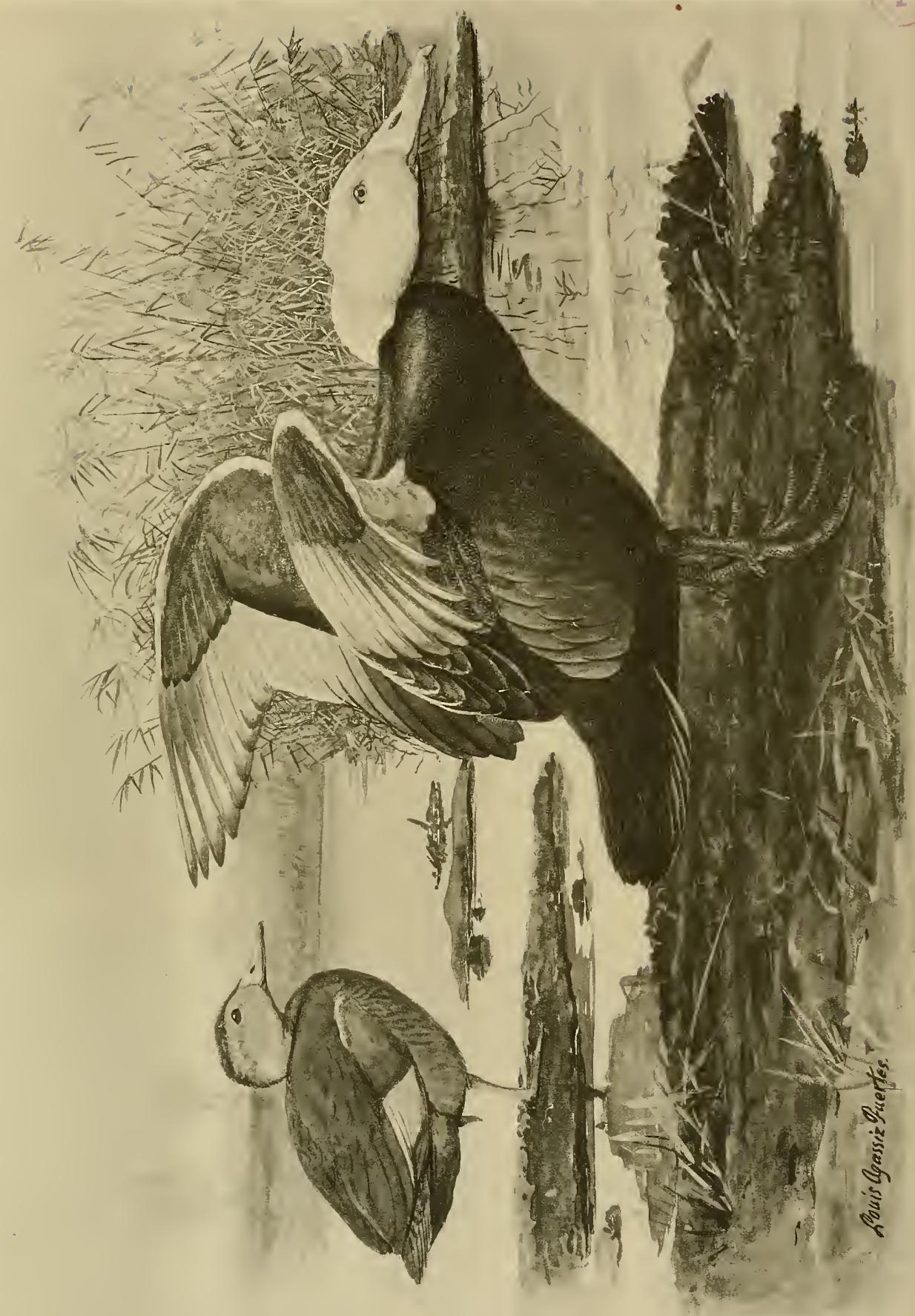

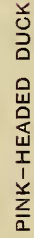





\section{DISTRIBUTION}

WIтH the exception of a very restricted area on the Ganges, this species appears to be everywhere rare. The area referred to, which all writers agree is its chief habitat, is located north of the Ganges and west of the Brahmaputra, and includes Purneah, Maldah, Purnlia, Bhagalpur and Tirhoot. In this region the species is common (Hume and Marshall, 1879; Baker, 1908; Simson, 1884; Blanford, 1898; Finn, 1909; etc.). Eastward it is found rarely throughout the rest of Bengal, and throughout the valley of the Brahmaputra as far as Sadiya (Hume and Marshall, 1879). The British Museum has specimens taken by Pemberton in Bhutan. Hume has recorded it from Manipur and Sylhet, but there is no evidence of its presence in Cachar, Tipperah or Chittagong. Blyth (1875) states that it is found in Arakan, but this stateBhutan ment has never been proved by later investigators. The same is true of Blyth's remark that the species had been discovered in Burma, nor is it known from Pegu or Tenasserim (E. W. Oates, 1883), or from the Shan States.

West of the Ganges the species is found rarely along the entire east coast, south to Madras (Hume and Marshall, 1879), occurring in Ranchi and Chota Nagpur and rather more commonly in Singboom (Baker, 1908). In Orissa it is rare, but is known to breed (J. H. Taylor, 1887). West of According to Hume and Marshall (1879), it is found southward through the northern Ganges Circars and Nellore to Madras. From the west side of the Eastern Ghats, however, there are only a few records of sporadic occurrences, such as those for Admednagar in the Deccan and Secunderabad and Jalna in Hyderabad (Hume and Marshall, 1879). In northern Deccan and northwestern India the species is also rare or sporadic. There are several records Nepal Terai for Nepal Terai (Hodgson, 1844) and it is not so very rare on the Ganges about Arrah (Baker, 1908). In Oudh it occurs regularly, though in very small numbers (Baker, 1908), and seems to be found chiefly in the eastern sections and in the Sal Forest, being resident, however, even in the western part (Hume and Marshall, 1879). It seems to occur not infrequently about Lucknow, especially during the rains (Jesse, 1903) but it is very rare in the Northern Provinces, Doab, and Rohilkand (Hume and Marshall, 1879). The only record for the Central India Agency that I know of, is the statement of C. Swinhoe and Barnes (1885) to the effect that the species is common (!) on Lake Depalpore, near Mhow, in winter. Baker (1908) adduces one very doubtful record of its occurrence in Sind, and he also says that it appears to have been taken about four times near Delhi. There is no evidence of its ever having been seen in the Central Provinces or anywhere south of Mysore or even in Mysore; nor in the northwest in Kathiawar, Rajputana, the Punjab or Kashmir. Nor as far as is known does it ever ascend into the Himalayas.

\section{GENERAL HABITS}

THis rare bird does not appear to be nearly as much of a forest lover as the Comb Duck or the White-winged Wood Duck. Its chief home is described by Simson (1884) as being vast, extensive, and much-neglected plains, studded at considerable intervals with small poor villages, and intersected with deep streams running from the north into the Ganges, and abounding with crocodiles. These plains are often subject to inundation. The Pink-heads inhabit small pools from ten to forty acres in extent, scattered about these plains, and surrounded by very high grass. There are a few stunted trees growing in this grass, and the pools are covered with lotus plants. In such surroundings this duck is found throughout the year. In other regions, however, the species seems to be found near the edge of jungle areas, but 
always on enclosed waters surrounded by much cover. Occasionally in cold weather it resorts to open rivers (Baker, 1908).

The Pink-head is not a perching duck and is seldom seen moving about from place to place. It seems to be a shy and wary bird. According to Jerdon (1864) it spends the heat of the day in the middle of a tank (pond), and Hodgson (quoted by Hume) states that it feeds at night. In general its habits are very unlike those of the treenesting species, such as the Comb or White-winged Ducks, and resemble much more those of a true surface-feeding duck like the Spot-bill. Finn (1915), however, once saw it dive very neatly, and stay under "as long as a Pochard," though apparently only in play. Nothing much has been recorded as to the nature of the flight of this species beyond a note of Parker's (quoted by Hume), who says the flight is powerful and rapid, and Finn's remark that it is "light and easy."

The Pink-head is seen during the cold season in companies of from four to eight, and rarely in flocks numbering twenty or even thirty (Shillingford, quoted by Hume). Simson (1884) did not find it associating with other ducks, though in winter it must almost of necessity be found associating with numbers of migrant species.

The voice of this bird is, in the male, a peculiar mellow two-syllable call, often uttered, and sounding like the syllables wugh-ah, with a metallic ring to it (Finn, 1901). Shillingford describes it as being similar to that of a common drake, "with a slight musical ring about it." The duck's call is said to be a loud quacking note. The trachea is entirely different in the two sexes, which probably explains the weaker voice in the male, in which sex there is a slight fusiform dilatation, and lower down, a well-developed syringeal box, larger on the left side. In the female the trachea and syrinx are simple. Anatomical figures are given by Garrod (1875). That authority remarks that the syrinx shows fuliguline affinities besides a superficial resemblance to that of the Comb Duck (Sarcidiornis).

FooD. Practically nothing of interest is recorded. One gizzard examined contained water-weeds and various small shells.

Courtship and Nesting. During the month of April these birds begin to pair, and are said by Shillingford to go up to the central or higher parts of the Purneah District. The nest is placed in the center of tufts of tall grass, well hidden, and difficult to find, generally not more than five hundred yards from the water. The nest is well formed of dry grass, interspersed with a few feathers, $227 \mathrm{~mm}$. in diameter and $102 \mathrm{~mm}$. to $127 \mathrm{~mm}$. deep, with no special lining. Both male and female have been found in the vicinity of the nest, and it is possible that the former occasionally assists in incubating, for Shillingford found that it lost much weight during the breeding season. Hume and Marshall (1879) describe the eggs as very peculiar, and quite unlike those of any other duck. They are nearly spherical, while the shell is 


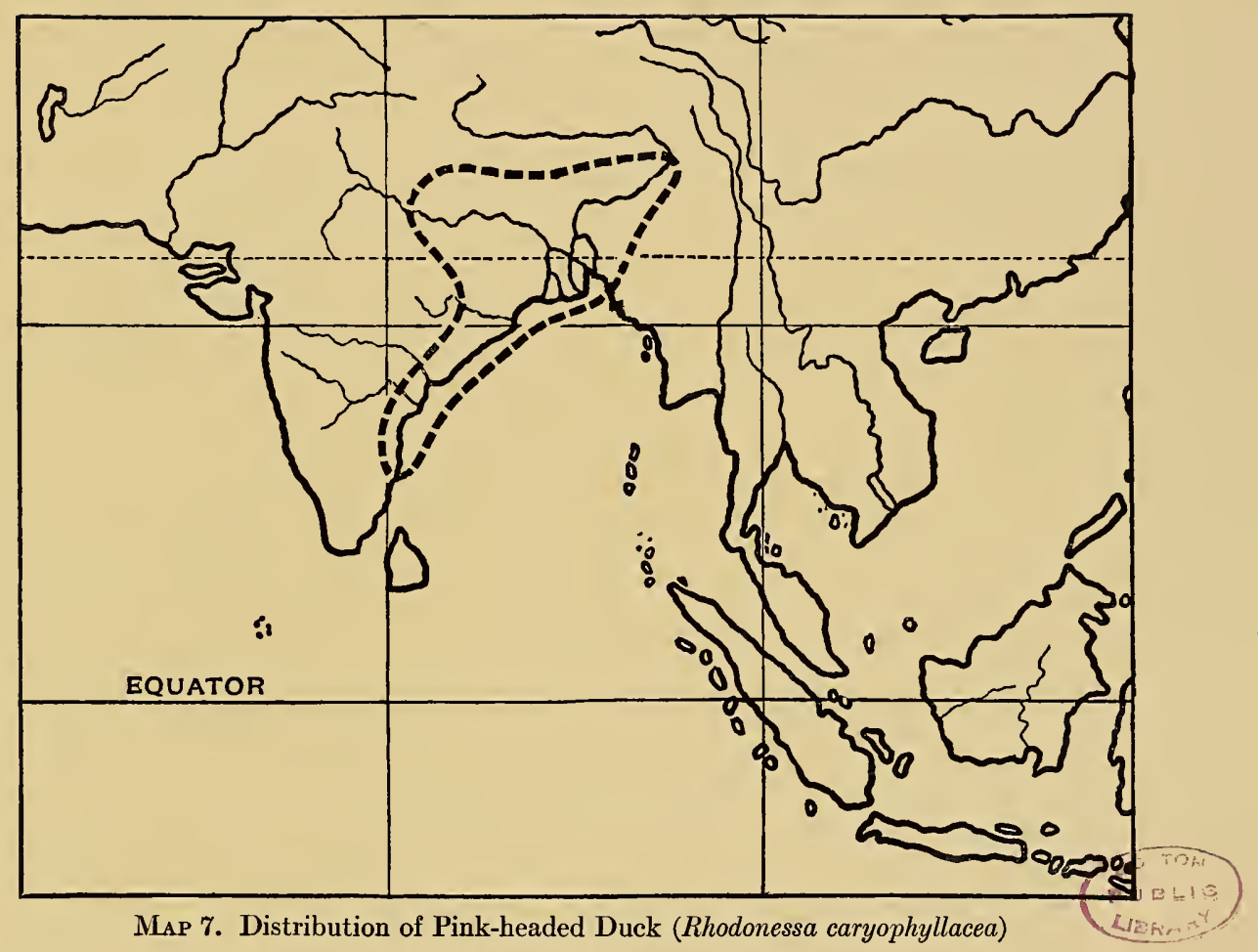



of close texture, but not "smooth or satiny," and without gloss. Finn (1919) says they remind one of a set of billiard balls. In color they are pure white or faintly yellowish, and measure about $45.7 \mathrm{~mm}$. by $42.2 \mathrm{~mm}$. This is the only duck that lays a spherical egg. The young are on the wing in September and October, and the birds then retire to their usual winter haunts.

Status of Species. According to Finn (1915) the Pink-head is not nearly as plentiful in the Calcutta Market as it used to be in the nineties of the last century. At that time they could be bought for fifteen rupees, but at present, informants tell him that probably an offer of one hundred rupees would not bring a single specimen. He thinks it is possible that the species has become shy by too persistent netting; certainly the birds, on account of their extremely limited range, should be given absolute protection. I understand this is now afforded them in the breeding season only.

Mr. Stuart Baker sent me an interesting note on the status of the duck in 1920. He regards protection as having little to do with its great rarity. He adds, "It is so seldom seen and so little known because it inhabits only the wildest country, the haunts of tigers and other animals that the native keeps as far away from as he can, whilst its malaria-stricken tracts are avoided by both white and black men during the breeding season. Forty years have elapsed since I first saw it and no reward has sufficed since then to induce 'shikaris' to visit its breeding places and find me a nest and eggs. As civilization and cultivation advance the bird may be driven back, but it will be many generations before it can be affected thereby."

Food Value. All authorities except Jerdon (1864) consider the flesh of this bird very inferior. The Pink-head is rarely hunted as game, not only because of its scarcity, but also because of its low value as food. Simson (1884) prefers every other duck, excepting the Shoveller, and considers it worse for the table than even the Brahminy or the Whistling Teal. Among large bags of other water-fowl, more than one or two of this species are rarely taken. Baker (1908) mentions six in a day as an unusual number.

Behavior in Captivity. The Pink-head has always been extremely rare in captivity, even in India. Very few have reached Europe, and apparently only one pair ever reached the London Zoological Gardens, and that in the year 1874. They did not live very long and never bred. Mr. G. D. Tilly, of Darien, Connecticut, received one specimen about ten years ago, but it lived only a few days. Several pairs that reached London in 1897 were sold at prices varying from $£ 40$ to $£ 60$ the couple (Hubbard, 1907). The only note on its behavior in captivity is supplied by Finn (1915), who tells of a characteristic wing-whistle heard from the birds when flying in an aviary. Mr. F. E. Blaauw writes me that he has never kept it. 


\title{
AFRICAN PYGMY GOOSE
}

\author{
NETTAPUS AURITUS (BODDAERT)
}

(Plate 9)

\section{SYNONYMY}

Anas aurita Boddaert, Tabl. des Planches Enluminés, p. 48, 1783.

Anas madagascariensis Gmelin, Linné's Systema Naturæ, ed. 13, vol. 1, pt. 2, p. 522, 1788.

Nettapus madagascariensis Brandt, Descr. et Icones Anim. Ross. Nov., Aves, fasc. 1, p. 5, 1836.

Nettapus auritus G. R. Gray, List Genera Birds, p. 73, 1840.

Nettopus madagascariensis Sundevall, Meth. Nat. Av. Disp. Tentamen, p. 146, 1872.

\section{Vernacular Names}

\section{English:}

African Dwarf Goose

African Pygmy Goose

Eared Pygmy Goose

French:

Sarcelle de Madagascar

German:

Afrikanische $Z_{\text {wergente }}$

\author{
Mozambique: \\ Sequiri \\ Madagascar: \\ Tatatsiry (Hova) \\ Voronandriana (Hova) \\ Maroampinga \\ Soafify \\ Vorontsara \\ Malagasy \\ Arabic:
}

Sililo

\section{DESCRIPTION}

Adult MaLe: Forehead, sides of head, and a collar around the neck white; top of head and a band along hind neck, back, rump, upper wing-coverts, scapulars and tertials dark glossy green; on each side of head and neck is an oblong pale-green patch separated from the white of the face and throat by a narrow black band; lower neck, upper breast and flanks rufous chestnut; lower breast and abdomen pure white; primaries and tail feathers black; a white speculum on the inner primaries and outer secondaries; under wing-coverts black.

Iris dark brown to crimson; bill bright yellow to orange with blackish nail; legs and feet bluish black. Hume believed that the iris changed to crimson during the breeding season.

Length $315 \mathrm{~mm}$; ; wing 158; tarsus 25; culmen 25.

Adult Female: Duller, more pale in color; no pale-green patch nor dark band on sides of neck, face being spotted and mottled with brown.

Iris dark brown; bill darker than in male, being dusky yellow, almost black at the tip; legs bluish black shading to yellowish gray on outer side. Size same as in male. 







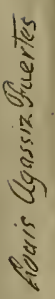

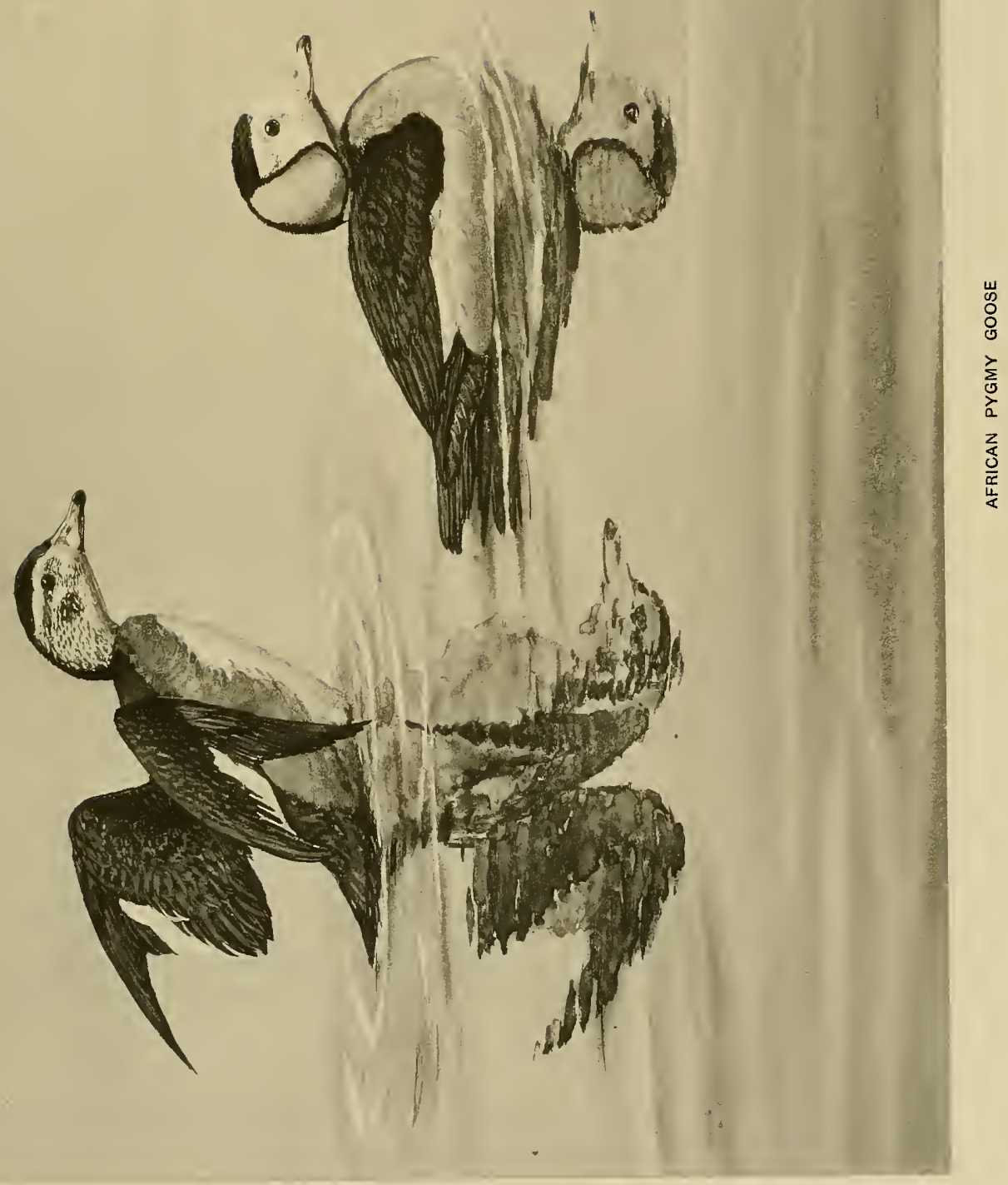



Young: Nearly the same as female; forehead more or less brown according to age, the black band on neck obscure or wholly lacking. Bill yellow; back side of tarsus and outer edge of toes yellow.

Young IN Down: Not described.

\section{DISTRIBUTION}

The Pygmy Goose is found in Africa south of the Sahara, and in Madagascar. On the west coast it has been found as far north as Senegambia (Rendall, 1892) and Casamance (Verreaux, 1851). Rochebrune (1883-85) also says it is common in the Senegambian region and it is re- Seneported in large flocks on the Soma Swamp in Gambia (British Museum specimen). gambia There are, however, few records of its occurrence from the coast of Portuguese Guinea to the Gold Coast. Presumably it inhabits these regions. In the British Museum there is a single specimen from Gunnal, Portuguese Guinea. From the Gold Coast it has been reported as occurring at Cape Coast (Fraser, fide Reichenow, 1900) and at Volta (Ussher, 1874). Hartert (1886) found it Gold Coast common at Porto Novo, Dahomey, and at Lagos, Nigeria, where it was also found Nigeria by Ussher (1874). In northwestern Nigeria it is quite common near Kaura, and near Zaria (Hartert, 1886, 1915) and on the Niger north even to Niamé (Hartert, 1915). The species is not yet known from eastern Nigeria or the northern Camerun, but it has been taken in central Camerun, 150 miles from the coast (Reichenow, 1911), and is common in the French Congo, Camerun in Gabun (Verreaux, 1851), Kamma (Cassin, 1859) and at Fernand Vaz (Bouvier, Gabun 1875). What its status in the interior may be I am unable to say, but it probably occurs sporadically throughout the Congo Basin, although Chapin tells me he did not find it. Congo There is a male specimen from the Belgian Congo (Lake Chiwakawaka) in the British Basin Museum taken by O. E. Wynne in 1912. It appears to be rare in Angola, whence it has been recorded for Cuce, Humbe, and Huilla (Barboza de Bocage, 1877-81; British Museum specimen, G. Blaine, 1920) but has never been seen in German Southwest Africa.

In Cape Colony it occurs only casually on the coasts and larger rivers (Stark and Sclater, 1906), the westernmost record being Mossel Bay (South African Museum). H. A. Bryden considered it "unknown" in Cape Colony in 1893. At Port Elizabeth it is rare (Brown, fide Stark and Cape Sclater, 1906) as presumably in other recorded localities, namely, Grahamstown (Lay- Colony ard, 1875-84), Alexandria and King William's Town (Trevelyan, fide Stark and Sclater, 1906), and the Umtumvumu River, Pondoland (Horsbrugh, 1912). I have not succeeded in discovering any records for the Orange River Colony, but in Natal it seems to be a fairly common bird (Gurney, 1859; Marshall, 1900; etc.) and has been reported from near Howick, Maritzburg and Durban Natal (Woodward, 1899), and from Zululand (Gordge, British Museum). In the Transvaal Transvaal again, as in so many inland districts, it is very rare, having, so far as known, been taken only near Potchefstroom (T. Ayres, 1886). In northeastern Bechuanaland, however, it is common in the lake region, on Lake Ngami (Andersson, 1872), at Nocana (Fleck, 1894), and on the Botletli River (Bryden, 1893). Neither is it a rare bird in South Rhodesia, where it was found at Sibanini in east Matabeleland (Hellmayr, Journ. f. Ornith., vol. 50, p. 237, 1902), and in Mashonaland (G. A. K. Marshall, 1900).

Rhodesia

The only record I find for southern Mozambique is that for Inhambane, where the species is not uncommon (Sclater, Ibis, ser.7, vol. 5, p. 114, 1899). It must be a fairly common species all along the coast. Kirk (1864) found it on the Zambesi, and it was found on the upper course of this river by both Holub (Holub and von Pelzeln, 1882), and Bradshaw (fide Stark and Sclater, 1906). Neave (1910) states that it is common in northern Rhodesia as well as in the Katanga region, southeast Congo. Capello and Ivens (1886) have recorded it from Luapala and the Nyassa country. It has been met with at Kotakota, Nyassaland (Shelley, 1898), and at Kachinda and Namaramba (Shelley, 1896). 
The species appears to be common in Tanganyika Province (German East Airica), having been found in the extreme southeast part on Mburu Lake (Grote, 1912) and farther north on the coast, in East Africa the Usuramo district (Reichenow, 1893). F. G. Jackson (1899) met with it on Lake Jipi, and Schillings (1905) on Lake Ndjiri. In the west-central part it was found to be not uncommon in Ugalla, Wualaba, on Itambe Lake and at Luwule (Böhm, 1882, 1885). It seems to be particularly abundant on Lake Victoria Nyanza, where Horsbrugh (1912) says it is to be found in flocks of thirty or forty. Van Someren (1916) also speaks of flocks on the lake, and on the west shore in Buddu, on Buvuma Island and at Kibango, essentially the same region in which Johnston (1902) found it abundant. Neumann (1898) states that it is equally common on the north coast, and the Ssesse Islands in May, and Hartert (1900) has recorded it from Ripon Falls in this region. I think very likely it occurs throughout Uganda and the Bahr-el-Ghazal region, for in this latter locality it was found not rare near Meshra-el-Rek, latitude $8^{\circ}$ north (A. L. Butler, 1905), the northernmost record for eastern Africa. Von Heuglin (1869) thought he saw it on the Ghazal. As far as I know it does not occur in eastern British East Africa, excepting on the coast, where it extends north to Kipini and Witu (G. A. Fischer, 1885) and Lamu (Shelley, 1881).

Madagascar The species is a fairly common one in Madagascar, inhabiting chiefly the ponds near the coast. It has been recorded from the most various localities by Pollen and Dam (1868), Roch and Newton (1863), Hartlaub (1877), Milne-Edwards and Grandidier (1876-81), Sibree (1892), etc., etc., and, as in Airica, is a resident bird.

\section{GENERAL HABITS}

THIs species does not seem so abundant as its congener the Cotton Teal (Nettapus coromandelianus) of India, for few observers speak of its occurrence in large flocks. The birds are usually found on lakes and streams as well as on lagoons, but rarely on large open sheets of water. They are also seen at the mouths of the larger rivers, and frequent both deep and shallow waters. Their disposition seems to depend on the locality, and where not persecuted they are apparently very tame, though on the whole they seem to be wilder than the Indian species. When flushed they are said to fly along waterways and never to fly across country (Kirk, 1864).

The Pygmy Geese spend the day until late evening on the water, seeking the land to rest, though they sometimes perch on trees in the heat of the day (Hartlaub, 1882). Roch and Newton (1863) also observed them perch on a tree in Madagascar. I do not know how much of their time these birds really spend on the trees. The absence of information on this point is very much in contrast to the evidence in the case of the Cotton Teal, which, according to Hume and Marshall (1879), spends almost the whole of its time perching, when not in the water.

Flight, Gait, Diving. The Pygmy Goose flies fast and low, but two observers in Madagascar (Pollen, 1863; Hartlaub, 1877) have spoken of the flight as clumsy, and not so rapid as that of other fowl. This last is certainly an exceptional observation, and not in harmony with what has been noted of the Indian species. In swimming the bird is said to sit rather low in the water (Roch and Newton, 1863), and all observers have noted its agility in diving. According to Kirk (1864) it often re- 


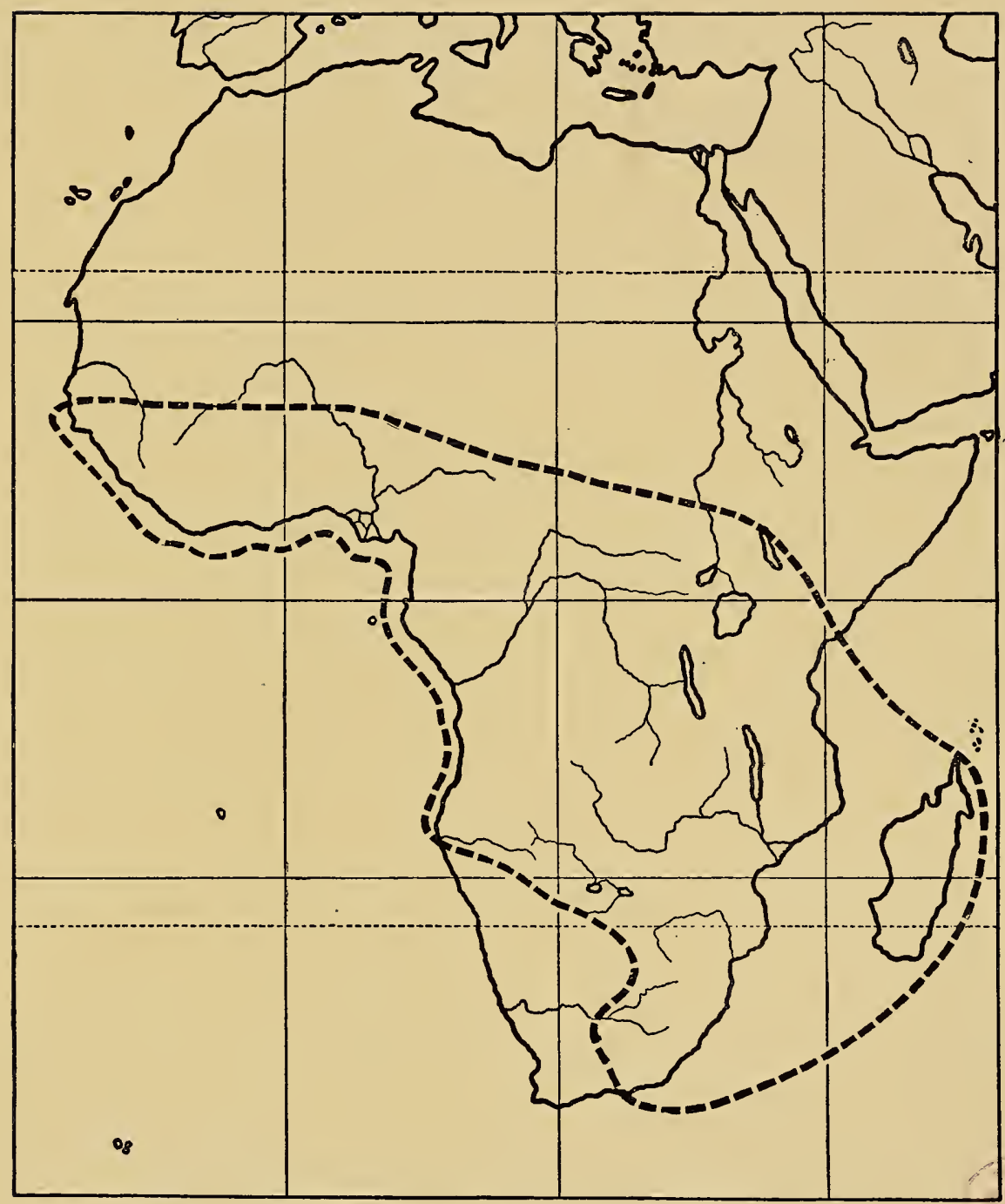

MaP 8. Distribution of African Pygmy Goose (Nettapus auritus) 

mains under water a long time, while Horsbrugh (1912) speaks of its behavior in the water as being very much like that of a Pochard.

Size of Flocks. These little ducks are usually seen in small companies, varying from five or six to ten or twelve. As far as I know there are only two records of their occurrence in large flocks. Hartert (1886) records thirty together in Nigeria, and Horsbrugh (1912) saw flocks of thirty or forty on Victoria Nyanza. I have been unable to find any information as to their association with other species.

VoIce. The note, according to Böhm (1885), is a clear, fine, chirping or twittering noise. In the Indian species the voice in the male has been described as a singular drumming quacking comparable to the words fix bayonets (Hume and Marshall, 1879).

Foop. Diet is probably taken chiefly from the bottom, and according to Hartlaub (1882) consists of little insects, fishes, crustaceans, mollusks, and water-plants, while Grandidier (Milne-Edwards and Grandidier, 1876-81) found them living on "little animals," young leaves, and seeds of aquatic plants.

Courtship and Nesting. There are no observations on the breeding habits of the African Pygmy Goose, but it probably nests in trees and lays a large clutch. The eggs have been described as "elliptical in shape, smooth, fairly glossy and creamcolored, measuring $43.2 \mathrm{~mm}$. by $31 \mathrm{~mm}$." (E. W. Oates, 1902).

Status. Nothing of a definite nature known.

Food Value. Two observers, Andersson (1872) and Horsbrugh (1912), have spoken of the Pygmy Goose as "pretty good" and "very good" eating.

Behavior in Captivity. This species is not known to have ever reached Europe or America alive, or to have been successfully kept in confinement even in Africa or Madagascar. No doubt it is difficult to handle on ornamental waters. 


\title{
GREEN PYGMY GOOSE
}

NETTAPUS PULCHELLUS (GoULD)

(Plate 10)

\section{SYNONYMY}

Nettapus pulchellus Gould, Proc. Zool. Soc. London, 1841, p. 89.

Nettopus pulchellus Sclater, Proc. Zool. Soc. London, 1880, p. 505.

\author{
Vernacular Names \\ English: \\ German:
Green or Australian Pygmy Goose
Green or Australian Goose Teal
Little Goose \\ Australische $Z$ wergente \\ Aborigines of Australia: \\ Loon-byte
}

\section{DESCRIPTION}

Adult Male (type specimen, ó, 5972, Acad. Nat. Sci. Phila.): An oval white patch $3 \mathrm{~cm}$. long, below, under, and behind eye; above, the head is brown, transversely barred with green on occiput; chin brown; the neck all around dark glossy green with bluish reflections. Back, scapulars and wingcoverts same color; a conspicuous white speculum on secondaries. Lower neck, upper breast, and sides white, with crescentic brown bands, giving a very conspicuous appearance. Lower parts white. Tail black, under tail-coverts black. In another specimen, possibly more mature, there is more white on sides of head, and the chin is white.

Bill: nail of upper, and whole lower mandible, flesh color; base of lower, and the rest of upper mandible black. Iris brown; tarsi and feet black.

Total length 375 mm.; wing, 168; tail 70; tarsus 26 (Mathew, 1914-15).

Adult Female: Similar in plumage to male, but having crown of the head uniform dark brown, and the entire sides of head and throat white, finely freckled with black (North, 1913). Size as in male.

Immature MaLe: The anterior parts of the cheeks and the throat tinged with blackish, while the posterior part of the cheeks and the ear-coverts are covered by a very conspicuous white patch (Salvadori, 1895).

Young IN Down (specimen Tring Museum): Easily distinguished from the young of the true surface-feeding and diving ducks by the presence of a broad white band across the hind-neck back of the occipital head patch, as in the Tree Ducks. There is a white, supraorbital streak and a dark transocular streak which merges behind with the occipital black patch. The rest of the upper side is dark gray to black getting darker on the back and rump. There are white patches on the wing-rudiments but none on the scapular and rump areas. The downy tail is very long, coarsely feathered and peculiar in texture. The lower surface is white.

Plumages: Meyer and Wiglesworth (1898) remark that there is no valid distinction between the male and female when the former is in winter or immature dress. 


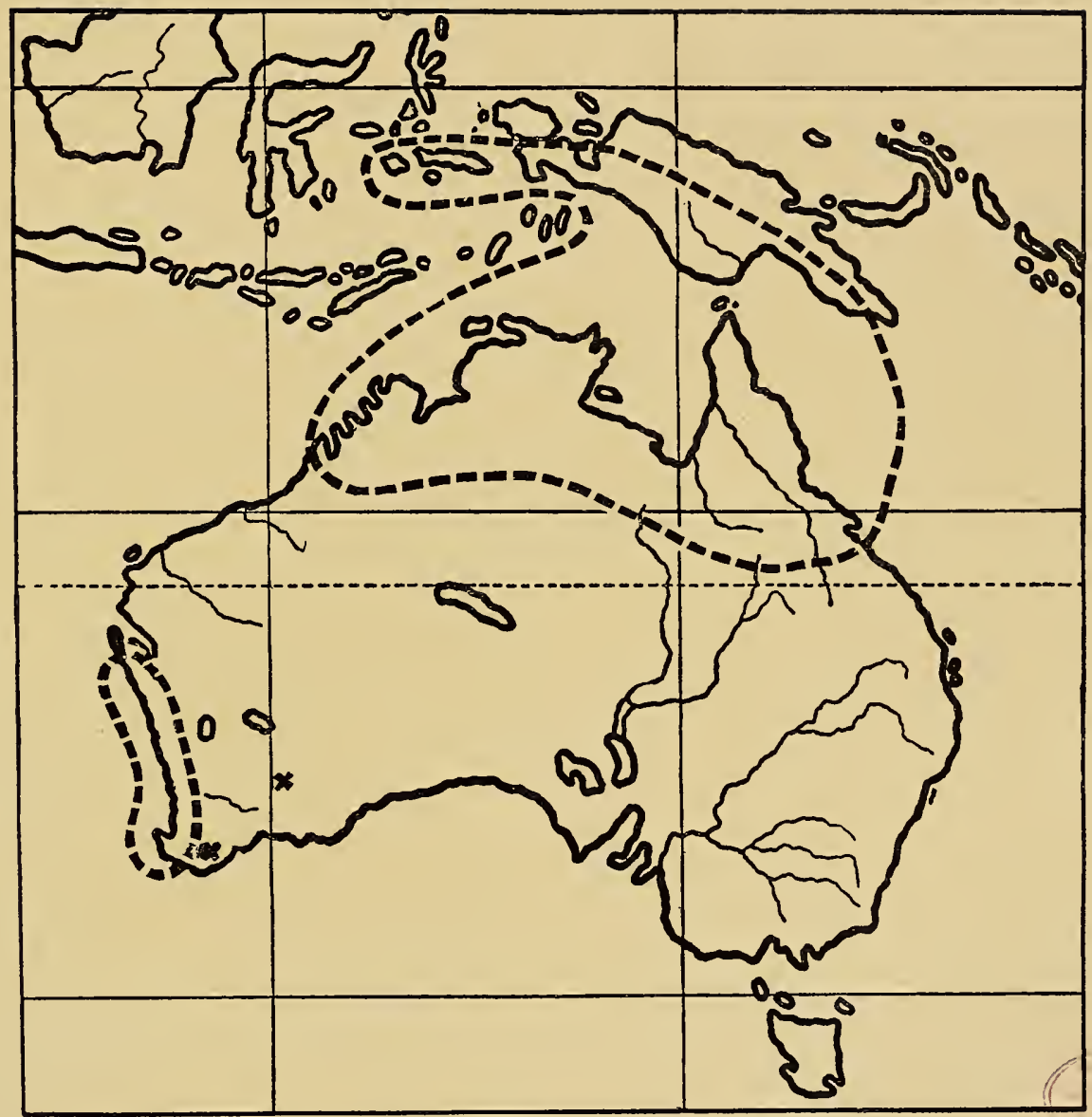

MAP 9. Distribution of Green Pygmy Goose (Nettapus pulchellus) Unusual localities are shown by crosses $(X)$ 



\section{DISTRIBUTION}

Trus Australian species has a limited range, being confined to northern Australia and neighboring islands. Its westernmost occurrence was in the Gorontalo region of Celebes, where Riedel took a single specimen, now in the Petrograd Museum (Blasius, 1886). It furthermore in- Celebes habits the southern Moluccas where a few were taken on Buru, near Wakolo Lake, and Buru small numbers were seen in July at Pasahari and Lake Tapala, Ceram (Stresemann, Ceram 1914). Both Hoedt (Leyden Museum) and Riedel (Dresden Museum) had previously found it on Amboina. According to Forbes it also inhabits the Tenimber Group, though appar- Tenimber ently it has never been taken on the Kei or Aru Islands (Salvadori, 1891). Group

In New Guinea it seems to occur only in the south, though the Dresden Museum has a specimen said to have been taken in the northwestern part. In the extreme west the species, which rarely occurs in great numbers anywhere, was found to be abundant on Lake Jamur in August New (de Beaufort, 1909), and on the south coast it was taken at Merauke (van Oort, 1909). Guinea There are, I believe, no records for German New Guinea, but it has several times been found in the British colony, on the Katau and Fly Rivers (d'Albertis and Salvadori, 1879), at Port Moresby (Tristram, 1889) and in "the south" (Finsch, 1884; Salvadori, 1895, British Museum specimen).

The present species rarely occurs far in the interior of Australia, and seems to be most plentiful on the northwest coast. It is fairly numerous on the west coast as far south as the Fitzroy River (North, 1898), but Ward and Fontain (1907) speak of it as rare along the coast from Sharks Bay, south to the Swan River. It has been recorded indirectly even from the Australia extreme southwestern part of Australia, from Lake Ewlymartiys and Lake Muir (Mathews, 1914-15). In northwest Australia Ramsay (1888) gives Derby as one of the fixed localities. Farther inland Kilgour (Emu, vol. 4, pp. 38, 42, 1904) noted it as common on the Ord River.

For the northwestern section of North Territory there are numerous records. Hartert (1905) has recorded it from the Mary, Margaret, and Alligator Rivers, and states that the species, while not very common, is found all through that region. Ramsay (1888) gives Port Darwin and Port Essington as specific localities, while North (1913) states that the birds breed on the Daly River. On Melville Island the species seems to be common from December to March, and probably breeds (Mathews, 1914-15). According to Eylmann (1911) the species is almost unknown in the interior of North Territory.

The Pygmy Goose is much rarer in northeastern Australia. Ramsay (1888) gives the Gulf of Carpentaria as its habitat, but states that it is very rare in eastern Queensland, though occurring on Cape York and even at Rockingham Bay. It breeds at Normanton, southeastern part of the Gulf of Carpentaria (Mathews, 1914-15), and at Byromine, Cape York (Macgillivray, 1914). On the east side of the York Peninsula, it is said to be common on the Kennedy and Hann Rivers (Robinson and Laverock, 1900) though only sporadic at Cooktown (ibid.). On the other hand Broadbent (1910) speaks of it as common in September on the Bellenden Plains and Herbert River. Its southernmost occurrence seems to be the Richmond district, Queensland, where, according to Berney (1907) it is very rare.

\section{GENERAL HABITS}

THere is a dearth of literature describing the haunts and habits of this species. In general it is found on swamps or lagoons where the rushes offer cover, and more rarely on rivers. It would appear to be an inhabitant of the coastal regions, retiring somewhat inland to breed in the wet season. With one exception observers are agreed that the Pygmy Goose is extremely shy. Gregory (Gould, 1865) during an early expedition to the Sherlock River is the only one who found it "remarkable for its tameness." 
Concerning the daily movements of this species there is no information recorded. As to its flight I can only quote Keartland (North, 1898) who says, "When disturbed they rose quickly and flew near the surface of the water, making a peculiar whistling noise all the time they were on the wing." Several ornithologists have noted its agility in diving. Gilbert (Gould, 1865) says that "at the slightest movement of anything near it, it dives and remains under water a long time"; while Eylmann (1911) noted that it attempted to escape by diving rather than by flight. Curiously enough there seems to be only one mention of this little goose perching in trees. Rogers (Mathews, 1914-15) saw several pairs perched on trees thirty yards from the water, and he states that they perch freely. As they appear ordinarily on the ground, and not so commonly in trees, as do their relatives in India, it is probable that they do not perch as freely as the Indian species.

Even the earlier travelers did not find this species plentiful, excepting possibly in northwestern Australia; it seems never to occur in large flocks, but in pairs or in small companies of from eight to ten or a dozen (Gregory in Gould, 1865; Keartland in North, 1913). Stresemann (1914), writing of Buru Island, says individuals were observed among large flocks of other ducks (probably Tree Ducks). According to Eylmann (1911), however, it keeps apart from all other water-fowl in the interior of South Australia.

The voice, says Rogers (Mathews, 1914-15), is a "fairly loud whistle," while Keartland (North, 1913) speaks of it as a "peculiar cry" uttered when disturbed. From this meager and insufficient information it is very difficult to form a satisfactory idea of the note.

Food. Data as to the food of the Pygmy Goose are just as deficient as the observations on other phases of its life-history. Keartland (North, 1913) states that it feeds "on grass, like the ordinary domestic goose," a very remarkable note, especially since Pygmy Geese are usually regarded as being not active on land. Mathews (1910) records that the stomachs of three specimens taken in northeast Australia contained seeds and grit.

Courtship and Nesting. Nothing has been written about the courtship of this species. As to the nesting, there is an interesting note by Gulliver (Mathews, 191415), who, after long observation, felt convinced that in the Gulf of Carpentaria region the birds breed inland on the fresh-water lakes, returning to the coast as soon as the young are on the wing. They nest during the wet season, from about the middle of January to the middle of March. Rogers (Mathews, 1914-15), on Melville Island, on January 10, took specimens with well-developed eggs, while Gulliver (Mathews, 1914-15) says they disappear from the coast about the middle of February. Fresh eggs were taken near the Daly River (North Territory) on the 7th and 10th of Feb- 





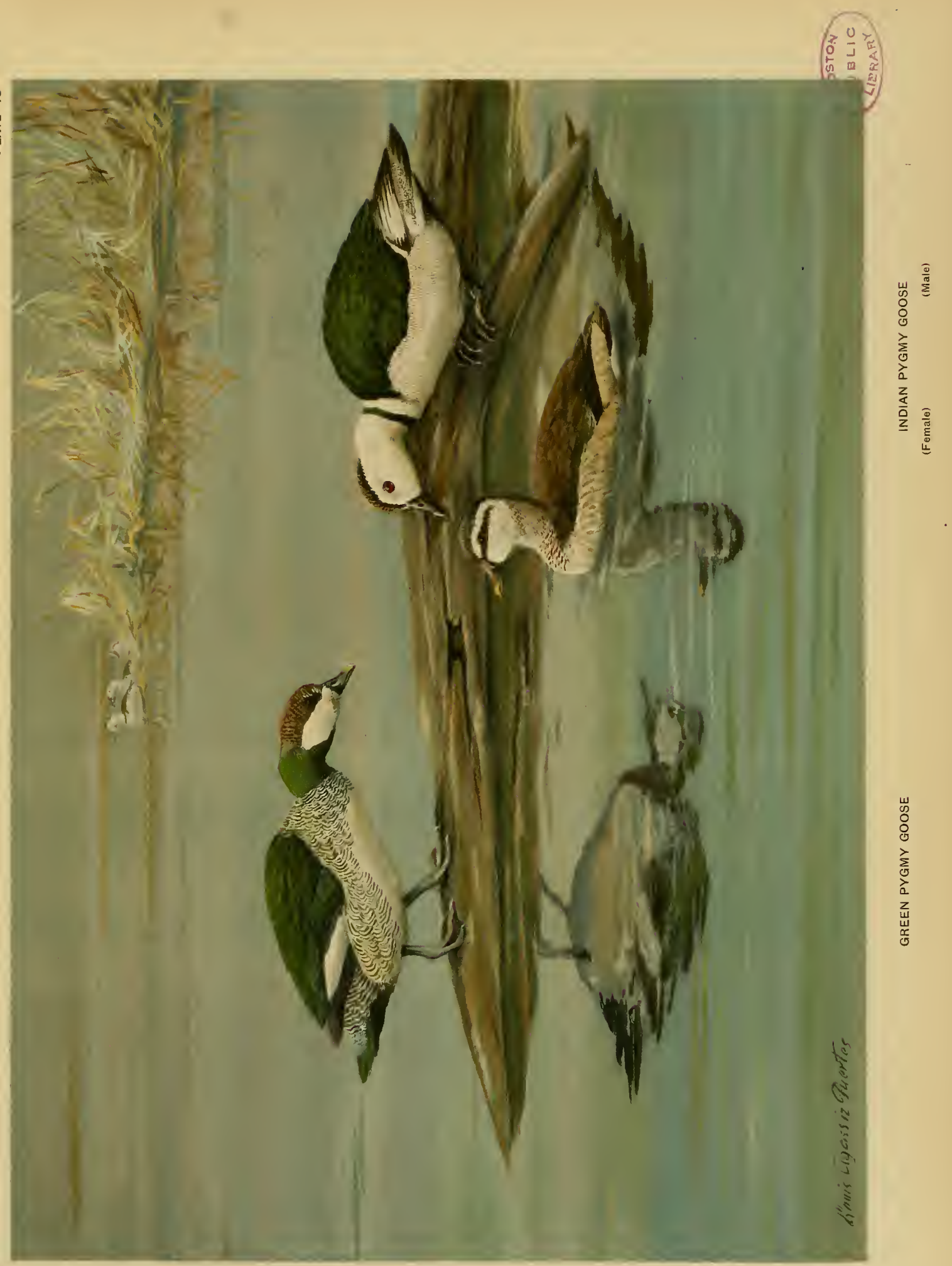



ruary (North, 1913). Gilbert (Gould, 1865), found a nest, January 16, at Port Essington. G. F. Hill (1913) had eggs brought to him on March 3 by a native and there are downy young from the East Alligator River (North Territory) taken April 24, 1913.

The Green Pygmy Goose has been found nesting both on the ground and in the trees, depending probably on the availability of suitable forest areas. Campbell (1901) describes the nest as "constructed of long dry grasses, the slight cavity for the eggs being sometimes lined with feathers and down; usually resting upon the surface of the water among the herbage of a swamp or lagoon. Possibly the eggs are occasionally deposited in hollow trees." An earlier observer, Gilbert (Gould, 1865), at Port Essington found a nest "built up in the long grass about a foot above the water, the bottom of the nest resting on its surface"; the nest was composed of dry grasses, and did not contain lining of any kind, but one obtained later was lined with feathers. Campbell's observations were apparently taken directly from Gilbert and therefore do not add much of value. In western Queensland on the Gulf of Carpentaria, G. F. Hill (1913) found it common in pairs during February in the submerged open-forest country, and a native who brought him some of the eggs said the nest was built in the grass near a swamp. Keartland (North, 1913), however, affirms that they usually lay their eggs in a "hollow branch" sometimes far from water, and Rogers (Mathews, 1914-15) also thinks they occasionally nest in trees. Macgillivray (1914) found the Green Pygmy Goose nesting at Byromine, North Queensland, "one nesting hollow [presumably a tree is meant] containing as many as eleven eggs." Keartland says he knows of as many as thirteen eggs being found. The normal clutch is probably nearer nine or ten. In color the eggs are creamy white, the shell smooth and lustrous, measuring 43 to $45 \mathrm{~mm}$. by. 33.8 to $36 \mathrm{~mm}$. (North, 1913).

Status of Species. No information is available besides what has been included under Distribution and General Habits.

Food Value. Robinson and Laverock (1900) considered these birds " a welcome addition" to their larder while traveling in North Queensland, and Rogers (Mathews, 1914-15) says he shot many for food on Melville Island. Beyond this nothing has been recorded.

Behavior in Captivity. Like the African Pygmy Goose this species has apparently never reached Europe or America alive. North (1913) mentions a gentleman who kept some in confinement in Sydney "several of which died." Like the other Pygmy Geese, the species is evidently ill-adapted to aviary life. 


\section{INDIAN PYGMY GOOSE or COTTON TEAL NETTAPUS COROMANDELIANUS (GMELIN)}

(Plate 10)

\section{SYNONYMY}

Anas coromandeliana Gmelin, Linné's Systema Naturae, ed. 13, vol. 1, pt. 2, p. 522, 1788.

Nettapus coromandelianus G. R. Gray, List Birds British Mus., vol. 3, p. 129, 1844.

Nettopus coromandelianus Blyth, Birds of Burma, p. 165, 1875.

Nettapus coromandeticus Gould, Proc. Zool. Soc. London, 1859, p. 150.

Nettapus albipennis Gould, Birds of Australia, pt. 6, pl. [17] and text, 1842.

Cheniscus coromandelianus albipennis Mathews, Birds of Australia, vol. 4, pt. 1, p. 35, pl. 202, 1914.

\section{Vernacular Names}

English:

Cotton Teal

Indian Pygmy Goose

Goose Teal

Green-backed Goose Teal

White-bodied Goose Teal

Quacky Duck

Rice Teal

French:

Sarcelle de Coromandel

German:

Indische Zwergente

India:

Girri, Girria, Girja or Gur-gurra - (Hindustani)

Ghangariel, Ghangani-(Bengali)
Bullia-hans - (Dacca Faridpur, Sylhet)

Lerreget-perriget or Merom-derebet - (Kole)

Ade or Adla - (Ratnagiri)

Karagat - (Burmese)

Malay:

Itik-laut

Manila:

Pa-ti-ki

Ceylon:

Rajah-tara

Singhalese:

Mal-saaru

Javanese:

Meliwies-batoe

\section{DESCRIPTION}

Adult MaLe: Forehead and crown brown, glossy green feathers along the lateral edges; a complete broad but irregular collar of black mixed with green feathers above, encircles the base of the neck; head, neck, under parts and a collar behind the black neck-band, white; flanks and sides of breast very finely freckled with black; under tail-coverts tipped with brownish black; back, scapulars and wingcoverts dark brown with green and purple iridescence; upper tail-coverts white thickly freckled with brown; tail dark brown with greenish gloss; primaries brown carrying a conspicuous white speculum 
about two inches long; white bar also formed by tips of secondaries; under wing-coverts blackish.

Bill black, but in summer time only, according to E. W. Oates (1883); in winter, brown above and yellowish beneath. Iris bright red; legs and feet black, tinged with yellow.

Length 318 to $343 \mathrm{~mm}$; wing 152 to 178 , rarely over 167 or under 160 ; culmen 23 to 24 ; tarsus 25.

Weight between 9 and 12 ounces (1.2 to 1.6 kilograms) (Baker, 1908).

Adult Female: Cap like that of male, but uniform brown; a well-marked line of brown running through the eye; rest of head and lower parts white, and on the lower neck an area spotted with brown in place of the collar of the male; face and neck more mixed with fine brownish vermiculations; in old specimens the under parts become pure white as in the male; in young birds they are more or less barred and streaked with light brown; upper parts very similar to those of male, but wing speculum much shorter.

Iris brown; bill brown above, yellowish beneath.

Length $305 \mathrm{~mm}$.; wing 152 or a trifle over; culmen 22.8; tarsus nearly 25 (Baker, 1908).

Female in Finst Plumage: Like the adult female, but lower side more or less streaked with gray and not so pure white. Tail feathers show bluntness characteristic of first plumage. The upper surface is nearly as in adult but the outer wing-coverts have little or no iridescence.

Male in First Plumage: Like the female, but the white patch on the primaries is always present, although not so large nor so well marked as in the adult male. Remainder of plumage almost exactly like the young female's except that the outer wing-coverts and speculum have more metallic-green color showing.

MaLe IN EcLipse: Ten or fifteen skins in the British Museum show adult males in a plumage which may be termed eclipse. There is no trace of the black breast band, and the coloring of head, neck, and breast is exactly like that of the female. The wings, however, remain as in full-plumaged males, retaining the white primary patch.

Young IN Down: General appearance very peculiar and different from other Anatida. Occiput black; a very broad whitish superciliary stripe runs back to the occiput, where it meets its fellow of the opposite side and forms a white band across the back of the head. There is a narrow but well-defined black streak from the culmen through and back of the eye. Remainder of face and neck whitish, except the upper side of the neck which is gray. The mantle is gray-brown and the back, rump, and tail nearly black. The most prominent features are very large white patches on the scapulars, wings, flanks, and sides of rump. The tail plumes are very long, coarse and stiff as in other members of this genus. The under surface is light buff except the flanks which are blackish.

Remarks: Two specimens in the British Museum show primaries with white patches lacking, as in the female, but with the black collar and the white face and neck of the adult male. These appear to be old females acquiring male plumage.

Note on Nettapus coromandelianus albipennis, the so-CALled White-quilled Pygmy Goose of Australia: This form was separated by Gould (Birds of Austr., part 6, plate 17 and text, 1842) from the Cotton Teal of India on account of its supposedly larger size. Hartert (Kat. Vogelsamml., p. 228, 1891) regarded it as only subspecifically distinct and Mathews (1914-15) considers the size character as unstable and so far as can be deduced from his plumage description, adds no other differentiating characters. Parrot (1910) does not think there is any real distinction between Nettapus 
coromandelianus of India and the Australian subspecies. The true Cotton Teal of India (Nettapus coromandelianus) is found as far east as northern Celebes and Java, and very likely on some of the intervening islands. The male of $N$. c. albipennis was said by Gould to be much larger than the female, but the sexes of the Indian species differ similarly in size. Gould's type specimen ( $\delta$ no. 5969) now in the Philadelphia Academy of Natural Sciences, has a wing of $19 \mathrm{~cm}$. which is at least $2.5 \mathrm{~cm}$. larger than the average of the Indian Pygmy Goose. The bill and tarsus are also slightly larger. I examined, however, a series of Australian examples in the Tring Museum (Mathews Collection) and could find no constant differences between these and specimens from India and the Malayan region.

\section{DISTRIBUTION}

ExcEPTING in the northwest the species is fairly common throughout India, becoming abundant in the northeastern parts. In Hume's day it was not known to occur in Sind, Cutch, Kashmir, RajpuIndia tana, except the east, or the Punjab. But since that time it has been found in Sind (Bacon, Journ. Bombay Nat. Hist. Soc., vol. 19, p. 264, 1909; Parrington, ibid., vol. 15, p. 143, 1903) and is known also from the Punjab, though it is very rare there (Baker, 1908). It is of unusual occurrence also in Kathiawar and Guzerat as well as along the northern part of the west coast, in the Deccan and in South Konkan, though common enough in Travancore (Hume and Marshall, 1879). In Ceylon it is of frequent occurrence and breeds in the northern and eastern sections while in the west and southwest it seems to appear only during the northeast monsoon (Legge, 1880; Wait, 1917). Throughout central and eastern India, north to the Himalayas it is fairly common everywhere in suitable localities, apparently migrating locally according to the weather conditions. Baker (1908) states that it is a fairly abundant bird in Madras but more abundant in Orissa. It is common and resident in Lucknow (Jesse, 1903), but probably does not occur north of Nepal Terai (Hodgson, 1844; Scully, 1881). All writers agree that its headquarters are lower and eastern Bengal, particularly the Deltaic districts where it literally swarms (Hume and Marshall, 1879; Baker, 1908; Finn, 1909; etc.). In this region it evidently goes north at least into the lower Himalayas, for the British Museum has a specimen from Bhutan. In Assam it is a well-known species (Baker, 1908).

The Goose Teal is probably found throughout the countries of Lower India and the Malay States. In British Burma it is everywhere common (Blyth, 1875; E. W. Oates, 1883) as also in Arakan (HopMalay wood, 1912). Rippon (1901) found it abundant in the Shan States, and Blanford (1898) and Burma says it is plentiful in Pegu. It has been taken also in French Tonkin at Yen-bai (Kuroda, 1917), Annam, March 1909, by Vassal (M.C.Z.) and small flocks were seen south of Bangkok, Siam, though it does not seem to occur very commonly in the interior of that State (Gyldenstolpe, 1913, Cochin 1916; Barton, 1914; Baker, Journ. Nat. Hist. Soc. Siam, 1920, p. 43). St. Pierre (British China Museum) took a specimen in Cochin China, and the Museum of Comparative Zoölogy has a specimen taken in Cochin China by Tirant, in October. It appears to be common in Tenasserim as far south as Tavoy (Hume and Marshall, 1879) and must occur throughout that region for it was found farther south in the Malay Peninsula. It is well known from the Andaman Islands (Kloss, Malay 1903) though apparently it has never been taken in the Nicobars. On the Peninsula Archipelago it was found at Patelung (Bonhote, 1901) and according to Kelham (1882) is not only abundant but breeds in the southern parts on the Perak River.

In the Sunda Group the Indian Pygmy Goose is found on Sumatra (Lichtenstein, 1854) and on Banka (Parrot, 1910). Vorderman (1883) and Koningsberger (1915) have recorded it from Java, and Sunda there is one from Batavia in March (Bryant, M.C.Z.). Grabowsky (1885) met with Group small flocks about Danan Bangkan, southeastern Borneo, while according to Moulton (1914) specimens have been taken near Kuching in the Sarawak region. It has twice been taken in Celebes, once at Minahassa and once at Manado (Meyer and Wiglesworth, 1898), both birds probably having been stragglers. In the Philippines it has been met with by several observers on 


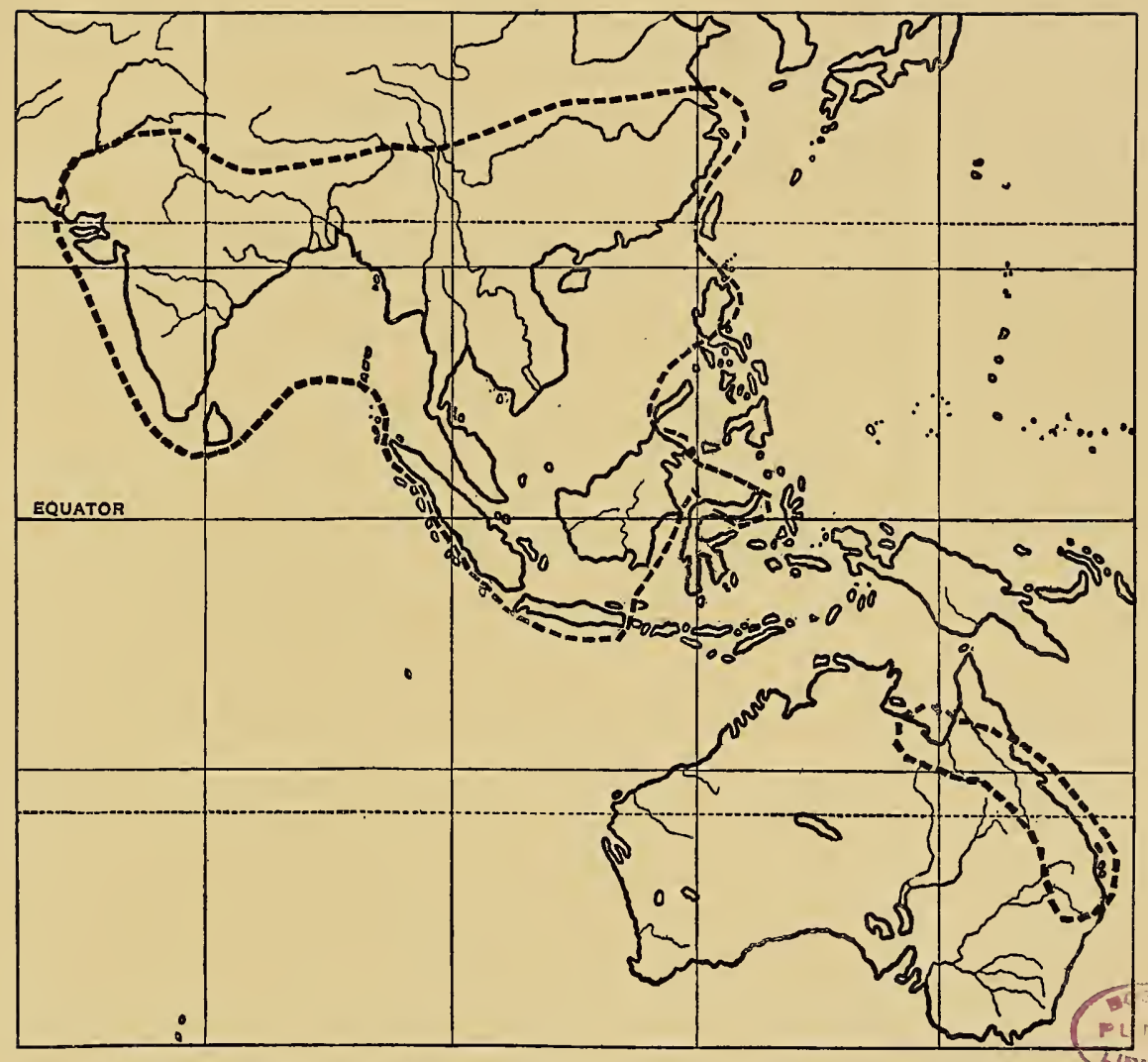

Map 10. Distribution of Indian Pygmy Goose (Nettapus coromandelianus) 

Luzon, namely, Manila, at Laguna de Bay, and in the Tarlac Province (Zeledor; Worcester and Bourns, 1898; McGregor, 1909; and others). Its occurrence on Sequijor is regarded by McGregor as very questionable, but there are three eggs from Sequijor in the British Museum (E. W. Oates, 1902).

Though it has never been taken on Formosa the present species is found commonly in summer in China north to the Yangtse. David and Oustalet (1877) state that small numbers breed throughout central China, but Styan (1889) and La Touche (1907) both found it abundant on the Lower Yangtse in early summer, and the former writer classes it as a common breeder there.

Seebohm (1884) also saw it at Kiukiang in June and July. On the other hand, La

China

Touche (1892) found it rare at Foochow and Swatow in October and November which seems to indicate that only a few remain in China during the cold season. It is somewhat irregular about Hong Kong, but seen at all times of the year (Vaughan and Jones, 1913). Styan (1893) and Hartert (1910) have both recorded it from Hainan, the latter as occurring in June! That there is no break in the range between Burma and China is indicated by the fact that the species has been taken in May near Mongtse, southern Yunnan (Ingram, 1912).

Almost nothing is known of the status of this species in Australia. According to Keartland (North, 1898) it occurs in the North Territory of South Australia, being commoner than N. pulchellus in the eastern parts. This is the only mention of its presence in North Territory that $I$ have been able to find. Its real home seems to be eastern Queensland and northeastern New Australia South Wales. Macgillivray took a specimen with a matured egg at South Grafton in October (North, 1913) and Ramsay (1888) gives Rockingham Bay as its northern limit. It breeds regularly near Charters Towers and Maryvale Station, North Kennedy (North, 1898), and has been taken at Port MacKay (Finsch, 1872a). According to Ramsay (1877) it is abundant about Rockhampton and Fitzroy Rivers and on Burnet's swamps, while he (Ramsay, 1888) has also recorded the species for Port Denison and Wide Bay. Gould (1865) records it at Moreton Bay. In New South Wales, it is found apparently only in the extreme northeastern parts, on the Richmond and Clarence Rivers (Ramsay, 1888).

\section{GENERAL HABITS}

Aıtноugh this bird is local in its habits over most of its range, it moves about in India according to the rains like most other water-fowl of those regions. In China, however, and perhaps in western India it becomes migratory in the true sense of the word.

The great centers of abundance are the delta regions of the Ganges and Brahmaputra in India, and also in Burma, and in these places it is very plentiful at all seasons. Whether the individuals that move up into the Yangtse Basin winter in Cochin China we do not know. In fact I have no information on the numbers of these birds in the latter country.

Distributed over an enormous area, and an extremely abundant species, the habits differ much in different places. Hume and Marshall (1879) said that in India it preferred moderate-sized pieces of water much overgrown with Singhara (Trapa bispinosa) and other water-plants, and more or less surrounded by trees. Village ponds also, where the Singhara is grown, are frequented as often as more secluded places.

E. W. Oates (1883) gives all swamps, marshes, and inundated paddy-fields, ponds 
and even road-ditches as frequented by these Goose Teal. Simson (1882) thought it occurred usually in deep water and Legge (1880) mentions this preference for deep water, especially for feeding purposes.

An exceptional note is that made by Schlegel (1866) that in Java it is commoner on the mountains than on the maritime swamps where it is quite rare, but he does not mention the season. In the Sunderbunds they are also found on the biggest and broadest stretches of water, where, however, they keep to weedy places with thick cover (Baker, 1908).

WARINess. Jerdon (1864) and Hume and Marshall (1879) and nearly all later writers concur in describing this little Goose Teal as exceptionally tame and likely to be found in intimate association with human beings. E. W. Oates (1883) found them exceedingly tame in Burma except when associating with other species. Legge (1880) speaks of their aversion to rising from the water, and says that when flushed they circle the tank a few times and then re-alight among the lotus. The birds when wounded allow themselves to sink in the water till only the head or even only the bill remains above the surface (Legge, 1880). This habit of sinking in the water instead of flying appears to be a common one. It is well described by Kelham (1882), who observed the birds near Perak, Malay Peninsula, as follows: One evening he "came upon a small pool completely excluded from the outer world by the most luxuriantly growing jungle. From the overhanging trees long slender creepers hung down in tangled masses to the surface of the water, which was almost covered with aquatic plants. To complete this beautiful piece of jungle scenery, in the center of the pool was a Goose Teal perfectly motionless; for, quietly as I had approached, it had heard me, and, thinking it was unobserved, did not rise, but, all the time intently watching my movements slowly and noiselessly sank under the water till nothing but its head remained above the surface."

Daily Movements. Commonly they feed during the daytime, roosting on the trees at night, though some observations are at variance with this general remark. Hume and Marshall (1879) say that occasionally on moonlight nights they have seen them on the water with other wild-fowl, and Tickell (ibid., 1879) asserts that they rest during the night "amid the tangle and coarse herbage matting over the center of the pool."

Flight, Swimming and Diving. The Cotton Teal rise rather awkwardly, fly low and very rapidly, only occasionally getting high in the air, and they dive skillfully. Their agility and dodging proclivities have often been attested. Hume and Marshall (1879) think that in this respect they are unequaled by any other Indian waterfowl, for they frequently saw Peregrines attempt to strike them down without ever 
succeeding, the little bird twisting out of the way "as easily as an unwearied hare from before a greyhound, and long before the Peregrine could recover itself was down on and under the water." Their activity on the wing is no doubt as remarkable as their ability to twist around tree stumps and other obstructions. Finn (1909) speaks of it as "the most active flyer of all our water-fowl." "They squat," says Baker (1908), "in the roadside ditches and tanks and, when finally leaving they scuttle away chattering and clucking for all they are worth, as if trying whether they could vociferate harder than fly, or vice versa, often only to return to some spot within fifty or sixty yards."

On the water this species has been noted as swimming "pretty rapidly though rather jerkily" (Hume and Marshall, 1879), and Finn (1909) describes it as a "very fast swimmer." Although in general a surface-feeder, "pecking about more like a coot or water-hen than a duck," they will on occasion dive, but not, so Finn says, readily or neatly like a duck; and when they tilt up their tails in ordinary duck fashion they do it quickly, not standing on their heads for several seconds at a time. Hume has likened their diving to that of a Dab-chick.

Though the older writers, notably Blyth (1867), thought that the Goose Teal was quite helpless on land, this is now known to have been an exaggeration. It is true that it is very seldom seen on dry land and it progresses on its legs slowly and clumsily, being apt to collapse when it tries to turn around or go quickly (Finn, 1915). Baker's captive birds "waddled about in complete comfort, though without any undue speed," but when they became excited or frightened, or hurried, they "at once flopped about in the most ludicrous fashion, tumbling over every little obstruction they met with, and appearing as if their hind quarters were going too fast for their heads and breasts to keep in front of."

Finn also noticed that they never stand on one leg like most ducks, although they perch readily and spend much time on trees. They are also reported as climbing up wire netting very easily. It is certainly curious that they exhibit so little aptitude in walking, considering the fact that they are such excellent perchers.

Stze of Flocks. In the breeding season they are found in pairs only, though numerous pairs may be seen occupying the same pond. Later on the families are seen together, and Hume and Marshall (1879) think the families do not coalesce until the middle of November. They are seldom met with in large flocks even in the winter, and Baker (1908) declares that flocks are composed usually of less than a dozen individuals. In one exceptional instance, however, he saw a flock of one hundred of these birds. In India, the Malayan countries, and apparently also in Borneo they are said to associate very commonly with the Whistling Teal (Dendrocygna javanica or D. arcuata) and Kelham (1882) mentions that on several occasions he got specimens of both species at one shot. 
Vorce. One of the characteristics of the Goose Teal is its very unusual voice, which is heard commonly, especially when on the wing. In fact, according to E. W. Oates (1883), the note is uttered only during flight. The birds are especially noisy during the breeding season and toward evening, when active on the wing. Observers are so hopelessly at variance in their description of the note that it is practically impossible to convey an adequate idea of it. There can be no doubt that a number of the native names are onomatopoetic, imitations of the bird's note. The call is described by Hume and Marshall (1879) as a peculiar sort of "sharp, short, chuckling cackle, which they sometimes utter very frequently, at others very seldom," without there being any apparent reason for this. In general, however, they appear to be quite silent when undisturbed. Tickell, quoted by these authors, remarks that in the Koli name of the bird (Merom-derebet) the "Merom" signifies goat, and that the bleat of that animal is not unlike the voice of the Goose Teal. The soldiers of India have long called the bird "Fixed Bayonets" because its note ludicrously resembles those words. A very recent writer (Wait, 1917) likens the call to the words quacky duck, quacky duck. The tracheal bulb is absent in the male and unlike many other ducks the male has a loud note, while the female does not seem capable of uttering anything beyond a squeaking note.

Foon. The food of this species is various, consisting chiefly of rice grains, especially the seed of the wild rice, as well as of shoots of various aquatic plants, in addition to worms, water insects and their larvæ. Occasionally they may eat small fish or fresh-water crustaceans (Hume and Marshall, 1879).

Courtship and Nesting. Throughout the greater part of India the breeding season coincides with the summer rains, that is, it falls chiefly in July and August, of necessity varying greatly in different places on account of the wide differences in the onset of the rains. In the north part of the Malay Peninsula, Kelham (1882) found it breeding in June. In Ceylon the breeding season is quite distinct, coming in the early months of the year (January to March), and Wait (1917) even speaks of a second nesting period in August! In the Lower Yangtse valley again, Styan (1891) found young, so he says, flying about in early June, thus suggesting a very early breeding season for these migratory individuals. He also took young in down early in August which he considers as belonging to a second brood. It is remarkable that they appear there in considerable numbers as late as early May and that young on the wing were noted only a month later.

In the Calcutta Zoological Gardens the courtship was carried on with the drake bending down his bill so as to arch his neck and show off its snowy whiteness, at the same time jerking open his quills to display the otherwise concealed white patch. The males were gentle and did not annoy the females even when closely confined 
(Finn, 1901). A. Anderson (1874) watched a pair in the act of selecting a nesting site. They both flew to the tree together but only the female entered the hole, while the male sat on a bough watching for her exit. When she reappeared they both flew away together, uttering their peculiar cackling sound. The visits were repeated every fifteen or twenty minutes, but the drake never entered the nest hole. The nest is usually, if not always, placed in hollows, ordinarily in trees not more than a few feet above the level of the ground or water, and very seldom over fifteen or sixteen feet high. There is one record of thirty feet in a mango tree (E. W. Oates, 1883), and another of forty feet in a niche of a factory chimney (Cripps, quoted by Hume and Marshall, 1879). Trees selected are frequently at a considerable distance from the water. At times they nest in more unusual sites, for Styan (1891) says that in the Yangtse Basin they frequent roofs of houses, and especially chimneys where they are said to breed. Jerdon (1864) also mentions their nesting in old ruined houses, temples and old chimneys, while other situations that have been noted are niches in brickwork (Simson, 1882), and old buildings (Legge, 1880). Two observers, Blewitt (quoted by Hume and Marshall, 1879) and Legge (1880), maintain that they at least occasionally nest on the ground or on the water!

The hollow itself is generally of considerable depth and such as have small entrances seem to be preferred by these birds. According to Hume and Marshall (1879) there is little lining to the nest beyond crumbling fragments of decayed wood, but Legge (1880) declares that at times the nest is lined with feathers, and Cripps (in Hume and Marshall, 1879) states that it is a "rough pad nest of fine grasses and twigs with feathers for a lining." A clutch numbers ordinarily from eight to fourteen eggs, ten being probably the average, and unusually large clutches have numbered sixteen, eighteen, and twenty-two eggs, these last quite certainly to be ascribed to two females. According to E. W. Oates (1902) the eggs are "generally truly elliptical in form, occasionally compressed at the smaller end, very smooth and glossy, and cream color. They measure from $39 \mathrm{~mm}$. to $44.5 \mathrm{~mm}$. in length, and from $29.7 \mathrm{~mm}$. to $35 \mathrm{~mm}$. in breadth." Connected with this Goose Teal there are, as with all hole-nesting ducks, the usual attractive anecdotes of mothers carrying their young to the water upon their backs or between their feet. Unfortunately no competent observer has actually witnessed the proceeding, so that further details seem to be, as yet, quite futile. I find no information regarding the habits of the male during the incubation period and afterward.

Status of Species. The older writers (Jerdon, 1864; Hume and Marshall, 1879) remark on the great abundance of this species in Bengal, as does E. W. Oates (1883) on its plentifulness in Burma. So far no recent writers have mentioned any considerable decrease in its numbers. Baker (1908) described them as swarming in thousands and outnumbered only by the Whistling Teal. Although netted in 
enormous quantities for the Calcutta market, it seems to bear persecution remarkably well. Baker speaks of one place, Moolna Bhil, where one gun could secure forty or fifty pairs in a single day. The fact that very few Indian sportsmen consider them as real game has no doubt tended to lessen the number destroyed. In Hume's day there were probably about twenty thousand taken in a year in the mouths of the Ganges and Brahmaputra. In more recent times it was referred to by Finn (1901) as "almost the commonest duck in India," though in 1909 he remarks that it no longer by any means outnumbers all the other ducks in the Calcutta market. It has never been common in Australia and its status in the East Indies is uncertain.

Food Value. Very few travelers have waxed enthusiastic over the flesh of the Goose Teal as an article of food, though both Blasius (1884) and Legge (1880), speaking of Borneo and Ceylon respectively, note that it is very good eating. Finn (1915) considers it no better than a common house-pigeon.

There is a good account of the methods by which the native fishermen of the Sunderbunds net these and other ducks for the Calcutta market, in Baker's "Indian Ducks" (1908). They set up nets fifteen to twenty feet high in some narrow part of the waters to be driven. "Then by night they pole silently up the lake towards the nets, driving the flocks of duck and Teal silently before them, nor is any noise raised until an approach has been made to within some two hundred yards, or even less, of the nets. Thus when the shouts are started many of the flocks have not time to rise high enough to evade the.nets into which they fly and are entangled." Goose Teal, because they fly low, fall easy victims to this method of capture.

Behavior in Captivity. Although Cotton Teal have lived in large aviaries or ponds in India, like the African and Australian species, they will not stand transportation, and very few have reached European zoölogical gardens alive. Mr. Frank Finn sent first examples to London in 1897 and the same year twenty or thirty pairs were imported, at a fancy price, by English dealers. Of this lot nearly all died and Mr. W. Jamrach, one of the importers, observed that they rarely lived more than a month in confinement. Mr. Lee S. Crandall informs me in a letter, February 28, 1917, that the Cotton Teal has been recently acquired by the New York Zoölogical Garden, the price paid being $\$ 24.00$ each. A male received in May lived until November and was then killed by accident. Mr. Crandall assures me that the bird was in fine condition when killed, and was just beginning to assume adult plumage.

Finn (1901) tells of a cage of twelve Goose Teal sent to England, out of which only three survived. Hubbard (1907) calls attention to an affection described as paralytic which she thinks may be analogous to the cramp known in connection with the Paradise Duck (Casarca variegata) from New Zealand. The birds that Finn 
kept in Calcutta fed upon paddy (raw, unhusked rice) and canary seed as well as on grass, cut fine, and maggots. His birds became very tame, even "cheeky," and at times showed a bold front even to a Crow. One, which he turned out on a large pond, lost its wildness so quickly that in a very few days it swam to him when he appeared. These birds went through courting activities but apparently did not lay any eggs, although Finn remarks that he thinks they would be easy to breed. Sanyal (1892) says that none ever lived more than five months in the Calcutta Zoological Gardens.

The only individuals I know of that attained any considerable age lived in the garden of Mr. Hubert D. Astley of Hereford, England. Mr. Astley wrote me that he kept a pair for nine years, when the male was accidentally drowned in a piece of wire and the female disappeared soon after. He found this species as hardy as other water-fowl, and says the male displayed constantly in the spring, uttering his curious call-note. They never dove, but reached their food by tipping up. 

SUBFAMILY DENDROCYGNINA 



\section{SUBFAMILY DENDROCYGNINA}

THE Tree Ducks include several very distinct species all, however, referable to the single genus Dendrocygna and constituting a well-defined group. They exhibit certain very gooselike characters that have induced some authors to associate them with the Anserince but the weight of evidence favors placing them among the ducks. Some have included them among the Anatina, or typical ducks, but their peculiar combination of characters seems sufficient to accord them the rank of a separate subfamily. As in the true ducks, the number of vertebræ in front of the pygostyle is never more than forty-four, whereas in the typical geese there are never less than forty-seven. Of external characters peculiar to the subfamily the more diagnostic are the long legs with the reticulated instead of scutellated skin of the lower tarsus. In addition, the skull is extraordinary in that the tip of the lachrymal bone, which is free in other Anseres, is here produced backward so as to unite with the squamosal process, thus completely enclosing the orbit in a bony ring. The pelvis is unusually shortened and bent down posteriorly, and the pubic bones are slender at their tips as in other ducks. The trachea of the males has a symmetrical enlargement at its base, corresponding to the asymmetrical osseous bulla in males of the more typical ducks. 



\section{WHITE-FACED TREE DUCK \\ DENDROCYGNA VIDUATA (LINNÉ)}

- (Plate 11)

\section{SyNONYMY}

Anas viduata Linné, Systema Naturæ, ed. 12, vol. 1, p. 205, 1766.

Dendrocygna viduata Eyton, Monograph on the Anatidæ, p. 110, 1838.

Dendrocycna viduata Reichenow, Vögel d. Zoöl. Garten, p. 58, 1882.

\section{Vernacular Names}

English:

White-faced Tree Duck

White-masked Duck

Brazilian Tree Duck

White-faced Visi-visi

Widow Duck

\section{French:}

Canard (percheur) à face blanche

Canard du Maragnon

Dendrocygne veuf

\section{German:}

Maskenente

Wittwenente

Nonnenente

Weissstirnige Baumente

\section{Spanish:}

Pato quiriri

Pato cara blanca
Portuguese:

Marreca-apahy

Marreca do Pará

Areré, Ereré, or Ireré

Chega e vira

Indians of Guiana:

Wawing or Vis-sisi

Indians of Trinidad:

Ouikiki bouriki

Dutch:

Braziliaansche Boomende

Matabele:

Idada

Madagascar:

Tsiriry

Angola:

Imbanteque

Arabic:

Agagarajh

\section{DESCRIPTION}

Adult MaLe: Fore part of the head, chin, and spot in the middle of throat white; back of head and upper part of the neck black, lower neck chestnut; back and scapulars brown, the feathers of the upper part of the back with narrow fulvous bars, the feathers of the middle part of the back and the scapulars margined with fulvous; in the center of the back a chestnut patch; lower back, rump and upper tail-coverts, black; center of the underparts, vent, and under tail-coverts, black; sides and flanks whitish buff, barred with black; lesser wing-coverts chestnut, remainder of wing-coverts slaty black, the median ones and the tertials with an olive tinge; quills, brown-black; tail, black. 
Iris dark brown (Salvadori, 1895). Bill black, occasionally a gray band behind the nostrils. Feet lead-gray to ashy gray.

Total length 420-500 mm.; wing, 205-220; bill 45-48; tarsus 47-48 (Reichenow, 1900).

\section{Addlt Female: Similar to male.}

ImMature Bird (in Museum of Comparative Zoölogy): No black on the head, nor has it any of the white face markings. The crown is dark gray, and the sides of the head rusty gray. The rich brown of the hind neck is lighter, and there is no black on the lower parts, which are light gray, lightly barred with darker gray. The upper surface is nearly similar to that of the adult.

Young IN Down: A specimen in the Tring Museum has the typical pattern of a Tree Duck with a yellow bar across the occiput and large yellow patches on wings, sides, scapular areas and sides of rump. All the light parts are light sulphur-yellow in color and the dark parts brown to black. A specimen hatched at Sandringham, England (Tring Museum), lacks the black band across the lower part of the face and has the white band under the eye very obscure.

VARIATION: There is a wide range of variation among individuals in the arrangement of the black and white patches on chin and throat. The black may be continuous over a large area, or broken all along the throat by a white patch. The crown and other white areas are often stained with brown.

\section{DISTRIBUTION}

Tris species is found in both the New and the Old World, inhabiting the tropical regions of South America and Africa. The northernmost limit of its occurrence in the New World is Cuba, and there Cuba it is only very rare (Gundlach, 1875). Cory was by no means certain that it had not been introduced in the island (Cory, Auk, vol. 5, p. 61, 1888), but it probably arrived there on one of those sporadic excursions, common to this species. It has, however, been found in Barbados, where Feilden (1899) saw a flock of twenty-seven in 1887; and it has been recorded also from Trinidad (Léotaud, 1866; F. M. Chapman, 1894). In Central America it also occurs only spoTrinidad radically. Specimens have twice been seen and taken at Bebedero, Costa Rica (Carriker, Costa Rica 1910), and von Berlepsch (1887) speaks of comparing a South American example with Panama one from Panama. I have been unable to trace this reference any further.

In South America the White-faced Tree Duck seems to be most common in the central and eastern sections. It must be rare in Colombia, for it is not recorded by F. M. Chapman (1917), though the Colombia British Museum has a specimen from Bogotá. As far as I know there is no record at all Peru for Ecuador, though the species probably occurs there. It has been variously recorded from Peru. Tschudi (1845-46) found it on the coast south of Lima, between Chorillos and Lurin, and Bartlett (Sclater and Salvin, 1866) found it in eastern Peru on the lower Ucayali River. It is probably not rare in eastern Bolivia though the only record I can find for this country is the Bolivia old one of d'Orbigny (1812). It does not appear to extend much south of the Buenos Argentina Aires region in Argentina, though it breeds in the Chaco (Hartert and Venturi, 1909), and has been taken in Jujuy Province (Lönnberg, 1903). It has also been met with in Tucuman (Burmeister, 1860), in Cordoba (Schultz, fide Dabbene, 1910), rarely in the La Plata region (Sclater and Hudson, 1889), and even in Buenos Aires (Durnford, 1878).

East and north of the La Plata it is more abundant. It unquestionably inhabits Uruguay (Tremoleros, 1920) and is found in southeastern Brazil in Rio Grande do Sul (H. and R. von Ihering, Uruguay 1907), in Paraná (H. and R. von Ihering, 1907) and on the Rio Paraná (von Pelzeln, 1868-71. Azara (1805) found large flocks in Paraguay, and since his time it has 






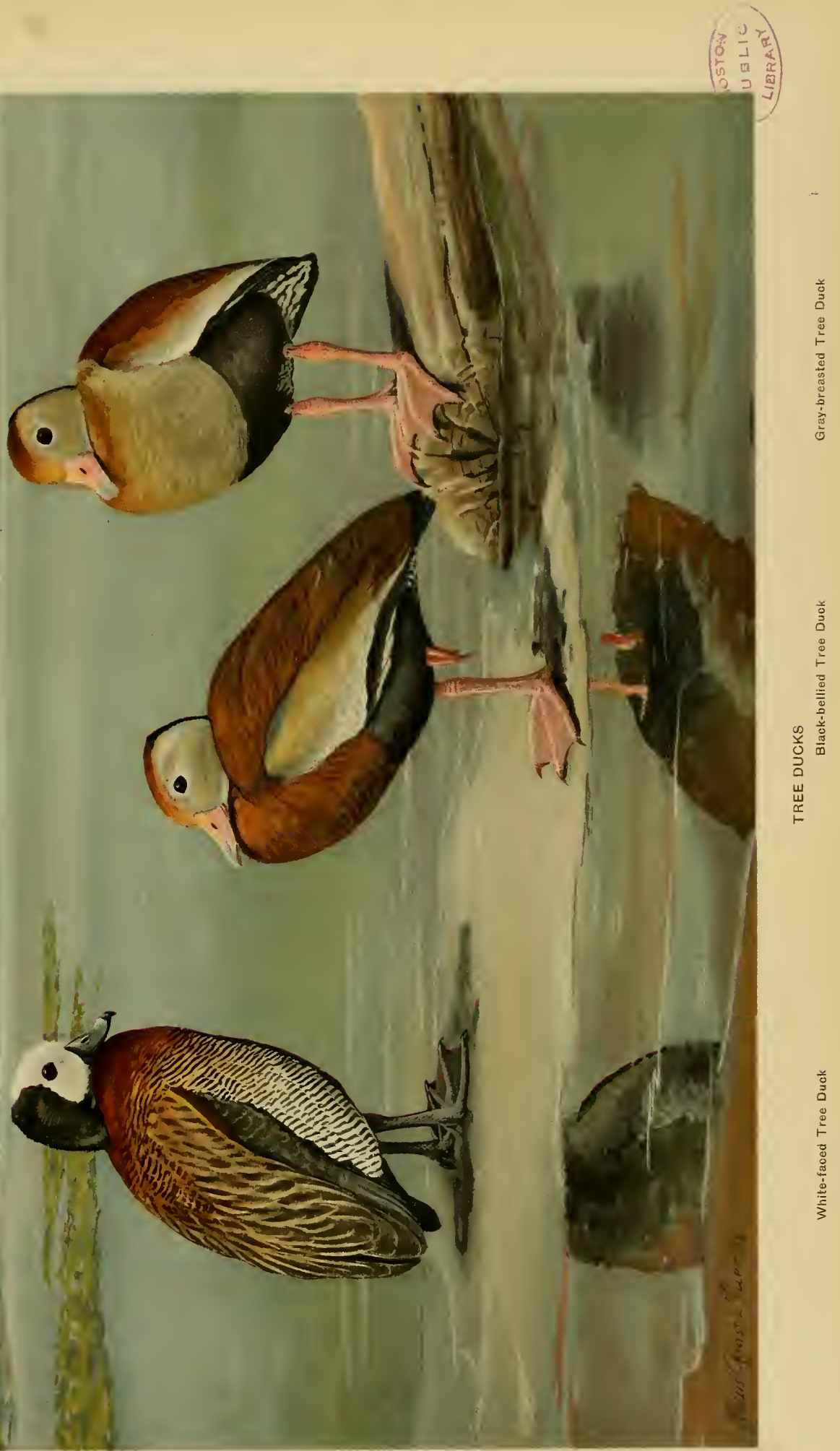



been recorded as one of the commonest ducks and as breeding in western Gran Chaco (Kerr, 1901). Von Berlepsch (1887) has reported it from the Lower Pilcomayo. Northward it is found throughout the interior of Brazil, in São Paulo (H. and R. von Ihering, 1907), Minas Geraes (Reinhardt, 1870, et al.), in Bahia (Wied, 1832), in Goyaz (von Pelzeln, 1868-71), throughout Matto Grosso (von Pelzeln, 1868-71; H. and R. von Ihering, 1907), in Amazonas on the Rio Branco (von Pelzeln, 1868-71), and eastward in Pará, on Marajo, and in Maranhao (Goeldi, 1894-1900).

On the north coast it appears to be common in all the Guianas. The Musée des Pays-Bas has a specimen from Cayenne, and F. and A. Penard (1908-10) state that it is abundant and that it breeds in the interior of Dutch Guiana. It was found common also in British Guiana (R. Schomburgk, 1848; C. B. Dawson, 1916), and Whitely (Salvin, 1886) met it on the Rupurumi River. It seems to be less common in Venezuela, where it was found by Ernst (1877). Beebe (1909), however, saw it only twice during a recent trip on the Upper Rio Guanaco in northeastern Venezuela. According to Sclater and Salvin (1876) the species

Venezuela extends west to the Magdalena River in Colombia.

The White-faced Tree Duck is a characteristic species in Africa, where it is found everywhere south of the Sahara, excepting Cape Colony and southern German West Africa. In the west it is known to occur as far north as Senegal (J. and E. Verreaux, 1851) and Gambia (Rendall, 1892) in which region it is said to be common in various localities. It is found also along the entire Guinea coast, in Portuguese Guinea at Bissao (Pimenta, fide Reichenow, 1900) in Sierra Leone, whence it has been recorded from the Karine District (Kelsall, 1914) where it is common at Rotifunk (Kemp, 1905), and in Liberia at Robertsport, at

Africa: Senegal Gambia

Liberia Marfa, and on the Sugary River, where it apparently breeds (Büttikofer, 1885). I have been unable to find any records for the Ivory Coast, though this is unquestionably due rather to the paucity of information than to the absence of the species. It has been recorded from the Gold Coast by Pel (Hartlaub, 1855) and has also been found there in the Fanti District (Blissett, fide Reichenow, 1900; Ussher, 1874) and at Accra where it breeds (Reichenow and Lïhder, 1873). From Togoland it has also been reported (Reichenow, 1897), having been found chiefly in the interior; at Kratschi (Reichenow, 1897), and in Mangu (Reichenow, 1899). Its presence in Dahomey must still be presumed, owing to lack of information, but there is reasonably full evidence of its status in Nigeria. From that Colony it has been recorded from

Gold Coast Togoland Loko, Dochibbu, Kaura, and Sokoto (Hartert, 1886) and also from Zaria (Hartert, 1915), as well as from the Benue River (Mockler-Ferryman, 1892), where it is very common (B. Alexander, 1907). Denham and Clapperton (1826) have recorded it from the Lake Chad region in the interior. In Camerun it has been found on the Wuri River (Reichenow, 1874) and in Hanu (Bouvier, 1875).

Eastward the species undoubtedly occurs throughout the Upper French Congo, for it is found in the Sudan and on the Nile north about as far as Khartum (von Heuglin, 1869; A. E. Brehm, 1857). There seems to be much movement according to meteorological conditions, and the birds are apparently found about Khartum only in winter and spring (A. L. Butler, 1905).

Sudan Many travelers have observed the species on the White and Blue Niles (von Heuglin, 1873; A. E. Brehm, 1857; A. L. Butler, 1905; Witherby, 1901; Jägerskiöld, 1904), as well as in the Senaar and Kordofan regions (Hartmann, fide Reichenow, 1900; von Heuglin, 1873; Strickland, 1850) and commonly south to Bahr-el-Ghazal (A. L. Butler, 1905, 1908). Ogilvie-Grant (1902) has recorded it from Kaka, and Sharpe (1884) from Kutchugali, in the same general region.

In Abyssinia also the species is frequently seen. Rüppell (1845) met with it on Lake Tana, Salvadori $(1884,1888,1888 \mathrm{a})$ has repeatedly recorded it on the basis of observations made and specimens taken by Antinori and Raggazzi at Lake Cialalaka and other localities in Shoa. It was found at Gura, southern Abyssinia, by Ruspoli (Salvadori, 1894), but there seems to be only one record of its occurrence in British Somaliland, namely, at Berbera (Shelley, 1885); and it 

that it arrives on the coast in flocks during November and December and that it breeds. In southern Zululand, according to Claude Grant (W. L. Sclater, 1912) it is a very common species. Woodward (1899) has recorded it from Durban Harbor, and W. Ayres (1887)

Transvaal

from the Umlazi River. But this record is the southernmost, and it serves to fix the southern limit of the range at exactly $30^{\circ}$ south latitude. There is only one record, so far as I know, for Cape the Cape Colony (C. G. Davies, 1908), and none for the Orange River Colony.

Colony

In Madagascar this species is very common, and apparently is found throughout the island (Roch and E. Newton, 1863; Pollen and van Dam, 1868; Hartlaub, 1877; Milne-Edwards and Grandidier, 1876-81). It is also fairly abundant on Réunion Island, where it was introduced (Sibree, Madagascar 1892) and on Mauritius, where it appears to have been introduced, though it is not so Réunion common there now (Meinertzhagen, 1912). It is common, however, on the Comoros Mauritius (Sibree, 1892) and has been specifically recorded for Mayotta Island in that group (Pollen and van Dam, 1868).

A specimen was taken on the Hackensack Meadows in the State of New Jersey (Grinnell, Auk, vol. 30 , p. 110, 1913), but this was almost certainly an escaped bird, as the species has New Jersey been very commonly kept in zoölogical collections everywhere.

Origin of the Species in South America: Various theories have been advanced in the attempt to explain the occurrence of the White-faced and Fulvous Tree Ducks in the Old and New Worlds. P. L. Sclater (1864, p. 299) suggests that Dendrocygna viduata may have been introduced into America at the time of the early slavers, as these birds are "very tame and domestic, and often carried about on board ship." This explanation can hardly be considered as reasonable. No more acceptable to students of zoögeography would be the theory that the genus is an extremely old one, possibly dating from Tertiary times, when a Brazilian-Ethiopian continent was in existence (Heinroth, 1918), because such a continent could only have existed previous to the development of highly specialized ornithological types like the ducks. Much more reasonable is it to suppose that they exist in the two continents simply because they are strong-flying birds of a wandering nature, and the trade winds would easily account for their crossing the scant twelve hundred miles of ocean that separate Africa from South America. The Scaup Ducks of South America and Africa, Nyroca nationi and Nyroca brunea, present a similar case, for as nearly as I can determine they will have to be considered as one and the same species.

\section{GENERAL HABITS}

THe name Tree Duck is a misnomer for this species, for most authorities agree that it is seldom seen perching. In captivity, certainly, it is never seen off the water or land, and spends most of its time walking or standing on the bank. Inhabiting as it does, almost the whole of South America and Africa, it lives, of necessity, in widely different types of country - treeless, semi-desert regions flooded during the short rainy season, tropical rivers, swamps, salt-water lagoons, and mouths of the larger rivers. Nearly everywhere it is extremely abundant, but less so as one enters the dense rain forests.

WARINESS. White-faced Tree Ducks are not particularly wary, and it is rather characteristic that when flushed they circle about without going off to any distance. Soon after they pitch down again. Von Heuglin (1873) speaks of it as less shy than most ducks, and, so far as I know, only Büttikofer (1885) considers it a particularly 
wary bird. All Tree Ducks are apt to be fairly easy to capture, and they respond to an imitation of their call-notes. In his account of the birds on the White Nile, Abel Chapman (1921) remarks that although these ducks are very tame for the most part, they will spring at two hundred yards if they get the wind of the hunter. $\mathrm{He}$ tested this out to his own satisfaction.

DaILY Movements. Throughout its range many observers have written of the great nocturnal activity of this species, of its passing to and fro all night in large flocks, uttering its peculiar triple whistling note. It is probably fully as nocturnal in its habits as other members of the genus, and like the Fulvous Tree Duck is seldom seen on the wing in the day, unless disturbed.

Fuight. As usual, in describing the flight of any species of duck, opinions vary as to the actual speed attained, the same species being reported as a slow, clumsy flyer in one place, and as an extremely powerful and rapid flyer in another. This species is no exception, but in general the flight may be described as typical of the Dendrocygna - gooselike, powerful, but not as rapid as that of the true ducks. In alighting on the water the neck is stretched down remarkably far, so that the bill and toes almost touch (Heinroth, 1918). Abel Chapman found on the White Nile that Gargany Teal whizzed past the slow-flying Tree Ducks as "a destroyer overhauls a mudhopper!"

GaIT. Their long legs and extended neck give them an extremely awkward appearance on land, although as a matter of fact their gait is not at all clumsy. Like the other species of Tree Ducks they stand with body and neck almost vertical.

Diving. The White-face is active on the water, and many observers have remarked its ability in diving. F. P. and A. P. Penard (1908-10) say they swim and dive well, and Sibree (1892) has recorded similar observations. According to Heinroth (1918) the birds procure much of their food in this manner. From the æsthetic standpoint they cannot be said to rank as particularly stylish in appearance either on land or on water.

Perching. It appears that this duck very rarely perches on trees (Woodward, 1899; Büttikofer, 1885; Reichenow, 1874; von Heuglin, 1873; etc.), and none of the members of this family seems to use trees except in certain cases for nesting, or for procuring food.

FLocks. These birds are often met with in large flocks, which at times number many hundreds. R. Schomburgk (1848) says that in British Guiana the flocks were 
so large that from ten to eighteen could be brought down at a shot. Recent investigators in the same region have made similar remarks (F. P. and A. P. Penard, 1908-10). Swynnerton (1908) says he has seen flocks of one hundred and fifty in the air at a time in Gazaland. In Paraguay Azara (1805) met with flocks of two hundred and over. A. E. Brehm (1857) speaks of "veritable clouds" as occurring in the Sudan. There is, however, no indication that any such numbers are ever met with on the coast. They seem to be more plentiful on inland waters.

Association with other Species. For the most part the type of country inhabited by this species is not rich in true ducks, but Holub and von Pelzeln (1882) saw the White-face together with Anas erythrorhyncha, on the Zambesi, and von Heuglin (1873) reports it mixing with flocks of Spur-wings and Comb Ducks, in northeast Africa. In Guiana, according to the Penards (1908-10), it lives in harmony with the Blue-winged Teal (Anas discors). In aviary life it has little to do with other ducks, and Tree Ducks of several different species may be seen standing closely together, and holding disdainfully aloof from all other aquatic birds.

Vorce. In the males of this species, as with other members of the genus, there is a swelling of the windpipe, representing a primitive bulla ossea, which attains its full development in the males of the true ducks. In this species it is very small and symmetrical. Heinroth (1918, p. 241) notes that in the female, there is, in the place of the tracheal dilatation a slit covered with a membrane. At any rate, as far as known the note is identical in both sexes. It consists of a clear whistle, sometimes double or even triple. The note is frequently repeated while the flock is on the wing, and there seems to be no variation in its character. This whistle is probably a flockcall, and it is worthy of note that small numbers of birds in aviaries or ponds where they cannot fly, are extremely silent. The actual sound of the voice has been variously described, as follows: two whistling notes, rarely three, frequently uttered by the whole flock when on the wing (Swynnerton, 1908); pyswy, pyswy, a piercing whistle, uttered constantly when on the wing (Sibree, 1892); three long clear whistling notes different from those of Dendrocygna bicolor (P. L. Sclater and Hudson, 1889). In Madagascar the native name "Tsiriry" is said to be onomatopoetic (Milne-Edwards and Grandidier, 1876-81), and it is interesting to compare this with the Spanish name "Quiriri."

Food. I have been unable in the literature to find any scientific analysis of stomach-contents, but the birds are omnivorous, and not only feed on insects, mollusks, and crustaceans, but also occasionally on fish, or even prey on the rice-fields (Hartlaub, 1877; Layard, 1875-84; Swynnerton, 1908). Büttikofer (1885) noted them feeding on small salt-water crustaceans and mollusks on the flats left by the receding tide off the coast of Liberia. They are equally fond of various vegetable seeds. 
Courtship and Nesting. In spite of the extensive literature on this species there is extraordinarily little known as to its sexual life, and particularly as to the location of its nest. The display is described by Heinroth (1911) as simple and very similar to that of geese, Comb Ducks, and the Mute Swan. There is a reciprocal invitation in the shape of an oft-repeated dipping and lifting of the head and neck. In the postlude (following the mating act) both sexes erect themselves, and facing toward each other, lift the wings, occasionally even spreading them upward. This display phenomenon is characteristic of the whole group of Tree Ducks, and has little in common with corresponding behavior among the true ducks.

Regardless of the fact that this bird is one of the most plentiful, if not the most plentiful, of all tropical ducks in both Africa and South America, actual records of the finding of nests are extremely rare. Most travelers confess that they have hunted diligently during the nesting season, without making a single find. About all the information which they contribute has been drawn from the natives. P. L. Sclater and Hudson in 1889 admitted that they knew nothing of its nesting habits in South America. Kerr (1901) says that they nest in palm trees in the Gran Chaco region of Argentina. In Dutch Guiana the Penards (1908-10) state that the birds usually, but not always, nest in hollow trees, sometimes at considerable altitudes.

Not a single observer in Africa has ascertained anything as to its nesting in trees and Reichenow (1874; Reichenow and Liihder, 1873) is of the opinion that it probably nests in the rushes near water, and that it is certainly not dependent on trees. Von Heuglin (1873) holds a similar view. In Madagascar it has been reported as nesting even on hills among grass (Sibree, 1892).

When all is said and done, we know less about the average nesting site of this bird than we do about that of any other common species of duck.

Like all tropical species the White-face has an extremely irregular and extended breeding period. Eggs were found in East Africa early in March (Böhm, 1885) and in western Liberia in August (Büttikofer, 1885). In Togo, also, half-grown young were found in August and September (Reichenow and Lïhder, 1873).

The clutch is given as consisting of from eight to twelve. In one case twenty-two is the number recorded (Antinori and Salvadori, 1873), probably representing the efforts of two females. The eggs measure $45.5-48$ by $36-37 \mathrm{~mm}$. and are yellowish white in color (Reichenow, 1900).

One of the most interesting characteristics of this species (which, however, applies also to Dendrocygna bicolor) is the participation of the male in the duties of incubation. Buittikofer (1885) speaks of a male being taken off a nest by a native, and Heinroth (1911) gives ample evidence supplied by German bird fanciers that the male assumes the principal part in the work of incubation. At the beginning the male seems to incubate alone. On the other hand, Pocock (London Field, January $9,1915)$ cites an instance of a pair that nested on Lord Lilford's estate. In this case 
the male took no part in the incubation, though he carefully guarded the nest. It appears probable, therefore, that like many other birds having no sex-dimorphism of plumage, the male often, though not always, assists the female.

The period of incubation is not definitely known, but has been given in a general way as from twenty-eight to thirty days (Bergtold, 1917). The pair that bred on Lord Lilford's estate hatched their clutch in twenty-eight days. It would not be out of keeping with the relationship of the genus if the incubation period turns out to be rather longer than twenty-eight days.

STATUS. This species is very abundant in almost all the central portions of its range except in the heaviest forest belts. Some reference to the size of the flocks that have been recorded, has already been made above. In many parts of its range it is the commonest duck, though in Guiana not so common as Dendrocygna bicolor (F.P. and A. P. Penard, 1908-10). It is especially abundant on the rivers of the Sudan, and, so far as is known, is holding its own better than other ducks. In the heavy jungles of the Upper Congo, however, I am told by Mr. J. P. Chapin that, like all other water-fowl, it is extremely scarce.

Enemies. No specific information is available. The young are no doubt preyed upon by alligators and crocodiles. Wounded individuals were pounced upon by the great White-headed River Eagle on the White Nile (A. Chapman, 1921).

Damage. Hartlaub (1877) and Layard (1875-84) speaking of Madagascar, say that these birds cause considerable damage to the rice-fields. Von Heuglin (1873) makes similar remarks as to northeastern Africa.

Food Value. The flesh of the White-faced Tree Duck is invariably excellent, regardless of the character of the country in which it is killed. The whole group is famed for the excellence of its flesh, and this species is no exception to the rule. Observers who have particularly noted its culinary value, are all of the same opinion (Hartlaub, 1877; R. Schomburgk, 1848; Milne-Edwards and Grandidier, 1876-81; Wied, 1832; Witherby, 1901; and numerous others).

Hunt. C. Grant (W. L. Sclater, 1912) speaks of the excellent shooting which he obtained in Zululand by lying between two lagoons and sending natives around to drive the birds up. The natives catch them easily on the Zambesi with traps consisting of a flat stone propped up by a stick (B. Alexander, 1900). They are not especially shy or hard to shoot, as was noted before under Wariness.

Behavior in Captivity. These Tree Ducks areone of the species most commonly 
seen in zoölogical gardens and private collections the world over. Specimens were first received by the London Zoological Society in 1835, and have, as a rule, been plentiful in the bird-markets of the world. Hubbard (1907) gives the price as from $£ 3$ to £5 per pair, and Mr. L. S. Crandall (in litt.) informs me that the New York Gardens have obtained them for as low a figure as $\$ 8.00$ each. I kept this species myself for five or six years, and always considered it one of the less interesting ducks, on account of its inactive and sluggish nature. In confinement they soon become very tame, learn to rely entirely for their food on the grain that is given them, and are seldom seen in active search for the wild food which may be present in the pond. Iike many other tropical species they are sufficiently hardy to need no special protection beyond the shelter ordinarily given to all water-fowl in northern regions. Horsbrugh (1912) found that they required protection in severe weather in England, and would often succumb to a "hard frost." They certainly suffer less from cold, however, than do Blue-winged Teal, Garganeys, and Shovellers; and they undoubtedly live as long as the true ducks if not longer. There is a record of eleven years for the Zoölogical Gardens at Frankfurt a. M. (Schmidt, 1878), and in 1883, the London Gardens possessed three specimens that had been living there since 1862, and another that had been received in 1863 ? (Sclater, 1883). Four specimens in the New York gardens lived from six and one half to seven and one half years.

None of the Tree Ducks breeds readily in captivity, and this species never nested, so far as is known, until recent years. Flower (1910) mentions sixteen bred in the Giza Gardens, Cairo, but does not say whether they were reared from home-laid eggs or not. Heinroth (1911) mentions a certain Mr. Sammereier, a Bavarian breeder, who had a pair which bred several times. It was with this pair that the male's participation in incubation was noted. In England the birds have nested several times on private estates, but the young nearly always died at an early age, in spite of all the precautions that were taken. A post-mortem examination in the case of young one week old showed pneumonia to have been the cause of death (Pocock, London Field, January 9, 1915). Mr. Wormald, however, in a letter (January 13, 1920) informs me that a friend of his who had failed for three consecutive years, sent him nine eggs, all of which hatched, and six of the young were reared to maturity. A pair kept by Mr. Duncan at Knossington Grange, Oakham, England, bred for three years, and in 1912 hatched out ten young ones (London Field, July 12, 1912). Heinroth (1911) mentions the fact that two were raised under a hen in the Berlin Gardens.

The nest which a pair built on Lord Lilford's estate was very cleverly hidden, long bents of grass being brought over so that the sitting bird was completely concealed (Pocock, loc. cit.); and this habit probably accounts for the extreme difficulty in finding their nests in the wild state.

By far the best account of these birds from the avicultural standpoint is to be 
found in Rogeron (1903). He emphasizes especially their stupidity, even as compared with related species, such as Dendrocygna autumnalis; but he also calls attention to their ability to protect themselves against larger and stronger species. My own observation has been that the Tree Ducks hold themselves aloof from other species and certainly never attempt to start a quarrel.

Several writers have referred to this species as one commonly domesticated by natives, but in my opinion the word "domestication" has been incorrectly used. It is true that they are commonly kept both in South America and in Africa, and particularly in Mauritius and Madagascar, but they are undoubtedly obtained or raised from eggs laid in the wild, or by the capture of young birds. The practice of taking the eggs of the Black-billed Tree Duck and having them hatched by hens is extremely common among the Cubans to-day. R. Schomburgk (1848) recorded the White-faced Tree Ducks as one of the commonest "domestic" animals among the Indians of British Guiana. Roch and E. Newton, writing in 1863, say that at that time large numbers were still exported from Madagascar to Mauritius, where they lived in a half-wild state, and were easily "domesticated." 


\section{FULVOUS TREE DUCK \\ DENDROCYGNA BICOLOR (VIEILLOT)}

(Plate 13, downy young; Plate 12, adult)

SYNONYMY

Anas fulva Gmelin, Linné's Systema Naturæ, ed. 13, vol. 1, pt. 1, p. 530, 1788 (not Anas fulva Meuschen, 1787).

Anas bicolor Vieillot, Nouvelle Dict. des Sci. Nat., vol. 5, p. 136, 1816.

Dendrocygna fulva Hartlaub, Syst. Verzeichn. Ges. Mus., p. 118, 1844.

Dendrocygna arcuata G. R. Gray, List Birds Brit. Mus., vol. 3, p. 131, 1844 (nec Cuvier).

Dendrocygna major Jerdon, Madras Journ., vol. 12, p. 218, 1840.

Dendrocygna bicolor helva Wetmore and Peters, Proc. Biol. Soc. Washington, vol. 35, p. 42, 1922.

\section{Vernacular Names}

English:

Fulvous or Fulvous-bellied Tree Duck

Larger or Greater Whistling Teal

Brown Tree Duck

Brown Vicissi

Yellow-bellied Fiddler

Rufous Duck

Mexican Duck

Squealer

Spanish Cavalier

Long-legged Duck

French:

Millouin du Mexique

German:

Madagassische Baumente

Gelbe Baumente

Rostgelbliche Ente

Spanish:

Chiquiote

Algarabia
Pat silvon or Silbon

Pato amarillo

Yaguasa - (Venezuela)

Mexican:

Tziquiotl

Trinidad:

Ouikiki ailes rouges

Portuguese:

Marreca puea (Brazil); also Marreca peba

Dutch:

Geelachtige Boomende

India:

Murghabi - (Lower Bengal)

Badak - (Deccan)

Silli-(Hindustani)

Sisalee-(Burmese) $\}$ Pegu

Madagascar:

Tahia

Etsoa 

N
$\frac{5}{5}$
$\frac{5}{0}$

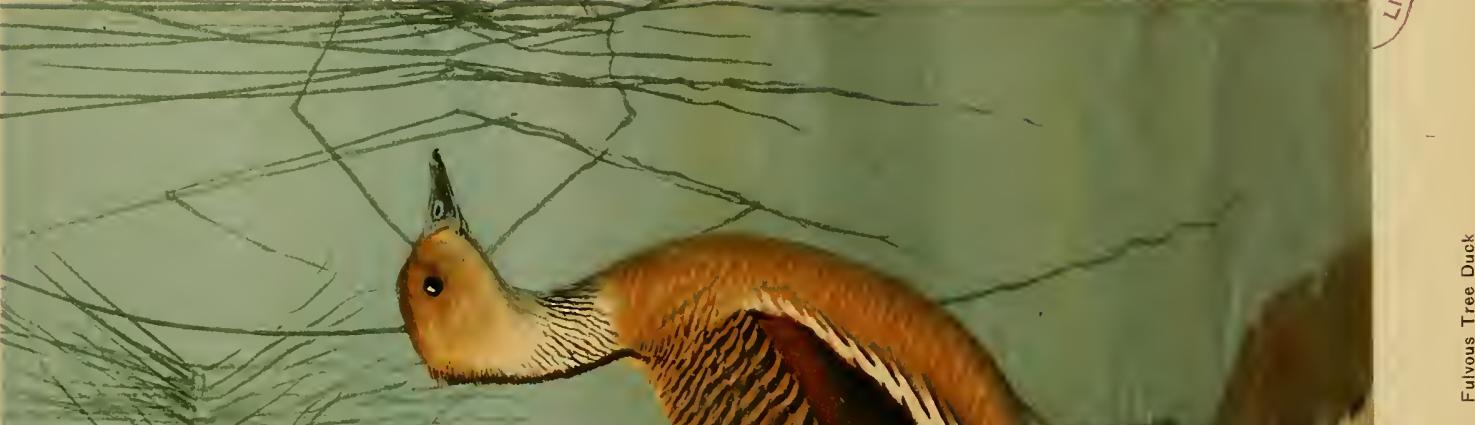

0
0
0
0
0
0
0
0
0

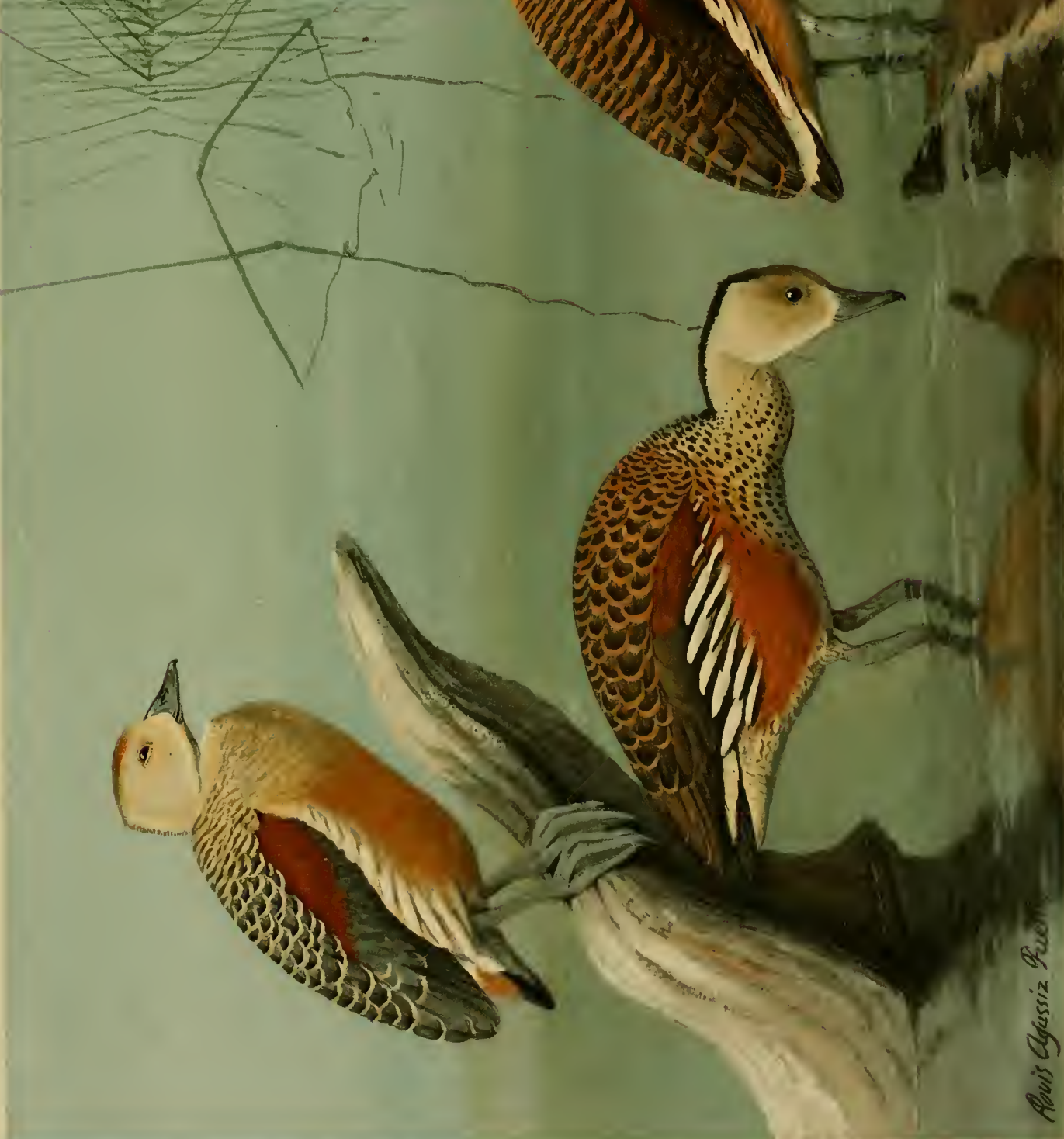

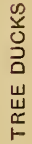





\section{DESCRIPTION}

Adult Male: Top of head rusty brown running into a black stripe on hind neck. Sides of head and lower parts pinkish buff-color, varying to a richer buff-color depending perhaps on age of feathers. A whitish ring streaked with black around neck. Mantle brown. Rest of upper parts black but feathers broadly margined with rusty brown. Primaries black. Flank feathers ornamental, with white centers. Rump buffy white; tail black; under tail-coverts creamy white.

Bill bluish black; legs bright slaty blue; iris brown.

Wing 204-226 mm.; bill 42-49.5; tarsus 49-61.

Adult Female: Similar.

Young BirDs: According to Salvadori (1895) there is very little chestnut color on the smaller upper wing-coverts; under parts paler; the upper tail-coverts narrowly margined with brown.

YouNG IN Down: Upper parts grayish brown; lower parts whitish; a white band across the occiput interrupted by the brown band which runs along the hind neck; a brown band from the ears to the hind neck; no white patches on the sides of the back; a whitish band across the wing (Salvadori, 1895). The specimens which $I$ have seen, one of which is figured here, show the characteristic head pattern of the other species of Tree Ducks very little, if at all developed. (See Plate 13.)

Remarks: A new race, Dendrocygna bicolor helva (Wetmore and Peters, Proc. Biol. Soc. Washington, vol. 35, p. 42, 1922), separating the birds of California and our Southwest from those of southern South America is based upon characters which do not seem to me to hold good.

\section{DISTRIBUTION}

No other known bird has a range so remarkable as this one, for it occurs unaltered in four distinct zoölogical regions. Even the boldest of the hair-splitting systematists must, I think, admit that there are no visible differences among the specimens from California, Argentina, East Africa, and India.

It is migratory to so slight an extent that it is hardly advisable, on the map, or in this discussion, to make any distinction between breeding and wintering ranges beyond calling attention to the few known differences as we proceed. In North America, where most is known of its movements, it is very hard to separate the breeding from the wintering areas and, as Cooke (1906) has so aptly pointed out, one of the northernmost records is a winter record, and one of the southernmost is a breeding one.

In North America the birds occur throughout the southern half of California, western Nevada, southern Arizona, southern Texas and southern Louisiana, as well as throughout most North of Mexico.

America

Barnston (Canadian Naturalist and Geologist, p. 337, 1861) claims that he shot a specimen of this species on the Columbia River above Okanagan, Washington. This record seems to have been overlooked by recent writers on the ornithology of this region. There was apparently a United stray flock in the Puget Sound region in 1905, for on November 29, five out of a group States of eleven were taken at Alborni, Vancouver Island, and on December 3, another was brought down from a flock of ten at Grays Harbor (Dawson and Bowles, 1909). The Vancouver Washingrecord is, to my knowledge, the northernmost one for this species. In California the ton northernmost records are those at Marysville in the Sacramento Valley in winter and at Inverness in Marin County (Cooke, 1906), and east of the Sierras at Owens Valley (A. K. Fisher, 1893). In general, however, the species is migratory in the southwestern United States

California

(Grinnell, Bryant and Storer, 1918). Farther south it breeds as far north as Los Baños in the San 
Joaquin Valley where it is common (Barnhart, 1901; Grinnell, Bryant and Storer, 1918). It nests commonly throughout southern California (Grinnell, Bryant and Storer, 1918), specifically at Los Angeles, San Jacinto Lake, Tulare Lake and Summit Lake (J. Grinnell, 1915). In Nevada it has Nevada occurred at Washoe Lake (Hoffman, 1887) and at Carson (Ridgway, Field and Stream, vol. 36, p. 435, 1890). According to Cooke (1906) it is a resident species at Fort Whipple, Arizona, and Brown (Auk, vol. 23, p. 218, 1906) states that it is fairly common in winter in the southArizona western part of that State. In Texas the species seems to be confined to the southTexas eastern part and perhaps the littoral north to Louisiana. In summer it is found in the Rio Grande Valley north to the sources of the Nueces, and in the winter is pretty common in the interior, on the North Concho River (Strecker, 1912). Dresser (1866) found it commonly at Galveston, while in the extreme southeast part of the State he found it occasionally at Brownsville. Merrill (1878), however, records it as common in the same vicinity, while Coues (1903) states that it is common on the Rio Grande. A recent writer (Strecker, 1912) gives Cameron and Hidalgo Counties as its habitat. In Louisiana the species seems to occur only in the southern parts, being resident at Louisiana Lake Catherine, the Rigolets and at New Orleans (Cooke, 1906). Strangely enough it almost invariably appears there not in summer, but in fall and winter. Though considerable flocks have been noted, its appearance in Louisiana is decidedly irregular (Beyer, Allison and Kopman, 1907). Besides the records for Washington and Vancouver above mentioned the species Missouri has straggled as far north as New Madrid, Missouri, in 1890 (Ridgway, Field and North Stream, vol. 36, p. 435, 1890), and on the east coast to Swan Island, North Carolina, Carolina July, 1886 (Pearson, Brimley and Brimley, 1919).

In Mexico the species is widely distributed and breeds from Lake Chapala and the Valle de Mexico north, while in winter it goes south to Guerrero and Chiapas (Cooke, 1906). Lawrence (1874) gives a Mexico full account of its occurrence on the west coast in Tepic, Sinaloa and Sonora; and Sanford, Bishop and Van Dyke (1903) speak of it as abundant at Mazatlan. It has been found also in Lower California (Cooke, 1906). For the interior it has been recorded from San Luis Potosi (Richardson, British Museum), while in the Valle de Mexico it is common, especially in winter (Herrera, 1888; Sanchez, 1877-78; Villada, 1891-92). Finsch and Hartlaub (1870) give Deppe's record for Vera Cruz, while in Tabasco it appears to be common, having been recorded from numerous localities in the Province by Rovirosa (1887).

It has been customary to speak of this species as not occurring between southern Mexico and southeastern Brazil. Those taken in Ecuador and Peru have been regarded as undoubtedly stragSouth glers; and its presence in Venezuela and Trinidad was regarded skeptically even by America Cooke (1906). This position has, to say the least, been hastily taken. Our ornithological knowledge of many parts of South America is very inadequate. Recent investigations seem, Trinidad I think, to indicate that the present species is of regular occurrence in northwestern South America. It certainly occurs on Trinidad and breeds there (Léotaud, 1866; F. M.

Chapman, 1894). It has furthermore been recorded as breeding, though not commonly, on the coast

Guiana of the Guianas (F. P. and A. P. Penard, 1908-10). C. B. Dawson (1916) also includes it in his list of the birds of British Guiana. In Venezuela it was found apparently not rare on the Caura River (André, 1904) while very recently F. M. Chapman (1917) has shown that it Venezuela is generally distributed and fairly common in the tropical zone of Colombia, occurring also at Bogotá, while specimens have been taken at Cali and La Herrera. In the light of these valuable investigations, we may regard the records for Vinces, Ecuador (Cooke, 1906) and Colombia Moyobamba, Peru (Taczanowski, 1886) as less remarkable than has been considered heretofore. A most astonishing locality for Tree Ducks is Lake Junin, Peru, altitude over 11,000 feet, where in April, 1920, Lord William Percy shot a single specimen and saw at least a Ecuador dozen others. I know of no other records for such high altitudes (W. Percy collection, Peru London). 
The usual range of the species in South America is, however, the valley of the La Plata. The birds are somewhat migratory in this region, breeding about Buenos Aires and wintering more commonly in northern Argentina (Cooke, 1906). Its breeding in considerable numbers about Argentina Buenos Aires is vouched for by Hartert and Venturi (1909), P. L. Sclater and Hudson (1889), and Durnford (1878). Aplin (1894) and Tremoleros (1920) have recorded it for Uruguay, while in Brazil it is regularly found in Rio Grande do Sul

Uruguay

Brazil (Cooke, 1906; H. and R. von Ihering, 1907). Cooke (1906) regards more northern records, such as Port Capuno and Rio Belmonte as accidental occurrences, but I think that considering Burmeister's (1872) report for Paraná, Wied's (1832) for Porto Seguro, and von Iherings' (1907) for Bahia, we must regard the species as of regular though not common occurrence on the coast, possibly as far north as $10^{\circ}$ south latitude. According to Goeldi (1894-1900) it is found occasionally even on Marajó Island in the mouth of the Amazons. If this information is correct it may be that the birds inhabit various localities on the entire coast, from the Guianas to the Argentine. In the interior the species breeds in southern Paraguay, north to Asuncion (Cooke, 1906) while Kerr (1901) found it common on the Lower Pilcomayo. Farther west it breeds in northern Argentina, in Tucuman (Burmeister, 1860), in Chaco, and at Salta and Oran (Hartert and Venturi, 1909; Bruch, 1904). It has been recently observed also in Cor-

\section{Paraguay}

North Argentina rientes Province (Marelli, El Hornero, vol. 1, p. 76, 1918), and in the Province of Buenos Aires (Hartert and Venturi, 1909; Gibson, 1920). There appears to be only one record of its occurrence in Chile, at Paine, Province O'Higgins, $34^{\circ}$ south latitude (Quijada, 1910).

Chile

In Africa, this species seems to be confined to the eastern half. No reliance is to be placed on Rochebrune's (1883-85) statement that it is very common and resident in Senegambia. G.R. Gray in his "List of Birds in the British Museum" (vol. 3, p. 131, 1844), under the name Dendrocygna arcuata lists a specimen from the "interior of Africa." Salvadori (1895) gives the reference for Lake Chad. I have been unable to trace this record any farther. At best it is unusual. There is, however, one other specimen from the west coast, from Landana at the mouth of the Congo, collected by Lucan (Barboza de Bocage, 1877-81). This, Congo too, must be regarded as exceptional until further records are at hand. In the east the species seems to be confined chiefly to the regions about the course of the Nile, and about the great lakes. The northernmost records for the Nile are those for Kordofan and Senaar (von Heuglin, Kordofan 1869; Finsch and Hartlaub, 1870; Kotschy, fide Reichenow, 1900). Von Heuglin found the birds common in this region, but did not know whether they are resident or not. Farther south on the Nile the species was found at Kaka (A. L. Butler, 1905) and apparently extends east through Abyssinia, having been repeatedly recorded by Salvadori $(1884,1888)$ from Lake Cialalaka in Shoa. Undoubtedly it occurs everywhere between the Nile and $40^{\circ}$ east longitude. West of the Nile the birds were found in Lado (Emin Pasha, fide Reichenow, 1900) and at Kageji (Reichenow, 1887). It is not very common, but breeds about Lakes Nakuru and Magadi, British East Africa (van Someren, 1916). Recently British Sjöstedt's (1910) investigations have shown that the species occurs, though not com- East Africa monly, in July and August about the Natron Lakes, Kilimandjaro. Dubois (1886) has recorded it from Lake Tanganyika, while about Lake Shirwa and the Shiré River (Somba and Fort Johnston) it appears to be common and breeding (Hartert, 1898; Shelley, 1894). Farther inland it has been recorded by Salvadori (1914) near Lake Bangweolo, northern Rhodesia and it was seen on the Upper Zambesi at Sesheke (Holub and von Pelzeln, 1882), and farther south on and about Lake Ngami (Fleck, 1894; Stark and Sclater, 1906). Recently it has been recorded even from Natal (Chubb, Journ. Abyssinia Lado Uganda So. African Ornith. Union, vol. 8, p. 1, 1912). As to the migration, we have no definite information on Africa, but from the few cases in which dates are given, it may be said that a general north and south movement takes place and that the birds move toward the warmer 
sections in summer. In Madagascar the species is not rare either on the coasts or in Madagas- the interior (Milne-Edwards and Grandidier, 1876-81; Hartlaub, 1877, and many car others); and it is probably a resident in the island.

The last distributional area of the Fulvous Tree Duck is India. In the peninsula it appears to be nowhere a common bird, and is especially rare south of the twentieth parallel of north latitude. It is India in the Punjab and Rajputana, as well as in the Northwest Provinces (Hume and Marrare but breeds in Sind (Barnes, 1891; Hume and Marshall, 1879; Blanford, 1898), rare shall, 1879). It is also rare in Cutch and the Bombay Presidency, and eastward through central Western India; though it occurs in the Central Provinces during the monsoon and breeds at India Rungpur, Nadia and Sangor (Hume and Marshall, 1879; Baker, 1908). Jerdon (1864) says it is common in parts of the Deccan, as in the northwest of the Nizam's dominions, but BlanCentral ford (1898) is probably more nearly correct when he speaks of the species as rare in India Madras and the Deccan. Sherman's statement (Hume and Marshall, 1879) that it is common in Travancore is generally regarded as erroneous. For a long time its occurrence in Ceylon was much questioned, but it now seems to be well supported by the evidence of Horsbrugh Southern (1912), who says that he often shot it on the island; and especially by the statement of India Wait (1917) who reports a few specimens taken near Mannar, and says it should be looked for on the north coast of the island. Parker (Stray Feathers, vol. 9, p. 487, 1881) also recorded Ceylon it from Ceylon. But the chief resort of the species in India is the Ganges Valley, and Bengal. Hume and Marshall (1879) state that it is not uncommon during the rains in parts of Rohilkhand, Oudh, Gorakhpur and Basti, but Jesse (1903) says it is not resident near Lucknow. It occurs in Nepal (Hodgson, British Museum) and is fairly common on the Ganges below Northern Purneah (Hume and Marshall, 1879). Baker (1908) says that it is common in parts India of eastern Bengal and in Jessore. Farther east it has in late years been found in Assam, and on the Brahmaputra (Baker, 1908) and undoubtedly occurs in Upper Burma. E. W. Oates (1883) Northeast states that it is common in Upper Pegu, and occurs in Lower Pegu; while Ramsay India (fide Hume and Marshall, 1879) found it less common on the Tonghoo side of the PeguBurma Yoma. According to Rippon (1901) it occurs also in the South Shan States, and Hume and Marshall (1879) are probably correct in thinking it may occur in Siam, meaning presumably northwestern Siam or West Laos. See also Gyldenstolpe (1920).

Mrgration: There is not much evidence of migratory movements of this species in India; the birds apparently breed in the northern sections and most of them stay there for the winter. Its rarity in the southern districts is, I believe, to be attributed to the fact that only a small number change their habitat for the winter. In general such birds as do migrate, start late in the spring, in March or April, and do not leave their breeding areas until November. This is to be explained by the fact that the species breeds very late in the season.

\section{GENERAL HABITS}

THw Fulvous Tree Duck inhabits climates and countries so varied that it is difficult to sum up in a few words the nature of its haunts. In general it is almost entirely a fresh-water species and occupies the same type of country as Dendrocygna viduata and Dendrocygna discolor - fresh-water ponds and lakes in the coast regions of the Guianas (F. P. and A. P. Penard, 1908-10), and in the Argentine, the great overflow regions of the pampas. It appears to be almost entirely absent from the heavy tropical forests of the Amazons basin. In India it is confined to the very humid districts (Hume and Marshall, 1879). 




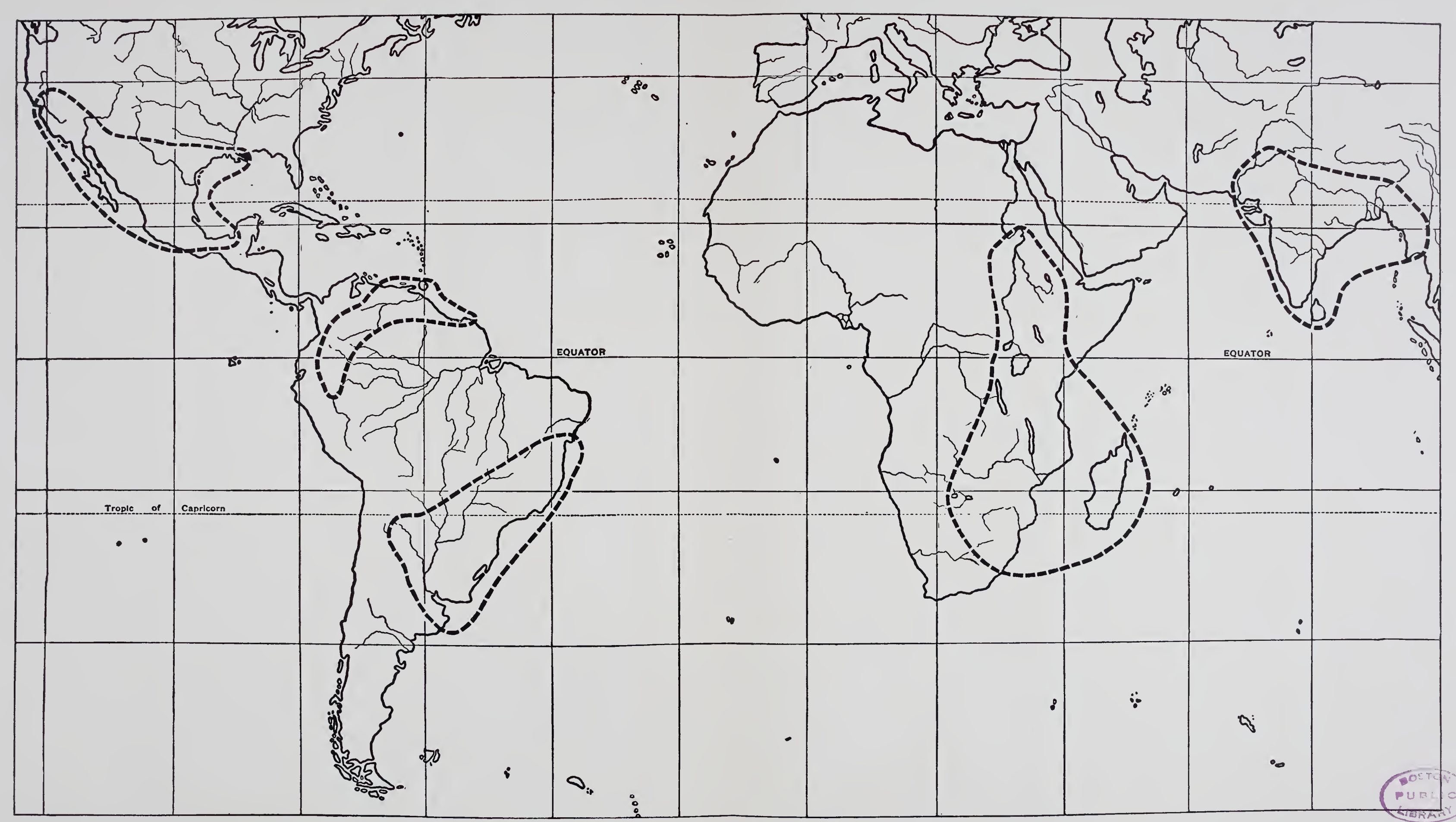

MAP 12. Distribution of Fulvous Tree Duck (Dendrocygna bicolor) 

WARINess. These birds like other Tree Ducks are comparatively tame and easy to shoot. But in northeast Africa they are more shy than the White-faced (von Heuglin, 1873), and in India several writers have noted their wildness as compared with the smaller Whistling Teal (Dendrocygna javanica). Hume and Marshall (1879) state that instead of rising at once when the first shot is fired they keep rising in ones and twos, thus affording numerous good, though all rather long, shots. In California they are said to be easily approached, though hard to find (Grinnell, Bryant and Storer, 1918). There are numerous other collectors and hunters who have found these birds tame in comparison with migratory ducks. In the Argentine, a recent writer, Gibson (1920), found them decidedly stupid birds.

DatLy Movements. These birds are remarkable for their nocturnal habits. In some places they are scarcely seen at all in the daytime and they certainly do almost all their feeding by night. In many places in the literature one finds references to their great activity at night, and the loud "whistling" or "cackling" of the flocks as they pass over. In California Grinnell, Bryant and Storer (1918) testify to their feeding chiefly by night, while in Africa von Heuglin (1873), found them spending almost the entire day in inaccessible thickets. In India we are told that they are often seen resting during the heat of the day on the grass-covered spits of land which run out into the larger jheels (Baker, 1908). Possibly these nocturnal habits may help to explain the rather tame and gentle nature of the Tree Ducks; for night-feeding species are apt to be less alert by day than other birds.

Fuight. On the wing the birds are strong and goose-like in their method of progression, the wing-beats less rapid than in the true ducks. Hume and Marshall (1879) say that, compared to their smaller cousins (Dendrocygna javanica of India) their flight is stronger and more rapid. They rise reluctantly, not in flocks, but in solid blocks and with great clamor (Gibson, 1920). Apparently the flocks are not orderly in their conformation, being described by P. L. Sclater and Hudson (1889) as not long trains or phalanxes like other ducks, but "clouds." Like the preceding species they are apt to congregate in enormous numbers, and five hundred or more have been noted in one flock. On the wing they are not good-looking, the head and neck seem to droop, and the tail and feet are similarly deflected below the level of the back, producing the effect of a ponderous and labored flight, totally distinct from that of other Anatidae (Gibson, 1920).

In India and Africa the species seems not to be anything like as abundant as in South America. In India it occurs only in small flocks, and can scarcely be called plentiful. A congregation of one hundred is considered an unusual number, the ordinary flock consisting of only about a dozen to fifteen birds (Hume and Marshall, 1879; Baker, 1908; Finn, 1915; etc.). In Africa, von Heuglin describes it as occur- 
ring in fairly large flocks in Kordofan, but others, like Sjöstedt (1910), never met with large flocks. Judging from the restricted number of references in the literature on African ornithology one is forced to the conclusion that it is, in general, an uncommon bird on that continent.

GaIT. On the ground, like its congeners, this species assumes an upright position, and progresses with an easy anserine walk. It spends much of its time walking and standing on the shore of a pond, as any one visiting a zoölogical garden may note. This habit has probably resulted from the fact that, like other tropical ducks, it is unable to remain long upon the surface of the water, because of the presence of crocodiles. When out of the water they crowd together, and if disturbed stand up, craning their necks and looking strangely tall on their long, blue legs (P. L. Sclater and Hudson, 1889). When winged they escape by running and springing with extraordinary agility (Lawrence, 1874).

Perching. It is very difficult to make a definite statement as to how much time these birds spend in trees. No doubt the character of the country has much to do with the practice of the birds in this matter, for Hume and Marshall (1879) report them perching a good deal in India, while Baker's (1908) observations are to the contrary. Horsbrugh (1912) speaks of their perching freely in Africa, but then again in Venezuela the birds are said not to frequent the trees at all (André, 1904). In the Valle de Mexico they perch, and as a matter of fact chiefly on thin branches (Herrera, 1881). In California, where they appear for the nesting season, they are almost entirely birds of the tule swamps and irrigated, overflow lands.

Swimumg and Diving. Having never watched these birds, except in confinement, I cannot say whether any of their food is procured by diving. I never saw my pinioned specimens dive, nor did they spend much time upon the water. Observers have described them as diving well (Lawrence, 1874; Finn, 1915), but this no doubt refers more to cases of crippled birds attempting to escape than to normal feeding habits. There is every indication that the Tree Ducks as a group are to be considered as surface-feeders and grazers only, although they are known to procure food by other methods, even resorting to trees to obtain fruit. I have never myself observed either this, or the preceding species, tipping up in the water like Mallards or Teal. When wounded, however, they are extremely agile divers, coming to the surface with only the head above water, like a grebe (Lawrence, 1874).

Association with other Species. The writers on India do not say whether the Fulvous and the Lesser Whistling Teal associate, hence one must assume that they do not. Occasionally in Africa flocks of Dendrocygna bicolor are found mixed with 
flocks of Dendrocygna viduata (von Heuglin, 1873). A. L. Butler (1905) shot one Fulvous from a flock of White-faces. On ornamental waters one sees the TreeDucks dotted about the margin, but the different species usually form separate groups. In the discussion of the nesting habits of these birds mention will be made of a very interesting habit of depositing the eggs in the nests of other species of ducks.

Voice. To one who has seen Fulvous Tree Ducks only pinioned and in parks, they appear to be extremely silent birds, and this trait is also found in the wild birds. But when a flock rises there is a sudden ringing chorus of whistling voices (P. L. Sclater and Hudson, 1889). The flocking-calls are described as like "the crackling of rain upon a hot iron plate" (Gibson, 1920); as a long "squealing whistle" (F. M. Chapman, 1908); and as a "high, short-cut whistle" (von Heuglin, 1873). In one case (Holub and von Pelzeln, 1882), the note is spoken of as resembling that of the African Red-bill (Anas erythrorhyncha). Finn (1919) says the birds are able to modify their voices almost like singing birds, and that they can utter a whistling cackle or a subdued twitter. So far as is known both sexes have an identical note, though very possibly there is a slight divergence, because of the somewhat different structure of the trachea in the male and female (Heinroth, 1918).

Food. Hume and Marshall (1879) have given by far the most careful details as to the stomach-contents. They found that the bulk of the food consisted of rice, but that the birds were miscellaneous feeders, and consumed all kinds of aquatic seeds, bulbs, leaf-shoots, and buds, grass, and rush, as well as small shells, insects, worms, and larvæ; in one case even a tiny frog. Other authors, too, have noticed their habit of feeding on rice, either wild or cultivated, and on corn, not only in India (Finn, 1915), but also in Mexico (Lawrence, 1874) and presumably in Africa. A very remarkable and hardly credible statement is that of Herrera (1888) who claims in Mexico to have observed great quantities of decomposing remnants of fish under the trees where the birds were perching. Numbers of young were running about in this refuse and regaling themselves on what the adult birds had left. On the whole the species is vegetarian, subsisting chiefly on seeds of various kinds.

Courtship and Nesting. Throughout its entire range the nesting period of this species is distinctly later than that of most ducks. In California, where they do not ordinarily arrive before June 1, the young are not seen much before July 8 (Grinnell, Bryant and Storer, 1918). The earliest date seems to be that given by Barnhart (1901), who took a set on April 28, and others between May 5 and 14. Lawrence (1874) writes of having found young unable to fly, in northwestern Mexico, as late as November, and considers this as a second or third brood. Gibson's (1920) experiences show the laying period in Buenos Aires to be between November 19 and Feb- 
ruary 9. Hartert and Venturi (1909) speak of a ripe egg having been taken from a female on November 3, in northern Argentina. Immature birds were seen on the Shiré River in Portuguese East Africa in October (Hartert, 1898). In India they breed in most places in July and August; in Nadia, at the end of June, and in Rungpur principally in August, with a few in September.

There are very few minute observations as to display and the details of the nesting operations. Pinioned specimens are so inactive, and are so seldom disposed to breed, that there are almost no notes from the zoölogical gardens. Finn (1919) observed no marked display before the pairing act, but noted a postlude in which both parties executed a step-dance in the water, with one wing held aloft. It is true of the Tree Ducks as a whole that, so far as is known, they have no marked display beyond the reciprocal dipping and lifting of the head and neck, mentioned by Heinroth (1911).

The nest is by no means invariably placed in trees. In California it is almost exclusively on the ground, and so far as the evidence goes, the same is true of Mexico and the treeless regions of the Argentine. In the tropical portions of South America, in India, and probably in Africa the birds make use of trees, depositing their eggs in the abandoned nests of other birds, or occasionally in hollows. Baker (1908) found nests in India which he believes were constructed by the birds themselves; but I am by no means convinced that any of the ducks are capable of building large and elaborate nests in the branches of trees. Very instructive is Finn's (1915) remark that in India they occupy old nests, holes in trees, or suitable boughs, on which they make a nest of their own, and that as yet they have never been found nesting on the ground. The trees selected are usually small ones located on tiny islands in jheels, or overhanging the water. Baker (1908) says the nests are very roughly constructed of twigs, sticks, and grass, and in a few cases covered with a dirty mass of weeds. They average some eighteen inches across and are placed, not so often in forks, as on tangles of branches, or where the first big branches spread from the bole of a large tree. One nest was in the crown of a date palm, while in another section of the country, Rungpur, they were found selecting large trees, and building thirty feet or so from the ground. Careful observation to see how much actual nest construction is carried out would be extremely interesting in these cases.

Where they nest on the ground they choose either marshy localities or dry land. In the former case, in the Argentine, the nests were built in dense flag-beds, and constructed of dry flags. When in the grass, they were unlined and it is indeed doubtful whether the nests are ever really lined like those of true ducks (Gibson, 1920). Other authorities found nests made of stems and leaves, on the water among reeds (P. L. Sclater and Hudson, 1889). The best account of the nesting habits of these ducks in California is that of Shields (1899), who discovered many nests in a large tule swamp, where they were formed by breaking off the adjacent stalks. These nests were usually, but not always, well hidden, but as compared to the preceding species the Fulvous Ducks are evidently less careful about concealing the nests. 
The number of eggs found in the nests is extremely variable. In California and in the Argentine large numbers, up to twenty or thirty are not unusual; but in India the ordinary set seems to be from six to eight. Even when breeding the birds are sociably inclined, and many may be found nesting together "as in a gullery" (P. L. Sclater and Hudson, 1889). The most recent writer on the Argentine, however, speaks of thirteen as the largest clutch found (Gibson, 1920), and very probably the large colonies are a thing of the past. Although the usual clutch in California is from twelve to seventeen, huge aggregations in one nest have been frequently reported, the most remarkable being the record of sixty-two eggs found in Los Baños County, and placed on a pile of dead grass, about four inches above the water, without any attempt at nest-building or concealment (Barnhart, 1901). These great accumulations of eggs occurred when the species first began to occupy an irrigated district of California in large numbers, but they have not been found since that time. Shields (1899) found a nest with thirty-two eggs and others containing from seventeen to twenty-eight. These large clutches are deposited in several layers. Doubtless the females are very prolific at times, and it is extremely difficult to determine the exact limit of individual fertility. Several observers who found late broods in tropical regions, have taken this to be an indication that the birds nest more than once a season; but this is undoubtedly incorrect, for in warm regions the reproductive period is long-drawn-out, extremely irregular, and may extend through the entire year.

An important and very interesting find was made by Shields (1899), when he took three of these Tree Duck eggs from the nest of a Red-head, and one from a Ruddy Duck's nest, and afterward found other cases of this incipient parasitism.

The period of incubation is long, and is given by Heinroth (1908) as thirty-two days. It is not known whether the male ever takes part in the incubation. The eggs measure 50.3 to 55.8 by 34.3 to $41.8 \mathrm{~mm}$., and are elliptical-ovate in shape, ivory white in color, with surface texture rather rough (Grinnell, Bryant and Storer, 1918).

Status. There is very little in the literature bearing on the present status of this species. In California, where the bird is almost entirely migratory, recent irrigation systems had actually produced a temporary increase. Gibson (1920), recalling the incredible numbers seen during the floods of 1877 in the Buenos Aires region, says that huge masses covered the grasslands immediately bordering the swamps for hundreds of yards in length, with a depth of from five to twenty yards. He adds, however, "But where are the birds of 1877, which lined the shores of the cañadas in serried brown phalanxes, and permeated the whole atmosphere with brown sunmoats?" In that part of the world the birds are at least partly migratory, but very irregular in their appearance. In Africa, as has already been remarked, they are nowhere so plentiful as the White-face. This applies also to Madagascar. 
Enemies. On this point there is no special information, but these ducks, like other species, are exposed to the usual dangers from predaceous animals.

Damage. Our only information on this point is the fact that they feed commonly on rice in India (Hume and Marshall, 1879) and in the cornfields in Mexico (Lawrence, 1874). It is possible that, like their cousins, the Black-bellied Tree Ducks, they at times cause much damage.

Food Value. In all parts of their range the Fulvous Ducks are almost universally considered as a delicate food for the table. A notably divergent opinion is that of Horsbrugh (1912), who, writing of South Africa, refers to them as "rank and fishy." Baker (1908) has nothing much better to say about them., He tells of their being shot in India for servants and boatmen, and classes them among those birds which are made edible only by the use of curry and when served as a stew, or in a mulligatawney soup.

Hunting. In Bengal, Baker (1908) speaks of their being shot very little for sport, as they are not considered game. All hunters have found them easier to shoot than the true ducks, and less rapid on the wing. No doubt, as with other Tree Ducks, natives have made a practice of searching out nests, taking eggs and setting them under hens, or catching and rearing young birds before they are able to fly. In Madagascar Roch and Newton (1863) speak of numbers being "caught alive."

They respond to an imitation of their note, and, according to André (1904), a good whistle, to which the birds will return again and again, can be made out of a couple of brass gun-shells.

Gibson (1920) called them stupid birds, and related how he had drifted past them in a canoe, between the rushes and the banks where they were assembled, and did great execution "shooting into the brown" as they arose; or similarly stalking a flock, most of which were asleep. I do not know that they are anywhere shot commonly over wooden decoys.

Behavion in Captivity. These ducks are perhaps as commonly seen on ornamental waters and in parks as are the White-faced Tree Ducks. Like the latter they do well, and become tame, and as a rule uninteresting, because of their inactivity. They do breed at times. They are hardy, more so than Dendrocygna javanica, and bear the English climate out of doors, where javanica will die. They need no especial care in our New England winters, beyond housing with other water-fowl of the same size and strength.

The first examples reached the London Zoological Gardens in 1867, and according to Hubbard (1907) this is the only species of Tree Duck that ever bred there. The 
nesting occurred in 1872; and the birds were hatched on August 4 (P. L. Sclater, 1883). The nest was on the ground and was concealed by a dome formed by the long grass surrounding it. Two birds which were hatched, were unfortunately killed by rats (P. L. Sclater, Proc. Zool. Soc. London, 1880, p. 510).

It has been bred at Woburn Abbey, on the estate of the Duke of Bedford (Avic. Mag., new ser., vol. 6, p. 306, 1908) where both Dendrocygna autumnalis and Dendrocygna discolor have also hatched out broods. It was kept there in a free-flying state for several years according to what Mr. F. E. Blaauw told me. It was said never to have bred in the Paris Gardens (de Montlezun, 1889). This duck is also said to have been bred by Mr. Henry Cook, of Woodbury, Long Island, New York (Job, 1915).

Finn (1915) says that they fight much in captivity, striking out with their feet and springing out of the water; but I have never seen them quarrel.

The price varied from $£ 310 s$. to $£ 5$ a pair in England, and the New York Zoölogical Society used to pay about $\$ 6.00$ each. The price to individual fanciers was of course a little more, and varied with the time of the year. They were selling in New York in June, 1920, for $\$ 17.00$ per pair.

In confinement they have been known to live for at least thirteen years (P. L. Sclater, 1883) and very likely that is by no means the limit.

There is no true domestication of the species. Like other Tree Ducks they are often reared from wild-caught young or wild-gathered eggs hatched under hens. They are kept by natives both because of their value as food and for use as pets. Very likely the natives also value them for their usefulness in sounding an alarm at the approach of strangers. 


\title{
WANDERING TREE DUCK
}

\author{
DENDROCYGNA ARCUATA (HORSFIELD)
}

(Plate 12)

\section{SYNONYMY}

Anas arcuata Horsfield, Zoological Researches in Java, pl. 62 and text, 1822.

Dendrocygna arcuata Swainson, Classif. Birds, vol. 2, p. 365, 1837.

Dendrocygna vagans Eyton, MS.; Fraser, Zool. Typ., pl. 68, 1849.

Dendrocygna javanica peroni Malhews, Austral Avian Record, vol. 1, p. 86, 1912.

Dendrocygna javanica gouldi Mathews, Novitates Zoöl., vol. 18, p. 237, 1912.

Dendrocygna javanica australis Mathews, Birds of Australia, vol. 4, pt. 1, p. 62, 1914.

Note: Oberholser (Proc. Biol. Soc. Washington, vol. 34, p. 166, 1921) has recently advocated the use of Fraser's name, Dendrocygna vagans, for this species instead of Horsfield's Anas arcuata, on the ground that the latter having been admittedly proposed as a substitute for Anas javanica is thus a pure synonym of it. An examination of Horsfield's excellent colored plate, however, shows conclusively that the bird to which he applies the name arcuata was not the species with unspotted breast to which javanica really pertains, but is after all the distinct species with crescentic markings on the breast feathers, for which therefore the name arcuata must continue to be used.

\section{Vernacular Names}

English:

Whistling Teal

Wandering Tree Duck

Black-spotted Tree Duck

Whistling Tree Duck

French:

Dendrocygne de l'Inde

German:

Bogenente

Indische or Celebes Ente
Spanish (Philippines):

Balinio - (Luzon)

Naga - (Ticao)

Gakit - (Bohol)

Java:

Meliwies

Meliwis kembang

Aborigines of Australia:

En-jep-ere

Chipala

\section{DESCRIPTION}

Adulr MaLE: Whole top of head and broad line down dorsal surface of neck black. Rest of head pale fulvous, lighter on chin and throat. Mantle and scapulars black, the feathers broadly tipped with golden brown. The feathers of the mantle are sometimes only barred with black. Rump black, central upper tail-coverts black but lateral ones white or spotted. Lower parts light chestnut, the breast more or less barred with black. Under tail-coverts whitish. The flank feathers are of the ornamented type seen in Eyton's Tree Duck and are broadly streaked with white, black and rufous. Lesser and median wing-coverts rich chestnut. Primaries black.

Bill black; legs and feet ashy gray. Iris brown.

Wing 186 mm.; bill 44; tarsus 50. 
Adult Female: Similar, but slightly smaller.

Young in First Plumage: Somewhat resembles the adult, but the mantle and scapulars are darker and lack the broad pale edges to the feathers, so that these regions have a more uniform appearance. The lower surface at first lacks the red color and is pale grayish or light fawn. The tail is nearly black. The wing-coverts have only a little chestnut on the lesser series.

Young IN Down: Not examined.

\section{DISTRIBUTION}

THE present species is practically confined to the East Indies and Australia, and very little is known as to its breeding and wintering localities. From what dates we at present possess, it appears that the species is not migratory to any extent, and that its breeding is controlled by the amount and distribution of the rainfall. In the Philippines the species is common in Philippines favorable localities throughout the islands and is frequently met with in large flocks (Worcester and Bourns, 1898). From R. C. McGregor's Manual (1909), in which all Philippine records are collected, it appears that the species is found from the extreme north on Camiguin southward through Luzon (Cuming, British Museum; Worcester and Bourns, 1898; R. C. McGregor, 1909; and others), Catanduanes (Ogilvie-Grant, 1895), Mindoro (Worcester and Bourns, 1898; R. C. McGregor, 1909), Ticao (R. C. McGregor, 1909), Sibuyan (R. C. McGregor, 1909), Masbate (Worcester and Bourns, 1898), Samar (Steere, 1890; Ogilvie-Grant, 1897), Negros (Clarke, fide R. C. McGregor, 1909), Panay (Worcester and Bourns, 1898), Bantayan (R. C. McGregor, 1909), Leyte (Everett, 1877-78), Guimaras (Steere, 1890), Cebu (Everett, 1877-78), Bopol (Everett, 1877-78; R. C. McGregor, 1909), Sequijor (Steere, 1890; Worcester and Bourns, 1898) and Mindanao (Everett, 1877-78; Worcester and Bourns, 1898) and apparently it nests also at Laguna de Bay (R. C. McGregor, 1909).

It is difficult to say how widely this species is distributed in Borneo. About all the records I have been able to find are for the southeastern part of the island, where it appears to be very common at Bangkau (Grabowsky, 1885) and at Banjermassing (W. Blasius, 1884; Mottley, 1863;

Vorderman, 1887). Snelleman (1887) records the species as common at Solok and

Borneo especially at Alahan Pandjang, near Danau di Atas, Sumatra. Hartert (1902) states on the authority of Hagen that the birds are very common in the island, but these statements are not yet sufficiently proved. Very probably Dendrocygna javanica is the bird meant (see also Robinson and Kloss, Journ. Federated Malay States Mus., vol. 8, p. 118, 1918). At any rate the species is probably found only in the southeast part of the island. In Java it appears to be common, especially on the coasts about Batavia (Vorderman, 1884; Koningsberger, 1915; Wallace, Leyden Java Museum). It has also been recorded from the islands of Bali (Stresemann, Novit. Zoölogicæ, vol. 20, p. 333, 1913) and Sumba (Hartert, 1896). It also seems to be common throughout Celebes from Minahassa and Tondano in the northeast, southward along the Gulf of Tomini at Gorontalo, Pagoneat and Limbotto, at Lura Lake and in the southwest at Macassar Celebes (Meyer, 1879; W. Blasius, 1886; Forsten, Leyden Museum; von Rosenberg, Leyden Museum). According to Meyer and Wiglesworth (1898) the species is resident on Celebes, and was found breeding at Paquatt on the Gulf of Tomini by von Rosenberg.

From the Moluccas the species has been recorded only from Amboina (Finsch, Neu Guinea, p. 183, 1865). It has also been found in East Timor (Wallace, British Museum). In New Guinea it appears to be unknown from the Dutch possessions though it has been found in Kaiser-Wilhelm's Land (Meyer, 1894) and seems to be quite abundant in British New Guinea, where it has been taken on the Fly River and at Bioto (d'Albertis, fide Moluccas New Guinea Salvadori, 1882), on the Laloki River (Goldie, fide Salvadori, 1882; Sharpe, 1877) and at Port Moresby (Ramsay, 1879). Far eastern records for the species are those of Marie (1877) and of the Layards (1882) 
for New Caledonia and of Rayner ( fide Wiglesworth, 1891) and E. L. Layard (1876) for the Fiji Islands.

It occurs and breeds in Australia, excepting in the southern part, though it is probably confined chiefly to the neighborhood of the coasts. In the northwest it was found common on the Fitzroy Australia River (North, 1898; Söderberg, 1919), in Meda (Hartert, 1905) and farther north on the South Alligator River (Hartert, 1905) and at Port Essington (Gould, 1865), at all of which places it seems to be common. It was also found in West Australia at Derby (Ramsay, 1888). In the north it is recorded from Port Darwin, Gulf of Carpentaria, and Cape York (Ramsay, 1888), and on the whole it seems to be most common in the North Territory of South Australia (North, 1913). Eylmann (1911) found it in the interior of this territory.

The species appears to be well represented also in Queensland at Rockingham Bay, Port Denison and Wide Bay (Ramsay, 1888) while it has been found breeding at Redcliff, Upper Dawson River, Queens- and at Coomooboolaroo, Duaringa (North, 1913). Robinson and Laverock (1900) land say it is common at Cooktown. According to North (1913) it is found chiefly on the northern coasts in New South Wales, though Ramsay (1888) has reported it for the interior, and Hall New South (1909) found it on the Murray River. Cox and Hamilton (Proc. Linn. Soc. New South Wales Wales, ser. 2, vol. 4, p. 422, 1890) state that it is rare at Mudgee, in the interior. It Victoria has also been found on the Richmond and Clarence Rivers (Ramsay, 1888), and rarely in Victoria (Mathews, 1914-15). In an old paper Ramsay (1876) even gave Tasmania as its habitat, though this was probably by error.

There is one record of this species occurring at Aigues Mortes, Dept. Gard, south France, March 30,1909 , by Menegaux (1909). It cannot have been anything but an escaped bird, though this well-

France known writer says none was missed from zoölogical gardens, and he is inclined to think it was driven by a storm.

\section{GENERAL HABITS}

Haunts. Very little is known of the life-history of these Tree Ducks. Mathews (1914-15) confesses that their habits in Australia are practically unknown. All species of Tree Ducks are more or less alike in so far as they are nocturnal and inhabit fresh-water swamps or lagoons, coming to the coast only in times of drought.

WARINESS. In northwestern Australia these birds were found to be exceedingly tame, permitting an approach to within thirty or forty yards before they moved. They then stood up and gathered closely together, their bodies and heads erect, affording a target that made it possible to bring down many at one shot (Keartland, fide North, 1913). Evidently, then, under primitive conditions they were extremely tame. Such appears to be the case also in the Philippines, for R. C. McGregor (1909) found that they could be killed without taking the precautions usually necessary in duck-shooting, and Whitehead (Ibis, ser. 7, vol. 5, p. 501, 1899), while hunting on Samar, had them rise time and again within thirty yards of his gun. The birds appear to be rather trusting in New Guinea, also (Meyer, 1894), but in southeast Borneo, where they have been systematically trapped by the natives, they are said to be very wild and difficult to shoot (Sclater, Proc. Zool. Soc. London, 1863, p. 224). According to Robinson and Laverock (1900) the birds are very shy and quick on the wing in North Queensland. 


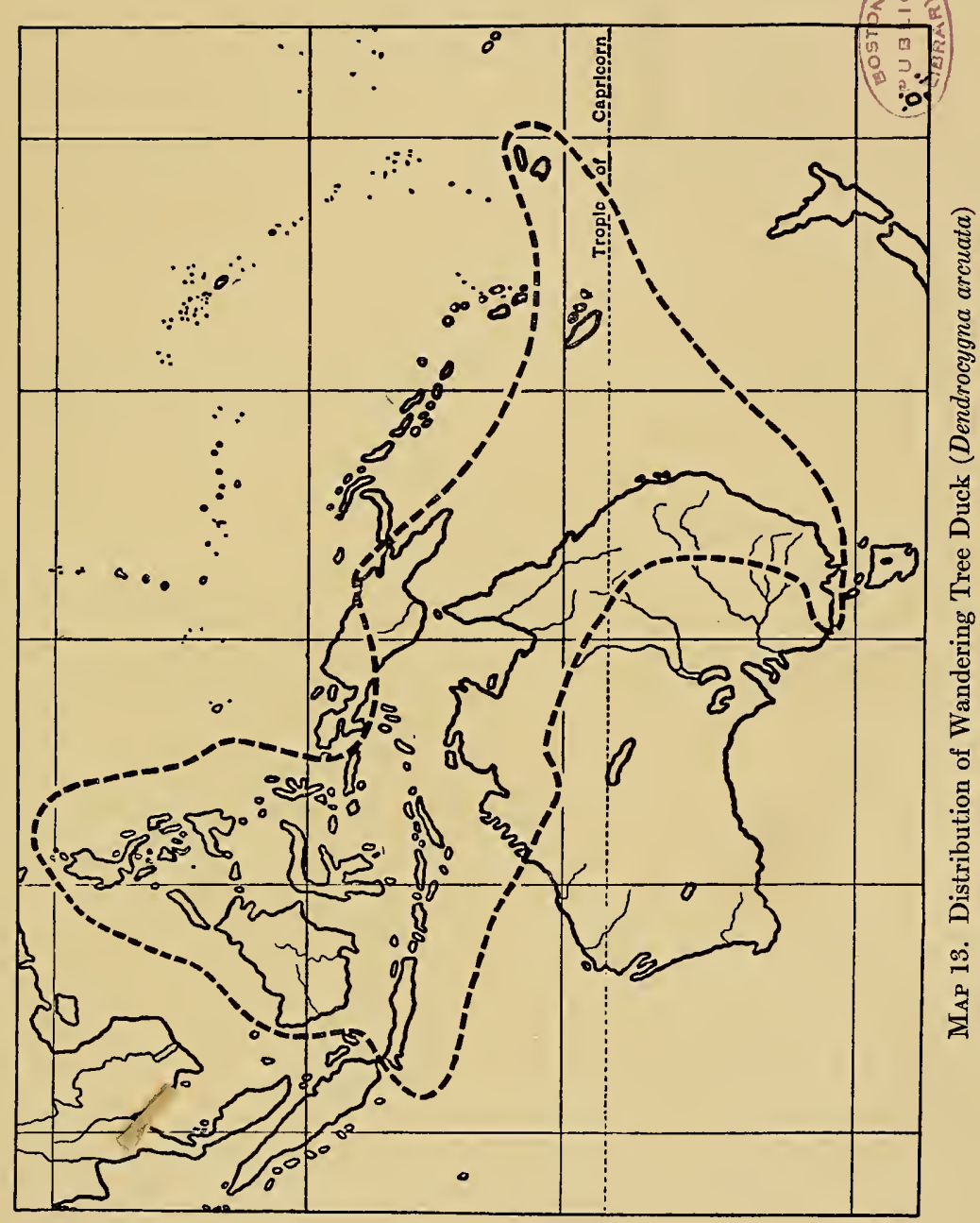



DaILY Movements. Undoubtedly nocturnal in habits, the Wandering Tree Ducks spend the heat of the day in shady places, and at evening fly to their feeding grounds. In North Queensland they come to the coast at night, returning inland at daylight (Robinson and Laverock, 1900). Their whistling notes, heard as they fly about at night are familiar to many naturalists. In the northern parts of Australia they are described by Keartland (North, 1913) as flying "inland on the Mitchellgrass or Flinders-grass Plains to feed, but towards daybreak they frequent the rivers or lagoons for a bath and a drink, and then cluster on the shady side of any thick bushes to sleep through the day, only moving when disturbed, or to escape the sun."

FLIGHT. On the wing they are described by Whitehead (Ibis, ser. 7, vol. 5, p. 501, 1899) as using their wings - which appear large for a duck - like a heron, but more quickly. There is no reason to suppose that the flight differs from that of other Tree Ducks. But both this species and the Indian Whistling Teal are said by Heinroth (1918) to have a peculiar projection on the inner web of the most external primary, which gives rise to a loud whistle during flight; but this unusual feather is not so well developed in Dendrocygna arcuata as in Dendrocygna javanica. As a matter of fact the primary in this species is simply notched, leaving two prominent projections, but there is no "thumb" as in Dendrocygna javanica.

Like their congeners, they sometimes assemble in very considerable companies. From Rockhampton large flocks have been recorded (Ramsay, 1876). At Port Essington, Gould (1865) found vast flocks from September to December. Grabowsky (1885) speaks of flocks numbering ten to fifty in southeastern Borneo, and in the Philippines it is frequently met with in large companies (R. C. McGregor, 1909). The largest flock referred to in the literature is one of three hundred, seen at Barramine Station in Australia (North, 1913).

GAIT. Rogeron (1903) speaking of his captive birds, described them as having a more horizontal posture than other Tree Ducks, with the back somewhat curved. But he says nothing about the gait, nor have I been able to obtain any special information on this point from any source.

Swimming and Diving. The species is a grass-feeder, is gooselike in its habits, and is therefore more active on land than on water. Grabowsky (1885) describes it as an expert diver, probably referring to its ability to escape when wounded. Finn (1909) states that they dive for food in the London Zoological Gardens, but several species, which never dive in the wild state, have been known to do so when pinioned in enclosures and consequently Finn's remarks are not conclusive. Nevertheless, Heinroth (1918) goes so far as to say that all species (of Tree Ducks) seem to get nourishment "chiefly" by diving. 
In spite of its being a grazing bird, it seems to be, if one may judge from Rogeron's remarks, more fond of the water than Dendrocygna viduata or Dendrocygna autumnalis, and spends at least a part of its time on that element.

Percurna. On this point also, our information is very meager. This species probably perches no more than do the other Tree Ducks, though Hall (Emu, vol. 9, p. 78, 1909) says he used to see them perching on the dead limbs of gum trees along the Murray River. Doubtless they seek the shelter of trees either to roost or to nest, or only when there is some definite necessity.

Association with other Species. Although in Australia they apparently feed in company with other ducks, at the approach of man or at the report of a gun they are said, on rising, to separate from the others, and form into a distinct flock (Gould, 1865). Keartland (North, 1913) recalls having shot numbers of Dendrocygna eytoni and Dendrocygna arcuata at one shot, and it is certainly true that wherever more than one species of Dendrocygna occur, they are usually found closely associated. Even in confinement it was noticed to prefer the company of its congeners to that of other ducks (Rogeron, 1903).

Vorce. Like other Tree Ducks this species is silent except on the wing, when it emits a note described by various writers as a "peculiar whistle." So far as is known, the note is the same in both sexes. Rogeron's (1903) tame birds emitted what he describes as a twittering note, which is probably quite different from the flockingcall heard in the field.

Heinroth (1911) describes the voice of all Tree Ducks as a peculiar "twittering whistle." As has been remarked before, this genus represents the beginning stage in the development of the peculiar syringeal box which reaches its highest stage in the bulla ossea of the male in the true ducks. In the male of Dendrocygna arcuata the last twelve tracheal rings are widened and enclose a spacious chamber about twice the diameter of the rest of the trachea. In the female eleven of the tracheal rings are imperfect posteriorly, being closed by a membrane, forming a modified region in the trachea (Beddard, 1898). This very possibly may result in a slight difference in the notes of the sexes, a difference which, however, it would be very difficult to determine, on account of the similarity in plumage and size between the male and the female.

Foov. Described as being primarily grass-feeders, they may, occasionally, procure fish, as noted by Gould (1865). In northwest Australia it was found to have native millet seed, grass-seed, and grit in the crop (Mathews, Emu, vol. 10, p. 106, 1910). 
Courtship and Nesting. There is no definite period of the year for the breeding cycle, which depends largely on the onset of the rains. In Australia they usually nest from December to March (Ramsay, 1876), but nests and eggs have been taken as early as November and as late as May (North, 1913). In Celebes a nestling was taken on July 29 and in the Philippines the species was found nesting in February, and a hard-shelled egg was taken from a bird in January (R. C. McGregor, 1909). In the British Museum there is an egg collected in the Philippines in May (E. W. Oates, 1902), and von Rosenberg took a young one in down in Celebes in July (Meyer and Wiglesworth, 1898).

There is no information about the display of the sexes, beyond what has already been given as characterizing the group as a whole. The nests themselves are very hard to find, and undoubtedly are usually well hidden in open grass country, or in thick reeds. Even in Australia, where the bird is so common, both Campbell (1901) and North (1913) base their accounts on the same clutch of eggs, as Mathews (191415) has aptly remarked. Keartland (North, 1913) found them breeding among the spinifex or coarse grass in northern Australia. If one is to judge from the meager information at hand, it appears that the nest is made in the grass, without any lining of feathers or down. The birds may at times breed in the holes of trees or on branches, in the tropics. Ramsay (1879) reports it following this practice in New Guinea. The eggs number twelve or thirteen (Kilgour, Emu, vol. 4, p. 38, 1904) and Barnard (North, 1913) found a clutch of fifteen. So few nests have been recorded that it is impossible to state with any degree of certainty the number of the average clutch. The eggs are of a creamy-white color and vary in size from 47.4 to $52 \mathrm{~mm}$. by 35.5 to $38 \mathrm{~mm}$. (E.W. Oates, 1902). As to the incubation period nothing is known, but it is undoubtedly longer than that of true ducks. (See information on other species.)

The male may take part in incubation as it sometimes does in the case of Dendrocygna viduata and Dendrocygna discolor.

Status. In Australia this species, like all water-fowl except the Black Duck, has suffered much from the advancing settlements. North (1913) speaks of having bought specimens in the Sydney markets in 1888, but mournfully remarks that he has seen none of these ducks in the poulterers' shops for a number of years past. In the Murray River district, where it was very plentiful thirty years ago, an observer has noted only one flock in the eight or nine years preceding 1909 (Hall, Emu, vol. 9, p. 78, 1909). But the species is still abundant in the more tropical and inaccessible portions of its range, although Ramsay (1879) found it less plentiful than Dendrocygna guttulata, even in New Guinea.

Governor Cameron Forbes tells me that he met with it in almost incredible numbers in the interior lakes of the Philippines, where huge bags were easily made with only a few discharges of his gun. These islands are perhaps the chief center of abundance. 
The future of all the water-fowl of Australia is very uncertain, especially of the less wary kinds, as I am informed by various letters from Australian bird-lovers, and this species, as well as all the more interesting of the ducks, is doubtless disappearing at the present time.

Enemies. Nothing especial recorded.

Damage to Crops. No information.

Food Valde. Reported as excellent table birds by several observers (Sclater, 1863; Grabowsky, 1885; and others).

Hunt. No particular information is at hand, and one would doubtless have to refer to local sportsmen's periodicals from Australia to gather information on this subject. According to Horsfield (1824) it was a favorite object of pursuit in Java a hundred years ago.

Behavior in Captivity. This Tree Duck has not been kept so commonly in collections as have Dendrocygna viduata, D. autumnalis, and D. bicolor, and is not even mentioned by Finn in his book, Fancy Water-fowl, published in 1900.

It was not present in the Zoological Society's Gardens in London in 1883 and there was only one specimen there in 1896. Finn (London Field, January 9, 1915) mentions several there at that date. It has been on exhibition in the Berlin Gardens, but like all the other Tree Ducks has never bred there (Heinroth, 1911).

In a letter to me, January 23, 1920, Mr. Hugh Wormald, the well-known and successful English breeder of water-fowl, does not mention this species as ever having been kept by himself. Nevertheless, it has seemingly been kept and also bred in private parks in England, for Heinroth (1911) mentions seeing two pairs of this Tree Duck leading downy young on the estate of the Duke of Bedford. In a letter to me of April 16, 1920, Mr. D. LeSouef, Director of the Zoölogical Grardens of Melbourne, Australia, informs me that Dendrocygna arcuata has been kept there, but has never bred. Mr. F. E. Blaauw writes that he has never kept it and knows of no authentic instance of its having bred in captivity, so that perhaps Heinroth's note refers to one of the other Tree Ducks.

Rogeron (1903) kept a pair of these birds for four or five years and has something interesting to say about them, but they never bred in his ponds, nor did they ever actually mate, according to his observations.

He describes them as very gentle and familiar in their habits, coming to him for food with a "twittering" refrain. Not so alert as other ducks, he had to take pains that they received their proper share of food. During the first two winters, which 
were not very cold, they remained out of doors without harm, but the third winter, which was severe for France, they suffered greatly, the female even taking shelter in a Mandarin box. The male withstood the winter, but the female died as the result of exposure. The birds were not left out on purpose, but because it was impossible to catch them.

The price is said at times to have been very low, for Hubbard (1907) reports a consignment which reached Marseilles and sold as low as five shillings a pair. I do not feel certain, however, that she is referring to this species, as she quotes Hume and Marshall on its habits in India!

The New York Zoölogical Society has purchased them for $\$ 8.00$ each.

It seems that they live to a considerable age. In the list of the Vertebrated Animals living in the Gardens of the Zoological Society of London in $\mathbf{1 8 9 6}$ there was a record of a specimen eight years old. Among Mr. Ned Hollister's records at the National Zoölogical Park in Washington are the dates of death of five individuals which arrived on September 25, 1903. They lived in the gardens as follows: ten years and six months; twelve years, one month; twelve years, four months; fifteen years; and fifteen years, three months.

They were at one time exported by natives from southeastern Borneo to Java (Grabowsky, 1885). They are said by Mottley (1863) writing of Banjermassing, to be taken when young in Borneo, to become very tame and to breed in confinement! This appears very unlikely in view of the fact that the most expert bird fanciers have found them breeding only very rarely The same writer remarks that they freely associate with other poultry, but become exceedingly pugnacious and tyrannical, even over geese! 


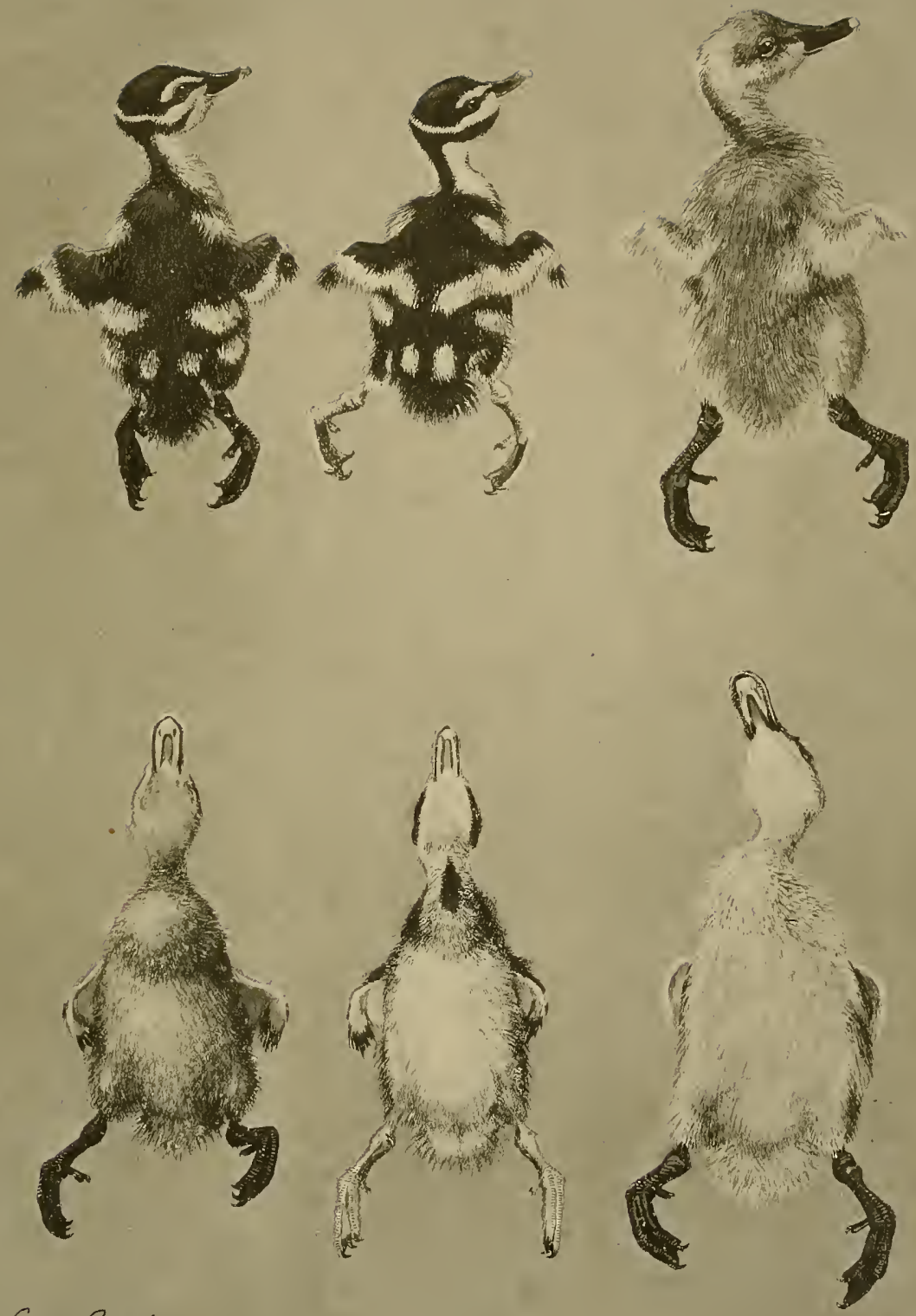

Auanßrooks.

DOWNY YOUNG OF TREE DUCKS 

ImMature: When just able to fly they do not differ very much from the adult, but are everywhere duller colored. The margins to the feathers of the interscapular region are inconspicuous and dingy fulvous, and the entire lower surface is a rather pale, dull, fulvous brown (Hume and Marshall, 1879). Young at a still earlier stage have the pileum almost black, and the mantle and scapulars uniform dark slaty brown. Lower parts uniform pinkish buff.

Young IN Down (specimen Port Blair, Andamans, Fleming Collection): General color dark brownish above and ash-color below, with the pileum black. From the culmen over the eye is a light band, while below this, running through the eye, and coalescing with the pileum patch is a broad blackish streak. Under this the cheeks are white and a white band runs around the back of the head, isolating the pileum patch as in other Tree Ducks. A black streak runs from the angle of the jaw around the back of the head posterior to the lighter streak, forming a very marked bridle pattern. There are white areas on scapulars, wings, sides of back and sides of rump, these patches being more prominent than in the true ducks.

\section{DISTRIBUTION}

The Javanese or Lesser Whistling Duck (for Teal is of course a misnomer) is a resident species and migrates only in so far as seasonal conditions require. It is confined almost entirely to India, the Burmese countries, the Malay Peninsula, and a few of the East Indian islands. In India, it is a very common bird and breeds everywhere in suitable localities. It is, however, rare in the Punjab and in Rajputana, and is not known to occur in Kashmir or the Himalayas, at least not west of Nepal (Hume and Marshall, 1879; Baker, 1908; Finn, 1909; Hodgson, 1844). On the whole it appears to be most abundant on the Lower Ganges. It has never been recorded from the countries west of the Indus, though it is found in Sind (Hume and Marshall, 1879; etc.). In Ceylon it is the commonest of all ducks, and it regularly nests on the island (Legge, 1880; Parker, 1883; Wait, 1917).

Eastward it seems to be common everywhere in Burma, the Shan States and at least in parts of Siam, but I find no records for Tonkin, Yunnan, or Laos, though it occurs in Cochin-China. Hume and Marshall (1879) state that it is common in Burma, and this statement is reaffirmed by E. W. Oates (1883) as well as by Blanford (1898). Salvadori (1887) has recorded it

Burma for Bhamo and Tienzo. It is a very common bird in Arakan (Hopwood, 1912; Baker, 1908) and in Pegu (E. W. Oates, 1883). According to Rippon (1901) it is abundant in the South Shan States, and the same is true of Tenasserim (Hume and Marshall, 1879). From Siam it has been recorded as common on the Menam and Chas Phaya Rivers, and south of Bangkok (Gyldenstolpe, 1913 and 1920), and as very abundant on the larger swamps of the north and central Siam parts (Gyldenstolpe, 1916). Gairdner (1914) has recorded it as very plentiful and probably resident in the Ratburi and Petchaburi Districts, west of Bangkok. The species is found also Andaman on the Andamans (Osmaston, Journ. Bombay Nat. Hist. Soc., vol. 17, p. 491, 1907), Isles and is common on the Nicobars (Hume, Stray Feathers, vol. 2, p. 315, 1874; Kloss, 1903). The British Museum has a specimen from Cochin-China, and both E. W. Oates (1883) and CochinBlanford (1898) state that it is found there. In the northern parts of the Malay Penin- China sula it is common about Tarang and in Langkawa, and has been taken also at Nong-Kok, Ghirbi, though in the southern sections it is less frequently met with, and in the Federated Malayan Malay States it is positively rare, except on the Perak and Pahang Rivers, where it is Region common (Robinson and Kloss, 1911; Kelham, 1882). It has been found also on Salanga Island (Mueller, Journ. f. Ornith., vol. 33, p. 162, 1885), and Bonhote (1901) has recorded it for the Malay Peninsula as occurring at Tale Nowy, Patelung, and in Tremangam. It has also been taken at Patani (Ogilvie-Grant, 1905) and at Tavoy (British Museum). According to Hume (Stray Feathers, vol. 8, p. 71, 1879), and Vorderman (1890), it is also found at Malacca. 
In the East Indies this species is common in Sumatra and in Java, specifically at Batavia, and on the coasts (Vorderman, 1884; von Pelzeln, 1865, Koningsberger, 1915), and it is found also in Borneo, East though records for this island appear to be exclusively for the southeastern sections at Indies Bangkan (Grabowsky, 1885) and at Banjermassing (W. Blasius, 1884; Mottley, 1863). It is not known to occur in the Philippines, nor in any of the islands east of Borneo. There are, however, several records for China. According to Hartert (1910) it has been found on Hainan in April China and May. Vaughan and Jones (1913) say it has been observed on several occasions during the summer months in the vicinity of Hong Kong and Macao. They speak of a company of twelve seen on July 23, and a flock of twenty seen on August 3 , in this general region. Another was flushed from a small island on the Upper Si-kiang in western Kwang-si. In view of these facts it seems to me quite evident that the species is more than a straggler in southwestern China. Rickett (Ibis, ser. 6, vol. 6, p. 225, 1894, and ser. 7, vol. 6, p. 58, 1900) took specimens near Foochow in November. Recently a specimen has been recorded from Formosa, June 16 (Uchida, 1912), and Styan (1889) has recorded it from Soochow on the Lower Yangtse, near Shanghai. This seems to be the northernmost record for the species, but off the coast it has been taken in the Loo-choo or Riu-kiu Islands. Specimens have been taken in this archipelago on the Yayeyama Group, specifically on Ishigaki, Kobama and Iriomoti Islands (Stejneger, 1887; Ogawa, 1905; Owston, 1899).

Speculation has been aroused by a specimen of this species found in the market of Turin, Italy, and killed near Canavese on December 3, 1876 (Giglioli, 1886). It was probably an escaped bird, though the fact that the species is not very commonly imported alive, and that very few were, at that time, in European zoölogical gardens seemed to militate against this view.

\section{GENERAL HABITS}

Practically all that is known of the habits of this species is to be found summed up in the works of Hume and Marshall (1879) and of Baker (1908). Its movements throughout India are dependent on the water supply, so that in some portions it is a seasonal visitor only.

Haunts. This is a bird of the low countries, rarely if ever ascending into the hills. Hume speaks of its preference for moderate-sized pieces of water surrounded by trees, and says it is absent in some treeless parts of Rajputana where other ducks abound. In spite of its partiality for lakes and ponds there are certain rivers in India where the species is found in tremendous numbers. Baker says, to find them on rivers or open, clean pieces of water is exceptional. In the southern Malay Peninsula they frequent particularly, small weedy lakes surrounded by jungle, where Kelham (1882) found them in thousands from February to April. The birds leave this region before the middle of June, only a few remaining to breed. In Ceylon, also, their habitat is the region of tanks surrounded by forests, especially such tanks as are overgrown with lotus leaves. They are not found on the river estuaries or brackish lagoons.

WARINess. The natural disposition of these birds is to be tame and far more trusting than other water-fowl, even more so than the Fulvous Tree Duck. A good 


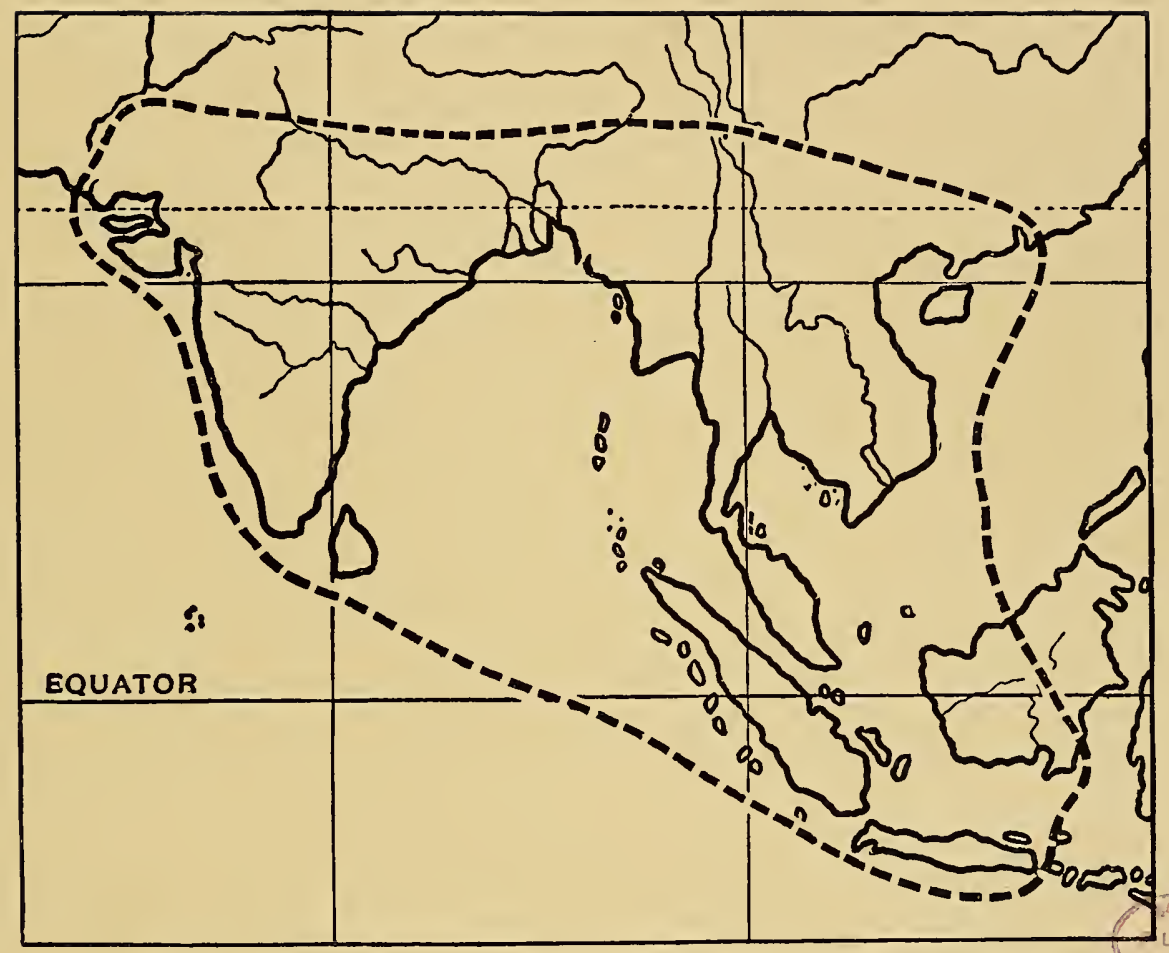

MAP 14. Distribution of Lesser Whistling Teal (Dendrocygna javanica) 

idea of their confiding nature may be obtained by reading Hume's remarks as to their living in trees growing inside the enclosures of cottages, or in some cases having been stoned from the trees if a flying shot was desired. Several writers have described their habit of circling round and round the pond when flushed, a practice which often proves fatal to a large number. Baker (1908), however, was much surprised to find them quite wary in the Sunderbunds. On those vast pieces of water in the delta of the Ganges, they form flocks numbering thousands, which, dividing up into smaller companies of two to three hundred, fly off to some other part of the swamp, with only a preliminary wheel or two.

Outside the limits of India they were found very tame in western Siam (Gairdner, 1914), but Kelham (1882), writing of the Straits region, says they are by no means easy to stalk, even in places where a gun has never been fired.

Daily Movements. The Common Whistling Duck is certainly less nocturnal in its habits than are the other members of the genus. According to Hume they feed almost exclusively during the day, chiefly in the early morning and evening, and rest in trees during the middle of the day. The night they also spend roosting in trees, but in river districts and in localities where they are more persecuted, it appears that they are nocturnal feeders like other Tree Ducks. Baker (1908) is of the opinion that in any case they pass the middle of the night in the trees. It would seem that in the Malay regions, the heat of the day finds them, not in trees, but on jheels among thick reeds (Kelham, 1882). Doubtless their habits are quite different according to the season, but intimate accounts of the life-history of this whole group are lacking.

FLIGHT. Many observers have contrasted the rapid wing-beats of these birds with their slow progression in the air. Baker (1908), speaking of the huge masses which rose from a famous shooting ground in India, says he was greatly struck by the attitude of the birds, which reminded him of ancient prints on duck-shooting; the birds with their long necks outstretched rising straight up to some height, until they got fairly started, when they flew off parallel to the water, generally about thirty or forty feet up. When on the wing the neck tends to droop, as in other Tree Ducks. On the whole the bird is a slower flier than the Fulvous Tree Duck.

A characteristic peculiar to this species is a projection on the inner web of the outermost primary which Heinroth (1911) pictures, and describes as producing a loud whistling sound during flight. It is remarkable that no observations made in the field have brought out this peculiarity, but it may be that the loud voice obscures this sound.

Existing as it does, in enormous numbers, and being like other Tree Ducks, gregarious by nature, it is not surprising that huge flocks numbering thousands have 
been frequently mentioned by observers. In fact, on Moolna Bheel, that great Indian shooting ground, Baker (1908) claims to have seen hundreds of thousands on the wing at once. Flocks numbering a thousand have been reported from Siam (Gairdner, 1914), while "large" flocks have been recorded from Burma (E. W. Oates, 1883), southeastern Borneo (W. Blasius, 1884), and Ceylon (Legge, 1880).

GaIT. Though not commonly seen on land, and preferring the water or trees, these birds walk well and gracefully, though slowly (Finn, 1915). In captivity they whistle freely as they walk or swim, and have a curious propensity for walking great distances, when tame, in search of food. On these foraging expeditions several birds will nearly always walk in a line, as geese so commonly do (Baker, 1908).

Swimming and Diving. The Common Whistling Ducks spend more time in the water, and are less commonly seen grazing than are the other Tree Ducks. They are described as quick, strong swimmers and very good divers. They sit rather low in the water, the neck seeming long compared to the narrow body and short tail, and the wings are folded so closely that the tips are not seen (Finn, 1915). When wounded they scurry under water at a great pace for about ten to twenty yards, reappearing and diving again, but they have not the power of holding on to weeds under water (Baker, 1908). Referring probably to its habits when in confinement Finn (1915) maintains that it dives for food freely, though its actions in so doing are like those of a Coot, for it springs high up lifting its whole body from the water. The fact that the birds dive cleverly when wounded is borne out by other observers (Hume and Marshall, 1879; Grabowsky, 1885; Jesse, 1903; etc.), but whether they actually procure much of their food from the bottom is not made clear by the information available.

Perching. The name Tree Duck is certainly appropriately applied to this species, perhaps more so than to any other of the genus. It seems to roost invariably on trees, and in India the banyans are a favorite resort on account of their large horizontal branches which afford a good hold, without taxing the bird's grasping powers (Baker, 1908). In other parts of its range, in Ceylon, for example, they are fond of roosting on dead branches near the water (Wait, 1917), though Legge (1880) asserts that they rarely perch except in the breeding season. He often saw them on partly submerged logs or low rocks. However, Baker (1908) says that he only once saw a very large flock perching in a tree, and it seems that the great aggregations must break up into small parties when they go to roost.

Association with other Species. The only note in regard to this point is a remark of Hume and Marshall's (1879) that the Whistling Teal is commonly found on the same tanks with the Cotton Teal (Nettapus). 
VoICE. The note is invariably described as an oft-repeated and regular whistle, uttered when on the wing, and probably the same in both sexes. Hume and Marshall (1879) speak of it as a "double hissing whistled note," and Baker (1908) calls it "not very clear, rather sibilant, and by no means harsh or shrill." Its voice, no doubt, suggested some of the native Indian names, "sili," "silhahi," etc. During the breeding season Baker heard the birds giving vent to a low chuckling, not unlike the garrulous notes of the Cotton Teal.

The lower trachea of the male is dilated into a simple symmetrical chamber, and in the female the tracheal rings in the same region are imperfect and filled in by a membrane (Heinroth, 1918).

Food. Although there are many references to its feeding in paddy fields, and living on a vegetarian diet, the flesh is so constantly disagreeable in taste that it seems likely that the bird indulges in some peculiar animal food, which causes the flesh to become distasteful. The old birds feed on anything and everything, but bring up their young principally on animal food. They graze in the rice-fields, but only when the plants are very young, and they have been seen in cold weather eating the coarse dhub-grass which grows in sandy spots by the edges of tanks (Baker, 1908). Legge (1880) and Hume and Marshall (1879) mention their feeding on the matured, cultivated rice, during harvest time. Baker (1908) lays particular emphasis on the fact that they devour large quantities of small fresh-water snails, which may, he thinks, account for the poor flavor of the meat.

Courtship and Nesting. In India the breeding season varies from the middle of June to the middle of October, but generally falls within the months of July and August (Hume and Marshall, 1879). In more southern regions, where the rains are heavy, the birds breed after the rains; that is, in the early months of the year in Ceylon, excepting in the western part of that island, where the breeding season extends, as in India, from June to August (Legge, 1880; Wait, 1917). In Pegu, July and August are the months of breeding (E. W. Oates, 1883), while in the southern part of the Malay Peninsula, Kelham (1882) found the birds breeding during the rainy season, that is from August and September to January or February. In the Andamans the breeding period seems to be somewhat later than in India, falling in August and September (Osmaston, Journ. Bombay Nat. Hist. Soc., vol. 17, p. 491, 1907). According to Owston (1899) eggs were found in the Loo-choo Islands on May 31st and June 21st.

As to courtship, nothing appears to be known, beyond what applies to all species of Tree Ducks and has been related for other species. The nests are variously located, depending largely on the physical characteristics of the region. Almost every kind of location is mentioned by Hume and Marshall (1879) who quote observers to 
show that the nest may be found, constructed of sticks, fairly high in the branches of large trees, in hollows between huge branches of old trees, in holes in trunks, on low palms or thorny bushes, in dense clumps of reeds, on the ground, in thick grass or on the water on floating patches of tangled water-weeds. Finn (1915) admirably sums up the situation when he says that the nest may be found anywhere except underground. Baker (1908), who personally took very many nests in Assam, makes some interesting observations. The typical sites he found to be: (1) the dense grass covering the sides of the banks raised by villagers across inundated land; (2) massive structures of grasses and water-weeds on tiny islands in flooded districts, and always completely covered with a dome, so that they could not be seen, even from above; (3) in Cachar, at the foot of the hills, in clumps of densely foliaged trees, generally babul, often growing actually in the water; at the height of the floods the tops of these trees may be only a few feet above water, and the nest is a rough and ready construction of weeds, sungrass and rushes, rarely lined with a few feathers, sometimes a few twigs being used; (4) near the top of dense cane-brakes, which will bear considerable weight, and are so thick as to offer good protection against rain; the nests themselves are here mere thick, coarse pads, about eighteen to twenty-four inches in diameter, with no especial depression in the center; (5) in large forks or hollows, and if in the former they may be quite well built of twigs, lined with grass and a few feathers.

When nesting in trees the birds commonly make use of the nests of other birds, such as Cormorants, Kites, Paddy-birds, or Crows (Hume and Marshall, 1879). When Crows' nests are chosen they are usually the ones built by Corvus splendens (Baker, 1908).

The clutch is not, as a rule, large, but averages from six to eight, or a slightly larger number, according to the locality. Clutches of twelve to fourteen have been reported (A. Anderson, 1874). Baker, with his wide experience, suggests that in the eastern parts of India the clutches are smaller than in the western districts.

We do not know whether the male ever actually assists the female in incubation, but he is so often found perching near the nest that he probably does take some part. Hume and Marshall (1879) speak of a case in which the two parent birds were found sitting on the nest together, which is at least suggestive. The female sits very closely and may sometimes be caught in the hand. The period of incubation is not known, but probably is longer than that of the true ducks; that is, from thirty to thirtythree days.

The observations made by Hume and Marshall (1879) as to the transportation of the ducklings to the water when the nest is in a tree must be included here. Hume claims to have seen a female carry down seven ducklings, one at a time, in her claws. Such statements have so frequently been made by natives, or unintelligent folk, that peculiar interest attaches to this case, and one is rather forced to the conclusion 
that ducks in general may at times transport their young, as Woodcock are known to do. But this, of course, is not the usual habit, even with species that nest in very high places.

It is, indeed, remarkable that so few observations have been made on the growing family, and so few specimens of young birds taken. The female must have the ability effectually to conceal the ducklings during the first period of their lives. The food of the young is said to consist chiefly of insects.

STatus. The species is holding its own in India according to recent writers. Baker (1908) estimated its numbers as at least one hundred to one of each of the common migratory ducks on the Moolna Bheel in India.

\section{Enemies. Nothing known.}

DAMAge. It feeds to a certain extent in rice-fields, both when the plants are young and during harvest time.

Food VALUE. Some of the earlier travelers in the East spoke of the bird as a welcome addition to their larder, but the residents of India are almost unanimous in denouncing it. Baker (1908) adds that young birds at the beginning of cold weather are more likely to furnish an edible dish. The flesh has been described as having a "peculiar, faint, half-muddy, half-fishy" taste that makes it unpalatable (Hume and Marshall, 1879).

HuNT. Indian sportsmen consider this bird as unworthy of their attention, and regard it as a nuisance when one is out to shoot other ducks. In Ceylon, however, they are said to afford good hunting (Legge, 1880) and in Borneo the natives kill many for export to Java (Grabowsky, 1885).

By wading quietly through the water, waist-deep, with reeds concealing head and shoulders, they can be approached and several killed at a shot, writes Kelham (1882) about the southern part of the Malay Peninsula. There are other accounts of many being killed at one discharge.

Behavior in Captivity. This species was apparently received for the first time by the London Zoological Gardens in 1857. The specimen presented then was still living in 1883, as were also three others received in 1858, making a longevity record of twenty-six and twenty-five years respectively; truly remarkable for any of the smaller water-fowl.

In confinement the birds become exceedingly tame, as do other Tree Ducks; it is frequently possible to keep them in complete freedom without their making any 
attempt to leave the home-pond (Baker, 1908). The same writer tells how they soon learn to come when called, and how they may be fed out of the hand, becoming so confiding that even strangers do not worry them. They are said to whistle even when walking and swimming, and when called they habitually whistle in reply. Whether this is the real flocking-whistle, or a modified form developed in confinement, or perhaps only a feeding-note, I cannot say.

So far as I know there are no recorded instances of the species having bred in parks or gardens in Europe or America, but they breed freely in such places if located within the regions where the birds are indigenous, particularly if allowed their full wings. Hume and Marshall (1879) tell of their settling down in the public gardens at Singapore and nesting there.

In New York the price paid for these birds by the Zoölogical Society was about $\$ 8.00$ each before the War (Crandall, in litt.) but they are not so common in collections as the Fulvous or the White-faced species. Two specimens lived eight and nine years respectively. 


\section{BLACK-BELLIED TREE DUCK DENDROCYGNA AUTUMNALIS (LINNÉ)}

(Plate 13, young; Plate 11, adult)

\section{SYNONYMY}

Anas autumnalis Linné, Systema Naturæ, ed. 10, vol. 1, p. 127, 1758.

Dendrocygna autumnalis Eyton, Monograph Anatidæ, p. 109, 1838.

Dendrocycna autumnalis Sclater, Proc. Zool. Soc. London, 1880, p. 509.

\section{Vernacular Names}

English:

Red-billed Whistling Tree Duck

Black-bellied Whistling Tree

Duck

Autumnal Whistling Tree Duck

Long-legged Duck

Cornfield Duck or Corn Duck

Fiddler

\section{French:}

Siffleur à bec rouge

Siffleur à narines jaunes
German:

Herbst Ente

Singente

Mexico:

Maizera

Pato maizal

Pichichi or Pechechene

Spanish:

Pato carretaro

Guatemala:

Pigije

Costa Rican:

Piche

\section{DESCRIPTION}

Adolt Male and Female: Forehead yellowish brown changing to deep cinnamon on crown, and to black on the occiput, where it forms a black stripe which extends down the back of the neck; remainder of head and neck ashy gray, paler on the chin; lower neck, breast and scapulars rich cinnamon brown; back, rump, upper tail-coverts and abdomen black, the black of the latter region sharply separated from the cinnamon breast; lesser wing-coverts yellowish brown. A white patch formed by greater wing-coverts and another at the base of the primaries; remainder of primaries and all the secondaries black. Tail black; under tail-coverts spotted with white and black.

Iris brown; bill brilliant rose-color to orange red, a space around the nostrils more yellow; nail bluish or "sky blue"; legs and feet pinky white or nearly "flesh color" (Nutting, 1882). The legs of some live specimens I have seen were very pale flesh-color.

Wing 217 to $246 \mathrm{~mm}$.; culmen 43 to 53 ; tarsus 52 to 65 .

Note: The Texas birds are slightly larger than birds from Costa Rica, which latter have a wing of only about $230 \mathrm{~mm}$. A specimen from Panama is still smaller, with a wing of $217 \mathrm{~mm}$., a bill of $43 \mathrm{~mm}$., and a tarsus of $52 \mathrm{~mm}$., smaller than the average for Dendrocygna discolor. The northern migrants into Mexico and Texas might possibly be regarded as a slightly larger race. 
ImMature Birds: Much like adult, but pattern of coloration much less distinct, and color duller; the reddish brown replaced by dingy grayish, tinged with rusty; the belly and flanks grayish white with dusky cross bars; bill and feet dusky.

Young IN Down (M. C. Z. specimens): General color above, black; below, sulphur yellow. Top of head black, patch above and forward of eye yellow. A broad yellow band from culmen extending below eye and meeting its fellow at the occiput as a narrower line. A broad black band runs down the dorsal side of neck, connecting with black of mantle. A small black spot on under side of neck. There are yellow patches on the back, wings, sides, and rump; in other words four pairs of these.

Downy Young (at later stage with scapular feathers just starting): The black color has faded to a brownish gray, and the yellow parts are nearly white (American Museum specimens).

\section{DISTRIBUTION}

THe Black-bellied Tree Duck, like most of its congeners, is practically a resident species, moving about only as meteorological conditions require, and breeding in essentially the same regions in which it winters. It is true, however, that this species is found only in summer in the northern part United of its range, which is southeastern Texas. It is abundant as a breeding bird in this States region, arriving in April or May and leaving in late September or October. From Texas it has been recorded for Corpus Christi (Cooke, 1906) and Dresser (1866) was told that some winter as far north as Galveston! This seems unlikely. It is common on the Lower Rio Grande (Sennett, 1879) especially at Fort Brown (Merrill, 1878), Matamoros, and at Lometa (Sennett, 1879). A very remarkable statement is that of W. Lloyd (1887) who says this species occurs in autumn on the southern Concho River in western Texas. Outside of Texas it has only twice been met with in the United States. On May 5, 1899, Brown shot six out of a flock of eight on the Santa Cruz River near Tucson, Arizona (Brown, Auk, vol. 23, p. 218, 1906) and in the fall of 1912 a specimen was taken in Imperial County, southern California (Grinnell, Bryant and Storer, 1918). Grinnell shows that an earlier record for Fort Tejon, California (Baird, Brewer and Ridgway, 1884), was probably reported erroneously.

In the northwestern sections of Mexico the present species is rare, if it occurs at all. Grayson (Lawrence, 1874) supposes that they pass north to Sonora, but there are no records either from that Mexico State or from Lower California. It has, however, been reported from Nuevo Leon at Monterey (Dresser, 1866) and from Tamaulipas (Richardson, British Museum; Berlandier, fide Baird, Brewer and Ridgway, 1884), and from Mazatlan on the west coast (Forrer, British Museum; Bischoff, fide Lawrence, 1874), where it is abundant and breeds. On the east coast it is common in April at Tampico (Sanford, Bishop and Van Dyke, 1903). Villada (1891-92) states that the species is resident in the Valle de Mexico, and it appears to be common at Jalapa (Ferrari-Perez, 1886) and in Vera Cruz (Trujillo, British Museum). According to Baird, Brewer and Ridgway (1884) it occurs also in Hidalgo, and specimens collected there are in the Museum of Comparative Zoölogy. The southernmost record for Mexico is that of Sumichrast (Lawrence, 1875) for Tapana, Chiapas.

The species is abundant in Central America, apparently, especially so on the Pacific Coast. It has Central been recorded for Guatemala (Salvin and Godman, 1897-1904; J. J. Rodriguez, 1909America 10) and Salvin (1865) found it there on the west coast at Acapam and Huamachal (British Museum). There are no records of its occurrence in Yucatan, though it has been taken on Cozumel Island, off the coast (Salvin, 1889, 1890). In Honduras it was found at Lake Yojoa (G. C. Taylor, 1860) and it has been recorded also from Sucuija and San Juan del Sur, Nicaragua (Nutting, 1885). Carriker (1910) states that it is abundant on the Pacific Coast of Costa Rica, though 


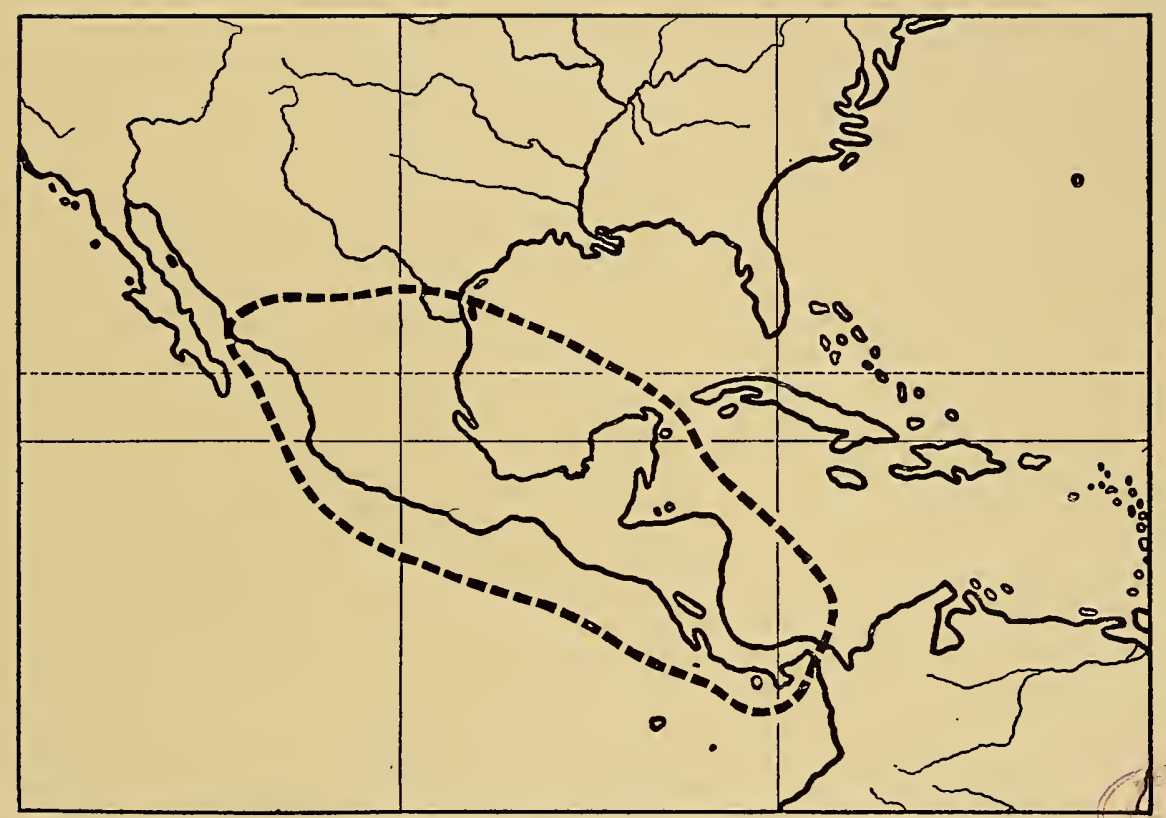

MaP 15. Distribution of Black-bellied Tree Duck (Dendrocygna autumnalis) 

quite rare elsewhere in that country. In Costa Rica also it has been recorded for Guanacaste (von Frantzius, 1869), Cartago (Boucard, 1878), Rio Frio and Rio Escondido (Richmond, 1893), between Bebedero and Miravalles (Underwood, 1896), La Palma (Nutting, 1882) and Nicoya (Arcé, British Museum). In Panama it was found at Loma del Leon (Salvadori and Festa, 1899; P. L. Sclater and Salvin, 1864), at Agua Dulce (Salvin and Godman, 1897-1904) and in the Canal Zone (Stone, 1918). The southernmost record for the species appears to be that of Wood (Proc. Acad. Nat. Sci. Phila., 1860, p. 197) for the Truando River, Colombia, near the Panama border, but this is held by F. M. Chapman (1917) to refer to Dendrocygna discolor.

The present species has been recorded as accidental in the island of Jamaica (Gosse, 1847; Newton, 1881; Cory, 1889). The statement that it is common and breeds in Porto Rico (Taylor, Ibis, ser. 1, vol. 6, p. 172, 1864) very probably refers to Dendrocygna arborea. Neither Gundlach (1878) nor Wetmore (1916) met with the species on that island, and it seems to me exceedingly unlikely that it should occur there, except as a possible straggler.

\section{GENERAL HABITS}

HaunTs. The species is an inhabitant of the tropical lowlands, and is said soon to die if taken to the cool highlands of Costa Rica (von Frantzius, 1869). It prefers shallow waters, probably in order to avoid alligators (Lawrence, 1874) and often frequents settled districts, feeding on the crops.

WARINess. All travelers have described this bird as very tame and easy to approach. In the Tampico region Sanford (Sanford, Bishop, and Van Dyke, 1903) says that at his approach they ran together and stood, raising their long necks like geese, before taking flight. Sennett (1879) found them especially tame during the mating season.

Daily Movements. Like other Tree Ducks this species is very decidedly a nocturnal bird. Grayson (Lawrence, 1874) considers them even more nocturnal than the Fulvous Tree Duck. He met them at night walking along the roads far from water, picking up grains of corn dropped by packers. During the day the flocks stay on the banks of some secluded lagoon, densely bordered with woods or waterflags, not often feeding or stirring about until dark.

FuIGHT. On the wing the Black-bellied Tree Duck is very conspicuous. The birds fly low and in line, the white wing-patches showing up in a striking manner (Sanford, Bishop and Van Dyke, 1903). In rising from the water, the birds, when pinioned, first skim along over the surface like Coots, and by occasional jumps finally get under good headway (Hubbard, 1907). They alight usually on land (Sennett, 1879) and like other Tree Ducks the neck is stretched down so far that the bill and toes almost touch. In Costa Rica flocks of over two thousand have been noted on the Rio Frio, but smaller companies on the Escondido (Richmond, 1893). Very large flocks seem to be exceptional. 
GaIT. They stand high on their long legs, holding the neck erect or curved slightly backward (Rogeron, 1903), and frequent the land more than the water. They are able to walk long distances, and in Costa Rica the semi-domesticated birds were seen toddling along in lines (Carriker, 1910). Hubbard (1907) credits them with the ability to run at a great rate.

Swrmming And Diving. Though the earlier writers (Lawrence, 1874; et al.) remarked that these birds were seldom seen on deeper waters, they do at times learn to dive when kept pinioned on enclosed ponds (Hubbard, 1907).

Perching. The Black-bellied Tree Duck seems to perch less freely than some of the other Tree Ducks. In the nesting season, however, it is frequently seen in trees, and it often alights on corn-stalks. One gets the impression from observing pinioned birds that they care nothing about perching, for they are usually seen standing by the edge of the water. Rogeron's were almost never observed off the ground, even though some enjoyed the use of their wings. Only once or twice did he find them awkwardly perched on wire fencing. Nevertheless one keeper in a zoölogical garden told me that his specimens perched rather frequently.

\section{Association with other Species. Nothing recorded.}

VoICE. Both this species and the very closely related Dendrocygna discolor are distinguished from other members of the genus by having similar and sharper, as well as louder voices. There is in the male the same tracheal enlargement described under Dendrocygna arcuata and other species, and this enlargement is strengthened posteriorly by a strong bony bar, or keel. The windpipe of the female is not modified posteriorly as in the case of the Dendrocygna arcuata for example (Beddard, 1898). The note itself has been described as loud, shrill and discordant, uttered chiefly when on the wing (Nutting, 1882). Grayson (Lawrence, 1874) has likened it to a peculiar whistle sounding like the syllables pe-che-che-ne, which is the name given the birds by the natives of Mexico.

Food. Nothing appears to be known of the natural food of these birds, but several observers have spoken of their fondness for Indian corn (maize). When the corn is nearly ripe they alight on the stalks, strip the husks from the ears, and pick the grain off the cob (Sennett, 1879). They no doubt also graze after the manner of the true geese, and other species of Tree Ducks.

Courtship and Nesting. Although so little has been recorded as to the intimate breeding habits of this species one must conclude that it is a tree-nester, perhaps 
seldom, if ever, nesting on the ground. Hollow trees, regardless of the proximity of the water, seem to be the most favored location. One nest, found by Sennett (1879), was in an ebony tree in an open grove, near a ranch house, nine feet above the ground, and in a hollow branch. There was no lining. According to Merrill (1878) the nest may be eight to thirty feet above the ground and sometimes as much as two miles from the nearest water. The nest is never carefully lined with feathers. In only one case, so far as I know, was the bird found nesting on the ground, the locality mentioned being a cornfield (Lloyd, U.S. Biol. Survey).

In Texas and Mexico the eggs are deposited in June and July, soon after the birds arrive from regions farther south. Merrill (1878) mentions broods still unable to depart for the south in November, but this must be exceptional. Grayson (Lawrence, 1874) thought that these late broods indicated a second nesting. Such may be the case, but more likely it signifies the premature destruction of the first clutch, or brood. The normal clutch seems to number twelve to fifteen or sixteen (Lawrence, 1874; Merrill, 1878). In color the eggs are pure white or creamy, measuring about 54.5 by $39 \mathrm{~mm}$. There is some indication that the male at times assists in incubation, for Sanford (Sanford, Bishop and Van Dyke, 1903) shot several males in the Tampico districts, whose breasts suggested that they had been sitting on eggs. Merrill's (1878) statement that the males leave the females and gather in large flocks is certainly erroneous. So far as known in all Tree Ducks the pairs remain together throughout the nesting season, although just how much longer it is impossible to say. The period of incubation is not accurately known, but is probably over thirty days.

Status. Merrill (1878) says that large numbers were brought to the Brownsville Market. It is still a common bird there, but the settlement of the tropics must eventually reduce all species of Tree Ducks.

Enemies. Grayson (Lawrence, 1874) suggests that alligators are dangerous to these birds.

Damage. Several writers (especially Lawrence, 1874, and Sennett, 1879) have spoken of the damage done by this species to the corn crops. This matter has already been discussed in connection with feeding habits.

Food VaLue. Excellent for the table (Sennett, 1879; Taylor, Ibis, ser. 1, vol. 2, p. 315,1860$)$.

Behavior in Captivity. The black-bellied Tree Duck has long been a favorite with aviculturalists the world over. It is, or rather was, readily obtainable from dealers in the United States. Specimens were imported into England as far back as 
1750, for Edwards (1743-51) drew his plate from a specimen which presumably was a live one, in Sir Charles Wager's gardens. The London Zoological Society possessed specimens before 1831 (P. L. Sclater, 1880). But apparently there is only one place in Europe where the birds have nested, and that is on the estate of M. Herbert, Sr., at Havre, France (Hilaire, Bull. Soc. d'Acclimat., Paris, ser. 2, vol. 10, p. 371, 1873).

Like other Tree Ducks these birds become remarkably tame in captivity, and, having passed one moult, they are quite hardy. Nevertheless they suffer when exposed to cold and wind, being subject to diarrhoea and kindred complaints. They require a little animal food during the fall and winter to enable them to pass safely through the moult (Hubbard, 1907). Rogeron (1903) also noted their sensitiveness to cold. On ornamental waters the birds usually keep very much to themselves, but sometimes associate with other Tree Ducks. As Rogeron (1903) has remarked, they will have almost nothing to do with ducks of other genera.

They attain an advanced age at times. In 1883 the London Gardens had four specimens which had been living there for the past nineteen years, and Rogeron (1903) says he kept a male for fifteen or twenty years. One in the National Zoölogical Park in Washington lived nearly ten years and a half.

The price paid for these ducks has varied from $£ 2$ to $£ 7$ per pair in England (Hubbard, 1907), and Mr. L. S. Crandall writes me that in New York the price averaged about $\$ 5.00$ each before the War.

Although never truly domesticated in the sense of perpetuating themselves like farmyard fowls, these ducks are very commonly kept by natives in various parts of Mexico and Central America. This tame stock is acquired both by rearing young birds caught in the wild state, and by hatching out eggs taken from nests. Not only do they serve as pets and as food, but they are also useful in sounding alarm notes at the approach of strangers. In Costa Rica they are found about almost every house, going off to feed in the daytime, but returning at night (Richmond, 1893; Carriker, 1910). M'Leannan (Sclater and Salvin, 1864) tells the story of two tame birds in Panama who entered the house at all hours and walked around the table looking for food. They commenced calling just before daybreak. 


\title{
GRAY-BREASTED TREE DUCK
}

\author{
DENDROCYGNA DISCOLOR Sclater aNd Salvin
}

(Plate 11)

\section{SYNONYMY}

Anas autumnalis Jacquin (nec Linné), Beytrage, vol. 1, p. 6, 1784.

Dendrocygna autumnalis G. R. Gray, List Spec. Birds Brit. Mus., pt. 3, p. 131, 1844.

Dendrocygna discolor Sclater and Salvin, Nomenclat. Avium Neotrop., p. 129, 1873. Dendrocygna autumnalis discolor Baird, Brewer and Ridgway, Water-birds of No.

Amer., vol. 1, p. 480, 1884.

\begin{tabular}{cc}
\multicolumn{2}{c}{ Vernacular } \\
English: & Portuguese: \\
Colombian Tree Duck & Marreca cabocla \\
Southern Red-billed Tree Duck & Marreca grande de Marajo \\
Gray-necked Tree Duck & Dutch: \\
Gray-breasted Tree Duck & Columbiaansche Boomende \\
Two-color Tree Duck & Spanish: \\
Vicissi Duck, or Visi-visi. & Pisesic \\
French: & Trinidad: \\
Siffleur de Cayenne & Ouikiki ailes blanches \\
Siffleur à bec rouge & Venezuela:
\end{tabular}

Guiriri

\section{DESCRIPTION}

Adult Male and Female: Differ from Dendrocygna autumnalis only in the mantle being gray, and sharply contrasted against the brown scapulars, and also in having the breast gray, especially at the lower margin; thus differing markedly from the chestnut breast of the northern species. Size smaller than Dendrocygna autumnalis.

Wing 230 mm.; bill 48; tarsus $\mathbf{5 5}$.

Note: This species may intergrade with Dendrocygna autumnalis. A specimen of the latter from Panama (M.C.Z. no. 7731), is not quite true to type and is small, but is certainly more like autumnalis than like discolor.

\section{DISTRIBUTION}

THE present species, which is the South American form of Dendrocygna autumnalis, is found in northern and eastern South America and in a few islands of the Lesser Antilles. It is a resident species and is not known to migrate to any extent. The northernmost record is perhaps that for Divala, Panama (Bangs, 1901). According to F. M. Chapman (1917) the record for the Truando River, Colombia, which is usually given as the southern limit of Dendrocygna autumnalis, really belongs to the present species. In Colombia it has also been found at Sipi (Hellmayr, 1911) and at Cali (F. M. Chapman, 
1917). M. A. Carriker (in litt.) reports that in Santa Marta the species is common. On the Pacific coast it is found south through Ecuador (Illingworth, British Museum; Brabourne and Chubb, 191215) and in eastern Peru on the Ucayali River (Bartlett, British Museum; Goeldi and Hagmann, 1902) as well as at Moyobamba (Taczanowski, 1886). It is a common bird in the countries along the north coast of South America, having been found in Venezuela abundant on the Orinoco (Cherrie, 1916), and on the Caura River (André, 1904), and apparently breeding at Altagracia (Berlepsch and Hartert, 1902). Both in Venezuela and in the Guianas it comes to the coast during the dry season and is found inland during the wet season. C. B. Dawson (1916), Young (1893), and Ernst (1877) have all recorded it from British Guiana, where it was also taken by Whitely (British Museum) on the Rupurumi River. In Surinam, or Dutch Guiana, it is abundant and breeds (F. P. and A. P. Penard, 1908-10). The type of the species was taken in this province by Kappler. There are various old records for its occurrence in French Guiana, especially about Cayenne (Berlepsch, 1908). Off the north coast it is resident and common in Trinidad (Léotaud, 1866; F. M. Chapman, 1894); and occurs occasionally on Barbados, Mustique, and St. Vincent (Clark, 1905).

This species is found throughout Brazil excepting in the southeastern sections. About the mouth of the Amazons it is common, having been recorded from Marajo (Goeldi, 1894-1900; Hellmayr, 1907) and having been found breeding on Marajo, Cavianna and Mexiana Islands (Hagmann, 1907; Hellmayr, 1912). Von Pelzeln (1868-71) and H. and R. von Thering (1907) have recorded it for Pará. It apparently occurs along the entire course of the Amazons and its tributaries. Von Pelzeln (1868-71) found it along the Rio Branco, Rio Negro and Rio Madeira, down through Matto Grosso and the Upper Paraná to São Paulo. Hellmayr (1908) also has recorded it from the Rio Araguaya, and young were taken at Goyaz; he furthermore (1907) has recorded a specimen from Obidos on the north bank of the Amazons. H. and R. von Thering (1907) state that it occurs in Matto Grosso, Amazonas, and also in Minas Geraes. Natterer (fide von Pelzeln; 1868-71) took specimens on the Rio Paraná, which appears to be the southern limit of its range, though a pair was taken near Corumba on the Upper Paraguay (Salvadori, 1900). The species does not seem to extend beyond the Tropic of Capricorn, except accidentally, nor has it been recorded from Bolivia. It undoubtedly occurs in that country, however, for von Pelzeln (1868-71) found it along the Guapore and Madeira Rivers. The birds are apparently very rare, if occurring at all, along the eastern coast of Brazil. I find no records for Bahia, Pernambuco or Ceara, though the species very likely occurs there. It has recently been recorded for northern Argentina, Dabbene (Bol. Soc. Physis, vol. 1, p. 533, 1915) stating that there are in the Shiptin Collection various specimens from Tres Pozos, eastern Salta, and that the National Museum at Buenos Aires has young specimens from that region.

\section{GENERAL HABITS}

Hadnts. From the Santa Marta district of Colombia, M. A. Carriker writes me that the Southern Red-billed Tree Ducks are like other Tree Ducks in being decidedly birds of the tropical lowlands, not going above three thousand feet, and scarcely above one thousand feet save under exceptional conditions, such as obtain in the Cauca Valley, which is very hot for its altitude. They are found in about all localities where ducks might be looked for: on lakes, ponds, marshes, rivers, and even brackish estuaries, but they prefer fresh-water lagoons, ponds or sluggish rivers, surrounded by, or near forests. In this part of Colombia the present species seems to be the only Tree Duck. In the Guianas the birds are said to come to the coast in the dry season, returning inland during the wet season (F. P. and A. P. Penard, 1908-10). 


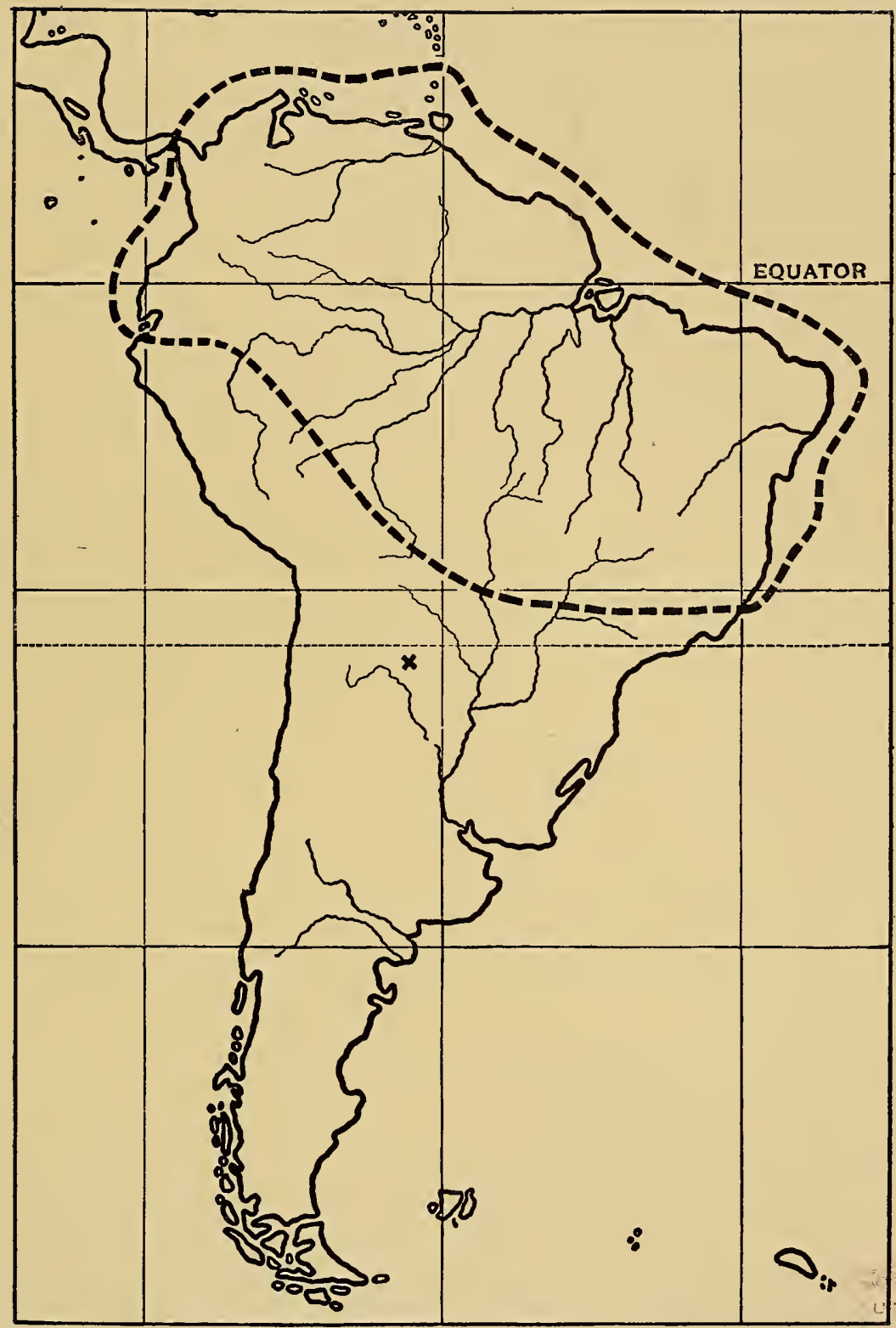

MAP 16. Distribution of Gray-breasted Tree Duck (Dendrocygna discolor) Sporadic record indicated by cross $(X)$ 

WARINESS. In the Santa Marta region of Colombia these birds are rather tame as ducks go, and not particularly hard to shoot (Carriker, in litt.); but in the Guianas they are considered harder to shoot than most ducks. When flushed they do not flock together (F. P. and A. P. Penard, 1908-10). It is unlikely that in this respect they are different from their near relatives of the species Dendrocygna autumnalis which are without question less wild than migratory water-fowl. The young, when captured and kept in confinement, are tamer even than domestic ducklings (F. P. and A. P. Penard, 1908-10).

DaILy Movements. Though I have been unable to find in the literature anything bearing on this point, I presume that this species is, like Dendrocygna autumnalis, decidedly nocturnal in its habits.

FLIGHT. Just before the breeding season these birds assemble in large flocks, flying rapidly and noisily (F. P. and A. P. Penard, 1908-10). Large flocks were also found on the Rio Paraná by Natterer (von Pelzeln, 1868-71), while Léotaud (1866) speaks of their occurring always in flocks in Trinidad. In British Guiana, R. Schomburgk (1848) found them in small companies, while the adults traveled only in pairs. This last statement probably refers to the breeding season.

Gait, Swimming, Diving, and Perching. There is little recorded on these points, but as the present bird is to be considered little more than a subspecies of Dendrocygna autumnalis, its intimate habits are doubtless very similar to those of the Northern Red-bill. Mr. Carriker has frequently seen them perched on limbs of large trees along the Atrato River in Colombia, around the big marsh near Fundacion, Santa Marta. Other writers have also seen them perching and even spending a considerable part of the day on trees (André, 1904; F. P. and A. P. Penard, 1908-10; Léotaud, 1866; R. Schomburgk, 1848).

Assocration with other Specres. Flocks of these birds unite at times with companies of White-faced Tree Ducks, but rarely with other ducks (F. P. and A. P. Penard, 1908-10).

Vorce. The note, like that of Dendrocygna autumnalis, differs from that of the other Tree Ducks in being peculiarly sharp. On the wing the note is trisyllabic and likened by the Penards (1908-10) to the sounds wiesie-wiesie-wiesie. Its Indian name, Ouikiki, is undoubtedly an attempt to imitate the voice.

Food. The only information I have been able to find is the note of the Penards (1908-10) that the diet is more vegetarian than that of most ducks. 
Courtship and Nesting. The Penards (1908-10) claim that in the Guianas the Red-bills nest in the middle months of the year, but this is somewhat at variance with records for the middle part of the range, where they nest in July and August. Young (1893) states that in British Guiana they hatch in August. Young males were taken on the Orinoco as late as December 31 (Berlepsch and Hartert, 1902) and a nest with thirteen eggs was found on Mexiana Island, in the mouth of the Amazons, on August 13 (Hagmann, 1907). On the middle of the Amazons, at Barre do Rio Negro, Natterer found large eggs in the oviduct of the female in September (von Pelzeln, 1868-71). In the southeastern part of the range, at Goyas, Brazil, young birds have been found as early as July (Hellmayr, 1908).

The nest is not found in the mangrove regions near the coast, but is usually placed farther inland in hollow trees, sometimes fifteen to twenty meters above the ground, and at some distance from the water. Occasionally, however, the nest is placed on the ground (F. P. and A. P. Penard, 1908-10). Writing about the same region, the Guianas, Young (1893) speaks of the nests as flat, built of sticks and grass, among reeds and rushes, or in swamps; only sometimes, he says, a low tree or the hollow trunk of a dead palm is chosen. Other naturalists have found nests in thick grass, so that it is obvious that the situation of the nest is very variable, a thing which appears to be true of all the Tree Ducks. A nest found by Hagmann (1907) was on the ground, carefully built in grass, well concealed and lined with down; the approach consisted of a path beaten in the grass and a tunnel, at the end of which the nest was located.

The clutch numbers from eight to twelve eggs, but at times thirteen are found. The information we possess as to these matters is very scanty. Mr. Carriker, who has lived for years in a region where the species is very numerous, says he has "no data whatsoever on their breeding habits, having never found or received reliable information as to their nests." In color the eggs are pure white, while in size they vary from 48.4 to $52 \mathrm{~mm}$. in length, and from 38.3 to $40.3 \mathrm{~mm}$. in width (Hagmann, 1907). The period of incubation is not known, but from what we know of other Tree Ducks it is safe to say that it is thirty days or more. Heinroth (1911) mentions a correspondent who told him that in Brazil he had taken only males at the nest, and from this, as well as from observations made on Dendrocygna viduata in confinement, he concludes (Heinroth, 1918) that the males take over a large share of the duties of incubation. There is evidence on this point for Dendrocygna viduata, Dendrocygna autumnalis and the present species.

Status. Nothing definite is known as to the increase or diminution in numbers of this species. The birds are not much hunted in Colombia, except by some of the "foreigners" (Carriker, in litt.). But many young birds are captured by the natives, who raise them and sell them in the markets of Guiana, and the old birds too are 
much hunted in that region (F. P. and A. P. Penard, 1908-10). The same authors remark that there seems to be a high natural mortality among the young birds.

Food Value. The flesh of this species, as of most Tree Ducks, is excellent (Léotaud, 1866; F. P. and A. P. Penard, 1908-10).

Behavior in Captivity. As long ago as Latham's time the Gray-breasted Tree Duck was frequently imported into Europe. In his supplement to the General Synopsis of Birds (1787, p. 274), he has a very interesting note in which he states that the species has propagated at Shonbrun in Sweden. There are no other records of its breeding in captivity.

The London Zoological Gardens first received this species in 1864. The three specimens obtained at that time were still living in the gardens in 1883, giving a longevity in confinement of at least nineteen years. Three in the New York gardens are twelve years old.

Frequently confounded by dealers and aviculturalists with the more familiar northern form (Dendrocygna autumnalis), this duck has nevertheless been commonly exhibited in both European and American collections. The natives in the tropics habitually keep them in their farmyards, but probably never really domesticate them. 


\title{
BLACK-BILLED TREE DUCK \\ DENDROCYGNA ARBOREA (LINNÉ)
}

(Plate 14)

\section{SYNONYMY}

Anas arborea Linné, Systema Naturæ, ed. 10, vol. 1, p. 128, 1758.

Dendrocygna arborea Swainson, Class. Birds, vol. 2, p. 365, 1837.

Dendrocycna arborea Sclater, Proc. Zool. Soc. London, 1880, p. 509.

\author{
Vernacular Names \\ English: \\ Spanish: \\ $\left.\begin{array}{l}\text { Black-billed } \\ \text { Antillean } \\ \text { West Indian }\end{array}\right\} \begin{gathered}\text { Whistling or Tree } \\ \text { Duck }\end{gathered}$ \\ French: \\ Siffleur de la Jamaique \\ Siffleur à bec noir \\ German: \\ Pijije \\ Pishishi \\ Yaguara - (Cuba) \\ $\left.\begin{array}{l}\text { Yaguaza } \\ \text { Chiriria }\end{array}\right\}-$ (Porto Rico $)$ \\ Iguasa - (Hayti) \\ Llagwasa - (Isle of Pines)
}

Kubanische Baumente

\section{DESCRIPTION}

Adult Male: Anterior part of crown brown; posterior, black, continuing as a black band down back of neck. Sides of head gray, chin and throat white. Around the lower neck is a region of white feathers edged with black, producing a collar effect. Mantle and scapulars dark brown, edged with lighter brown. Wings dark brown except for a grayer area on the outer coverts and primaries, which form a poorly developed speculum. Breast tawny brown, merging lower down into an area which is nearly white, broadly spotted and barred with black. Abdomen nearly white. Flank feathers broadly margined, barred or spotted with black. Tail black, under tail-coverts white with large black spots.

Bill lead gray to black. Legs lead color, webs lighter. Iris brown.

Wing 226-265 mm.; bill 47-53; tarsus 66-72.

Adult Female: Slightly smaller.

ImMature: No specimens at hand.

Young IN Down: Silvery white on the under side and black with white spots on the upper side. A darkish gray spot on the fore-neck. The black of the back continues over the hind neck and almost to the base of the bill, being separated from it by a white line, which widens on each side and runs over the eyes. The black zone on the occiput and hind neck is interrupted by a white band, which begins at the base of the bill on each side and runs under the eyes and around the head. This circular marking seems to be characteristic of the young in down of the genus Dendrocygna. Under this white circular line the black of the hind neck sends a black line forward on each side of the head. Legs and 



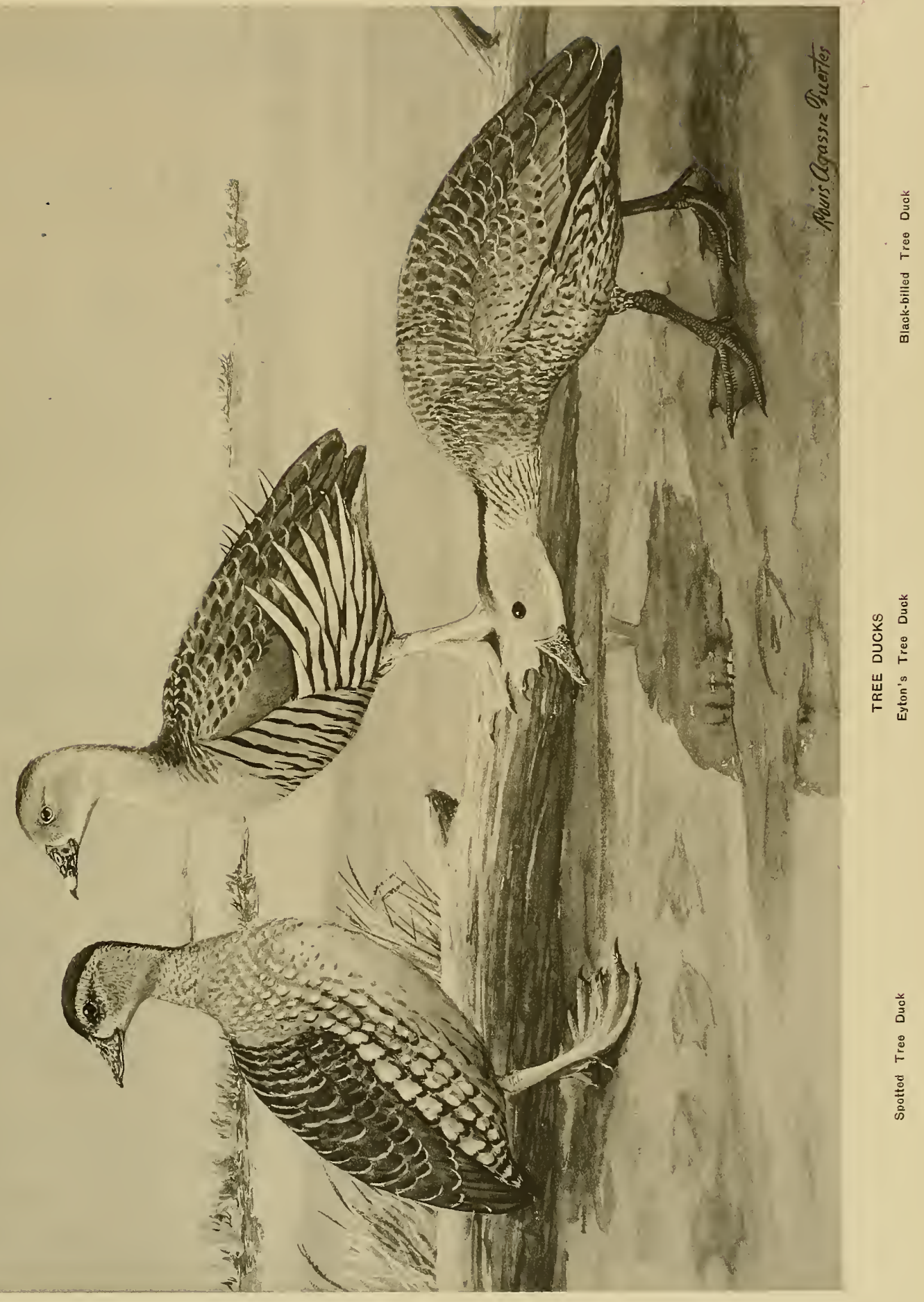



bill dark olive-green (Blaauw, 1912). This plumage, which I saw in the Leyden Museum, has the Tree Duck type of pattern and is very much like that of the downy young of Dendrocygna javanica but more tinged with yellowish. The white body- and wing-patches are very prominent.

\section{DISTRIBUTION}

The Antillean Whistling Duck is resident in the West Indies and is not known to occur with certainty in any other region. Burmeister (1856) early recorded it for Brazil, but he must have meant Dendrocygna discolor or some other species. More recently Rovirosa (1887) has stated that it is more abundant than Dendrocygna bicolor in the Macuspana region of Tabasco, Mexico Mexico. This author probably confounded the present species with Dendrocygna autumnalis, though it is not altogether unlikely that the West Indian form may occur on the mainland. But it has never been discovered in Florida, though in the Bahamas it is not uncommon and resident especially on the larger islands (Cory, 1890) such as Andros (Cory, 1890; Riley, 1905; Bonhote, 1903) and Great Inagua (Bryant, Proc. Boston, Soc. Nat. Hist., vol. 11, p. 70, 1866; Riley, 1905). It has also been found not uncommon and breeding on San Salvador or Watling's Island (Todd and Worthington, 1911). In Cuba the species is said to be common and breeding (Gundlach, 1875; Rodrigues, 1917) and the same is true of Jamaica (Gosse, 1847; March, 1864; Newton, 1881). It has been repeatedly met on the Isle of Pines (Bangs and Zappey, 1905; Todd, 1916), and is reported to be resident on Grand Cayman Grand (English, 1916). It is also fairly common in Hayti (Gosse, 1847; Cory, 1885) and in Cayman Santo Domingo (A. E. and A. H. Verrill, 1909; Cherrie, 1896; Cory, 1885). Gundlach Hayti (1878) states that it is not uncommon in Porto Rico, especially at Mayaguez and Porto Rico Arecibo, where it is plentiful. Taylor (Ibis, ser. 1, vol. 6, p. 172, 1864) has also recorded it from the island, but Wetmore (1916) did not find it, and thinks it must have become very rare.

In the Virgin Islands the present species was found on Virgin Gorda (British Museum) and on St. Croix, where it is quite common (Newton, Ibis, ser. 1, vol. 1, p. 366, 1859). It is Virgin known from the Lesser Antilles, and has been recorded from Barbuda (Clark, 1905), Islands Guadeloupe and Martinique (Lawrence, 1879) and even from Barbados (R. H. Schom- Lesser burgk, 1848). There are no records of its occurrence farther south, nor has it ever Antilles been found on the mainland of South America.

\section{GENERAL HABITS}

Haunts. The Black-billed Tree Duck is an inhabitant of forested swamps or even of mangrove regions. It is seldom seen swimming on open water, but will wade about the swamps, in the evening sometimes traveling long distances to its feeding grounds.

WARINeSS. Judging by the evident success with which the natives of the West Indies kill or capture these birds, they cannot be considered as very intelligent or shy. It is said that when a flock is shot into, and some of the number killed or wounded, the remainder will return and settle by the injured birds, provided the hunter keeps quiet (Gundlach, 1875). One collector, however, considered the species shy on Watling's Island (Todd and Worthington, 1911).

Daity Movements. All writers describe the crepuscular flights of this duck to and from its resting places in the swamps to its feeding grounds. Bangs and 
Zappey (1905) found them carefully concealed in the cienagas (swamps) during the day, leaving, toward dusk, to feed on the fruit of the royal palms. These habits are uniform and have been noted by numerous observers in the West Indies. A curious trait is mentioned by English (1916), who says that they seem to wander a good deal during the night and by no means infrequently alight on the galvanized iron roofs common on Grand Cayman, mistaking them perhaps for pools of water. Dr. L. C. Sanford tells me that he never saw them on Andros Isle during the day, but only on moonlight nights when they came into a small fresh-water pond to feed.

FuIGHT. Like related species the Black-billed Tree Ducks fly steadily, but without the speed of true ducks.

GaIt. These birds walk slowly and with stately carriage, the necks stretched upward, alert and noting every danger; at other times the neck is gracefully bent. When wounded they are particularly difficult to secure for they run with great rapidity, outstripping a man if they have only been winged, unless, as Gosse (1847) puts it, "he be very nimble."

Swimming, Diving, And Perching. They are rarely seen in the open water, where they are, no doubt, exposed to the attacks of lurking crocodiles. Whether or not they ever dive I cannot say, but in general, Tree Ducks acquire this habit in captivity. As to perching, they are frequently seen in high trees, and are partial to palm trees.

Association with other Species. Over the entire extent of its range there are comparatively few other ducks and no geese. A few Black-bellied Tree Ducks may occur in Jamaica, and the Bahama Duck is a scarce resident throughout the West Indies. The northern migrants of other species occur only irregularly in any numbers. It is, therefore, unlikely that the present species has anything to do with other ducks.

VoIce. One of the older writers (Gosse, 1847) referred to the peculiarly shrill whistling notes uttered during the crepuscular flights to and from the feeding grounds, and also when alarmed, and likened them to the sound produced by blowing forcibly over "the pipe of a draw key." Other observers describe the note as an agreeable whistle, and Bangs and Zappey (1905) compare it with that of the Carolina Duck. Besides the whistling flight note the birds have a feeding call which Gundlach (1875) describes as monotonous but not loud. The voice is doubtless the same in both sexes and the syrinx, a symmetrical, diamond-shaped pouch with a shallow keel down its middle, is also the same in the two sexes (Newton, Ibis, ser. 1, vol. 1, p. 366, 1859, plate). The whistled note can be heard at a great distance and 


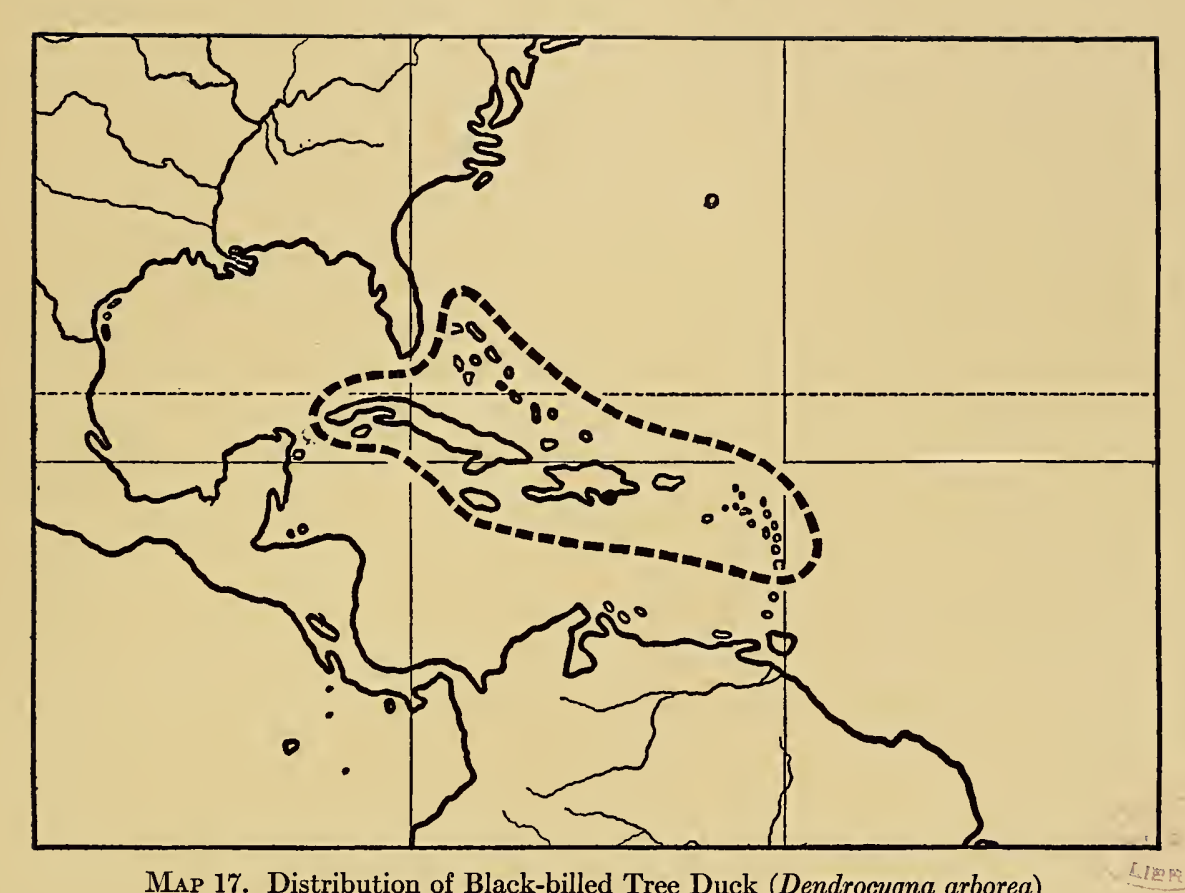



it is uttered not only during flight, but also at times when the birds are on the water (L. C. Sanford in litt.).

Food. The most noteworthy characteristic of the feeding habits of these birds, and one that has been remarked again and again, is their practice of alighting in the tops of royal palms and devouring the fruit. They are very fond also of the so-called "guinea-corn" when it is in milk (Gosse, 1847; Gundlach, 1875). They are essentially vegetarian in their diet and eat grass, seeds, berries, small fruits and on occasion tadpoles. They were noted as being very particular to dip under water and pound up any hard object, before eating it (English, 1916).

Courtship and Nesting. The nesting season of the Black-billed Tree Duck extends from June to October in Cuba (Gundlach, 1875) though it must occasionally nest earlier, for March (1864), speaking of Jamaica, states that young birds were for sale in the markets as early as May. On Watling's Island, Worthington (Todd and Worthington, 1911) found a deserted nest on February 20. All the Tree Ducks are late nesters, and, being largely tropical species, their reproductive period is much more extended than that of more northern ducks. Dr. Sanford's guide on Andros Isle told him that he had found them with young in every month of the year.

The courtship of this species has never been described, and I am unable to offer anything beyond the general notes of Heinroth (1918) that all Tree Ducks indulge in a peculiar lifting of the wings, which, possibly, may have some connection with the exposure of the ornamental flank-feathers.

Specific information as to the nesting localities is very sparse, many collectors having relied chiefly on the stories of the natives. Gundlach (1875) was told that they nested occasionally in tall palms, but according to his own observations the nest is made of twigs and leaves, spread over parasitic plants, or formed on horizontal branches, especially when overgrown with Tillandsia versiculata. A more recent naturalist (English, 1916) found nests on Grand Cayman mostly of grass, without down-lining, well hidden in dry places among bushes, while Worthington (Todd and Worthington, 1911) found one on Watling's Island built between the roots of an upturned tree in the middle of a swamp. The eggs are from ten to twelve or sometimes fourteen in number (March, 1864; Gundlach, 1875), milky white in color and measuring about 55 by $40 \mathrm{~mm}$. (Gundlach, 1875). The only observations as to the incubation period were made by Mr. F. E. Blaauw on a pair of pinioned birds in his aviary. They laid five eggs and hatched them in thirty days (Blaauw, 1912).

Status. When Mr. Outram Bangs was collecting in Jamaica in 1907 an old negro hunter told him that when the mongoose was first introduced into that island the Tree Ducks were nesting on the ground, even in the open fields, and he used to see 
them walking about with their broods. In a very few years, however, these destructive animals almost succeeded in exterminating the species; but the survivors took refuge in different nesting sites, perhaps in deep swamps. They then gradually increased in numbers. In Porto Rico, where they were said to be abundant in 1864 (Taylor, Ibis, ser. 1, vol. 6, p. 172, 1864) and later, Wetmore (1916) in 1911 found them representing a vanishing species, a condition due chiefly to the drainage of swamp-lands and probably also to the mongoose. In Cuba, though still abundant in the great swamps and lagoons of the south coast, particularly the Cienaga de Zapata, I am told that the draining of swamps and other agricultural improvements have greatly diminished their number in the western part of the island. The mongoose is also present in that region although still absent from the rest of the island.

Enemies. Dr. Thomas Barbour informs me that the boas (Epicrates) are said by the natives to rob Tree Ducks of their eggs in Cuba. Crocodiles no doubt catch some young, as these animals are very plentiful on that island. The mongoose is now distributed over most of the Lesser Antilles, besides Jamaica, Santo Domingo and western Cuba. On the whole the future of this species is not a bright one.

Damage. Where numerous, the damage caused by these birds to palm seeds, which are useful as fodder for pigs, is considerable (Gundlach, 1875). The same writer states that they also resort to rice-fields. According to Gosse (1847) they are busy in the millet-fields and they do particular damage to the guinea-corn, by dashing into it forcibly, in compact flocks, and breaking it down.

Food VALUE. The flesh of these birds has been invariably described as excellent.

Hont. As early as 1839 D'Orbigny was told that native hunters waded out naked into the water and took the birds, who through curiosity would allow themselves to be closely approached. But the favorite method is to wait for them when they come to the palm trees at sundown. They are said to decoy readily to an imitation of their whistling note (Gundlach, 1875).

Behavior in Captivity. Edwards (1743-51) drew his plate from a specimen living in the garden of Sir Charles Wager, in England. Latham (Synopsis, vol. 3, pt. 2, p. 499, 1785) received a specimen from Jamaica and kept it in his garden sometime before 1785. The London Zoological Gardens had specimens before 1831 (P. L. Sclater, 1880).

The species certainly breeds very rarely in confinement. Besides Mr. F. E. Blaauw's (1912) record for Holland there are only two other instances of its having reproduced. In the Cologne Gardens, Bodinus (Journ. f. Ornith., vol. 20, p. 72, 
1872) describes how a female coaxed her young to drop from a tree, and Hilaire (Bull. Soc. d'Acclimat., Paris, ser. 2, vol. 10, p. 371, 1873) simply states that they had bred several times in France. He gives no details, and I hardly think it wise to take these old records too seriously. Blaauw's pair made a nest under a bush some distance from the water, and laid five eggs, which were successfully hatched after thirty days'.incubation. The young did not survive long on account of cold weather. The skins of some of them are now in the Leyden Museum.

These Tree Ducks have been known to live to a considerable age in captivity. In the London Gardens, where so many were successfully kept, there were four specimens still living in 1883 that had been received there just twenty years before.

In England before the War these birds were occasionally for sale at $£ 3$ to $£ 4$ the pair (Hubbard, 1907), while in New York they sold for $\$ 7.50$ each.

Throughout the Bahamas Black-billed Tree Ducks are frequently seen about the houses of natives, where they are raised from wild-caught young or hatched from eggs taken from nests. They are easily tamed and English (1916) even tells of endeavoring to set free a pair that he had raised from the duckling stage; - after being at liberty for several weeks they returned to their accustomed quarters, calling vigorously until they were admitted. They could not again be induced to leave.

It has even been said that tame birds go out and bring back wild flocks to the farm ponds, often from some distance (Gosse, 1847). Tamed birds are also kept pinioned, and it is said that natives frequently capture young birds in the wild, cut one wing and give them back to the parents to rear, not recapturing them again until they are full grown. It appears that they dominate other ducks and poultry, and are invariably seen at the head of a flock of these. They have a curious habit of caring for strange young birds, either chickens or ducks, and defending them against all enemies, even dogs (Gundlach, 1875).

It is certainly a remarkable fact that birds which take so readily to the surroundings of a farmyard should be so difficult to breed, but this is true of the whole genus. 


\title{
SPOTTED TREE DUCK \\ DENDROCYGNA GUTTULATA Wallace
}

(Plate 14)

\begin{abstract}
SYNONYMY
Anas guttata Forster (MS.).

Dendrocygna guttulata Wallace, Proc. Zool. Soc. London, 1863, p. 36.

Dendrocygna guttata Schlegel, Mus. d'Hist. Nat. Pays-Bas, Anseres, p. 85, 1866.

Dendrocygna arcuata Rosenberg (nec Cuvier), Reis naar Zuidoostereil., p. 54, 1867. Dendrocygna vagans Rosenberg (nec Eyton), Malay Archipelago, p. 373, 1878-79.

Vernacular Names
\end{abstract}
English:
White-spotted Tree Duck
Wandering Tree Duck

Ternate:

Gaboera

Goram:

Bebeka
$K e i$ :

\author{
Larlelat
}

Aru:

Bursil

Talaut:

Taminga

Celebes:

Manu Lantang
Bebetalaga

\section{DESCRIPTION}

Adult Male and Female: Head above, brown of burnt-umber tint, a stripe down hind neck darker brown; upper parts dark brown, feathers broadly edged with pale brown; remiges dark brown; lower back and rump blackish with pale tips; upper tail-coverts black, the basal ones conspicuously barred or spotted with white; tail blackish, paler at tip; eyebrow, face and sides of upper neck grayish brown, mottled with whitish; upper throat whiter, tinged with rufous; loreal stripe passing through the eye, dark brown; lower neck and under parts yellowish rufous, becoming almost white on the abdomen, the bases of the feathers of the neck and breast white, marked with brown, so as to enclose white spots, these spots larger and very conspicuous on the sides of body and on flanks; under tail-coverts barred black and white; wing below dark brown, some of the wing-coverts and ends of the axillaries barred with white (Meyer and Wiglesworth, 1898).

Bill black; tarsi and feet ashy, more or less tinged with reddish; irides brown or chestnut (d'Albertis, fide Salvadori, 1895).

Wing 212-223 mm.; tarsus 47-51; culmen 41-46.

Immature: The young in first plumage have the white spots on the feathers of the flanks whitish, broadly edged with black, and the feathers of the sides and breast with the white spots drawn out into irregular mesial streaks (Meyer and Wiglesworth, 1898). 


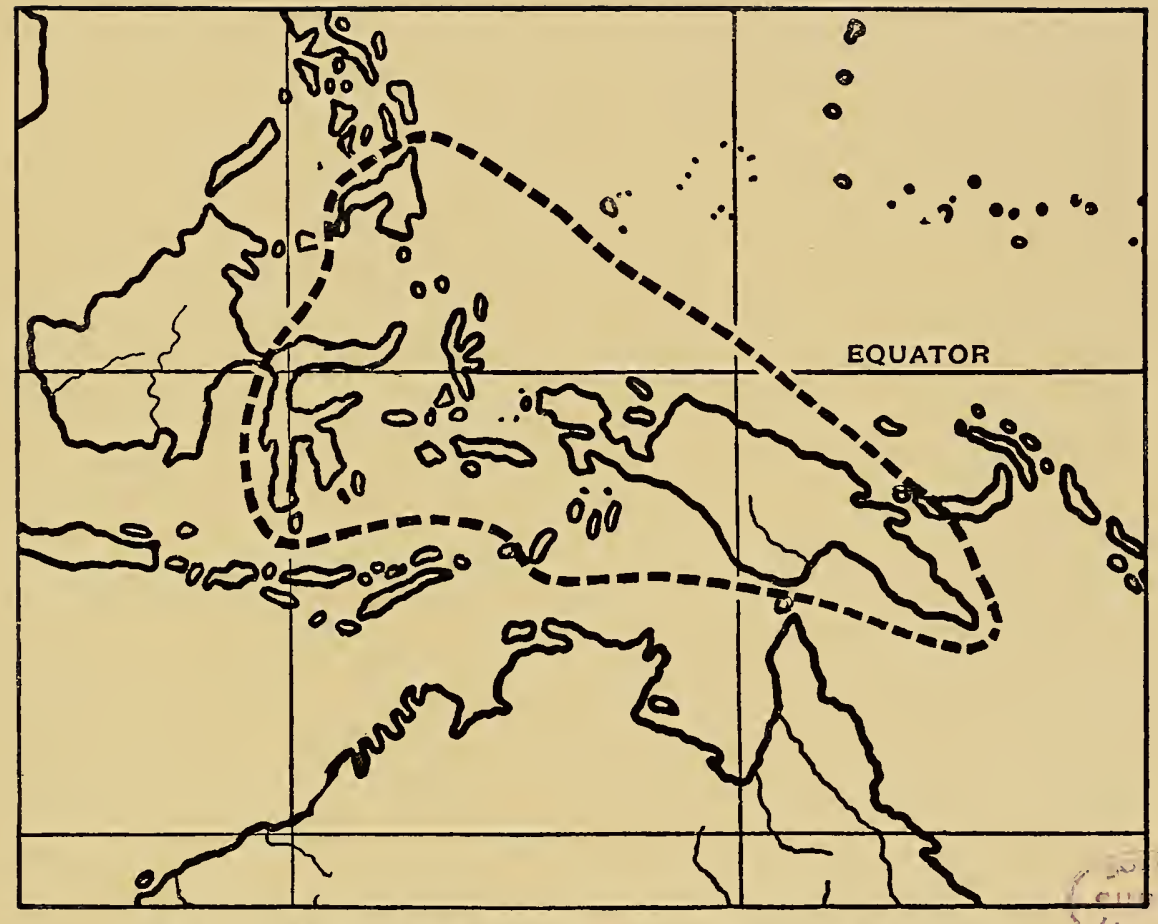

Map 18. Distribution of Spotted Tree Duck (Dendrocygna guttulata) 



\section{DISTRIBUTION}

The Spotted Tree Duck is a common species in some of the East Indies, but is confined to a relatively small area. It has been found in the Philippines at Davao and Zamboanga, Mindanao (Platen, Journ. f. Ornith., v0.. 38, p. 146, 1890; U.S. Biol. Surv.) and on Basilan Island (R. C. McGregor, 1909). The species is not known to occur in Borneo or even western Celebes, Philippines though in the eastern section of this island it appears to be common. Von Rosenberg (Leyden Museum; Zool. Garten, vol. 22, p. 167, 1881) found it abundant in the Minahassa and Gorontalo districts. Walden (1872) has recorded it from Panybie, and Meyer and Wiglesworth Celebes (1896) report it common in northeastern Celebes. It is also said by the same author to be quite common on Kabruang, Talout Islands. Bernstein (Leyden Museum) has re- Talout corded it for Ternate and Halmahera Islands and according to Finsch (Neu Guinea, Islands p. 183, 1865) it is found also on Batjan. Wallace (1863), Hoedt (Leyden Museum), Moluccas Bruijn (Salvadori, 1882), and more recently Stresemann (1914), recorded it from Buru Island; Hoedt found it on Kelang, and Wallace (1863) as well as Moens (Leyden Museum) met with it on Ceram. According to Stresemann (1914) it is common on this island at Pasahari,

Buru Island and Lake Tapala, and Martin (1894) states that on Buru it is abundant at Wakollo. Schlegel (1866) states that the species is found on Ceram-laut, and it is known to occur also on Amboina (Hoedt, Leyden Museum) and on Goram (von Rosenberg, Leyden Museum).

In the Kei Group the species was found by von Rosenberg (Leyden Museum). Kei Rothschild and Hartert (1903) state that it was taken there on Ohoitil, and Hoitil Islands Islands. It is found also on Larat in the Tenimber Islands, and has also been taken by Tenimber von Rosenberg (Leyden Museum) in the Aru Group.

Islands

The status of the species in New Guinea is not yet certain. It seems to be common and breeds in the southeastern section. D'Albertis (d'Albertis and Salvadori, 1879) found it there on the Yarru Islands at Hall Bay, Nicura and Bioto (Salvadori, 1882), and Salvadori (Ann. Mus. Civ. New Storia Nat., Genova, vol. 10, p. 19, 1877) has recorded it for Fly River and Kataw Guinea River. Many specimens have been taken in the vicinity of Port Moresby, where the species breeds (Ramsay, 1879). There are no records for German New Guinea, but a specimen was taken from a flock of three on Gunantambu Island in the Bismarck Archipelago (Heinroth, Journ. f. Bismarck Ornith., vol. 50, p. 400, 1902). Recent years have also brought proof of its occurrence in Archipelago Dutch New Guinea. Both Van Oort (1909) and Ogilvie-Grant (1915) have reported its presence in the vicinity of Merauke in that province; nor is it by any means certain that the Tree Duck so commonly seen by de Beaufort (1909) at Lake Sentani (northeastern Dutch New Guinea) did not belong to this species.

\section{GENERAL HABITS}

Alтнобgh almost nothing is known of the habits of this species, it appears to be plentiful enough in several of the East Indian islands. Collectors have left few notes as to the intimate habits and characteristics of these ducks. In New Guinea they are said to frequent the water-holes and creeks behind the coast range (Sharpe, 1877). The species is probably of a confiding nature, and has been described as very bold on the Island of Buru (Martin, 1894). Of the voice nothing has been reported, but it is probably similar to that of its nearest relative, Dendrocygna arborea of the West Indies.

The food of the Spotted Tree Duck is said to consist of the seeds of aquatic plants 
and "piccole chiocciolette" (d'Albertis, fide Salvadori, 1882). Of the nesting habits nothing is known except that the season is a long one. D'Albertis (Salvadori, 1882) in New Guinea took a female with a mature egg in April, but in another district found the species nesting in September. According to Ramsay (1879) the nests in southeastern New Guinea are placed in the hollows of trees.

So far as I have been able to discover, this species has not been kept in any of the large public collections of Europe or America, but it was brought alive to England from Celebes by Mr. Jamrach in 1888 (Hubbard, 1907). 


\section{EYTON'S TREE DUCK}

\section{DENDROCYGNA EYTONI (EYTON)}

(Plate 14)

SyNONYMY

Leptotarsis eytoni Eyton (ex Gould MS.), Monograph Anatidæ, p. 111, 1838.

Dendrocygna eytoni G. R. Gray, List Birds British Mus., pt. 3, p. 132, 1844.

Dendrocycna eytoni Sclater, Proc. Zool. Soc. London, 1880, p. 510.

Dendrocygna eytoni munna Mathews, Austral Avian Record, vol. 1, p. 86, 1912.

\section{Vernacular Names}

\section{English:}

Eyton's Tree Duck

Plumed Whistling Duck

Wood Duck
German:

Gelbfüssige Baumente

Aborigines of Australia:

Now-ē-rāyen

Nowee

\section{DESCRIPTION}

Addet Male and Female: General color above, brown with an olive shade, the feathers of the upper back and some of the scapulars conspicuously margined with straw color or yellow-white; wings like the back; upper tail-coverts yellowish buff, each feather having a rounded spot on either web, and a broad tip of dark brown; rump and tail dark brown; crown of the head and hind neck pale ochreous brown; breast pale chestnut brown, transversely barred with black, which is richer in color, and more marked at the sides; abdomen and under tail-coverts buffy white; lengthened lanceolate flank plumes, pale yellowish buff margined with black.

Bill pale reddish brown, the upper mandible conspicuously blotched with black; legs and feet fleshy brown; iris dark brown.

Wing $241 \mathrm{~mm}$.; bill 43; tarsus 53 (North, 1913).

Note: The iris in the few specimens I have seen is orange yellow to orange brown; the legs and feet pink-flesh color and the bill dull pink but heavily mottled all over the culmen with black. Nail of bill horn color.

IMmaTURE: Some specimens, apparently immature, have the dull white of the throat extending on to the sides of the neck, which is grayish white; also the upper part of the fore neck; the black transverse barrings on the breast are narrow and less distinct, and the lanceolate plumes have broader blackish margins. The wing is smaller (North, 1913). In the young specimens which I have seen the barring on the upper abdomen first appears on the sides and the ornamental plumes are at first quite different from adult ones.

Remarks: The ornamental flank plumes are carried for the most part outside of the wing and reach up in a sort of fan to about the level of the back, or even above it. However, when alarmed, the birds seem to be able to depress them so that they are scarcely noticeable. 


\section{DISTRIBUTION}

THE present species of Tree Duck is confined to the continent of Australia, though it has been known to straggle to New Zealand. There it has occurred several times, and in some numbers at Kaitangata New and on the Thames in Otago (Purdie, 1872; Finsch, Journ. f. Ornith., vol. 22, p. 201, Zealand 1874; Buller, 1888) as well as on the Ashburton Domain (W. W. Smith, 1897), being therefore recorded only from the southeast coast of South Island.

In Australia it is resident, but appears to be most common in the north and west, and is quite rare in the south (North, 1913). Ramsay (1888) and Fraser (1903) have both, however, recorded it from Australia the southwest and west, while in the northwest it is seen in large numbers. Carter ( $f i d e$ Mathews, 1914-15) says it is a common duck in this region, especially east of Point Cloates, while Söderberg (1919) states that it is rather common and that it nests near Mowla Downs and on the Fitzroy River. It was found breeding at Jimbaloora Swamp and Parry's Creek (Rogers, fide Mathews, 1914-15), and Hartert (1905) has recorded it from South Alligator River, Mary River, Glencoe Station, Mt. Ringwood and Meda Station. Keartland (North, 1898) also states that it is abundant on the Fitzroy River and that it breeds about Mt. Campbell. Stokes (Gould, 1865) saw it in great numbers on the Adelaide River. It breeds on the Daly River (Keartland, fide North, 1913) and has been recorded for the Gulf of Carpentaria region by Stokes (Gould, 1865) and Ramsay (1888). Ingram (1907) took specimens in the Alexandra District (19 ${ }^{\circ}$ south latitude) and according to Stokes (Gould, 1865) it is found inland south as far as $18^{\circ}$ south latitude to the Albert River.

Although this species has never been found in New Guinea or any of the Melanesian Islands, it appears to extend north to the very coast in Australia. Ramsay (1888) has recorded it in Queensland Queens- $\quad$ from Cape York, Rockingham Bay, Port Denison and Wide Bay; while Berney (1907) land states that it is common in North Queensland. According to Macgillivray (1914) the species breeds in North Queensland on the Cloncurry River, and about Cape York. In New South Wales it is no doubt much less common. Ramsay (1888) has recorded it for Richmond and Clarence Rivers, however, and North (1913) states that it breeds on the Macquarie Marshes and that it is New South abundant after the rains in the northwestern sections of New South Wales, on the Wales Barwon, Warrego and Culgoa Rivers.

There is very little information as to its status in Victoria, but that region is included in Ramsay's Victoria (1888), and more recently in North's (1913) list. Of its occurrence in Tasmania I have Tasmania been unable to find any specific records, but it occurs there according to Legge (1887), South North (1913), Littler (1910), and Mathews (1914-15). In South Australia it is common Australia in the interior, on Strzelecki Creek, Cooper's Creek, etc., but not north of the Stony Desert (Sturt, fide Mathews 1914-15). It is of rare occurrence on the southern coast, and in general it is more abundant in the interior than along the sea. Mr. Edwin Ashby writes me that the species does not now visit South Australia, though it is believed to have done so thirty years West ago, at least south on the Murray River to Moama. Mr. Ashby, himself, doubts the Australia validity of these early records. In West Australia, he says, it ranges farther south, at North least as far as Perth. In North Territory he thinks it is far more numerous on interior Territory water-holes and lagoons, than on the coast.

\section{GENERAL HABITS}

The strongholds of Eyton's Tree Duck are the rivers and swamps of northern and northwestern Australia. According to Stokes (Gould, 1865) it is not to be met on the upper waters of rivers, nor near their mouths. He also states that he never found it in swamps, but many observers since his time speak of swamps as its habitat. In the 


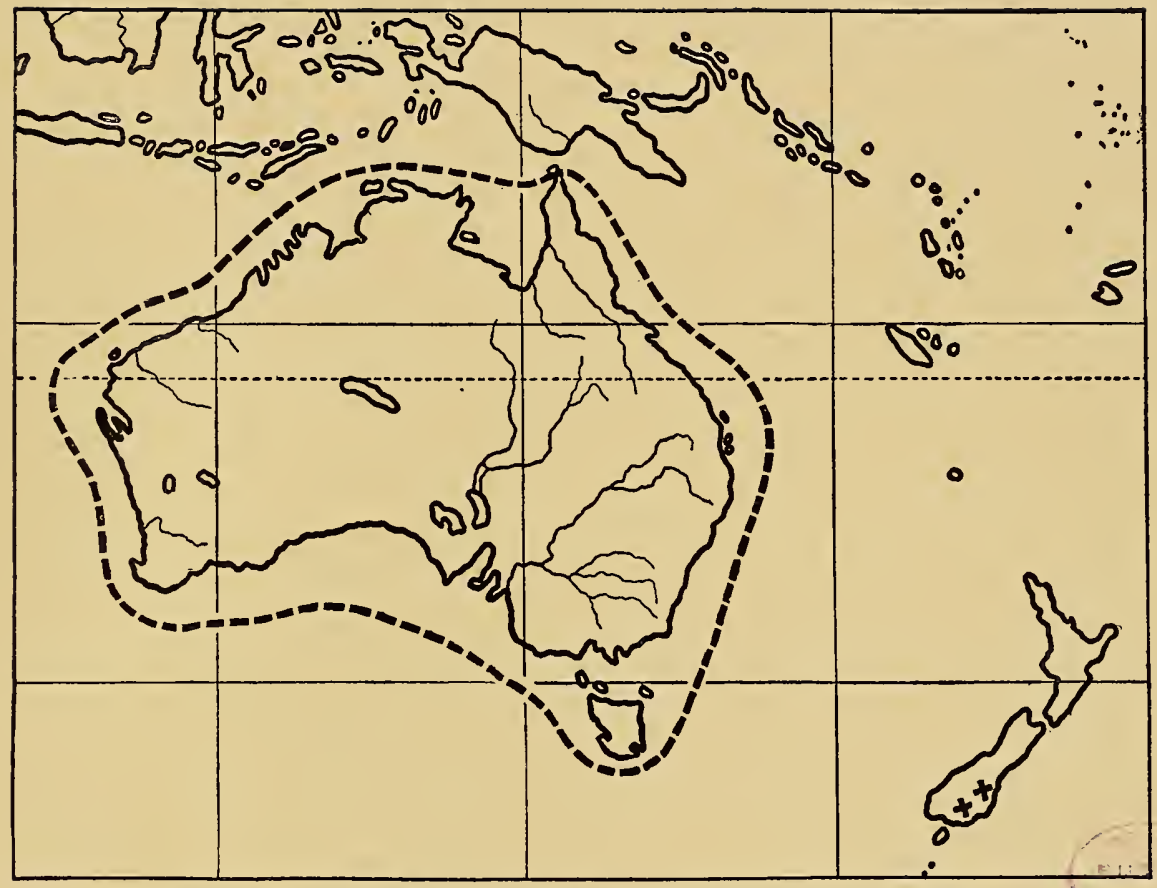

MaP 19. Distribution of Eyton's Tree Duck (Dendrocygna eytoni)

Sporadic records are indicated by crosses $(X)$ 

breeding season the birds retire to the well-grassed country, and usually some distance from the water (North, 1913). In general this species is found in the same localities as the Wandering Tree Duck (Dendrocygna arcuata). and is similar in its habits.

WARINESS. Even the early travelers speak of these birds as being very wary, a characteristic that is at variance with the habits of other Tree Ducks (Stokes in Gould, 1865; Sturt in Mathews, 1914-15; Leichhardt, Journ. Overl. Exp. Austr., 1847).

Darly Movements. This species is nocturnal and crepuscular in its habits, and in this respect resembles its congeners. Keartland (North, 1898), in northwest Australia, often disturbed flocks numbering thousands, feeding at night in the dry grass. Toward morning these flocks returned to the water, and after a short bath repaired to the shelter of bushes on the bank, packing so closely together when sleeping, that seven or eight could be taken at a shot.

Furght. The flight of this duck is powerful, and some writers speak of it as laborious (Berney, 1907). Doubtless it is gooselike and not so rapid as that of true ducks. One of Gould's (1865) correspondents spoke of "large V-shaped flights" passing in March, from southeast to northwest. Few observers have ever noted Tree Ducks on migration, and it may well be that when traveling long distances they fly in orderly flocks like geese. But this is certainly not true of these birds when flighting about their feeding grounds.

Flocks of from 120 to 150, and one of 300, have been seen in North Queensland (Berney, 1907; Macgillivray, 1914) while in the interior of northwest Australia much larger aggregations have been noted. Leichhardt (Journ. Overl. Exp. Austr., 1847) speaks of "large swarms" and claims to have seen the sky black with these water-fowl.

Swrmming. There are very few references to the behavior of these birds on the water. The species is an inhabitant of the plains and shallow swamps and is extremely gooselike in its mode of living.

Perching. Where trees exist it has been noted to perch in a "very clumsy manner, swinging and pitching to and fro" (Stokes in Gould, 1865), but the species certainly spends very little time on trees. In captivity they do not seem to care about perching, even when they have full wings.

Association with other Species. The Plumed Whistling Duck seems to associate freely with its congener Dendrocygna arcuata in northwest Australia, and 
Keartland (North, 1913) mentions killing five of the former and six of the latter at one shot. Females and young must at times associate with other species of ducks, for Rogers (Mathews, 1914-15) found a brood of Dendrocygna eytoni together with broods of Anas superciliosa and Nyroca australis. The small aggregations in New Zealand are said to have fed freely with Anas superciliosa and other species.

Vorce. The note is a shrill whistle that can be heard at a considerable distance. This note seems to be uttered chiefly during flight. It is probably the same in both sexes, although the female's trachea resembles that of the females of Dendrocygna viduata, Dendrocygna bicolor and Dendrocygna javanica in having the lower rings imperfect posteriorly, and closed by a membrane (Heinroth, 1918). I have heard specimens in zoölogical gardens utter a low note, like cheep-cheep. All Tree Ducks seem to have low chirping or "twittering" calls besides the loud flocking whistle.

Food. The food is chiefly vegetarian, consisting of tender buds of aquatic plants (North, 1913) and probably the seeds of grasses on the plains (North, 1898). Mathews (1910) examined stomachs that contained seeds and grit. A small group of these birds that lived on Ashburton Domain fed on oats and wheat scattered on the water's edge (W. W. Smith, 1897).

Courtship and Nesting. In New South Wales the months from September to December constitute the breeding season, while in the North Territory of South Australia breeding begins in the rainy season, in February, and extends to the end of May or middle of June (North, 1913). In North Queensland eggs were taken in February (Berney, 1907).

The real breeding grounds of these birds are the interior and northern rivers, lagoons and water-holes. From time to time, so Mr. Ashby writes me, all these interior regions suffer from severe drought. In such years, most of the ducks leave, and come southeast and south, where they remain until the drought is over. But during their stay in the south, strange as it may appear, they never breed. Of this Mr. Ashby seems certain. Robinson (North, 1913) states that in 1897, for example, no water-fowl could breed in New South Wales, because of the drought. The reedbeds, he said, were dried up and eaten or burned off to destroy the wild pigs and water rats.

Although there are no observations on the display of Eyton's Tree Duck, beyond the general notes of Heinroth (1918, p. 241) and a curious posture noted by myself under Captivity, it is very interesting to speculate as to whether the remarkable flank feathers of this species are more elevated at this time. These feathers, which are so highly developed in the present species, are to be found also in Dendrocygna arcuata. In Mathews' (1914-15) plate, the flank feathers of Dendrocygna eytoni are repre- 
sented as lying in a fan-shaped group, outside, and covering all the basal part of the wing, even projecting up over the back and this is correct in spite of the fact that the plate has been criticized.

The nest is placed on the ground, either on the plains far from water (sometimes three or four miles according to Macgillivray, 1914) or in long cane-grass near the water. If in the latter situation, it is said that the birds build long tracks through the cane from the nest to the water. The nest is a slight hollow in the soil, lined only with short grass (Robinson in North, 1913). Like other Tree Ducks these birds apparently never use down or feathers in lining the nest. Gould (1865) mentions a nest that was in a hollow log, presumably lying on the ground. There is no indication that the species ever nests in trees, though it may very probably do so in the parts of its range where trees are found.

The clutches described by North (1913) numbered seven, nine, and ten eggs respectively. Campbell (1901) gives ten to twelve as probably the normal number, but Gould (1865) is perhaps more nearly correct in placing the number at eight to ten. Macgillivray (1914) says that as many as ten may be found. Söderberg (1919) found a nest in northwest Australia that contained eight eggs. One found by F. C. Morse in New South Wales contained sixteen eggs (White, Emu, vol. 22, p. 168, 1922). In color they are almost pure white. They measure about 48.5 by $35.8 \mathrm{~mm}$. (average of twelve eggs given by North, 1913). The extent of the incubation period is not known, but it is probably thirty to thirty-one days. Possibly the male assists in incubation, as is the case in some other Tree Ducks, but nothing definite is known on this point.

Status. I have no specific information as to the present status of this species, but Mr. Ashby writes me that it is never seen now in South Australia. I presume that it has become exceedingly rare in New South Wales also, but I have no reason to suppose that its numbers have greatly diminished in the interior or the northwest districts. From a careful perusal of the literature one certainly gets the impression that the species is still plentiful in the more inaccessible regions. During certain seasons it is still frequently seen in some numbers in the poultry shops of Sydney (North, 1913).

ENEMIES. Keartland (North, 1898) in writing of these birds, states that in northwestern Australia the natives "make sad havoc amongst their eggs." Considering the excellence of the flesh I dare say they make away with large numbers of the adult birds also. From a note of Robinson's (North, 1913) one is led to suppose that in New South Wales the wild pigs and water-rats prove very destructive to this as well as to other species of wild-fowl. 
Damage. There is no mention in the literature of any damage done by these birds, though they may at times cause detriment to fields of grain.

Food VALUE. Early writers invariably described this duck as excellent for the table, and it is still thought by some to surpass all other Australian ducks in flavor (North, 1913).

Behavior in Captivity. The Plumed Whistling Duck is rare in European and American collections and for some reason has never been imported in any numbers. It was, however, represented in the Knowsley Collection, the property of the Earl of Derby, which was sold in 1851. The London Zoological Gardens had specimens in 1838 (Eyton, 1838) and also received two specimens in 1867, which were still living sixteen years after (in 1883). In England, specimens sell at prices varying from $£ 8$ to $£ 10$ per pair (Hubbard, 1907). In the United States the species has rarely been imported, and has only recently been represented in the New York and Washington gardens. A number were brought over to this country in 1920 by Ellis S. Joseph and were quoted at $\$ 75.00$ per pair. I think these were the first ever seen alive in America.

Mr. Blaauw told me that he kept them several times but that they never bred, and so far as I know they have never done so in confinement anywhere. Those I have seen do not seem to care much about perching and keep strictly by themselves, even disdaining the company of their immediate relatives. They have a very strange appearance with their great fans of flank plumes sticking up on each side. Seen from the front when they are perching they look as if they were sitting in a kind of basket.

Once while I was watching a couple of pairs at the Zoölogical Park in Washington I noticed one walk across the aviary floor actually on the tips of its toes, holding itself very erect and stiff and the head high up. The keeper told me he had seen them do this before and it is possible that some such action may be part of the display. It would be somewhat akin to what we see in the Egyptian Goose and in some of the Antarctic Geese of South America. 
SUBFAMILY ANATIN 



\section{SUBFAMILY ANATINE}

THIS group includes the so-called Surface-feeding Ducks. In addition to the more typical ducks, it comprises several slightly aberrant or specialized forms such as Nesonetta and Malacorhynchus, as well as others whose position is perhaps more or less annectant between this and other groups. Such are the Sheldrakes, whose general appearance and habits are somewhat suggestive of the geese; the Mandarin and the Carolina Ducks, by some placed with the Plectropterina, but probably more nearly allied to the typical ducks; and finally the peculiar Stictonetta and Heteronetta, isolated forms of the Southern Hemisphere. The members of the subfamily agree with the Diving Ducks (subfamily Fuligulinoe) in having the lower part of the tarsus scutellate, but differ from them in having the swimming membranes of the feet less developed and the hind toe without the marked lobe of these latter. They have rather flattened beaks, and the males nearly always have an asymmetrical osseous bulla at the base of the trachea whose effect seems to be to modify the voice in this sex.

Although a great number of genera have been currently recognized by various writers, yet in considering the group as a whole it becomes exceedingly difficult to find adequate characters on which to base many of these. A somewhat conservative course has therefore been adopted in this work, and only the following are given generic rank, the chief diagnostic characters of which are grouped in the key appended:

a. Lower portion of tarsus with transverse scutellæ in front; males with an osseous bulla at the base of the trachea; hind toe without a conspicuous membranous lobe.

b. Edges of bill without prominent lamellæ; size larger..................Alopochen.

$\mathrm{b}^{\prime}$. Edges of bill provided with more or less prominent lamellæ.

c. A wing speculum present.

d. Tail feathers broad and rounded at the ends.

e. Nail of the beak hooked.

f. Nail narrow, less than one-half the width of bill at tip.

g. Bill at base deep as compared to width, flat and broadening toward tip; lamellæ of upper mandible strongly developed, especially toward tip, those of lower mandible projecting strongly outward.

f.' Nail broad, occupying whole tip of beak.

....... Tadorna.

h. Feathering at sides of upper mandible forming almost a straight line from forehead to angle of mouth; feathers of sides of neck in male elongated; innermost tertial very broad, its shaft bent down...Aix.

$h^{\prime}$. Base of upper mandible forming a deep reëntrant angle between feathering of forehead and that of lores; inner tertials somewhat broadened, but the shafts straight.............Lampronessa. 
$e^{\prime}$. Nail of the beak not hooked; wide, more than or about half the width of bill at tip; culmen nearly straight, bill not broadening toward tip, not so deep in proportion to height.

i. Lamellæ equally developed along edge of upper mandible; neck feathers normal............................ Casarca.

i.' Lamellæ of upper mandible only moderately developed; anterior edge of feathering on forehead convex; nuchal feathers elongated.

$d^{\prime}$. Tail feathers usually more or less narrowed or pointed at tip.

.......Pseudotadorna.

j. Bill not or not noticeably broadening toward tip, its depth at base much less than length from forehead to nail; the nail distinctly hooked, its width less than half that of the tip of beak.

k. Lamellæ moderately developed.

1. Wings normal but not reaching end of tail.......... Anas.

$l^{\prime}$. Wings very small, useless for flight............. Nesonetta.

$\mathrm{k}^{\prime}$. Lamellæ extremely developed, wings normal........Elasmonetta. $j^{\prime}$. Bill decidedly spatulate.

$\mathrm{m}$. No soft membrane on sides of bill near its tip......... Spatula. $\mathrm{m}^{\prime}$ Bill with a soft membrane on the sides toward the tip

$\mathbf{c}^{\prime}$. No wing speculum present, tail very short.

Malacorhynchus.

n. Bill longer than head, at its base much higher than broad; culmen concave ................................

$\mathbf{n}^{\prime}$. Bill about equal to length of head, nearly as high as broad at the base; culmen not very concave...................... Heteronetta. 


\section{EGYPTIAN GOOSE \\ ALOPOCHEN AEGYPTIACUS (BRISSON)}

(Plate 15)

SYNONYMY

Anser agyptiacus Brisson, Ornithologie, vol. 6, p. 284, pl. 27, 1760.

Anas agyptiaca Linné, Systema Naturæ, ed. 12, vol. 1, p. 197, 1766.

Chenalopex agyptiaca Stephens, General Zoology, vol. 12, p. 43, pl. 42, 1824.

Chenalopex agyptiacus Wagler, Oken's Isis, 1832, col. 1235.

Alopochen agyptiaca Stejneger, Standard Nat. Hist., Birds, p. 141, 1885.

Vernacular Names

English:

Egyptian Goose

Nile Goose

Mountain Goose

Zambesi Goose

German:

Nil Gans

Egyptische Gans

Fuchsgans

Buntgans

Entengans

French:

Oie d'Egypte

Oie égyptienne

Oie du Nil

Oie renard

Italian:

Oca egiziana

Dutch:

Berggans

Nijlgans

Slovene:

Nilska Gos
Arabic:

Wuz

Bahh

Hitt

Maltese:

Wizza tal'Egittu

Egyptian:

Bauk

Abyssinian:

Jebra

Somali:

Etal-jaz

German East Africa:

Bita hosorongi

Congo:

Vwadungu

Bunda

Portuguese East Africa:

Nango

Kaffirs:

Esikwi

Basutos:

Lefalva 


\section{DESCRIPTION}

Adult Male: Head gray except for a large patch around the eye, an area at base of bill, and a ring around the lower neck, which are ruddy brown. Mantle rusty gray, finely lineated with black. Scapulars dark brown vermiculated with lighter colors; back, rump, upper tail-coverts and tail black. Breast almost like the mantle, but lighter; middle of abdomen white; flanks almost like breast; lower abdomen and under tail-coverts rust color. There is a prominent dark maroon patch in the middle of the breast, at junction of breast and abdomen. All of upper wing-coverts white, with a narrow black line; secondaries rich metallic green, forming a marked speculum. Primaries black.

Iris dark yellow; bill pink, with tip, margins, and base black; tarsi and feet flesh-color to blood-red.

Wing 370 to $405 \mathrm{~mm}$.; bill 48 to 55 ; tarsus 80 to 85 .

Weight up to 6 pounds (A. Chapman, 1921) (2.7 kilograms).

Adult Female: Similar but slightly smaller. Colors not quite so brilliant.

Weight, about 4 pounds (about 2 kilograms), and up to 4.5 pounds.

ImMatuRE: The head is much darker, the colors are nowhere so brilliant and the maroon patch on the breast is wanting. The bill is pale and yellowish, and the legs are yellow, becoming more pink with age.

Young in Down: Resemble very closely the young of Tadorna and Casarca. Above striped lengthwise with gray-white, alternating with dark brown; lower part of the rump white, in this respect being entirely different from geese (Naumann, 1896-1905).

Note: Coloring becomes more brilliant with age, and at base of bill in male there is a slight swelling which becomes larger at the breeding season. Feet become darker red with age (Naumann, 18961905), and are richer in color during the reproductive period.

\section{DISTRIBUTION}

The Egyptian Goose is, perhaps, the best known and most abundant of all African Anatida. It is found throughout the whole continent, excepting, of course, the arid regions, and even northward General to the eastern Mediterranean countries. It is non-migratory, its movements being only local and conditioned by the water supply.

Like other African or southeastern European species, these birds have often occurred beyond the confines of the usual range, notably in Europe. Since the birds are commonly kept in zoölogical Sporadic gardens and private parks the records of appearance in Europe have frequently been flights taken to refer to escaped birds. But the peculiar circumstances attending certain of these records have led many authorities to accept some of them at least as being cases of sporadic flights. We have here, I believe, a situation analogous to that presented by the appearance of the Ruddy Sheldrake in large numbers outside its usual range.

In the British Isles eighty Nile Geese are said to have once appeared in Hampshire; three were shot near Glasgow in 1832, and others have been taken in Durham, Somerset, Cornwall, Norfolk, Suffolk, European Devonshire, Berkshire, Westmoreland, Cambridge, Hampshire, Northumberland, records Dorset, Kent, Sussex and Oxford (F. O. Morris, 1903). In Ireland the species has appeared at least a dozen times, sometimes in considerable parties (Ussher and Warren, 1900). According to G. R. Gray (1871) very many appeared in south Scotland in 1832, while twelve were seen on the Tyne in 1846, and flocks were observed in 1865 and 1867 in the Montrose Basin. On the continent these birds have been repeatedly seen in Germany. A large flock is said to have appeared in 



Anhalt in 1770 (Reichenow, Journ. f. Ornith., vol. 47, p. 115, 1899). Others have been seen or taken in Alsace (Schneider, Ornis, vol. 3, p. 546, 1887), near Gotha (Hertwig, Ornith. Monatsschr., p. 167, 1888), near Offenbach on the Main (Preuschen, Ornis, vol. 7, p. 494, 1891), between Wesel and Emmerich (Hartlaub, Journ. f. Ornith., vol. 35, p. 268, 1887), in Westphalia (Landois, Zool. Gart., p. 251, 1871), near Breslau, Karlsruhe and Heidenheim (Altum, Journ. f. Ornith., vol. 25, p. 107, 1877) and recently a flock appeared (October, 1910) in Silesia (Kollibay, Ornith. Monatsschr., p. 3, 1915). There are also several records for Belgium, the species having been taken at Namur in 1835 and at Liège in 1837 (Degland, 1849), near Arlon in 1846 (de la Fontaine, 1868) at Wyneghem in 1870 and at Herinnes in 1906 (Dubois, 1912). Paris (1911) gives the departments of Saône-et-Loire, Eure-etLoire, Calvados and Allier as localities in which Egyptian Geese have been taken. To these might be added the records for St. Omer, 1905 (van Kempen, Bull. Soc. Zool. de France, 1905, p. 150), Metz, 1833 (Degland, 1849), Lorraine, 1850 (d'Hamonville, 1895), Caen, 1862, and the Lower Seine, 1906 (Ternier and Masse, 1907). There seems to be only one record of its occurrence in Spain, on the Rio Jarama, 1853 (Reyes y Prosper, 1886) and, so far as I know, the species has only been found once in Portugal (Seabra, 1910). There are apparently no records of its occurrence in Italy, though it has been found in Sicily (Malherbe, 1842-43), and recently in Malta (Despott, 1917). In Greece the species is said to breed (von der Mühle, 1844), but it is evidently not a common bird, occurring irregularly in pairs in the spring (Lindermayer, 1860). I have been unable to find any specific records of the appearance of these birds in Anatolia, though Naumann (1896-1905) says it has been found there, as well as at the Danube Delta (!) and in Syria. Recently two specimens were taken south of Urfa, in northern Mesopotamia (Weigold, Journ. f. Ornith., vol. 61, p. 34, 1913). Quite inexplicable is the capture of one of these birds near Peking, China (!) (David and Oustalet, 1877).

To return to Asia Minor. We know now that this species is by no means rare in Cyprus, where it has been repeatedly taken during the winter months (Bucknill, 1911). It is said by Naumann (1896Regular 1905) to have been taken in Syria, and has been recorded as frequently seen throughout Range: Asia the year about the Dead Sea (Tristram, 1884). Still, the birds seem to be rare in Lower Minor Egypt (W. Raw, Ibis, ser. 11, vol. 3, p. 371, 1921), though Shelley (1872) states that they are found throughout Egypt and Nubia, where they breed. Adams (1864) met with them in the vicinity of the Second Cataract, and I saw a few near Abou-Simbel in 1908, but probably it is not till one reaches the Sudan that the species is found in abundance. It is said to be very common at Shendi Egypt below Khartum (Rothschild and Wollaston, Ibis, ser. 8, vol. 2, p. 31, 1902), and in Sudan Kordofan (Strickland, 1850). Numerous travelers found it in great abundance, and discovered it breeding in the basin of the White Nile, which appears to be one of the headquarters of these birds (Ogilvie-Grant, 1902; Witherby, 1901; JaegerskiöId, 1904; A. L. Butler, 1905, 1908). No doubt the species inhabits the comparatively unknown region from Kordofan and Darfur west to Lake Chad, at least during the rains.

In Abyssinia the species is everywhere abundant, from the northwest (Zedlitz, 1910) and northeast (Finsch, 1870; Blanford, 1870), through Shoa (Harris, 1844, etc.), to the southern parts (von Northeast Erlanger, 1905). It breeds throughout this entire region and has been recorded for the Africa following localities: Gasciani River (Antinori, 1864), Ciacia (Salvadori, 1888), Waliko and Maragaz (Jesse, 1869), Aschangi Lake and Ansebathal (Blanford, 1870), Senafe (Finsch, 1870; Blanford, 1867), Sheik Huseim (Sharpe, 1895), and Dembea, Takaze and Anseba (von Heuglin, 1873; Finsch, 1870). Whether or not the species is found in Eritrea I am unable to say definitely, though there can be little doubt of its occurrence there. At any rate it has been found along the coasts of French and British Somaliland (Speke, 1860; Blyth, Ibis, ser. 1, vol. 2, p. 248, 1860; von Heuglin, 1873; Salvadori, 1884), and is said to breed throughout that region (Peel, 1900). G. A. Fischer (1884) has recorded it from Barawa, Italian Somaliland.

In British, and in German East Africa (now Tanganyika Province) Egyptian Geese are no less common than in Abyssinia. To attempt a catalogue of all the known records for this region would 
be hopeless, and it will therefore be necessary to restrict ourselves to the more important and recent literature. One may assume that the species is less common in the eastern, more arid and lowlying East part of British East Africa, though specimens have been taken on the coast at Lamu Africa (G. A. Fischer, 1884; F. G. Jackson, 1899). It is more common in the central and western parts of the Colony, in Tana (G. A. Fischer, 1884), about Kilimandjaro (F. G. Jackson, 1899; Sjöstedt, 1910) and especially in the Massai country (Neumann, 1898; Schillings, 1905) and about Lake Naivasha (G. A. Fischer, 1884; F. G. Jackson, 1899; Dearborn, 1909; Stone, 1906; van Someren, 1916). Other localities in British East Africa where specimens have been taken are Guaso Nyiro (Lönnberg, 1912), Bussissi (Emin, 1891) and Rikwa Lake (Kothe, 1911). No doubt the birds are abundant throughout Uganda, though there are, so far as I know, no records for the northern portions. In the south it was seen about Lakes Albert Nyanza (Emin, 1891), Albert Edward (Johnston, 1902) and on the west coast of Victoria Nyanza, at Toro and Jinja (van Someren, 1916). Salvadori (1914) gives other localities.

Egyptian Geese are plentiful also in Tanganyika Province (German East Africa), having been met with in the north on the Pangani, about Arusha, and at various other places near Kilimandjaro (G. A. Fischer, 1884). In the western districts the species was found at Ugalla, on the shore of Lake Tanganyika, at Luwule and Lufira (Böhm, 1882, 1885; Matschie, 1887). Weigall (Tristram, 1888) took specimens at Newala. According to Grote (1912) the birds are not found in the southeastern part of the Colony, yet Schuster (1913) had specimens from Rovuma River, and Fülleborn (fide Reichenow, 1900) met with the species in the Langenburg district.

Little is known as to the status of this species in the Congo Free State, but it is certainly abundant along the eastern border, having been taken on the Congo side of Albert Edward (Lönnberg, 1917) and at Mukimbungu (Lönnberg, 1907) as well as on the west shore of Tanganyika (Dubois, 1886a). In the extreme southeast, Neave (1910) found it common in Katanga. The same author states that the species is plentiful in northern Rhodesia, as it is also on the Upper Zambesi, where it breeds (Livingstone, 1857; Bradshaw, fide Stark and Sclater, 1906). Shelley (1882) and Buckley (1874) have recorded it from Mashonaland, while Kirk (1864) and B. Alexander (1900) met with the birds on the middle or Lower Zambesi. Buckley (1847) has recorded it for Matabeleland.

In Portuguese East Africa Egyptian Geese have been found at Lake Nyassa (Hartert, 1898) and on the Shire River (Kirk, 1864). No doubt it inhabits the southern as well as the northern parts of this Colony. At any rate it has been recorded from the Limpopo River (Buckley, 1874) and is everywhere common in the southern and western parts of the Transvaal (Holub and von Pelzeln, 1882). The same is true of the Orange River Colony, where the species is everywhere abundant, and where it breeds (Holub and von Pelzeln, 1882; C. H. T. Whitehead, 1903; Haagner and Ivy, 1908). Murray ( $f$ ide Stark and Sclater, 1906) met with it in Basutoland. In Natal, however, this species does not seem to be common, either in the northern parts, where it was found near Newcastle (E. A. Butler, Feilden and Reid, 1882) and near Maritzburg (Woodward, 1899), nor in the south, where it has been described by various writers as rare though breeding in Pondoland (Shortridge, 1904; Horsbrugh, 1912).

In Cape Colony these birds seem to be less common in the eastern than in the western parts. In the east the species has been recorded from Port St. John (Shortridge, 1904), from Aliwal North (C. H. T. Whitehead, 1903) and from King William's Town, where it is said to be rare (Trevelyan, fide Stark and Sclater, 1906). As one goes west the species occurs more frequently. Layard (1875-84) has recorded it from Knysna and from the Gouritz River, as well as from other coastal localities such as Caledon, Pearl and Piquetberg. Sclater (Ibis, ser. 8, vol. 4, p. 86, 1904) found the birds not uncommon in Saldanha Bay. In the interior, specimens have been met with near Fraserburg (Burchell, 1822-24), and near Carnavon (Littledale, 1908), as well as on the Orange River at Upington (Bradshaw, fide Stark and Sclater, 1906) and on the Kuruman River in Bechuanaland (Burchell, 1822-24). Howard (fide Stark and Sclater, 1906) has reported the species from the mouth of the Orange River. The Egyptian Goose breeds throughout South Africa, as it does in almost every part of its range. 


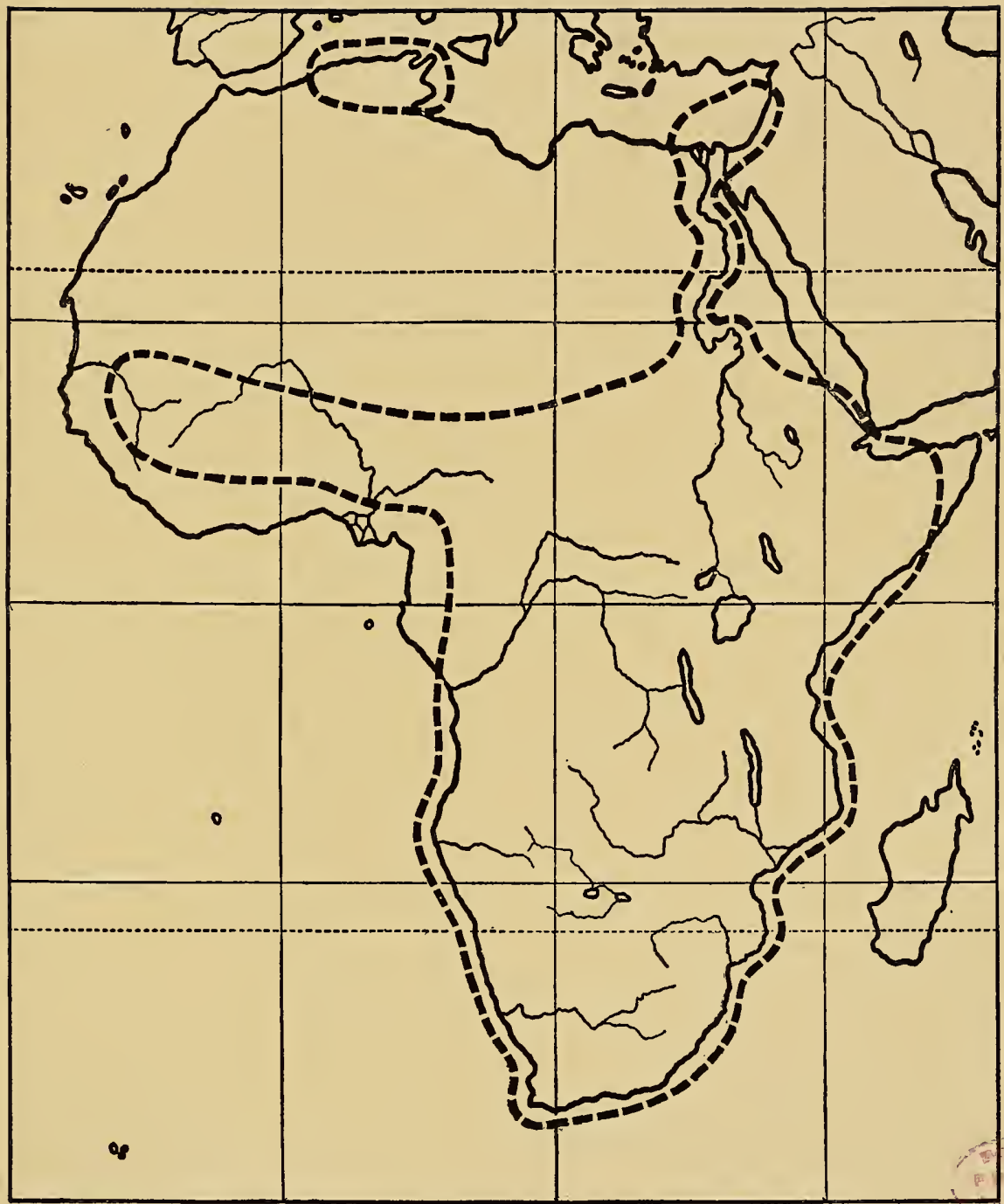

Map 20. Distribution of Egyptian Goose (Alopochen agyptiacus) 

In German Southwest Africa this species is said to be a common resident in the south and central parts (Andersson, 1872), which is remarkable considering the nature of the country. It is hardly likely that any are to be found in the great Kalahari Desert (Bechuana Protectorate), Southwest but though Andersson (1872) does not mention seeing the species on Lake Ngami it un- Africa doubtedly frequents the salt pans of the Okawango Basin, and has been recorded from Victoria Falls on the Upper Zambesi (Sclater, Ibis, ser. 8, vol. 5, p. 109, 1905). From Portuguese West Africa there are records only for the southeast, where the species appears to be common on the Cunene River, having been taken at Humbe and Coroca (Barboza de Bocage, 1877-81). Though not West recorded from other parts of this Colony, $\mathbf{I}$ am inclined to believe that the species in- Africa habits every part of the regions on the Gulf of Guinea, though it is certainly a much rarer bird there than in East Africa. Recently, however, flocks have been recorded from Zambi on the Lower Congo (Menegaux and van Saceghem, 1918). There are no records of its occurrence in the French Congo, but it was met with in Ubangi, northwestern Congo Free State, by Dybowski (Oustalet, 1893), and has been taken in the interior of Camerun at Tibati, Laro, Bansso and the Nun River (Reichenow, 1911). It does not seem to occur on the coast of Camerun, and the same remark appears applicable to Nigeria, where it has been taken in the interior at Loko and commonly in North Haussaland (Hartert, 1886) as well as about Lake Chad, where it commonly breeds (B. Alexander, 1907). There are no records of its occurrence on the littoral of Dahomey, but specimens have been taken at Kariniama and north well into the arid regions to Say on the Niger (Bouet, 1914). The only record for Togo is also for the hinterland, the species having been seen at Mangu (Reichenow, 1899). So far as I know it has not yet been recorded from the Gold or Ivory Coasts, nor from Liberia or Sierra Leone. In French Guinea the species has been found on the Niger, 450 miles from the coast; and is said not to occur in the coastal districts (Klaptocz, 1913). Beaudouin (Hartlaub, 1857) has recorded it for Bissao, however, which is on the coast of Portuguese Guinea. According to Rochebrune (1883-85), the species is not common, but occurs in the interior of Senegambia.

In northwestern Africa the Egyptian Goose is practically unknown. Carstensan's (1852) statement that it breeds in Tangiers requires further evidence for substantiation. There are no records of its occurrence anywhere between Senegal and Algeria. In this latter Province it was recorded as a bird of passage by Loche (1867) and later by Koenig (1888). A flock was observed at Batna, Province Constantine (Taczanowski, 1870). But only recently the species has been met with in Tunis. MilletHorsin (1912) states that it is a rare bird there, but he gives numerous localities where it has been observed or taken.

\section{GENERAL HABITS}

Haunts. The Egyptian Goose, being a large and showy bird, familiar to travelers of all ages, has been the subject of field notes so numerous that all of them cannot possibly be referred to. The best general accounts are those of Naumann (18961905), A. E. Brehm (1879), von Heuglin (1873), Layard (1875-84).

The species has a place in the literature and art of the ancients: Egyptians, Greeks and Romans. It was also a favorite with the Dutch painters of the middle seventeenth century. It inhabits all parts of Africa, excepting the heaviest-forested areas and the permanently desert tracts, but it is nowhere a bird of the coastal regions. In the highlands of Abyssinia it is found at altitudes up to 7000 and 8000 feet (von Heuglin, 1873) and Markham (1869) found that it was particularly fond of the high marshy plains. Its habits in northeastern Africa closely resemble those of the Ruddy Sheldrake, but it is more apt to frequent the meadows (Blanford, 1870). In Egypt 
the traveler may still see a few pairs resting during the heat of the day, on the exposed sand-banks of the Nile when it is low. I noted them first in the vicinity of the Temple of Abu-Simbel, in 1908. A grazing bird, the species is not dependent on large bodies of water, and being extremely adaptable, it is able not only to support itself, but to rear its young in almost any locality. But it prefers the wide sandy banks of river-islands, and is not so commonly found in reedy districts. In the rainy season it, like other water-fowl, disperses over wide areas and is to be found especially in districts recently flooded. According to Brehm even the few puddles that remain after the rains will suffice for its needs. Holub and von Pelzeln (1882) state that in South Africa it is to be found also on salt lakes, in the great bushy treeless regions, in fact everywhere except areas overgrown with a thick tropical vegetation.

WARINEss. My own experience with these birds on the Blue Nile was that, though not particularly shy, they were sufficiently intelligent to spend the day in open places, where it was not easy to approach near enough to kill them with a shot-gun. Shelley (1872) considered the birds very wary in Egypt, and says that sometimes they would walk away from the river-bank to avoid an approaching boat. On the White Nile also they appear to be shy, though the natives are said to have difficulty in driving them away from their bean-crops (Witherby, 1901). In South Africa these birds are universally regarded as shy, and very difficult to shoot, excepting when they are shedding their feathers. Only in some of the less-settled regions, such as Abyssinia and Tanganyika Province (German East Africa), do they seem to be less timid (G. A. Fischer, 1879; Böhm, 1882; von Heuglin, 1873; Zedlitz, 1910; Schillings, 1905; von Erlanger, 1905).

DaILy Movements. The Egyptian Geese rest throughout the hot part of the day, but are on the wing in the early morning and late afternoon. They may be described as principally crepuscular, and as sometimes nocturnal, being especially restless on moonlit nights (Böhm, 1882).

FLight. Nile Geese usually go about in pairs, and the male when flying is more frequently behind the female. Their flight is said to resemble that of Sheldrakes and ducks, rather than that of geese (von Heuglin, 1873; Blanford, 1870). According to Naumann (1896-1905) the flight is quite characteristic and peculiar, resembling that of neither geese nor ducks. When rising they fly rather clumsily at first, but having once gotten under way their flight is rapid and is accompanied by a loud rustling noise. They usually fly rather low, sometimes only one-half to one and onehalf meters over the water, but at other times twenty to thirty meters high (Holub and von Pelzeln, 1882). Although keeping in pairs throughout most of the year the 
families occasionally gather in larger companies, which, however, do not have the "united volition" of an ordinary flock of wild-fowl (Blanford, 1870). When about to proceed for a considerable distance these flocks do, however, appear to assume the well-known wedge-formation. Heinroth (1911) says that they announce their intention to fly by an up-and-downward movement of the bill, a fact which he recorded in the Berlin Gardens.

GAIT. As von Heuglin (1873) remarks, these birds do not easily take to flight, but walk or run slowly, chattering as they go, and finally take wing, only to alight again in the same place. Their gait is gooselike and erect, the neck being carried straight or in S-shape; occasionally the male will even hold it as arched as a swan's. Though they are able to run rapidly, one may detect a slight waddling motion, if the bird is observed from behind (Naumann, 1896-1905).

SwImming AND Drving. Naumann (1896-1905) gives an excellent account of the behavior of these birds when on the water. In swimming, the forward part is submerged to an unusual depth, while the rump is carried so high that when paddling away the bird's feet are ordinarily visible. When worried, pursued, or weary, they carry the body more horizontally, and it is submerged as far as the wings, the tail dragging and the neck stretched forward. On the whole the birds seem averse to swimming and are not really at home on the water.

It is rather remarkable that this goose should be an agile diver, but the extensive testimony of observers eliminates the possibility of doubt on this point. A. E. Brehm (1879) states that they dive for food, swimming considerable distances at some depth, and paddling with wings and feet. Certainly when wounded, they show great skill in effecting their escape by diving. Even when moulting and incapable of flight, they dive with such agility that they are exceedingly difficult to kill (Layard, 1875-84; Finsch and Hartlaub, 1870; A. Chapman, 1921). The young birds also are excellent divers (von Heuglin, 1873; R. and V. van Someren, 1911).

Abel Chapman in his account of these geese on the White Nile thought that the great facility in diving was merely a temporary faculty developed to tide moulting birds over the danger period, and he did not consider that full-winged birds when wounded were particularly clever in this respect.

Perching. Where suitable trees are to be found, the Egyptian Geese perch readily and probably roost in them. R. and V. van Someren (1911) state that each bird has its particular roosting place on the tree, and pushes off any intruder. In northeastern Africa the birds apparently perch less commonly than in the more tropical regions, such as equatorial Africa. 
Assocla tion with other Specres. Since they are of an exceedingly quarrelsome nature and probably remain mated throughout the year, it is not likely that other species willingly associate with them. The pairs I myself saw during the winter months were always alone, and the only reference to their living in company with other birds is a note by Layard (1875-84) that one of his informants found them nesting on ledges of rock together with Kolb's Vulture (Vultur kolbii) and appearing quite friendly with them.

VoICE. Egyptian Geese have a remarkable vocabulary of sounds, and the voice is distinctly different in the two sexes. Finn (1900) describes the note of the male as a husky chatter, and that of the female as a harsh barking quack. Roughly described, the notes resemble those of the Domestic Goose. When a pair is on the wing one is heard to chatter like a common Goose, while the other utters a rather hoarse gasp (Böhm, 1882). The note of alarm, or perhaps of anger, is given by one of the birds sounding a hoarse $k a h k$, kahk, to which the others reply by a sharp tang, tang, whereupon they all cry together, raising their voices higher and higher, till a sort of tangtangterrangtangtangtang results (Naumann, 1896-1905; A. E. Brehm, 1879). When about to rise they are especially noisy, uttering a harsh kor-kor (C. H. T. Whitehead, 1903), and when vexed a hissing note is heard. Even when quietly feeding they keep up an incessant conversation. The note of joy is an oft-repeated tettet-tet-tet-tet-tet uttered by the female, and the male utters a much hoarser sound, during which they stand close together and open their wings wide (Heinroth, 1911). In general the voice is quite loud, remarkably hoarse and out of tune, sounding like the notes produced by a cheap tin-horn (A. E. Brehm, 1879). In my own notes I described the female's voice as a loud, rough call something like that of the Ruddy Sheldrake, chow-chow-che-chow-che-che-chow, etc., continually repeated. The male's note has a coughing or wheezing character and is much softer so that it does not carry anywhere near so far.

Yarrell (Proc. Zool. Soc. London, p. 3, 1833) first called attention to the fact that in the male there is a very highly developed tracheal pouch, and he later figured this in his British Birds (1856). In the Egyptian Goose the bulla ossea of the trachea consists of a bony enlargement on the left side, much broader than it is high, hollow, and generally of rounded form. Presumably the trachea in the female is simple.

Foon. In some parts of their range where grass is plentiful, these birds seem to live entirely on herbage. But they will also eat animal food, and on occasion will dive to procure nourishment. Young grass and grain, maize and beans, worms, larvæ, crabs, smaller insects, etc., have been mentioned as articles of their diet (von Heuglin, 1873; Barboza de Bocage, 1876). A. E. Brehm (1879) states that the young are particularly fond of locusts. A very interesting observation is that of 
Böhm (1885), who says that in the Tanganyika region he saw these birds dancing about on the ground and then picking up the insects and small animals which had been scared up in this way. This habit is common also to the Sheldrakes.

Courtship and Nesting. The breeding season of this Goose is irregular, long drawn out and widely different in the various parts of Africa. In Egypt it probably nests in very early spring (A. E. Brehm, 1879), and flappers were taken in May (Shelley, 1872). Farther south, in the Sudan, where the rains set in during July and August, they breed much later, from July to September (von Heuglin, 1873) and sometimes even later (A. Chapman, 1921). In Abyssinia the season seems to be markedly different, extending from late April (Zedlitz, 1910) to mid-July (Blanford, 1870), but von Erlanger (1905) reports a much-incubated egg taken in eastern Abyssinia in late October. Schillings (1905) found unfledged young in June in Tanganyika Province (German East Africa), and later found others in August. G. A. Fischer (1879) gives August, September, and October as the breeding season in this part of Africa. In the southern parts of Africa the breeding records cover the months from August to January (Stark and Sclater, 1906; Kirk, 1864; Littledale, 1908; Hartert, 1898; B. Alexander, 1900; C. H. T. Whitehead, 1903). No doubt some breed in every month of the year.

Notes on the courtship of the Egyptian Goose are extremely scanty, but as far back as 1738, Albin mentioned that he could tell the male, "by the cock running to the hen with open wings, clasping or embracing her around with them." Hubbard (1907) noted the male puffing out his breast, stretching wide his long wings and dancing around the female with a singular "gobbling cry." Their actions are no doubt those of the victor and protector rather than those of actual display, and Heinroth says there is no real display, but the sexes stand side by side, moving their heads against each other and uttering characteristic notes. The male of a pair which I watched in the Amsterdam Zoölogical Gardens on April 8, 1922, held himself very erect with bill and head pointed straight up, while he continually uttered a short rattling, coughing note, not very loud, as he walked nervously about. The female responded with her loud hoarse note chow-chow-che-chow, etc., etc., which she kept up for long periods. The erect attitude of the male in courtship is characteristic of the Orinoco Goose, as well as of the Antarctic Geese of the genus Chlö̈phaga. Gerhardt (1904) writing of his observations in the Gardens at Breslau, says that both sexes walk around in a circle, moving their necks downward rhythmically. The actual mating always took place on land, but other observers speak of it as taking place in shallow water (Heinroth, 1911). There is a postlude during which the male lifts his wings high up (Heinroth, 1911). Hybrids with the Sheld-duck, described by the same author, have a very different display, just like that of the Ruddy Sheldrake and the true geese, and unlike that of either parent. 
The normal nesting site is undoubtedly in trees, often in the old nests of other species, and sometimes in holes or hollow places. Many other locations have been described, however, and where suitable trees are not available it nests in rushes, on cliffs, and even among the grass and rock of the open kopjes in South Africa (Haagner and Ivy, 1908). When placed in a tree the nest is usually on an overhanging stump, in a hollow, or among the tangled roots on the shore, but never more than four meters above the ground. Acacia, Tamarix and Zizyphus are commonly chosen (von Heuglin, 1873). A. E. Brehm (1879) says that they are especially partial to the Mimosa. Von Heuglin (1873) was not certain that they appropriate the nests of other species, but since his time they have been found using the nests of the Hammerhead Stork (Haagner and Ivy, 1908) and the Vulture's nest (Horsbrugh, 1912). The nest itself is usually constructed of twigs, broken from trees, but sometimes of cane carried into the tree by the bird. In any case it is lined with grass (A. E. Brehm, 1879; von Heuglin, 1873). In South Africa nests have been found on cliffs two hundred feet above the water (Layard, 1875-84). Other nests have been found that were only slight depressions in the sand lined with reeds and down (R. and V. van Someren, 1911). In Lichtenstein's Travels (vol. 2, p. 559, 1812) a nest is mentioned which was floating on the water, fastened only by a few reeds. This must have been the nest of some other bird, I think, or possibly a nest which had become flooded.

The usual clutch numbers from five to eight eggs, but there are very few references to the contents of individual nests. The average number is probably six. They are yellowish white in color, very round and, for such a large bird, very small. They vary in length from 55 to $68.6 \mathrm{~mm}$., and in breadth from 44 to $48.3 \mathrm{~mm}$. Eggs laid in captivity are said to be distinctly larger, measuring from 68 to $72 \mathrm{~mm}$. in length by 48 to $53 \mathrm{~mm}$. in breadth (Kuschel, 1895). The female performs the duties of incubation alone, but is constantly guarded by the male (A. E. Brehm, 1879), who remains with the family during the entire breeding period (Layard, 1875-84). The incubation period according to A. E. Brehm (1879) is twenty-seven to twenty-eight days, but this is without doubt, an understatement. Heinroth (1908) hatched eggs under a hen in twenty-eight days, while under a Muscovy the period was thirty days. Judging from related species I should say that the period is at least twenty-nine and probably thirty days. While incubating, the female leaves the nest once a day, in the afternoon, carefully covering the nest with down before leaving (A. E. Brehm, 1879). Von Heuglin (1873) says that at the approach of a human being the old bird (male?) seeks to attract attention to itself by running about, chattering and stumbling, as though unable to fly.

After hatching, the parents lead the young to deep water, where they soon learn to dive expertly, and are guarded very closely by both the parents. When the young are on the wing several broods flock together, such parties occasionally numbering 
as many as fifty birds and flighting about the country during the dry season (von Heuglin, 1873). By January and February immense congregations are seen on the White Nile, where they moult, shed their quill-feathers and become incapable of flight (A. L. Butler, 1905; Koenig, 1911; Ogilvie-Grant, 1902). As many as sixty out of a flock of two hundred have been found incapable of rising from the water at this season (A. L. Butler, 1905). Layard (1875-84) mentions similar large congregations on the vleis of South Africa, and notes that they are much sought after at that time because they are fat; but they dive so readily that even when they are flightless they are very difficult to kill.

Status. Though said to be not so common as formerly in lower Egypt, many still breed in upper Egypt (Nicoll, 1919). They are holding their numbers so far as known in other localities.

Enemies. According to A. E. Brehm (1879) eagles and crocodiles constitute a menace to these birds in eastern Sudan. Zedlitz (1910) also speaks of their "being in constant danger from crocodiles" in Abyssinia.

Food VaLUe. The flesh of this species has been almost invariably described as unfit for the table, even the young being unpalatable, according to Horsbrugh (1912). Blanford (1870), however, speaks of it as good eating, and A. E. Brehm (1879) says the young are "very tasty," while the mature birds make "excellent soup."

Hunt. Layard (1875-84) describes lying in ambush to shoot these geese on their evening flights, in South Africa, where they always shifted their quarters at night. The first night they succeeded in killing a large number by the discharge of eight barrels. The next night they were able to repeat the performance, though the geese had changed their line of flight. The third night, however, the geese avoided that part of the country altogether, making a tremendous circuit to reach their feeding grounds.

As remarked above, the birds are very difficult to kill even when moulting, and at all times require a hard-hitting gun, if they are to be brought down. British officers stationed at Khartum told me of their hunts for Nile Geese, and how seldom they were able to make a large "bag."

Behavior in Captivity. This goose was well known in ancient Egypt where it was perhaps domesticated, but this does not seem to be certain. Ancient paintings from Thebes portray the Nile Goose on the front of a boat, being used as a decoy bird in a hunting scene. It is often seen figured on Egyptian monuments and when used as a hieroglyphic means "son," apparently because the birds are so solicitous of their young. In Egyptian mythology they were sacred to Seb, God of the Earth, and father of Osiris. Their mummies have been found at Thebes and in the Temple of Thotmes Third at Gurnah. 
The Greeks regarded Seb as the Nile God, like the eel and the lepidotus, and both Greek and Roman writers mention the bird frequently, for example Herodotus, Aristophanes, Aristotle, and Pliny. Artists commonly made use of it, and it appears on the mosaics of Pompeii (No. 9990, Museum of Naples).

The old generic name, Chenalopex, means "fox goose" in Greek, which is not to be regarded as derived from any characteristic of the bird itself, but rather from a corruption of the Egyptian name. Thus in the Periclean Age the bird was used as a symbol of rascality, "foxlike" (Keller, 1913).

They seem to have been greatly admired by Dutch painters of the middle seventeenth century for their portraits occur over and over again. Willoughby and Ray (1678) saw and described this species among the King's wild-fowl in St. James Park and called it the Gambo Groose. Albin (1738) pictures a specimen which was one of a pair presented to him by Lord Burlington, and Latham speaks of numbers having been imported prior to his time, 1785. Indeed it was "not uncommon" in gentlemen's parks in England when the latter's work was written.

The species breeds freely in captivity, and was represented in the earliest list of animals in the London Zoological Gardens (1830). They are extremely hardy, aggressive and very dangerous to other water-fowl, so that they must usually be kept on ponds by themselves. An example of their ferocity is given by Schoff (Zool. Garten, vol. 8, p. 186, 1867) who tells of a young gosling only two days old, which when liberated on a pond in the Dresden Gardens attacked ten young Mallards fourteen days old, jumped on their backs and picked them until they left the pond. A. E. Brehm (1879) gives a very vivid account of a fight between two males, in which not only bills and wings, but claws also came into play; the scene ending by the victor leaping upon his exhausted antagonist's back and holding his head under water until the victim was drowned. Not only other members of the species, but water-fowl of all sizes, quadrupeds, and even human beings may become the objects of attack for these quarrelsome birds.

This pugnacity is connected, no doubt, with the mutual attachment of the mated pairs, for all evidence indicates that the birds pair for life, and even in confinement are monogamous. In this respect they resemble the true geese and Sheldrakes. An excellent old account of the behavior of these birds in captivity is to be found in Naumann (1896-1905) who says that they nest on the ground. He calls attention especially to the permanent attachment between the sexes.

In France, during the middle of the last century, when the Société d'Acclimatation was making great efforts to introduce exotic and possibly useful birds, the present species was cultivated to such an extent that a distinct race was produced, which, although it retained all the original plumage characters, was considerably larger in size. When first systematically bred (1839-43) it nested in early January or even late December, as it does in its native haunts, but gradually the nesting period was 
postponed, first to February in 1844, and then to March, 1846. By 1854 the birds were nesting in April (I. G. de St. Hilaire, Domestication et naturalization des animaux utiles, p. 85, 1854). The hatching dates given by P. L. Sclater (1880) for the London Gardens are very irregular, extending from March 4 to July 18, for the period from 1837 to 1879 . Free-flying birds in the Berlin Gardens bred at the end of the first year (Heinroth, Journ. f. Ornith., vol. 63, p. 301, 1915).

A most interesting note on the fertility of these birds was given me by Donald MacVicar, head keeper on the Deering estate near Miami, Florida. He writes me that a pair which he had in 1918 reared three broods during that season, the last one in the autumn. There could have been no mistake because he had only one pair. This habit of nesting more than once has been continued since that time and the Australian Black Swans have done the same thing.

Egyptian Geese live to a considerable age in confinement. The Giza Gardens had specimens twelve years old (Flower, 1910) and the London Gardens in 1883 had one specimen that had been received twenty years before, while others were nineteen, sixteen, and fifteen years of age (P. L. Sclater, 1883). Schmidt (1878) states that in the Gardens at Frankfort a. M. they lived from sixteen and a half to seventeen years. The price of the birds has always been reasonable, both in England and in this country, and although they could formerly be purchased at from $\$ 12.00$ to $\$ 15.00$ a pair, aviculturalists have usually hesitated before acquiring such obstreperous pets. Wallace Evans, however, raised many on his game-farm at St. Charles, Illinois, and informed me that he found them extremely prolific and the young easy to rear.

Heinroth's observations on the Nile Goose and the Ruddy Sheldrake led him to suppose that brother and sister will not pair, a fact of great interest and significance.

Domestication. Next to the Mallard, the Muscovy, and the Domesticated Goose, this species is more susceptible of true domestication than any other of the Anatida. Some believed it to have been truly domesticated by the ancients, but I must confess that I am by no means convinced of this. It is possible, however, that a domesticated breed of Nile Geese in Egypt was superseded by the European Gray Goose which was domesticated later by the Greeks. At any rate the Egyptian Goose was highly prized during the early dynastic period, and was doubtless kept for its ornamental value. In our day some of the Boers of South Africa keep Egyptian Geese in a semi-domesticated state, chiefly because of their vigilance and promptness in sounding an alarm in case of danger, just as Tree Ducks are kept. Holub and von Pelzeln (1882), who give a full account of this practice, dilate especially on their attachment to certain localities and on their great usefulness in giving the alarm.

These geese have hybridized in confinement with the Mallard, the Spur-wing Goose, the Orinoco Goose, the Ruddy Sheldrake, the Chinese Goose (Cygnopsis cygnoides) and the Common Sheldrake. 


\section{ORINOCO GOOSE}

ALOPOCHEN JUBATUS (SPIX)

(Plate 15)

SYNONYMY

Anser jubatus Spix, Av. Brasil., vol. 2, p. 84, pl. 108, 1825.

Anser polycomos Cuvier (Paris Mus.); Lesson, Traité d'Ornith., p. 627, 1831.

Chenalopex jubatus Wagler, Oken's Isis, 1832, col. 1235.

Chenalopex jubata G. R. Gray, List Birds British Mus., pt. 3, p. 126, 1844.

Alopochen jubata Stejneger, Riverside Nat. Hist., vol. 4, Birds, p. 141, 1888.

English:

Orinoco Goose

Spix's Goose

\section{German:}

Orinoco Gans

French:

\section{Vernacular Names}

Dutch:

Orinoco Gans

Spanish:

Carretaro - (Venezuela)

Portuguese:

Marrecão - (Brazil)

Bernache de l'Orinoque

\section{DESCRIPTION}

Adult MaLE: Head, neck and breast gray, darker on occiput and hind neck; upper mantle and scapulars rusty brown; lower mantle and inner scapulars blackish. Back, rump, upper tail-coverts, tail and primaries black, with slight purplish gloss. Lesser wing-coverts black, with purple metallic gloss; secondaries green metallic, but with a white speculum; abdomen and flanks rusty red, except for a whitish area in mid-line; under tail-coverts white.

Iris brown; feet and legs dark salmon-red to pink flesh-color; bill black, except flesh-colored on lower mandible, and at base of culmen (Carriker on M. C. Z. specimen).

Wing $326 \mathrm{~mm}$.; bill 41 ; tarsus 80 .

Addlt Female: Similar, but slightly smaller. Wing 305 mm.; bill 36 to 37 ; tarsus 70 .

Immature: Said by Mr. F. E. Blaauw to be a "weak, washed out copy of the dress of the adults" (Hubbard, 1907).

Young IN Down (specimens in Leyden Museum): This is very easily distinguished from the young of the Egyptian Goose by a large square dark-brown patch behind and below the eye. It has a general resemblance to the young of the Cape Barren Goose (Cereopsis) and also to the Common Sheldrake. The occiput is dark brown to black and this color extends down the back of the neck as a narrow band. There is a broad, white supra-ocular band extending down the sides of the neck over the square brown face-patch, combining with the white of the neck and breast. There is also a narrow and poorly defined trans-ocular streak. The remainder of its upper side is almost as in the Sheldrake. There are broad white "lateral-line" patches running from under the wings to the tail and there are large white 




Map 21. Distribution of Orinoco Goose (Alopochen jubatus) Sporadic records are indicated by a cross $(X)$ 

patches on the wings and scapulars. The color of the upper side is in sharp contrast to the pure white of the lower side and forms a striking color pattern. According to F. E. Blaauw (Bull Soc. d'Acclimat. Paris, vol. 37, p. 60, 1890) the bill and feet are black.

\section{DISTRIBUTION}

LIKE its congener, the Egyptian Goose, this species is non-migratory. It is a strictly tropical bird, and makes its home in the basin of the Orinoco and of the Amazons, with their tributaries. On the Orinoco it is the commonest species of duck (Cherrie, 1916; Taylor, Ibis, ser. 1, vol. 6, p. 96, 1864; Sclater and Salvin, 1876; André, 1904; Ernst, 1877). South of the Orinoco it was also met with in great numbers (Burger, Reisen eines Naturforschers, p. 329, 1900). In British Guiana R. Schomburgk found it on the Lower Takutu, while Burmeister (1856) and the Penards (1908-10) have recorded it for Dutch Guiana.

The Orinoco Goose has a wide distribution in the interior of Brazil, but it is rare on Mexiana Island (Hagmann, 1907) and seems to be absent from the coastal regions. Its headquarters are unquestionably the basins of the Amazons and its confluents. Natterer met with the species throughout the immense region of Matto Grosso, and along the courses of the Rio Guapore, Rio Madeira and Rio Negro (von Pelzeln, 1868-71), and the type specimen came from the Rio Solimoens (Spix, Av. Brasil., vol. 2, p. 84, 1825). Westward the species extends to Peru, where it was taken by Bartlett (P. L. Sclater and Salvin, 1866) on the lower Ucayali. Southward the species seems to occur in Bolivia, for the British Museum has a specimen from there and another was taken at Tatarenda, near Caiza, in the Bolivian Chaco (Lönnberg, 1903). In this same general region a specimen was taken near Oran, Salta Province, Argentina (Bruch, 1904).

\section{GENERAL HABITS}

Haunts. The Orinoco Goose is practically confined to the basins of the Amazons and the Orinoco, being the commonest "duck" on the latter river (Cherrie, 1916). In spite of its abundance, and of the fact that it is kept in European collections, very little has been recorded concerning its habits or life-history. In posture and general appearance it closely resembles its congener, the Egyptian Goose, but unlike that species it inhabits wet and densely wooded tropical forests. On the other hand, it resembles its relative in being absent or rare in coastal areas, and in its habit of living in pairs in the higher alluvial regions (F. P. and A. P. Penard, 1908-10). It is rarely met with in flocks, although large gatherings have been described. The birds may assemble to moult as do Egyptian Geese (F. P. and A. P. Penard, 1908-10).

WARINESS. The travelers who mention this bird do not speak of it as particularly shy, and were evidently able to kill many in one day, when they so desired.

VoIce. I do not know how the voice of this species compares with that of the Egyptian Goose, but the sexes probably have entirely different call-notes. When, during the breeding season, the males engage in fierce battles, they utter a constant, loud, guttural honking, making a deafening racket (Cherrie, 1916). In the Orinoco 
region the local name "Pato Carretaro" has been given to the bird because of the resemblance of its note to the hoarse cries of a driver urging his horses onward (André, 1904).

Food. Practically nothing is known about the diet of these birds, but Hagmann (1907) found the larvæ of butterflies among the stomach-contents. Another stomach contained small seeds (Sclater and Salvin, 1876).

Courtship and Nesting. The breeding season on the Orinoco is said to begin in December and January, during which time the males engage in the fierce struggles referred to above. The blows of their wings and their constant loud honking seem to have no effect on the females, who feed quietly and take no interest in the proceedings. The nest is placed in a hollow tree (Cherrie, 1916), a habit which is sometimes shared by its African relative. The nest-down is white like that of the Sheldrakes. Nothing is known as to the number of eggs in a normal clutch, but a female in Mr. F. E. Blaauw's collection laid ten eggs. The incubation period is probably the same as that of the Egyptian Goose, that is, twenty-nine or thirty days (28 days according to Mr. Blaauw). The eggs laid in confinement in the London Gardens are like those of the African species, slightly glossy, and of a pale brownish cream-color, measuring from 59 to $61 \mathrm{~mm}$. in length by 41 to $45 \mathrm{~mm}$. in breadth (E. W. Oates, 1902).

Food Value. André (1904), who shot a number of these geese on the Orinoco, considered them good eating, though if eaten on the same day as killed they proved tough and without flavor. In view of the low culinary value of the Egyptian Goose, and of the closely allied Sheldrakes it would be surprising if these birds were ever well flavored or tender.

Behavior in Captivitr. This species is kept tamed by the natives on the Orinoco, but it is not known whether it breeds there in this semi-domesticated state (Cherrie, 1916). In Europe it was apparently introduced by Lord Derby, who succeeded in breeding it for many years on his Knowsley Estate (Cat. Knowsley Menagerie, 1846). The London Gardens received specimens as early as 1830, but have had little success in breeding them (P. L. Sclater, 1880). In more recent times Mr. Blaauw has apparently been the only aviculturalist to breed them successfully. In 1889 a female laid ten eggs, from which only two young hatched, the others dying in the shell (Blaauw, Bull. Soc. d'Acclimat. Paris, vol. 37, p. 60, 1890). This was the first case of its breeding on the continent, but it has done so repeatedly since then on Mr. Blaauw's estate. Mr. Blaauw wrote me about his stock as follows: "My birds did not breed every year, but only occasionally when we had a warm spring, which 
unfortunately is not often the case. My females always made a nest in a box and usually laid eight or ten eggs, laying every day. The time of incubation was about twenty-eight days. The male has a whistling sound and when courting throws his body backward keeping himself very upright. At the same time he keeps his shoulders (wings) away from his body and shows the wing-speculum and white patch. When he does this he emits a puffing sound, and whistles. The female gives vent to a harsh scream, keeping her head very low. They live very well in confinement but cannot stand frost and have to be taken in during the winter." When I saw Mr. Blaauw's collection in April, 1922, his stock of these birds was very low, only one or two remaining.

In 1904 Heinroth (Journ. f. Ornith., vol. 52, p. 134, 1904) reported that one of his two females laid six eggs in a hollow tree and incubated them assiduously; but none has been reared in the Berlin Gardens.

In confinement these geese are not hardy, but if kept inside during frosty weather they do well and live many years. The London Gardens, which have always kept a considerable number, in 1883 possessed a specimen which had been purchased in 1865. Unless the birds are given a good supply of animal food (worms and meat chopped fine) their eggs prove to be infertile. The young birds are very active and easy to rear, feeding chiefly on duck-weed, bread-crumbs and ant larvæ (Blaauw, fide Hubbard, 1907). The adult birds are of a pugnacious temperament, and when approached will raise "their bodies nearly erect, swelling out their breasts and flapping their wings against the legs of the intruder. They sometimes bend themselves backward to such an extent that they appear as if they would fall on their backs" (Derby, Cat. Knowsley Menagerie, 1846). According to Mr. Blaauw the bill, as well as the wings, is used in attacking. 


\section{COMMON SHELDRAKE}

\section{TADORNA TADORNA (LINNE)}

(Plate 16)

\section{SYNONYMY}

Anas tadorna Linné, Systema Naturæ, ed. 10, vol. 1, p. 122, 1758.

Anas cornuta S. G. Gmelin, Reise Russl., vol. 2, p. 189, pl. 19, 1774.

Anas damiatica Gmelin, Linné's Systema Naturæ, ed. 13, vol. 1, pt. 2, p. 535, 1788.

Tadorna bellonii Stephens, General Zool., vol. 12, pt. 2, p. 72, pl. 45, 1824.

Tadorna vulpanser, Fleming, History British Animals, p. 122, 1828.

Vulpanser tadorna Keyserling and Blasius, Wirbelth. Europas, pp. lxxxiv, 225, 1840.

Tadorna cornuta G. R. Gray, Hand-list, vol. 3, p. 80, 1871.

Tadorna tadorna Fleming, Philosophy of Zool., vol. 2, p. 260, 1822.

\section{English:}

Common Sheldrake, Sheld-duck, Shieldrake, etc.

Burrow Duck

Damietta Duck

Bargander

Skeeling Goose

Stock Annet

Sly Goose

Strand Goose

St. George's Duck

Bardrake

Bay Duck

French:

Canard tadorne

Tadorne de Belon

Tadorne commun

Houad-trocale

Canard hollandais

Canard de flandre

Canard renard

Ringan

Vollandoise, etc., etc.
Vernacular Names

German:

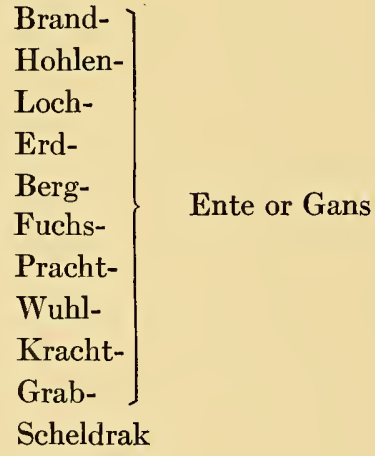

Gaelic:

Cradh-Gheadh

Craigag

Icelandic:

Brandgas

Norwegian:

Fagergaas

Gravgaas

Gravand

Brandgaas

Ringgaas 




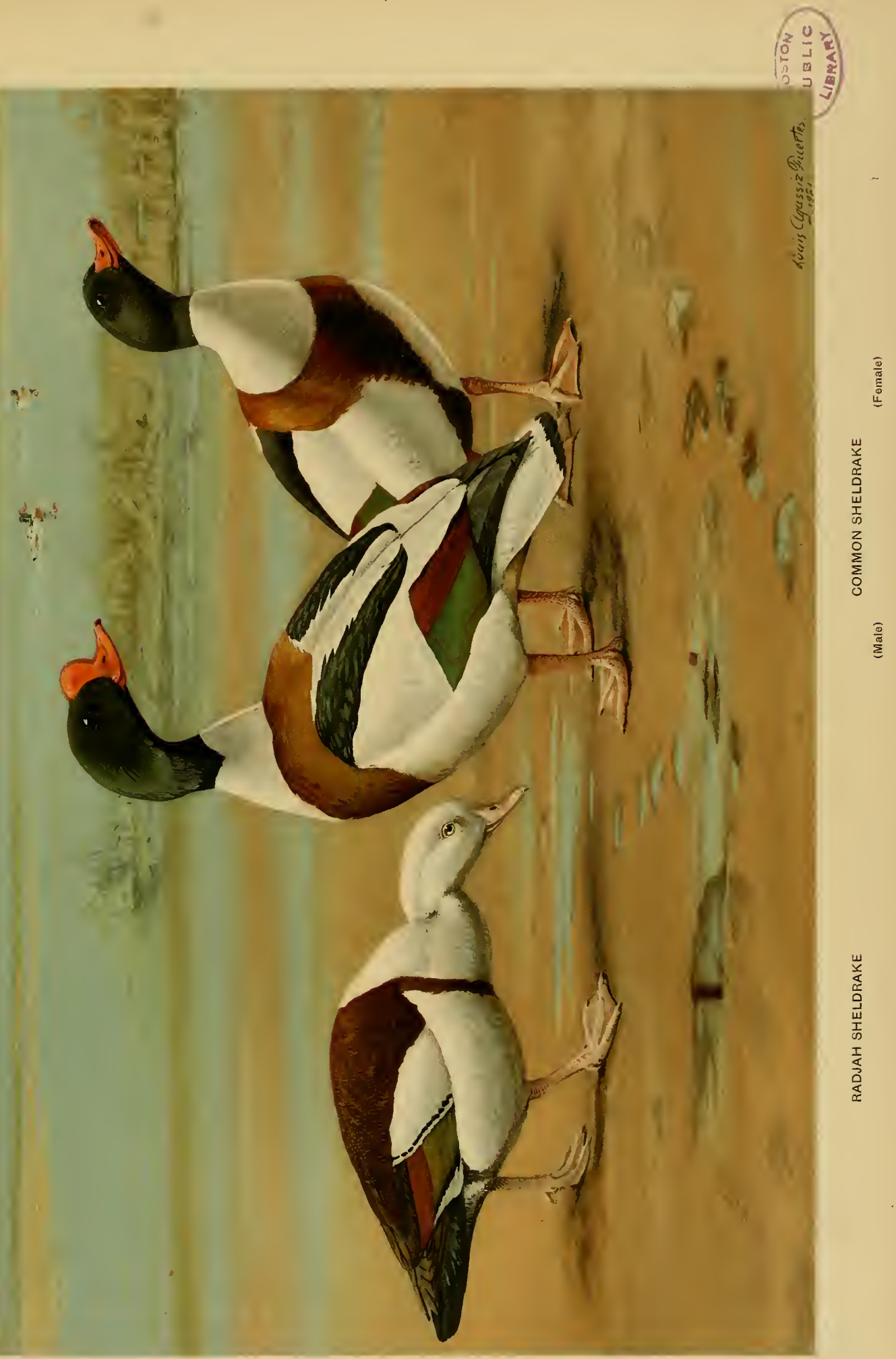



Swedish:

Grafand

Grafgas

Brandgas

Jugas

Rafgas

Ringgas

Danish:

Gravand

Gravgaas

Brandgaas

Fagergaas

Finnish:

Ristisorsa

Kivisorsa

Kivihanhi

Lettish:

Juhras pihle

Polish:

Kaczka ohar

Russian:

Utka peganka

Peganuka

Dutch:

Berg-eend

Spanish:

Pato tarro

Pato urraco

Italian:

Volpoca

Anitra maltista - (Sicilian)

Anariera - (Sardinian)

Anatra volposa

Anara rossa

Nedar d'mar

Cherse

Belladonna

Ciccalona

Anatra francese
Fiscone

Cruciatu

Anatra cruciata

Anitra janca

Anatra imperiale

Anadiera

Anariera, etc.

Maltese:

Culuvert ta Barbarja (or Barberia)

Moorish:

Bou-ha-baida

Croatian:

Utva turpan

Czech:

Husa lisci

Hungarian:

Butykos asolud

Roka lud

Tengesi lud

Foldben lako lud

Tulkos rucza

Tartar:

It-kas

Hindu:

Shah chakwa - (Upper India)

Mekaz, Alikaz - (Sind)

Japanese:

Tsukushigamo

Kanakamo

Siberia:

Ataika

Kalmucks:

Chonchotu-alak-nogossun

Mongols:

Angatu

Alaktu

Zoochor-galu 


\section{DESCRIPTION}

AddLt MALE: Head and neck dark glossy green, almost black, a broad white collar encircling upper breast and upper mantle. Posterior to this is a broad band of chestnut, covering rest of mantle and sides of breast. Outer scapulars black, inner ones white. Back, rump and upper tail-coverts snowwhite, tip of tail black. Wing closely resembles that of Egyptian Goose, having the coverts white, secondaries metallic green, except inner ones which are brown on the outer web, and primaries black. Lower parts blackish along median line; flanks white, under tail-coverts rusty red.

Bill sharply turned up and having a large knob at base 8 to $10 \mathrm{~mm}$. long in the breeding season. Bill and knob bright red; nail black; irides dark reddish brown; legs and feet flesh-pink.

Wing 325-330 mm.; bill 41-45; tarsus 47 .

Weight, 2 pounds 6 ounces to 2 pounds 14 ounces (1.1 to 1.4 kilograms) (Hume).

Adult Frmales: Smaller than male, head not so green, and other colors less brilliant. Bill without a knob or with a very small one in the spring of the year, increasing with age.

Weight, 2 pounds to 2 pounds 14 ounces ( 0.9 to 1.4 kilograms) (Hume).

Young in First Plumage: At this stage there is no likeness to the adult plumage and the sexes are the same. The head and upper side of the neck are dull black except for a large white patch between the eye and the bill merging with the white of the throat; the whole lower surface is pure white. The mantle is white, mixed with gray along the posterior part and also along the median line. The scapulars are gray and dark brown in color, while the back and the rump are white. The outer wingcoverts are whitish to dull gray, not pure white as in the adult. The speculum is less brilliant than in the adult stage, and the chestnut patch on the tertials is poorly developed. According to Naumann (1896-1905) the bill is at first reddish gray, changing gradually to red. Iris grayish brown changing to dark reddish brown. Legs light lead color changing gradually to clear flesh color. Male coming into adult plumage in mid-winter can be told from female by his solid black head.

Young IN Down: A small occipital patch, a narrow streak down the back of the neck, mantle, some scapulars and a narrow region in mid-back rich brown. All the rest is snow-white sharply contrasted with the brown of the upper side. There are large white areas on the wing rudiments, sides of back and rump, more or less confluent in the last two regions, and forming a lateral-line patch.

Remarks: Some writers, as Meves (Ofv. Kungl. Vet.-Akad. Forh., Stockholm, 1867, p. 287) and later Bonhote (1909), think there is a definite eclipse plumage, and the former gives a description of it. The fact is that there are two moults in the Sheldrake just as there are in other ducks, but the summer plumage does not differ from that of winter and spring in a very striking way. Details of this plumage are well given in the Practical Handbook of British Birds (Witherby et al., 1919-22).

\section{DISTRIBUTION}

BEFORE discussing the distribution of the Sheldrake it is important to point out that this species is essentially marine in its habits. In Europe especially it is almost wholly confined to the seacoasts; and it is not to be supposed that, because in plotting the range on the map it is impossible to avoid including large interior areas, the writer means to convey the impression that the species inhabits all parts of the range in equal numbers. It is true, however, that in Asia the birds regularly breed far inland, usually on saline marshes or lakes, and it may also be said that in Europe the local reports from England and Germany show an ever-increasing tendency in this species to select inland haunts. 


\section{Breeding Range}

THIS species belongs primarily to the temperate zone of Europe and Asia and is not to a great extent migratory. In western Europe its breeding range extends very far north, reaching $70^{\circ}$ north latitude on the Norwegian coast. As far as I know, there is only one record of its occurrence in Western the Faroe Islands (Andersen, 1902; Seebohm, 1885) and I am unable to say whether it Europe bred there or not. The only unquestionable record for Iceland is a winter one for the vicinity of Reykjavik, January 27, 1894 (Hantzsch, 1905). In the Shetlands, too, the species seems to be rather rare, and its breeding on the islands at present is not yet proved beyond question (Saxby, 1874; Buckley and Evans, 1899). According to Raeburn (Proc. Roy. Phys. Soc. Edinburgh, vol. 11, p. 72, 1891) there are only two reliable breeding records: one for 1829, the other for 1832 . In Scotland, however, the species is abundant and breeds regularly. It breeds commonly in the Orkneys, particularly on the North Isles (Buckley and Harvie-Brown, 1891). Gray (1871) states that in Sutherland and west Scotland, in the Hebrides on Skye, Mull, Islay, Jura, etc.,

Orkneys Scotland it is everywhere quite common. According to Dresser (1871-81) it is a resident species in Argyll and Wigtown, but Robertson (1911) claims it is not common in Renfrew. On Solway Firth, however, it has recently been reported as nesting in ever greater numbers (Service, Trans. Edinburgh Field Nat. and Micr. Soc., vol. 5, p. 185, 1905). On the east coast it appears to be, if anything, at least as abundant as on the west. Harvie-Brown and Buckley (1887) state that in Sutherland, Caithness, West Cromarty and Ross it is common on the northeast coasts, but rarer on the west. They furthermore (1895) record it as common in the Moray Basin, and it is fairly so as a breeder in the Tay Basin and Strathmore (Harvie-Brown, 1906).

In England the Sheldrake breeds on all coasts, though rarely in the southern counties such as Dorset or Kent (Dresser, 1871-81). It is said to be rare also in Northumberland and Durham, though it used to be common in Norfolk, and in recent years has begun to increase again in that county (Noble, British Birds, vol. 2, p. 19, 1908). It has been recorded from the interior as England occurring, but not breeding, in Northampton, Oxford, Cambridge, York, Nottingham, Lancashire, Lincoln, and on the south coast in Hampshire, Dorset and Cornwall; rarely also in Devon (F.O. Morris, 1903). On the whole the species seems in England to be more common on the west and north than in the east or south, though this does not bold true in winter (Stonham, 1908). In Wales the species appears to occur regularly (F. O. Morris, 1903) and on the south coast Wales is known as St. George's Duck (Horsbrugh, Zoologist, ser. 4, vol. 1, p. 508, 1897). Ralfe (1905) has recorded its breeding on Anglesea and on the Isle of Man.

From all indications the species is rare but of regular occurrence in Ireland (F. O. Morris, 1903) and seems to have been commoner in the first half of the last century (W. Thompson, 1851). The same observer states that it used to breed at Dundrum and Belfast as well as in Donegal, and that in his time it still bred about Londonderry. Stonham (1908), as well as Ussher Ireland and Warren (1900), states that now it is found in limited numbers along the entire Irish coast, being most frequently met with in the south and west. The chief breeding area of the species in Ireland seems to be the region about the mouth of the Shannon, but various other nesting localities are mentioned by Ussher and Warren (1900).

On the continent the Sheldrake is an abundant breeder on the Norwegian coast almost to the North Cape. Collett (1873) states that it nests north as far as Skjaergaard ( $70^{\circ}$ north latitude), and that it is very abundant on the coast south of Trondhjem. Schaanning (1913) sets its northern limit at the Lofotens $\left(69^{\circ}\right.$ north latitude), and according to Boie (1869) Norway it is uncommon and irregular both on the Lofotens and on Vesteraalen. Hartwig (1889), however, found it breeding in Tromsö, and Pearson and Bidwell (1894) on the Lofotens. Farther east it occurs in western Finmark. Von Heuglin (Journ. f. Ornith., vol. 19, Finmark pp. $10,82,1871$ ) found it there breeding on Karlsö ( $70^{\circ}$ north latitude), and Collett (1873) states that 
it occurs sporadically east of the Russian frontier and frequently on Varanger Fjord. Schaanning Lapland (1913) records it for eastern Finmark, as does also Passler (Journ. f. Ornith., vol. Lapland 1, p. 243, 1853), while von Nordmann (1864) says it is occasionally found in Lapland. A valuable record is Pearson's (1899), who found it in northwest Lapland. In 1903 a specimen was taken in Finnish Lapland, near Muonio (latitude $68^{\circ}$ north, longitude $24^{\circ}$ east), according to Montell (1917).

In Sweden, however, the species is not recorded as breeding north of $60^{\circ}$. Nilsson (1858) gives its range as the entire coast from Skane to Nordland, but especially the south. It breeds commonly Sweden in Gothland and in Schonen, Bohus, Kalmar and Sodermanland (Wallengren, 1854). Sweden It has, however, been found on the Aland Islands (Palmgren, 1913) and on the extreme southwest coast of Finland, ordinarily not east of Hangö, though there are a few records for Helsingfors (Palmgren, 1913; Palmén, 1876).

In Denmark the Sheldrake breeds abundantly everywhere, but particularly on the islands off the west coast (Kjaerbölling, 1850; Winge, passim). The same holds true of Schleswig-Holstein; on the islands off the coast, that is on the North Friesian Islands of Sylt, Norderoog, etc., as well as in the Denmark East Friesian Islands of Juist and others, the birds are so common and tame that they are kept in a semi-domesticated state by the natives who make a business of robbing the birds of their eggs (Möbius, Zool. Garten, vol. 11, p. 133, 1870; Schuster, ibid., vol. 45, p. 288, 1904; Hagendefeldt, Zeitschr. f. Ornith., 1906, p. 121; Leege, Ornith. Monatsschr., vol. 34, p. 119, 1909; Dietrich, ibid., vol. 35, p. 51, 1910; Bau, Journ. f. Ornith., vol. 25, p. 336, 1877). On the mainland the Germany birds breed along the coasts and to a considerable extent in the interior, where they have been recorded from Oldenburg and East Friesland (Negelein, 1853; Löns, Ornith.

Monatsber., 1907, p. 5), Hannover (Leverkühn, Journ. f. Ornith., vol. 35, p. 212, 1887), Kiel (Floericke, Journ. f. Ornith., vol. 40, p. 251, 1892), Lubeck (Hagen, Ornith. Monatsber., vol. 17, p. 109, 1909), Mecklenburg (Wüstnei, 1898), Brunswick (R. Blasius, 1896), Brandenburg (Schalow, 1915; Grote, Ornith. Monatsher., 1905, p. 6), Pomerania (Löns, Ornith. Monatsber., 1908, p. 99; Quistorp, Naumannia, 1858, p. 51; Holland, 1857), East Prussia (Henrici, Ornith. Monatsber., 1902, p. 101; Floericke, ibid., 1895, p. 160), Posen (Hammling, 1917; Löns, Ornith. Monatsber., 1908, p. 99), possibly in Silesia (Floericke, 1891), Saxony (Helm, Hennicke, fide Naumann, 1896-1905) and on the Rhine (W. and T. Heussler, 1896; Brahts, 1855), and very rarely in Bavaria (Jackel, fide Naumann, 1896-1905).

As far as I am able to determine, the species is a rare breeder in the Netherlands, nesting chiefly on the islands off the coast (Dresser, 1871-81; Schlegel, 1859; van Oort, 1908), and also in Belgium Netherlands (Ternier and Masse, 1907; Raspail, 1913). Its status as a breeding bird in France is much the same. Ternier and Masse (1907) state that it breeds on the coasts of Normandy,

Picardy, and at Havre. Degland (1849) and Berthelot (1875) also reported its nesting in this region,

France remarking that it is never common. In the south of France it has been questionably reported as nesting about the mouth of the Rhone in Carmague (Müller, Journ. $f$.

Ornith., vol. 4, p. 252, 1856; l'Hermitte, 1916) and in Aude and Hérault (La Croix, 1875), though these localities cannot be regarded as within the regular range. A. Chapman and Buck (1910) state

Spain that the species is said to nest in the marismas of Spain, but I find no other reliable information of its status as a breeder in the peninsula.

It breeds commonly in Sardinia, however (Picchi, 1904; Brooke, 1873), and there are two records Sardinia of its breeding on the mainland of Italy, namely, at Ostia and at Massaciuccoli Italy (Whitaker, 1905). According to d'Aubusson (1911) it breeds rarely on Malta. It Malta has been occasionally seen in summer around Venice (Arrigoni degli Oddi, 1898) and may breed there.

Dalmatia It has been met with and young specimens have been taken at Salona, Dalmatia (Kolombatovič, 1903). The only other record of its occurrence in summer in the former Austro- 


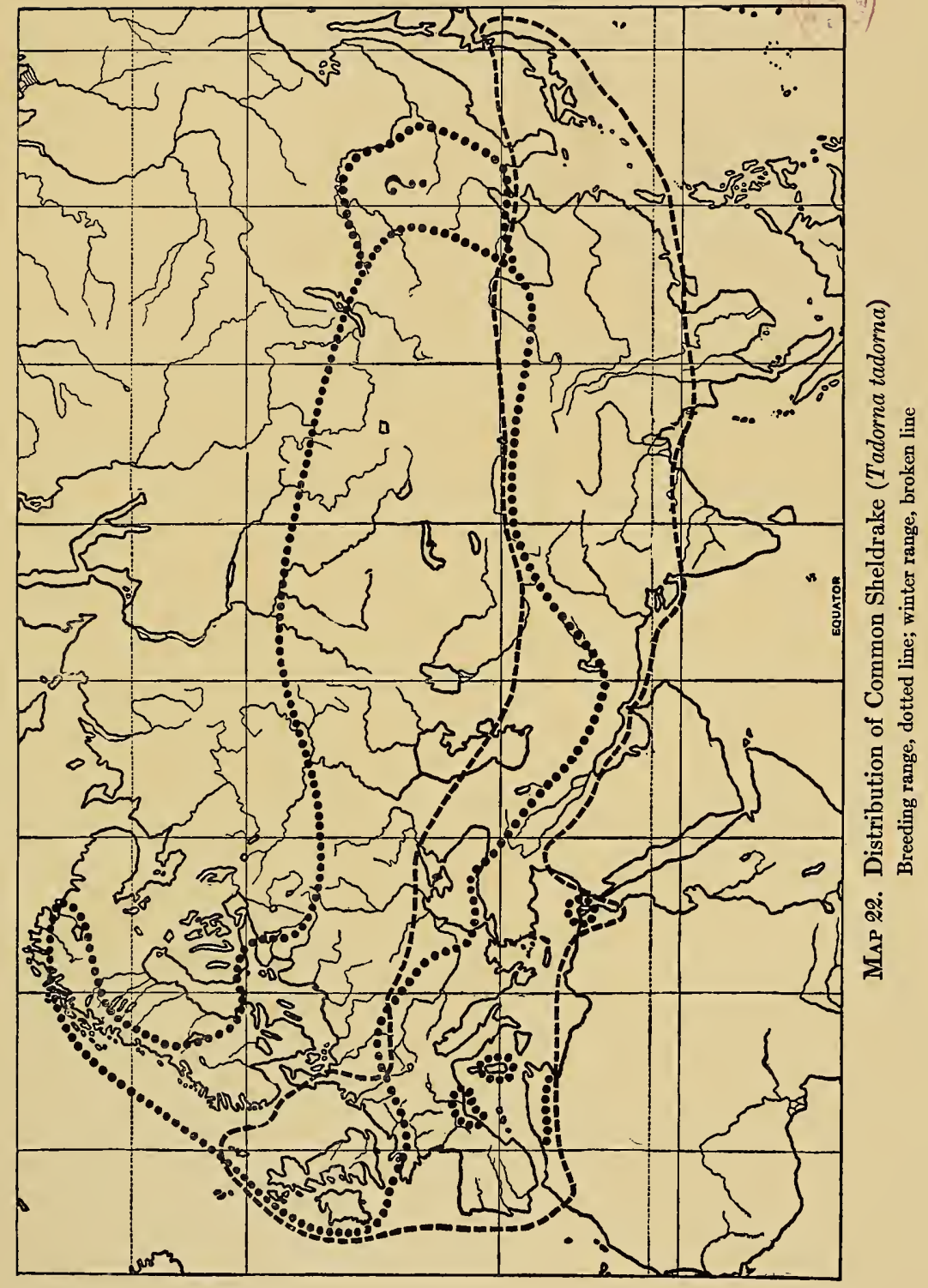



Hungarian Monarchy, is that of a specimen taken on June 22, 1907, in Moravia (von Tschusi zu Schmidhoffen, Zool. Garten, vol. 49, p. 276, 1908). It never breeds regularly any- Moravia where south of the Carpathians. The two records of its nesting in Switzerland at Bas SwitzerValais and in the Sarine Valley, are regarded, and I believe justly so, as very doubt- land ful (Fatio, 1904).

In Russia the Sheldrake breeds on the coasts of the Baltic Provinces, in Esthonia and Livonia (Loudon-Lisden, 1909). J. von Fischer (1872) reported it common at Petrograd, but it appears from later writers that at best the birds are very rare in that region (von Brandt, 1880; Büchner, 1887). There is no evidence of its having bred in the interior in Lithuania, Russia Poland or Little Russia, though Taczanowski (1888) bas recorded a small flock in Poland in August, and I think we may assume that the species breeds there sporadically as in the interior of Germany. It certainly breeds along the northern shore of the Black Sea and about the Danube Delta, where von Almásy (1898), Sintenis (1877) and Allson, all found it abundant. Reiser (1894) says it is very common all along the west shore of the Black Sea and Radakoff (1879)

Black Sea had already recorded it so at Burgas, while Elwes and Buckley (1870) found it not uncommon at Kustendje. Lintia (1909) records it for Rumania, but Reiser (1894) remarks that in Rumania Bulgaria at least it is a very rare bird in the interior. On the Russian shore of the Bulgaria Black Sea the species has been found very common (Seebohm, 1885), and has been recorded as breeding at Odessa (Goebel, 1869), sporadically in Podolia (Zarudny, 1886) and in the Valley of the Pruth (Radakoff, 1881). Radde (1854), as well as Brauner (1899), states that it is coinmon in the Crimea and Tauria; and Goebel (1870) makes similar remarks concerning its occurrence at the mouth of the Dnieper River. Brauner (1894) has recorded its breeding in Cherson, while Valkh (1911) states that it nests commonly in the south part of Ekaterinoslav and E. von Middendorff (1891) found it nesting in numbers about Birjutshi and Jenikale Lights in the Sea of Azov. As to its status in the interior we are dependent wholly on the excellent observations of Sabanaëff (Harvie-Brown, 1878). He tells us that the species probably breeds in Tula and Tambow, and that in spring it is found and probably nests in the Urals up to $56^{\circ}$ north latitude and even up to Cheliabinsk, Shadrinsk and Ekaterinberg. However this may be, the birds certainly breed in the steppes north of the Caspian (Nazarow, 1887) and abundantly in Astrakhan (See- Caspian . bohm, 1882; Cornelius, 1895; Moeschler, 1853; Becker, 1853). It furthermore breeds Sea throughout the Caucasus, though of course rarely in the mountainous interior (Radde, 1884; Seebohm, 1883). On Gotschai Lake it appears to be particularly common (Radde, 1884). TransIt is also quite plentiful in eastern Transcaucasia (Stanchinsky, 1914), and is an caucasia abundant breeder in Armenia (Nesterov, 1911). Djerjugin (1900) also found it at Armenia Trebizond. I find no evidence of its nesting on the south coast of the Black Sea west of Armenia. Meinertzhagen (1920) records having seen a pair in south Palestine in June.

In Africa the species has been recorded as nesting in the west in Morocco (Carstensen, 1852), and is said to be partially resident in Algiers (Loche, 1867; Whitaker, 1905). It has been recorded as resident in small numbers in Tunis also (Zedlitz, 1909), and it is said by Blanchard to Morocco have nested there at Bizerta, Djebel and Eshkul (Whitaker, 1905). In Egypt various Algeria travelers have met with the species during the breeding season, and von Heuglin Tunis (1873) is of the opinion that it probably nests in Lower Egypt and the Fayum, where he found it very common in May and June. Parrot (1903) has reported it from Lake Menzaleh Egypt and the Cairo region in April, and Kaiser (Ornis, vol. 6, p. 540, 1890) states that it is resident on Lake Kurum and on the ponds of Abusir, but I note that the most recent list of Egyptian birds says nothing of any breeding records (Nicoll, 1919).

In Persia the species breeds in most sections, though apparently it is not common there. Zarudny (1911), the autbority on this region, says it breeds in the northwest, in the Kuhistan- Persia Kirman, in the Seistan and possibly the Zagross sections. In the desert regions of western Russian 
Turkestan it breeds on the east coast of the Caspian (Radde and Walter, 1889; Zarudny, 1885), though rarely if ever in the interior. There is one record of its occurrence at the mouth of the

\section{Turkestan}

Oxus, or Amu-Daria (Molcanov, 1912). Farther east it has been found in the Pamir, though it is extremely rare (Severtzoff, 1883; Lansdell, 1885). It nests all over Turkes$\tan$ (Severtzoff, 1883), and though Lansdell (1885) says it breeds at altitudes as great as 3000 to 4000 feet, it is probably rare everywhere but on the low-lying saline marshes. Its great breeding Central area in this region is no doubt Central Asia. I have already noted that it breeds in the Asia Kirgis (Nazarow, 1887; Suschkin, 1900). It has been recorded also from Akmolinsk (Bianchi, 1902), and is common apparently as far north as Omsk and Lake Chany. Popham (1901) records a specimen apparently taken near Jeneseisk. Farther east it has been found on the SaissanNor (Finsch, 1879; Suschkin, 1913), the Ala-Kul (Finsch, 1879), and probably breeds in suitable places in the Tarim Basin, Sungari and Gobi deserts. Its southern limit in Asia during the summer seems to be $38^{\circ}$ north latitude, or the line of the Altyn-tag Mountains. Prjevalski (Deditius, 1886) says it is a characteristic summer bird in the Gobi, latitude $42^{\circ}$ to $44^{\circ}$ north and longitude $98^{\circ}$ to Gobi and $102^{\circ}$ east, and Hume and Marshall (1879) state that it is found even in eastern Tibet Tibet in summer. This I believe is probably erroneous, for Bailey (Journ. Bombay Nat. Hist. Soc., vol. 21, p. 178, 1911) in four years at Gyangtse took only one specimen. Berezowski and Bianchi (1891) found the birds in Kan-su, on the Chagan-Nor and in the Ordos in August, and it is reasonable to suppose they breed as far south as the Hoang-ho. Sowerby (1912), however, states that Mongolia it is only of occasional occurrence in the Shen-Kan region. At any rate it is a regular breeding species in Mongolia (Prjevalski, 1878; David and Oustalet, 1877) and nests north of Mongolia to perhaps $53^{\circ}$ north latitude. Suschkin (1913) states that it breeds in southern West Siberia and about Minussinsk, Baikal and Mongolia, straggling occasionally even to the Lower Jenesei. It has been recorded repeatedly for Transbaikalia and the Amurland by von Homeyer (1870), Taczanowski (1877) and Radde (1863). There is every reason to suppose that it breeds also in Manchuria, where, according to Bianchi (1902), young birds have been found. Seebohm (1890) Japan thinks possibly the species is resident in southern Japan. I find not the least evidence to support the statement of Naumann (1896-1905) that the species is found as far as Kamchatka and the Aleutian Islands.

\section{WINTER RANGE}

I HAVE already referred to the winter record of the occurrence of this species in Iceland near Reykjavik, January 27, 1894 (Hantzsch, 1905). There is no evidence of its having ever wintered on the Iceland Faroes and it is very rare in the Shetlands during the cold season (H. L. Saxby, 1874; Shetlands Buckley and Evans, 1899). In the British Isles, however, it is abundant, especially on the east coast, to which many birds from the continent resort (Stonham, 1908; R. Gray, 1871; Scotland etc.). In Scotland a few winter on the Orkneys (F. O. Morris, 1903; Buckley and Harvie-Brown, 1891), while on the west coast as well as in Sutherland, Caithness and Cromarty it is rare (Harvie-Brown and Buckley, 1887). Still, in the Hebrides it appears to be not Wales uncommon (Harvie-Brown and Buckley, 1888, 1892), while on the east coast, in the Ireland Tay Basin and Strathmore, it is fairly abundant (Harvie-Brown, 1906). In England it is generally distributed in winter (Seebohm, 1885; etc.) and is considerably more numerous on the south and east coasts than is the case in summer (Stonham, 1908). It occurs in the Isle of Man and also in Ireland (Ralfe, 1905; Ussher and Warren, 1900).

On the continent it may be that a few birds winter on the southern coasts of Norway and Sweden or on the Baltic coast of Germany, but I have been unable to discover any evidence to that effect.

Norway

Sweden

Denmark Collin states that it is resident on some of the North Friesian Islands, and Bau (Bau et al., 1877) says it winters in Schleswig-Holstein. According to Reichenow (1889) it occasionally wintered in the past on the Upper Rhine near Mayence, a place that seems a not unusual winter resort for several marine species. I find no information 
as to its occurrence in winter in Holland, but there can be no reasonable doubt of its presence there. In Belgium it is more or less common on the coast and in the mouth of the Scheldt Holland according to the severity of the weather (Dubois, 1912).

Belgium

In France the species is common on the west coast according to Berthelot (1875), while Ternier and Masse (1907) state that it occurs on the north coast only in severe seasons. Degland (1849) has reported its occurrence at Dunkirk and even inland at Lille. The species has been found a few times in Luxembourg too, though it appears to be chiefly a bird of passage

France in that section (de la Fontaine, 1868). In the south of France the birds winter in Aude and Hérault, as well as in the eastern Pyrenees (La Croix, 1875).

To all appearances the species is of common occurrence in Spain. In cold winters it is found at Gerona (Vayreda, fide Reyes y Prosper, 1886), while it is common on the Albufera de Valencia, in Andalucia and Murcia (H. Saunders, 1871), in the marismas at the mouth of the Guadalquivir (H. Saunders, 1871; A. Chapman, 1888) and at Malaga (Reyes y Prosper, 1886). Arévalo y Baca (1887) has recorded it for Malaga and Seville. In Portugal it

Spain

Portugal has been found regularly at Ovar and Aveiro (Tait, 1887) and is not rare at Ribatejo (Barboza de Bocage). A. C. Smith (1868) states that it is of occasional occurrence in Portugal.

Across the Straits the species winters sparsely in Morocco (Whitaker, 1905), though not uncommonly in Algeria, especially at Lake Fetzara (Rothschild and Hartert, 1912), and near the sea (Whitaker, 1905). Tristram (1860) found a few even at Tuggurt in the North Sahara. Morocco In Tunis it appears to be common in winter, according to the testimony of Zedlitz Algeria (1909), Koenig (1888), Whitaker (1905), Millet-Horsin (1912) and Bédé (1915). Tunis

On the other hand the birds seem to be rare in winter in Sicily, at Terranova, very rare at Messina, and rather rare in Calabria, though regularly found in all these places (Giglioli, 1886). A few winter at Malta (C. A. Wright, 1864), but the species is of irregular appearance there Sicily (Despott, 1917). In Apulia it is common, though northward through Campania, the Malta Marches, Tuscany, Liguria and Emilia, it is everywhere a rather rare bird, possibly a bit more common in the vicinity of Padua and Venice, but very rare in Lombardy (Giglioli, 1886; Italy Arrigoni degli Oddi, 1898). Some winter in Sardinia, though not large numbers (Salva- Sardinia dori, 1865; Brooke, 1873), but the species appears to be regular and of frequent occurrence in Corsica (Jourdain, 1911). According to Soffel (Zool. Garten, vol. 56, p. 245, 1915) it occurs occasionally on Lago Maggiore, but Althammer (1857) states that it is met with rarely in the SwitzerTyrol. It seems to be not uncommon in Switzerland, especially in the western parts, land and has been recorded from Neuchatel, Bienne, Morat, Geneva, Bâle, Zurich, Constance and Lucerne, in some of which places it is common in cold winters (Fatio, 1904).

In the former Austro-Hungarian Empire the species has been recorded from almost all sections in winter. Mojsisovics (1887) summarizes the records for Trieste, Dalmatia, Krain, Tyrol, Galicia, Transylvania and East Slavonia. Supplementary records are those for Bohemia Austria (Fritsch, 1872), Styria (Washington, Mitth. Ornith. Ver. Wien, 1887, p. 182), Vas, Bohemia southwestern Hungary (von Chernelhaza, Aquila, vol. 14, p. 180, 1907), Komorn, Hungary southwestern Hungary (von Hegymeghy, ikid., p. 336, 1907), Hunyad, southeastern Dalmatia Hungary (von Barthos, ibid.), Nyiregyhaza, north-central Hungary (von Szomjas, Aquila, vol. 20, p. 464, 1913), Szegedin, central Hungary (Hung. Ornith. Club), Dalmatia (Kolombatovič, 1903) and Transylvania (Danford and Harvie-Brown, 1875). It is very important to note, however, that in all of these localities, that is throughout the former Austro-Hungarian Monarchy, the species is exceedingly rare, and probably occurs only in the severest winters.

Farther north it occurs rarely in Poland (Taczanowski, 1888) and has been found on the Baltic coast in the winter of 1911 (Grevé, 1911). It also straggles as far as St. Petersburg Poland (Bianchi, 1907), but does not seem to winter regularly in Russia anywhere farther Russia north than the littoral of the Black Sea. It winters in the Crimea (Radde, 1854; Brauner, 1899) 
and in Bessarabia (Radakoff, 1881). It no doubt occurs in small numbers throughout the Balkans,

Crimea

Greece only occasional appearance in Greece (von der Mühle, 1844). Powys (1860) states though it is rare inland about Sofia (Reiser, 1894). In Macedonia it is common about that in severe winters it is found on the Ionian Isles and in western Greece.

The species apparently winters throughout Asia Minor at least on the coasts. It has been so recorded in general by Kruper (fide Dresser, 1871-81) and specifically for Smyrna by Antinori (Journ. f. Ornith., vol. 6, p. 484, 1858) and Strickland (Proc. Zool. Soc. London, 1836, p. 102), while in Cyprus Asia Minor it is found in the cold season (Lilford, 1889; Bucknill, 1911). It does not appear to Egypt winter in Palestine, but is found in Egypt up the Nile as far as Siout (Shelley, 1872; von Heuglin, 1873; etc.).

According to Zarudny (1911) and Meinertzhagen (1914) the birds winter also in Mesopotamia, and the species has been recorded from the Caucasus, especially from the Caspian coast, and in Mesopo- severe winters also from the interior at Tiflis and from the salt lakes, particularly tamia Gotschai (Radde, 1884; Seebohm, 1883). On the southwest Caspian, however, it is not common (Radde, 1886). I find no evidence of its wintering on the north of the Caspian. In Caspian Persia it is found in the cold season on the south Caspian, and rarely in the Atrek, Sea Seistan, littoral of the Persian Gulf and Arabian Sea and in Zagross regions (Zarudny, 1911). Baker (1908) states that it is common in Afghanistan and not rare in Baluchistan. North of Persia Persia it has been found a few times in Transcaspia on the Teshen (Loudon, 1911), but does not seem to winter farther north in western Turkestan.

According to Hume and Marshall (1879) it is not rare about Kabul and Khandahar and Whitehead (Ibis, ser. 9, vol. 3, p. 281, 1909) says that although it is of regular occurrence it is not common about India Bannu. In India it is generally distributed (but nowhere common) as far south as the is really common only on the coasts of Sind (Blanford, 1898), but has been recorded from Lucknow (Jesse, 1903), Punjab, the Northwest Provinces, and Oudh (Baker, 1908). It is very rare in Kashmir and quite rare in Bengal (Baker, 1908). According to Hume and Marshall (1879) it is found also in Cutch and Kathiawar, but not in Rajputana. There are two extreme records for Nemuch and Poona (Hume and Marshall, 1879). Its status in the east is very vague. It has not been recorded from Assam, but it occurs in Chittagong (Hume and Marshall, 1879), and more recently specimens have been taken in Burma at Myitkyina (E. W. Oates, 1902), at Meiktilla (Kinnear, Journ. Bombay Nat. Hist. Soc., vol. 20, p. 519, 1910) and as far south as Kyaukpyu (Baker, 1908). Hopwood (1912) met with it in Arakan. I think the species will yet be discovered to winter in rare cases in Assam and Upper Burma. At any rate it seems to winter in the Chinese Empire south of the fortieth parallel, rarely of course in the interior. On the coast it has been recorded from Hongkong China (R. Swinhoe, 1860), Swatow (la Touche, 1892), Amoy (R. Swinhoe, 1860), Formosa (R. Swinhoe, 1863; la Touche, 1892; Uchida, 1912), Foochow (R. Swinhoe, 1862; la Touche, 1892), Shanghai (Styan, 1891), Kiau-Chau (Kleinschmidt, 1913), Taku and Peking (David and Oustalet, 1877; R. Swinhoe, 1861). I have no evidence as to its winter status in the interior, but I think we may assume that, as in other parts of its range a few individuals may linger in Tibet and in China proper.

Korea The species has been recorded from the Keiki District, Korea, and is said to be very Japan common in spring farther north on the Yezanko River (Kuroda, 1918). In Japan it is Japan not uncommon except in Yezzo (Seebohm, 1890). Ogawa (1908) gives Tokio, Nagasaki and questionably Suruga as specific localities in which it has occurred. On the Loo-choo Islands it is also found, a specimen having been taken on Ishigaki (Ogawa, 1905). 


\section{Accidental Occurrencte}

A single specimen was shot October 5, 1921, in Essex County, Massachusetts (Auk, vol. 39, p. 104, 1922). I believe there is little chance that this was an escape.

North

America

\section{Migration}

BEING essentially a marine duck, we find that most of the occurrences of this species in the interior, in Europe at least, take place while it is on migration. There seems to be reason to suppose that the birds commonly migrate overland along river courses. At any rate in Switzerland, southern Germany, northern Italy, etc., it is known chiefly as a bird of passage. In the springtime the species seems to leave its winter quarters in the Mediterranean as early as February (Morocco, Favier fide Dresser, 1871-81; Cyprus, Bucknill, 1911), passing Italy in March (Giglioli, 1886), Dalmatia in March (Kolombatovič, 1903), and arriving in north Germany not before March (Naumann, 18961905). They arrive also in England in March (F. O. Morris, 1903) while in Scandinavia they do not ordinarily appear before late March, April, or May (Nilsson, 1858). They reach Finland by May (Palmgren, 1913).

In the autumn they leave Scandinavia in August and September, some staying till October (Nilsson, 1858). Germany they leave in October (Naumann, 1896-1905), pass Dalmatia in October (Kolombatovič, 1903), reaching Malta in late October or early November (C. A. Wright, 1864), and Morocco, as well as Cyprus, in November, or even December (Favier, fide Dresser, 187181; Bucknill, 1911).

On the Black Sea, E. von Middendorff (1891) made some valuable observations. He found that on the Sea of Azov the first did not arrive until March 27, and that the species was not common till May 21. In the autumn the last left by September 21.

In Asia the species occurs on passage in northern Persia (Zarudny, 1911), in southern Kashgaria and northern Tibet, as well as on the Kuku-Nor $-37^{\circ}$ north latitude, $100^{\circ}$ east longitude (Koslow, 1899; Prjevalski, see Deditius, 1886). In Nepal it occurs chiefly on passage and only rarely (Hume and Marshall, 1879), and Prjevalski observed it on migration on the Lob-Nor. There are practically no dates available for this region. They leave northern India by the middle of April and return by the middle of November (Hume and Marshall, 1879; Baker, 1908). The fact that Prjevalski saw them on the Lob-Nor as early as February, and says that they arrive in Mongolia by late March, would seem not only to indicate an overlooked route but also to lend probability to the fact that some of the birds winter in Tibet.

Recovery of Banded Birds. From a brood of ducklings banded in Hampshire, England, in July 1912, three were recovered as follows. One at Saltash, Cornwall, February 10, 1913, one in Schleswig-Holstein, Germany, August 12, 1913, and one at the mouth of the Weser in Germany, August 18, 1917, thus demonstrating an eastward dispersal which is interesting (Ibis, ser. 11, vol.3, p. 517,1921$)$.

\section{GENERAL HABITS}

Characteristics and Haunts. The Common Sheldrake is a salt-water duck, preferring a shore-line with wide flats, partly sand and partly mud, where it feeds, and deserted sand-dune areas on islands where it breeds. Its occurrence inland, in western Europe, except during the breeding season, may be regarded as accidental, and it very rarely visits fresh water. Naumann (1896-1905) tells of a large decoy 
on the Island of Sylt, where these ducks were abundant. The decoy was only a "few steps" from the sea-shore, on a pond, and yet it was said that no Sheldrake was ever taken there among the thousands of other ducks captured. MacPherson (1892) says that they prefer to feed with an ebbing tide, and, avoiding the higher ridges of sand, which the wind soon dries, they obtain their shell-fish chiefly on the lower well-watered stretches of sand, which being more firm and clay-like in composition, retain perhaps half an inch of water on their surfaces. Rushy or reedy places are not to their liking, and they resort to them only in case of necessity, to hide the young, and occasionally to conceal themselves during the period when they moult and are incapable of flight (Naumann, 1896-1905). In boisterous weather they often shift from exposed situations to more sheltered feeding grounds, and at such times appear on sand-beds which at other times they rarely visit.

Ancient legend connected this duck with the companions of Diomedes, the national hero of the Apulians, who had been transformed. In Pompeii there is a fine mosaic of the species. Pliny mentions them as breeding in holes in an island off the coast of Apulia.

WARINEss. As all English shooters know, these are the very wildest of all the duck tribe. They will not usually allow a punt to approach within three hundred yards in the British Isles (Cordeaux, 1896) and similar habits are common to them in India (Hume and Marshall, 1879). When not persecuted, however, they readily become tame, especially in places where they have been encouraged to associate with man, and nest among his dwellings, as on the Friesian Islands. But living as they do throughout almost the entire year on open stretches and deserted flats, they are among the most difficult water-fowl to observe at close quarters. Their natural shyness has been the subject of remark by naturalists and sportsmen in all parts of their range. Only at times of severe frost did that ardent sportsman, Payne-Gallwey (1882), find them at all approachable, and Colonel Hawker classed them as among the tamest of wild-fowl when half starved, during the frosts. At such times their food becomes inaccessible, and the vitality of the birds is much reduced. In February and March, when they begin to pair, they lose some of their habitual shyness and sit apart from other water-fowl in some sheltered bay near the sand dunes where they intend to nest (Millais, 1901). Colonel Hawker found that when a brood was approached in open water the old birds flew away, but even then only one or two young could be shot, because they dispersed so quickly.

DaIly Movements. The movements of Sheldrakes are governed almost exclusively by the tides, since they ordinarily cannot feed except at low water. They are most active on the ebb-tide, either in the daytime or at night, although they are likely to be more active in the morning and evening, as are most ducks (Naumann, 
1896-1905). One observer thinks that they feed both by day and by night during the summer, but during the winter almost exclusively at night (Cordeaux, 1896). Between tides they rest on the shore, and conceal themselves between hillocks, or they may resort to nearby meadows or patches of turf, rocks or sand mounds (Naumann, 1896-1905).

Gart. Since this bird spends most of its time on land, or in very shallow water, its gait is less clumsy than that of true ducks. Seebohm (1885) thinks they walk about as well as geese, and they run quickly for long distances. Their posture is that of the Mallard, excepting that the hind parts appear somewhat longer. The neck is bent back in S-shape. When resting they usually stand on one leg, like other ducks, the neck being then laid on the back, or turned with the bill hidden among the scapulars (Naumann, 1896-1905).

Swimming AND Diving. Although seldom seen on the open water, and apparently not fond of swimming, the Sheldrake will take to the open sea for protection. On the water its appearance resembles that of the Mallard, though it carries the neck somewhat higher (Naumann, 1896-1905). Finn (1915) says it appears high in the stern, and the male especially sits high in the water, looking much larger than the female, and this is certainly noticeable in captive birds. The young are very expert divers, and fully able to take care of themselves when first brought to the sea from their underground nests. As they reach maturity, however, this habit is lost, or rather it is made use of only rarely when an individual is wounded or suddenly frightened (Bodinus, 1862; Baker, 1908; Cordeaux, 1896). Though they usually feed by wading in shallow water, a few observers have occasionally remarked them tipping up perpendicularly, with only the posterior part out of water, like the Mallard (Naumann, 1896-1905; Dixon, 1893).

FLight. They rise easily from the water, not like geese or swans, and usually fly about rather close to the surface, presenting a striking appearance with their white plumage and bold color-pattern. Many describe their flight as closely resembling that of geese or swans, or even as gull-like, with slow and regular beats (Seebohm, 1885; Blathwayt, Avic. Mag., ser. 1, vol. 8, p. 251, 1902; Payne-Gallwey, 1882), but Naumann (1896-1905) does not consider the flight as gooselike or slow, comparing it rather with that of the Mallard and other non-diving ducks. Only when flying at a considerable height and in a still, heavy atmosphere do their wingbeats become more measured and gooselike. The birds alight easily, but have some difficulty in dropping upon smaller bodies of water, as Heinroth (1911) noted in the ponds of the Berlin Gardens. As with most other ducks, the female usually leads when they fly in pairs (Naumann, 1896-1905). 
Ordinarily Sheldrakes are seen in small parties or collections of several families, but in favorite localities, such as the west Scotland and other North Sea coasts, they assemble in flocks of several hundred after the breeding season. When on the wing these flocks assume the wedge formation, or else they fly in a slanting line (Naumann, 1896-1905).

Association with other Species. Seldom seen alone, these birds are very sociable among themselves, even in the breeding season, but they show little inclination to associate with other species. This may be explained by the fact that their habits are so unique, for they are essentially land ducks. Stragglers that have wandered inland have been found in the company of other species, or even with Domestic Ducks, but these are usually immature individuals (Naumann, 1896-1905). In confinement they have been noticed to have a particular aversion to geese, and to bully them. They have also attacked and beaten swans, and even given battle to game-cocks. An abnormal nest found in an exposed situation in England contained nine eggs of the Sheldrake and two of the Red-breasted Merganser (Foster, British Birds, vol. 6, p. 190, 1912).

Vorce. The trachea of the male in this species is highly specialized, having a double, globular, hollow, bony protuberance at its lower end. The enlargement on the right side is very much greater than that on the left. The bony walls of these diverticula are thin and flexible, and when fresh may be indented by pressure. The trachea itself is smaller toward the lower end. It has been figured and described by various authors, notably by Latham and Romsey (1798), Eyton (1838) and Yarrell (1856).

The voice of the male is modified, like that of all true ducks, and consists of a korr, korr, and during the breeding season there is a whistling note which Naumann describes as a "soft, whistling singing; slowly uttered and continued sometimes for half a minute at a time, reminding one of the jodel of various snipe-like birds." This note, which I heard only once, I described as a sort of short, very abrupt whistle, quickly repeated and rising to a crescendo, then dying away. The female meanwhile answered by a few low grunts. This whistling note is heard only during the breeding season and at that time the male does not ordinarily sound his loud call. The note of the female is usually described as quacking, much like a duck, but less resonant. More specifically it is spoken of as "a harsh long-drawn bark or chattering quack, like a peregrine falcon heard at a distance" (Blathwayt, 1902). These are not particularly noisy birds. The young peep like young domestic ducks, but not so frequently

FooD. The Sheldrake is chiefly dependent for its nourishment on minute marine 
animals: univalve and bivalve mollusks, insects, small crustaceans and worms. Occasionally a small fish or some fish-spawn is taken. At times it visits pastures, where it feeds on worms and slugs rather than on grass (Seebohm, 1885), but it does at times feed upon vegetable matter, presumably more so during the breeding season. Naumann, whose observations were made chiefly on Sylt during the summer months, speaks of vegetable matter as comprising "a large part" of its diet. This includes the tender parts and seeds of various maritime plants, and in the spring, on the Friesian Islands, at least, the newly sown grain, particularly barley. The sea food is rarely obtained in deep water, nor is the bird often seen tipping up, but is usually found wading in shallow water, or poking through seaweed on the shore, or fishing in puddles left on the mud-flats. Here it obtains chiefly small shrimplike animals of the genera Crangon, Palaemon, Gammarus and seaworms (Arenicola lumbricoides). During moult and rearing of the young, reedy districts are occasionally resorted to, where small frogs and even fish become the objects of prey. As many as twenty thousand small shells have been found in the stomach and crop of one individual, shot in Belfast Bay, Ireland, in February. Most of these were Mya purpurea, Skenea depressa and Paludina muriatica. To give an idea of the size of these animals, it might be added that the Skenea is about as large as a clover seed, and the Mya is somewhat larger. This is the same food on which the gray mullet attains a great size (W. Thompson, 1851). The following species of shellfish have also at various times been found in the stomachs of Sheldrakes: blunt bubble-shells (Cyclichna obtusa), small cockles (Cardium edule), porcelain tellina (Tellina tenuis) and the laver spire (Rissoa ulva) (Gladstone, 1910). The young in down are said to feed almost exclusively on sand-hoppers (Dixon, 1893).

Old birds have been seen stamping and paddling on the mud to bring up cockles, and tame birds in a poultry-yard were seen doing the same thing while waiting for their food (Cordeaux, 1896).

Courtship and Nesting. Sheldrakes pair in February or March, perhaps in this respect not differing from the true ducks, some of which pair even in January. They are rather late breeders, nesting in April and May in the regions about the North Sea; in May in south Russia (Radde, 1854); and as late as the first week in July in north Finland (von Heuglin, 1871a). In Europe the species is a maritime breeder except for isolated occurrences (see London Field, July 2, 1921), but in the Caucasus and in Asia it is an inland breeder, frequenting the saline marshes and lakes. The birds pair when they are two years old, at which time they assume full plumage. MacPherson (1892) cites the case of a one-year-old male, who refused to breed though confined with an amatory female, but voluntarily mounted guard over some flappers of its own kind. Mr. Hugh Wormald also finds that they never breed in his ponds the first year. The couples are exceedingly attached to each 
other, and may, like the geese, pair for life. This is, at least, the opinion of many writers, but it is one very difficult to verify. Radde (1854) mentions the case of a male who remained by the dead body of his mate for eight hours. On the Island of Sylt, where the birds nest in artificial burrows, one male is said to pay attention to several females.

The display is not at all specialized or characteristic. Both sexes dip their heads like geese, but according to Heinroth (1911) not even this is always seen. The male meanwhile utters a peculiar cooing note. A complete submergence of both birds follows, as if in the bathing play, and when the couple comes to the surface the male has assumed the mating position, and seized the female by the feathers of the head (Heinroth, 1911). In other cases the submergence is not so complete (Bodinus, 1862). A peculiar habit, which may be part of the display, was noted by Macgillivray (1852). In spring and summer, he says, the birds "erect themselves, thrusting forward the neck and shaking the head as though endeavoring to swallow or trying to get rid of something too wide for the gullet." Can this be allied to the tongueswallowing movements observed by Heinroth (1911) in the Muscovy?

In western Europe the nest is almost always located in rabbit-burrows, among sand-hills, but the holes of foxes and badgers are also used. Sometimes the nest is made in hollows at the foot of cliffs, or in clefts in the rocks, but it is always concealed from above. A few nests have been described as located beneath very thick bushes, such as the furze. Stone fences and openings under the flooring of houses and barns have also been selected. It has even been said that hollow trees are occasionally occupied, as on the Island of Poel, off Mecklenburg (Wuestnei, 1898; Naumann, 1896-1905). In southern Russia, and once even in Lincolnshire, England, the nests were placed in holes in straw or hay-stacks (Radde, 1854; Brauner, 1899; Cordeaux, 1896). The burrows may be situated in barren tracts of sand or moor a short distance from the water; but at other times the nests are at some distance from the shore, even several miles (Collett, 1873), in open regions, on the edge of woods or even in open places in wooded tracts (Naumann, 1896-1905).

Sheldrakes prefer burrows already formed by other animals, but they will enlarge or improve these to suit their own tastes. Occasionally, on islands where there are no burrowing mammals, they will dig hollows of their own, which, however, are not as long as fox-holes (Bechstein, 1791; Macgillivray, 1852; Naumann, 18961905; Kretschner, Ornith. Monatsber., vol. 1, p. 156, 1893). On Juist, and on Norderoog, since rabbits were exterminated, Sheldrakes are said to be nesting in the open (Schuster, 1904; Dietrich, Ornith. Monatsschr., 1910, p. 53); but this, if true, is very exceptional. Most older German writers were fully convinced that they sometimes nest in complete amity in the same burrows with the fox or badger, even using the same entrances. Naumann recounts in great detail the experience of a reliable acquaintance who actually observed Sheldrakes nesting in burrows known 
to be inhabited by foxes and badgers, and on close examination the fresh tracks and excrements of these different animals were found in the holes themselves. Naumann himself, and most of the later German writers, were fully convinced by this sort of testimony, and the case has been likened to that of the prairie-dog, snake, and owl colonies of western North America. To account for this phenomenon, various explanations have been offered. It has been said that the flesh and even the eggs of the Sheldrake have an odor or taste repulsive to the fox, and a recent author (Floericke, 1898) makes the suggestion that the plumage, and especially the eyes of the bird have a phosphorescent gleam in the dark, which repels other animals. But even the German writers are frank in admitting that no explanation will really fit the case. British writers have generally ignored, or received with great skepticism, all stories about Sheldrakes making their homes with foxes or badgers, but they are quite ready to admit the extremely dominant nature of the bird and the possibility that continental foxes may not have the same tastes as the English ones! In the literature may be found stories of a fox-terrier being seized by the ear, and a man by the trousers (Percival, Avic. Mag., ser. 1, vol. 8, p. 255, 1902), of a rabbit being dragged away by the ear (Payne-Gallwey, 1882), and of dogs chased and put to flight. Dogs seem to have a fascination for them, for male birds, ignoring the man, will often fly after his dog during the breeding season (W. Thompson, 1851). They are known also to have completely mastered birds much larger than themselves, even swans, and they have chased Black-headed Gulls who have carried off one of their young (London Field, Dec. 3, 1921).

The pairs fly about examining nest-holes in the early morning, the male usually remaining outside, while the female enters and explores the various burrows. The male also takes part in the nest hunting, though he has not been noticed assisting in the actual formation of the nest (Yarrell, 1856; Naumann, 1896-1905). Some of the early eggs are dropped on the marsh, or among the sand-hills, and Yarrell (1856) found that these were not always sterile. The birds are very fond of their nesting places, and will return year after year to the same burrows. This fact, and their habit of breeding in colonies, have been taken advantage of by the inhabitants of several of the Friesian Islands, notably by the dwellers on Sylt, off the west coast of Schleswig. Here for over two hundred years artificial burrows have been provided for the birds, and they have been scrupulously protected while their eggs and down have been systematically gathered. The inhabitants dig holes near their houses, with many branches, but a common exit, and so arranged that the turf over each nest may be lifted at will. From five to ten nests are excavated in each colony, though as many as thirty-one have been fashioned with a common entrance. The birds begin to lay from the middle to the end of May, and continue laying until the end of June. Several females may lay in the same nest. Sometimes only one nestegg is left, but usually several of the first eggs are allowed to remain, and then, as the 
nests are robbed each day, the duck will continue to lay, even up to twenty or thirty eggs. The normal clutch, however, is seven to twelve, though as many as sixteen have been noted. The down is also utilized and is said to be nearly as good as that of the Eider. In color the eggs are yellowish white, with the slightest greenish sheen. They are very fine in texture, and measure 64.7 to $68.7 \mathrm{~mm}$. in length by 48.1 to $49.1 \mathrm{~mm}$. in breadth. On the breeding colonies of Sylt, the reader is referred to the excellent accounts of Naumann (1896-1905), Möbius, Zool. Garten, vol. 11, p. 133, 1870, and Hagendefeldt, Zeitschr. f. Ornith., vol. 30, p. 121, 1906.

In wild colonies the male stays in the vicinity of the nest, and is ready to join the female when she leaves the burrow to feed. At times he enters the hole, but there is no adequate evidence that he takes part in the incubation, as stated by Bewick (1821), Stevenson and Southwell (1890), and others. The incubation period is twenty-eight to thirty days in length. There is a difference of opinion as to whether the female leaves any tracks on entering the burrow. Some writers have maintained that the female dashes in on the wing without leaving any tracks (Cordeaux, 1896), but most others insist that the nest may easily be found by the prints of the feet, though these are soon covered by drifting sand.

When the young are hatched, they are conducted by both parent birds to the water, which in some cases may be at a distance, thus entailing a long walk through dangerous neighborhoods. There are the usual stories of the young being carried down from elevated cliffs, etc., in the bill, or on the back of the female. PayneGallwey (1882) claims to have seen ten to twelve ducklings carried down on the mother's back. Such stories have been repeated in many ornithologies, but these occurrences are at best very exceptional. Bodinus (1862) proved to his own satisfaction that the young are allowed to drop from elevated nesting sites.

During the walks to the water many of the young are captured by fishermen, who attempt to raise them in captivity. Cordeaux (1896) noticed a brood of ten young with the female leading and the male bringing up the rear some six yards behind and guarding the flock. This brood walked about one-half mile in half an hour. The young are not always taken directly to the sea, and the early growing period may frequently be spent on some small body of fresh water near the nest, where grasses and rushes offer a place for concealing the young in case of danger. It is not known exactly how long the male remains with his family, but he probably does so for a short time only, as he moults in late June or in early July. The female stays with her young until they are active on the wing, her moult taking place at least a month later. In the British Isles home-bred birds leave by mid-October, and there is a period of five or six weeks between this time and the arrival of more northern or eastern breeders that winter in the islands. Many non-breeding birds spend the summer months on the coasts (Cordeaux, 1896; and others). Before migrating the old and young birds assemble in separate flocks, the former on the sea-coast, the 
latter more commonly on inlets or ponds close to the shore. Naumann (1896-1905) is authority for the statement that the young birds are the first to leave for the south.

Status. Formerly, no doubt, Sheldrakes were far more abundant on the coasts of western Europe than they are now. In Yarmouth, before 1815, Dresser (187181) says they were so abundant that they were supposed to disturb the rabbits, and pains were taken to destroy them. The same writer notes that in Ireland there was a steady decrease in numbers after 1830. The destruction of rabbits on the Copeland Islands led to the Sheldrakes' leaving them. The lowest ebb was reached in the British Isles about 1890 (Southwell, British Birds, vol. 2, p. 62, 1908), but since then there has been a decided increase both in the British Isles and on the continent. It was increasing and common on Iona and Mull in 1887 (Harvie-Brown and Buckley, 1887), and a remarkable increase was noted on Solway Firth (Service, Trans. Edinburgh Field Nat. and Micr. Soc., vol. 5, p. 185, 1905). It is greatly on the increase also at Wolverton, Norfolk (Noble, British Birds, vol. 2, p. 19, 1908), and in Dumfries (Gladstone, 1910). In Mecklenburg it is said to be not decreasing (Wuestnei, 1898), though it has lately been reported decreasing on Sylt (Hagendefeldt, Zeitschr. f. Ornith., vol. 30, p. 121, 1906). Recent literature indicates a tendency to an inland dispersal during the breeding season on the continent, and Service has noted the same fact in Scotland. The gradually increasing population on the coasts has, no doubt, driven the birds to seek more secluded surroundings. It is certainly gratifying to find this, one of the most beautiful of all ducks, holding its own or even increasing at the present day.

ENEmies. Man is the principal enemy of this species, but the Gray Sea-eagles have been mentioned as a menace in former times (Naumann, 1896-1905), though they can hardly be a factor of any importance at present. The domestic cat and the hedgehog, which last had been introduced, are important enemies to the Sheldrakes on the island of Röm (Naumann, 1896-1905).

In the feathers of the birds are found parasitic insects of the genera Philopterus and Liotheum, while various intestinal worms afflict them. These worms belong to the following species: Sclerostomum tadornœ, Heterakis vesicularis, Heterakis dispar, Spiroptera crassicauda, Hystrichis tricolor, Echinorhynchus polymorphus, Distomum oxyurum, Distomum oxycephalum, Distomum echinatum, Monostomum attenuatum, Holostomum erraticum, Notocotyle triserialis, Taenia anatis tadorna, Taenia gracilis and Taenia destituta (Linstow, fide Naumann, 1896-1905).

Damage. Although Sheldrakes are known to have fed on new-sown grain on one or two of the Friesian Islands, this is apparently an exceptional practice, and would 
hardly justify one in accusing them of serious damage. Their destruction of edible shell-fish has not been estimated, but it probably could never be serious.

Food VALUe. The flesh is very rank, and the bird is unfit for the table, even when skinned. I find but one writer who considered the bird edible, and it is probable that his taste was not very discriminating. There are, indeed, people who prefer Mergansers to other ducks, but these "otherwise-minded" folks are best left out of account. The eggs of the Sheldrake have a rank taste, not suited to every palate, though apparently held in high esteem by the inhabitants of the Friesian Islands.

HUNT. These birds are seldom shot for their flesh, and fortunately they are wary enough to be well able to take care of themselves. English puntsmen, it is true, occasionally take a shot at them, but hold them in ill-favor because when among Widgeon they are sure to give the alarm and spoil a good shot (Millais, 1901). Sometimes they are taken by placing nets over their burrows, but fortunately this practice is not common. They are but rarely taken on the fresh-water decoys of western Europe, where ducks are led into pipe-nets by tame flocks. A. Chapman and Buck (1910) were told that in the marismas of southern Spain they are easy victims for any sort of imitation, provided it be white. A local fowler said he had killed many by using the dry bones and skulls of cattle in place of decoy ducks.

Behavior in Captivity. Sheldrakes are very commonly kept on ornamental ponds in Europe, but are almost never seen in America, as they are unable to stand the ocean voyage. The only pair that I ever had lived only two or three months. This is very unfortunate, for no bird is more striking or beautiful, and it has the advantage of retaining its gorgeous plumage throughout the summer. It was often kept in the parks of French gentlemen in the early part of the sixteenth century (Loisel, Hist. des Ménageries, 1912). In India it is said not to bear captivity well (Finn, 1909). In European markets the birds are easily obtainable, being raised chiefly from eggs taken in the wild. The price before the War was only 18 to 25 shillings per pair.

In confinement they will not thrive unless some animal food is supplied, and they do best if given an opportunity to obtain insects for themselves. Lacking these they should be given fish or meat scraps with their grain. If too closely confined, or if fed exclusively on barley, they develop an eye-disease which is at first an abscess of the cornea, and finally extends to the antrum. Other water-fowl also contract this disease, but are not nearly so susceptible as the Sheldrakes, which have been known to die in eight days (Liebrecht, Zool. Garten, vol. 43, p. 62, 1902). Under favorable conditions, however, the birds will live for many years. In 1883 the London Gar- 
dens possessed a pair that had been purchased in 1860 , but in general from three to five years is the ordinary length of life in confinement.

The species is not one that is easily bred in captivity, and it will never do so until two years of age. It nests later in the season than most other ducks. In former years it was bred quite regularly in the London Gardens, having reproduced seven times between 1835 and 1848 (P. L. Sclater, 1880). In recent years the Gardens have been far less successful, though in other places young have been hatched and reared. It has never reproduced at the Berlin Gardens, though a few eggs were laid. A few were raised in the Dresden Gardens (Reeker, Münster Jahr. Prov. Wiss., 1909, p. 46). Bodinus (1862), the former director of the Zoological Gardens at Cologne, has given detailed directions about rearing the young. They can, he says, be easily reared if a small pond with plenty of insect life is provided. The food should be vegetable, with ant larvæ, water lentils, chopped lettuce, etc. If fed on barley alone they contract the eye-disease mentioned above. Some even become blind in spite of all that can be done in varying the diet (Niemeyer, Zool. Garten, vol. 9, p. 71, 1868). They seldom reproduce on small ponds, and require a larger sheet of water with suitable burrows for nesting sites.

Young birds only a few days old have been noted stamping about on the grass in imitation of the means employed by older birds to entice shell-fish from their holes. They keep rather aloof from other species, but, though of a dominant disposition, are not so pugnacious as their relatives, the Sheldrakes of New Zealand and South Africa. If kept with poultry they soon lord it over the whole barnyard. W. Thompson (1851) speaks of one bird which completely mastered some tame swans, alighting on their backs and buffeting them with its wings. In another case a male Sheldrake is reported to have thrashed a game-cock.

No wild hybrids have been described, to my knowledge, but in confinement the following crosses have been successful:

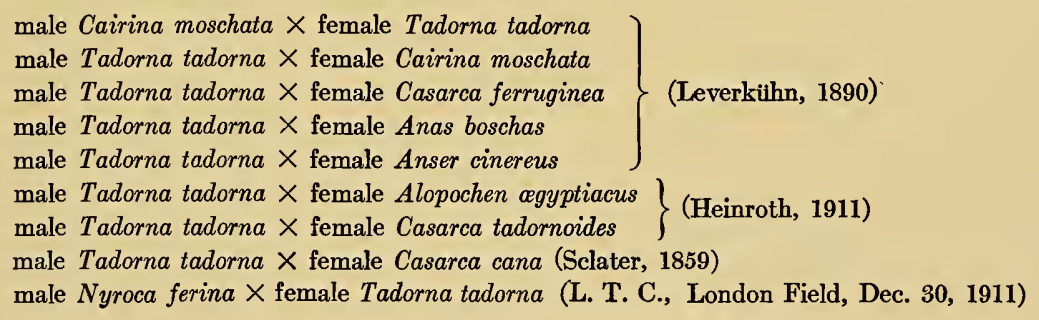




\title{
RADJAH SHELDRAKE
}

\author{
TADORNA RADJAH (GARNOT)
}

(Plate 16)

SYNONYMY

Anas radjah Garnot, Voyage "Coquille," Zool., atlas, pl. 49, 1826.

Tadorna radjah Eyton, Monograph Anatidæ, p. 106, 1838.

Vernacular Names

English:

Radjah Sheldrake

White-headed Sheldrake

White-necked Sheldrake

White Duck - (Northwest Australia)

Burdekin Duck - (Queensland)

French:

Sarcelle des Malais
German:

Radjah Gans

Aborigines of Australia:

Comerdo

Mahdo or Mardo

Aru Islands:

Bursil

- Birgual

Anda Island:

Umukia

\section{DESCRIPTION}

AdulT MALE: Head, neck, breast, abdomen and lesser wing-coverts pure white, mantle black, vermiculated with narrow chestnut lines. Back, scapulars, rump, upper tail-coverts and tail black. There is a very marked chestnut-colored pectoral band on each side of breast. Bastard wing, primary coverts, and primaries black; a bright-green speculum on the secondaries, which are broadly tipped with white. The speculum is bordered anteriorly by a black line on the lesser coverts, and posteriorly by a black line on the secondaries. A dark chestnut patch on the outer margin of the tertials.

Iris white; bill fleshy-white; legs and feet white, tinged with flesh-color.

Wing 260-270 mm.; bill 42-44; tarsus 54-57.

Adult Female: Similar.

IMMATURE: Have the upper part of the head and the nape dark reddish, the upper wing-coverts edged with blackish, the black band near the tips of the greater wing-coverts broader, and the green speculum duller (Salvadori).

Downy Young: Have brown-black upper side, with four large white spots, two on each side, and white under side (Meyer, 1884).

\section{DISTRIBUTION}

The White-headed Sheldrake is a bird confined to the East Indies and Australia. Like many Moluccas tropical Anatide, it is a non-migratory species, its seasonal movements being only local. The northwestern limit of its range seems to be Ternate (Bernstein, Leyden Museum) and Halmahera (Bernstein, Leyden Museum) in the Moluccas. It has been recorded also 


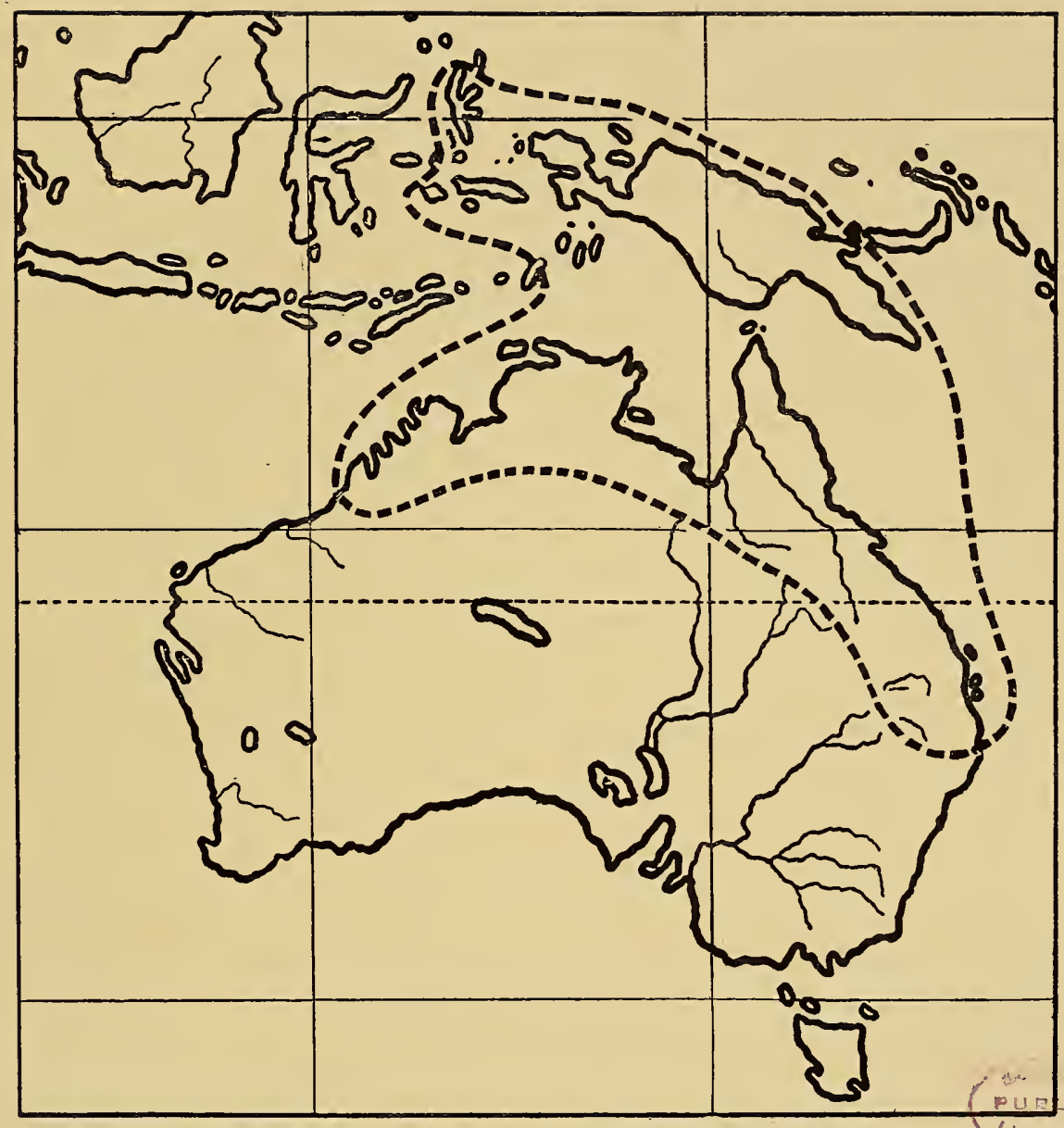

Map 23. Distribution of Radjah Sheldrake (Tadorna radjah) 

for the islands of Batjan (Wallace, British Museum), Obi (Bernstein, Leyden Museum), Buru, where it is a fairly common bird (Hoedt, Leyden Museum; Wallace, 1863; Stresemann, 1914), Kelang (Hoedt, Leyden Museum), Carem, where it is occasionally seen (Wallace, British Museum; Moens, Leyden Museum; Lenz, Journ. f. Ornith., vol. 25, p. 381, 1877; Stresemann, 1914), and Goram (Rothschild and Hartert, 1903). Hoedt (Leyden Museum) took it on the Island of Gebe, in the Halmahera Sea, and Guillemard (Proc. Zool. Soc. London, 1885, p. 665) on Waigiou. There are records also for the Island of Salawatti (Bernstein, Leyden Museum, et al.).

In New Guinea the species seems to be distributed throughout. It has been recorded from Sorong on the northwest, and from Anda, Warbusi and Nicura (Salvadori, 1882). Guillemard (Proc. Zool. Soc. London, 1885, p. 665) found it on the Island of Jappen, off the northwest coast. New The British Ornithological Expedition found it on the southwest coast, on the Mimika Guinea and Satakwa Rivers (Ogilvie-Grant, 1915). In this region it was found also at Van Weels Camp, and at Alkmaar (van Oort, 1909) as well as on the Tami River (de Beaufort, 1909). From eastern New Guinea there are records for Kunirira (Salvadori, 1891), Laroki and Lalake Rivers (Sharpe, 1877, 1878) and Port Moresby, where the species is common and breeds (Ramsay, 1879). On the northeast coast it was found at the mouth of the Kabena River, Finisterre region (Madarász, 1894), and on the Huon Gulf (Meyer, 1894). Heinroth (1903) has reported it from Hercules Bay, and the Bubui River in this same region. The eastern limit seems to be Ferguson Island (Tristram, Ibis, ser. 6 , vol. 1, p. 558, 1889).

To return to the west - the White-headed Sheldrake has been found on the Aru Islands (Meyer, 1884; Rosenberg, Leyden Museum) and at Larat in the Timorlaut Group (Büttikofer, Aru 1886a; Sclater, 1883).

Islands

In Australia the species is rather widely distributed as a breeder in the northern parts. It has been found in the northwest at Derby, Port Darwin and Port Essington (Ramsay, 1888; Masters, 1878), on the South Alligator River (Hartert, 1905), the Kimberly Region (North, 1898) and Parrey's Creek. Farther east it is known to inhabit the regions about the Gulf of Carpentaria (Ramsay, 1888), and it is a fairly common bird in Queensland, north of the Mary River (Ramsay, 1877), whence it has been recorded for Rockingham Bay, Port Denison and Wide Bay (Ramsay, 1888), Cardwell and Herbert Rivers (Broadbent, 1910) and Charo Bay, Cape York (Macgillivray, 1914). In northern New South Wales it has been found in the Moree and Narromine districts (North, 1913).

\section{GENERAL HABITS}

Haunts. The present species differs from the Common Sheldrake in being a bird of rivers and fresh-water lakes, perhaps frequenting the coast during droughts only. Mathews (1914-15) remarks that its life history is very imperfectly known, though it is a common bird in northern and northwestern Australia. We certainly do not know what its seasonal movements are; whether it goes inland merely to breed, or whether it breeds both in the interior and on the coast. In northwestern Australia it appears to spend most of the year on inland rivers, and to be extremely local in its habits (North, 1898).

FuIgHt. The Radjah Sheldrake is said to fly like the Common Sheldrake, but somewhat more rapidly, due to its smaller size (Heinroth, 1903). By this I presume that the writer means that the wings move faster, not that the flight itself is any quicker. Ordinarily the birds are seen in pairs, but small flocks of four to eight are not uncommon (North, 1898). 
Perching. Radjah Sheldrakes have frequently been seen walking about on the river banks, or perched on horizontal branches of low trees near the water (Gould, 1865; Ogilvie-Grant, 1915).

Association with other Species. Keartland (North, 1898) mentions seeing single birds in the company of flocks of Black Ducks (Anas superciliosa), or Teal (Anas gibberifrons).

Voice. The notes of the two sexes are different, as in Tadorna tadorna, but the voice is hoarser, while the whistle of the male is less clear, and the quacking of the female is less distinct than in the Common Sheldrake (Heinroth, 1911).

Food. In the stomachs of various specimens the following food has been found: grass seeds, shell-fish and grit (Mathews, 1910); crustaceans (Broadbent, 1910); snails (Meyer, 1884); and fresh-water mollusks (Madarász, 1894). Gould (1865) says, "When the rainy season has set in, and the water of the lakes has become too deep for them to reach the roots of a species of rush, upon which they feed, they scatter over the face of the country, and are then to be seen wading through the mangrove bushes, and over the soft mud left by the receding tide, the surface of which affords an abundant supply of food, consisting of crabs, mollusks and other marine animals."

Courtship AND Nesting. Nothing is known of the courtship or display in this species. In Australia the breeding season falls in the months of December and January in North Queensland (Ramsay, 1875); while in northern Australia it probably begins after the rainy season sets in, in February and March (North, 1913). In the Keartland Collection there is an egg from the Daly River, North Territory, taken on April 6 (North, 1913), while in northwestern Australia clutches were taken at Port Darwin on February 2, 4 and 6, on April 24, and on May 1 and 21 (D. Le Souef, 1902). On the Island of Halmahera young in down (now in the Leyden Museum) were taken by Bernstein on November 24 .

The nest is usually, but not invariably, placed in a hollow tree (D. Le Souef, 1902). All the nests described by North (1913), Keartland (North, 1898) and Ramsay (1877) were in hollow trees or hollow limbs near the water. Keartland tells of a pair which nested in a tree close to where people passed, and which, toward the end of the incubation period, became so tame that the female would not leave the nest. According to D. Le Souef (1902) the number of eggs in a clutch varies from four to eleven. They are creamy white in color, and slightly glossy, measuring from 57 to $61.5 \mathrm{~mm}$. in length by 39 to $43 \mathrm{~mm}$. in breadth. The incubation period is not known, but is probably close to thirty days. 
STATUS. It is doubtful if it is holding its own in the more settled parts of Australia. In North Australia at the mouth of the Little Archer River a flock of two hundred was recently seen (H. L. White, Emu, vol. 16, p. 214, 1917). There is no reason to suppose that the species is in any immediate danger.

ENEmiEs. Keartland (North, 1898) speaks of the natives raising havoc with the eggs of these birds in northwestern Australia.

FooD VALUE. Hubbard (1907) remarks (on what authority I do not know) that the flesh of this species is coarse and of an unpleasant flavor.

Behavior in Captivity. Mr. F. E. Blaauw has written me that he first saw this Sheldrake about 1886 at Monsieur Cornely's estate at Tours, France. They did not live there very long and never bred. This striking bird was again imported into Europe in the year 1901, when the Berlin Gardens received specimens, which were considered to be the first of their kind to reach Europe alive (Heck, Verh. 5te Intern. Zool. Congr. Berlin, p. 925, 1911). Hubbard (1907) states that a few pairs were imported into England between 1900 and 1904, the price varying from $£ 12$ to $£ 20$. The New York Zoölogical Park received a pair from Australia in the summer of 1922, apparently the first to reach America alive. It has never been bred in confinement.

\section{GEOGRAPHICAL RACES}

\section{TADORNA RADJAH RUFITERGUM HARTERT}

\section{SYNONYMY}

Tadorna radjah rufitergum Hartert, Novitates Zool., vol. 12, p. 205, 1905.

Tadorna rufitergum Mathews, Handlist Birds Australia, p. 35, 1908.

Tadorna radjah flindersi Mathews, Austral Avian Record, vol. 1, p. 86, 1912.

Radjah radjah rufitergum Mathews, List Birds Australia, p. 90, 1913.

Characters: This race differs from the true Tadorna radjah radjah in its larger size and in being a richer chestnut color on the mantle and back. Wing $284 \mathrm{~mm}$.; bill 46 ; tarsus 61 .

Distributron: Australia. 


\section{CRESTED SHELDRAKE}

PSEUDOTADORNA CRISTATA KURODA

\section{SYNONYMY}

Tadorna casarca $\times$ Querquedula falcata? Sclater, Proc. Zool. Soc. London, 1890, p. 1, pl. 1.

Pseudotadorna cristata Kuroda, Tori (Aves), no. 5, p. 1-6, 1917; Kuroda, Annotationes Zool. Japonenses, vol. 9, p. 495, 1918.

\section{English:}

Crested Sheldrake

Kuroda's Sheldrake
Vernacular Names

Japanese:

Kammuri-tsukushi-gamo

Chosen-oshi

\section{DESCRIPTION}

Advut (type of species and probably a female, shot on the Naktung River near Fusan, Korea, December, 1916): Crown of head, nape, a broad longitudinal band on the hind neck, upper tail-coverts and primaries black, with some greenish luster; nuchal feathers considerably elongated, forming a pendant crest or tuft; in ocular region a conspicuous spectacled patch prolonged to side of occiput; under this patch a blackish-brown band, continued alongside the black of the head and nape; forehead, base of bill, chin and upper throat pure white; sides of neck and upper forehead white, sparsely and indistinctly barred and spotted with dusky brown, but more distinctly near the cheek (Kuroda, 1917). Mantle, back, chest, sides of body and abdomen dark brown with narrow but distinct white lines; upper parts darker than lower parts. The wing is that of a typical Sheldrake; wing-coverts white, bastard wing and primaries black, a green speculum on the inner secondaries, tertials gray with large blotch of brownish chestnut on outer webs.

Bill and feet light colored.

Wing $310 \mathrm{~mm}$.; culmen 41.5 ; tarsus 47 .

\section{DISTRIBUTION}

THIs duck is known from Korea, and from Ussuri Province.

Remarks: This species was first described by Sclater (Proc. Zool. Soc. London, 1890, p. 1) from a specimen taken near Vladivostok in April, 1877, by Lieut. Fr. Irminger. Dr. Selater supposed the bird to be a hybrid between the Ruddy Sheldrake and the Falcated Teal, and at the same time published a fine plate, figuring the specimen. In 1917, Mr. N. Kuroda described a second specimen taken near Fusan, Korea, in December, 1916. He gave it the name Pseudotadorna cristata, and later published a plate. It is evident that the supposed hybrid described by Sclater and this new Sheldrake are one and the same bird. According to Uchida (Tori, vol. 2, no. 6, p. 6-8, 1918) birds of this species seem to have been imported from Korea to Japan some two hundred years ago. It was known by the Japanese name "Chosen-oshi," and both sexes are described in an old Japanese ornithological work called "Kanbun-kinpu." Mr. Kuroda has been kind enough to send me a photograph of an ancient Japanese drawing in which both sexes are shown. The female in the drawing evidently corresponds to the new Sheldrake, while the male is represented as also carrying a crest, and as having, in addition, a sharply defined black or perhaps dark-red breast. In his letter Mr. Kuroda says that he has recently 
received information from Korea that the Crested Sheldrake is frequently observed or captured by Japanese hunters in south Korea. But he has not yet succeeded in obtaining a second specimen.

From such evidence it is necessary to give the species provisional rank, but I must say that I cannot help still being skeptical about it. The difficulty remains that, supposing it to be merely a hybrid, we cannot imagine what its parents were (except that the Ruddy Sheldrake may have been one of them) because it does not seem to be intermediate to any two known species of Anatida. Mr. Kuroda himself wrote me that if his Sheldrake was a hybrid between the Ruddy Sheldrake and the Falcated Duck the color of the bill and feet should have been black. But they were in fact pale-colored, and far from blackish. He adds, "My specimen is no doubt a female of this rare duck and the male has not yet been seen by me, although the old Japanese ornithological book gives a description of both sexes."

Mr. George D. Wilder, of Peking University, in a letter written to Mr. Outram Bangs from China in 1921, says he thinks that he saw a specimen of Kuroda's Sheldrake in the hands of a Chinese hunter about twenty-five years ago. He had no idea of its rarity, and the Chinaman did not wish to sell it. 


\section{RUDDY SHELDRAKE \\ CASARCA FERRUGinea (Pallas)}

(Plate 17)

\section{SYNONYMY}

Anas ferruginea Pallas, in Vroeg's Catalogue, Adumbratiuncula, p. 5, 1764.

Anas casarca Linné, Systema Naturæ, ed. 12, vol. 3, app. p. 224, 1768.

Anas rutila Pallas, Nov. Comm. Petrop., vol. 14, pt. 1, p. 579, pl. 22, fig. 1, 1770.

Tadorna rutila Boie, Oken's Isis, 1822, p. 364.

Casarca rutila Bonaparte, Comp. List, p. 56, 1838.

Tadorna casarca Macgillivray, Man. British Ornith., vol. 2, p. 163, 1842.

Casarca ferruginea Witherby et al., Practical Handb. British Birds, pt. 12, p. 263, 1921.

\section{Vernacular Names}

English:

Ruddy Sheldrake

Röthalsad And

Brahminy Duck

Ruddy Goose

Collared Duck

French:

Tadorne casarca

Casarca roux

German:

Rostente

Fuchsente

Zimmetente

Rote Hohlenente

Rote Pfeifente

Persische Ente

Rote Kasarka

Danish:

Rustand

Norwegian:

Rustand

Rötgul And

Tartar-gaas

Swedish:

Rostand

Braminand

Dutch:

Berg-eend

Kasarka-eend

Icelandic:

Rydond

Finnish:

Ruostesorsa

Hungarian:

Vörös lúd

Török lúd

Rö-rucza

Orvös röt-recze

Téglarécze

Georgian:

Garieli

Tartar:

Aat or It-kas

Mongol:

Lama Shubu

Polish:

Rödgul And

Kaczka kasarka 




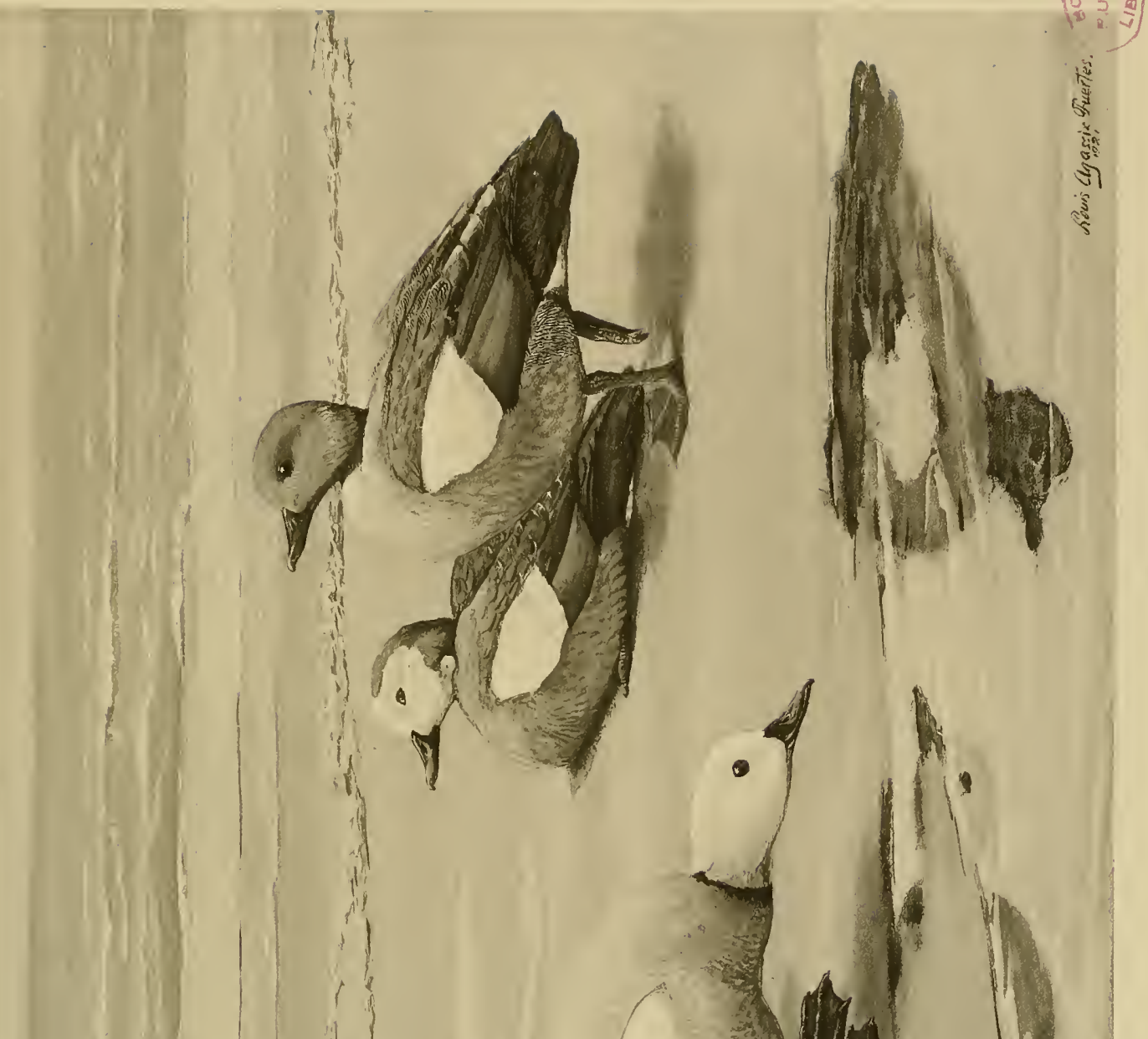

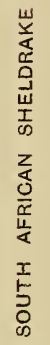
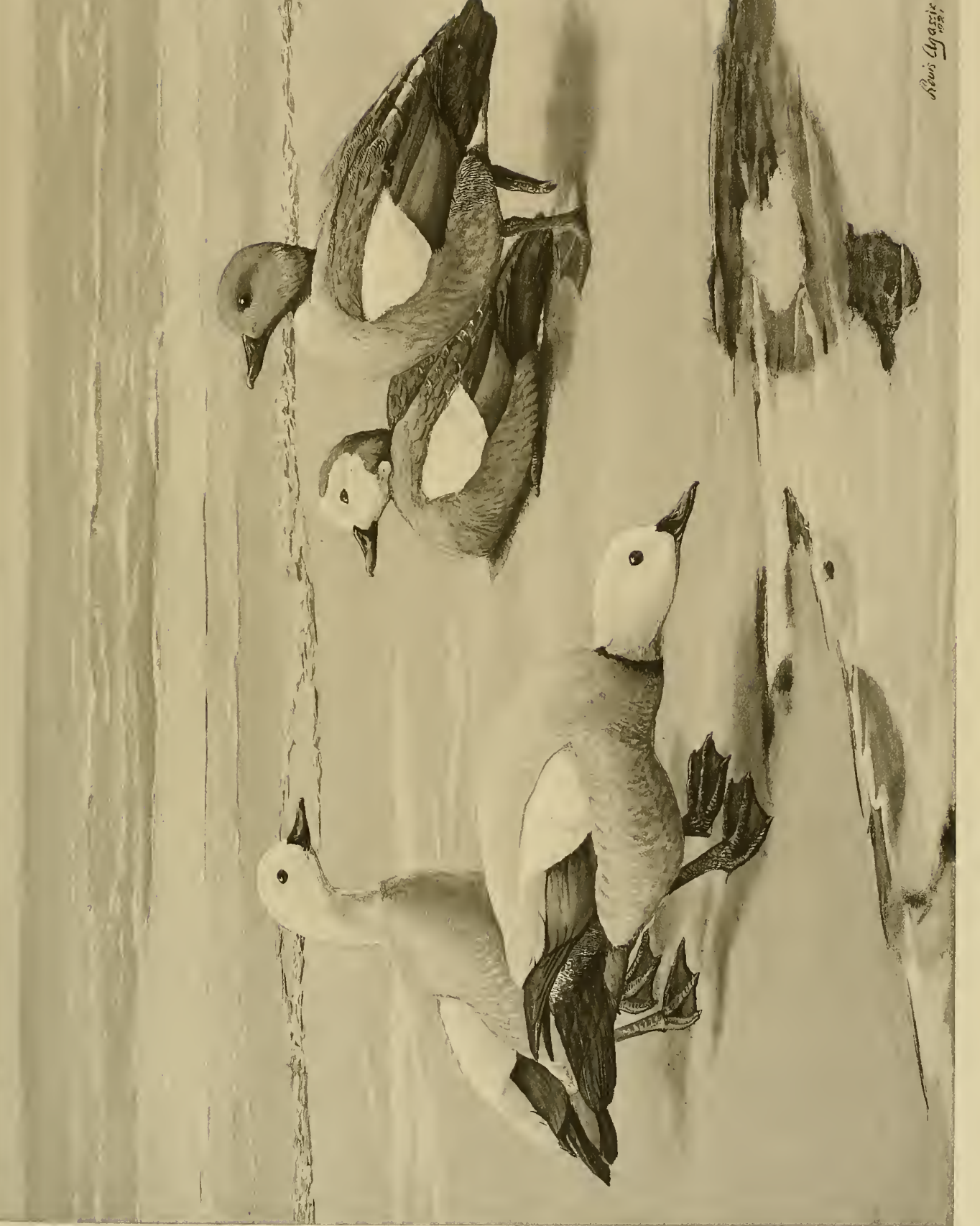

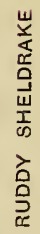



Russian:

Krasnaya utka

Karagatka-(Cossacks)

Krasnaja utica

Turpan-(Caucasus)

Spanish:

Pato tarro

Pato de color de canelo

Labanco

Italian:

Casarca

Germano forestiero

Fiscuni imperiali

Fiscuni furastieri

Moorish:

Bou-ha

Maltese:

Culuvert ta Barbaria ahmar

Arabic:

Wuz-abu-faroa

Ijogeh

Turkish:

Kermesi erdek
Bulgarian:

Kilifari

Angut

Croatian:

Utva zlatokrila

Czech:

Husa ruda

Hindustani:

Surkhab

Bengali:

Boogri

Yarkand:

Hangat

Ngooroo ngaupa

Chinese:

Hwang-ya

Japanese:

Aka-tsukushigamo

Kalmucks:

Aangir

\section{DESCRIPTION}

Adult Male: Head light buff, throat and chin darker buff, neck rusty brown with a black ring, more or less perfectly developed. Mantle, scapulars, breast and lower parts rich foxy red; back reddish, vermiculated with black lines; rump and tail black. 'Wing-coverts white, secondaries metallic green on outer web, forming a speculum; primaries black. Tertials red on outer web, nearly white on inner web.

Bill bluish black, nail black. Legs ashy gray, with black claws. Iris hazel-brown (according to Naumann, darker color in young specimens).

Wing 330-350 mm.; bill 42-45; tarsus 59-66.

Weight: male, 3 pounds 2 ounces to 4 pounds 7 ounces (1.43 to 2.02 kilograms).

Addut Female: Black collar wanting, head and neck lighter color; general color lighter.

Weight: 2 pounds 3 ounces to 3 pounds 8 ounces (1.00 to 1.60 kilograms).

IMmatuRE: Resembles the female, but is duller in color; the tertials and scapulars are brown, marked with yellowish red, and the white on the wings is washed or soiled with gray (Dresser).

Young IN Down: The specimens which I have examined in the British Museum and at Leyden 
seemed to me not to differ in any way from young of the Common Sheldrake. Seebohm says that the brown of the upper parts is paler, and the white of the underparts is suffused with brown on the breast and belly. I am often surprised at the amount of individual variation in the coloring of downy young in ducks and think more and more that large series have to be considered to get correct ideas.

Variations: Color in this bird ranges from rich dark chestnut to a washed-out buffy tint, and no two birds are exactly alike, regardless of sex. In some specimens the feathers of the interscapular region are tipped with a very pale buff, which gives the bird a more or less barred appearance. No careful study of the moult has been made, but it is very likely that there is a more or less complete double moult, the summer plumage being practically the same as that of winter.

\section{DISTRIBUTION}

BeING essentially a resident species, the Ruddy Sheldrake inhabits practically the same areas in winter as in summer, and is only to a slight extent migratory. It is above all an eastern palæarctic General species, its habitat being Asia. Still it is not uncommon in parts of southeastern Europe and northern Africa; in western and northwestern Europe, however, it is to be regarded strictly as a straggler. As a matter of fact it is impossible to say how many recorded instances of its occurrence there are simply cases of birds escaped from captivity. No doubt a good many records would come under this category if all the facts were known. There can be very little question, however, that a genuine flight, probably from southern Russia, took place in the summer of 1892 when the birds were successively seen in Denmark, England, Ireland, Iceland, and eventually in high latitudes on the coast of West Greenland! I shall revert to this phenomenon below, in connection with the various countries. Suffice it to say that it was probably due to drought in southern Europe; and that its occurrence in Greenland and Iceland is a unique event in ornithoGreenland logical history. Specimens were taken in West Greenland at Augpalartok, near Upernavik, latitude $73^{\circ}$ north, and at Ritenbenk, latitude $70^{\circ}$ north (Vanhoffen, Verh.

Ges. f. Erdk., Berlin, 1893, p. 460). Mention should perbaps be made here of the capture of a specimen of this species on November 14, 1916, at Barnegat Bay, New Jersey; the bird seemed to be a North wild one, and it is said that three other specimens were taken on Currituck Sound, America North Carolina, in 1886. The reputed capturer claims to have seen others there at various times since then (Grinnell, Auk, vol. 36, p. 561, 1919). Not much weight is to be given to Iceland these unusual statements. In Iceland three specimens were taken on the southwest coast near Eyrarbakki, July 20, 1892, and at the end of the same month four more were taken on the north coast at Akureyri (Hantzsch, 1905).

In Denmark the species had previously been taken only once, at Bornholm (Kjaerbölling, 1850), but in 1892 a flock was seen at Vordingborg (Winge, 1895). There is one old record of its occurrence Denmark in Sweden, near Stockholm, May 22, 1854 (Nilsson, 1858), and another for Isbo, FinDenmark land, July, 1887 (Palmgren, 1913). Schaanning (1913) gives seven as the total number of recorded instances for Norway. They are: Trondhjem, October, 1887; Jaederen, August 15, 1898; Scandi- Kristiania, August 2, 1892; Solor, August 2, 1892; Stenkjaer, September 11, 1892; navia Skudesnes, October 12, 1892; and Fitjar, April 24, 1909. It is obvious from this enumeration that Norway too was touched by the flight of 1892 .

There had not been many records for the British Isles previous to 1892. Specimens had been taken in Dorset, 1776; Suffolk, 1834, 1864; Orkney, 1831; Caithness; Wicklow, 1847; Kerry, 1869 (Dresser, British 1871-81; Seebohm, 1885; etc.). The flight in 1892, however, was particularly noted in Isles the British Isles. Mr. Ogilvie (Zoologist, ser. 3, vol. 16, p. 392, 1892) gives an interesting and detailed account of the event. In Ireland flocks were seen or specimens taken in Donegal, Dublin, Drogheda and Limerick, while in England the species occurred in Cumberland, Sutherland, 
Suffolk, Elgin, Lincoln, and Norfolk. Earlier records for Ireland are those for counties Wicklow, Waterford, Kerry and Down (Ussher and Warren, 1900). More recent records for the British Isles are: one for Romney Marsh (Parkin, Zoologist, ser. 3, vol. 8, p. 469, 1884), another on Suliskerry, off the Orkneys, June, 1909 (B. O. U. Checklist), a pair for Caithness, June 27, 1910 (Bruce, Glasgow Nat., p. 134, 1910), and repeated occurrences in Norfolk (Gurney, British Birds, vol. 11, p. 255, 1918).

In Germany the species has been met with a few times. I find records for the Rhine Provinces (Le Roi, 1906-07), Silesia (Naumann, 1896-1905), Lusatia (Tobias, Journ. f. Ornith., vol. 1, p. 217, 1853), Brandenburg (Schalow, 1915) and Hamburg (Reichenow, Journ. f. Ornith., vol. 30, p. 122, 1882). In July, 1895, four specimens were taken near Koenigsberg, in east

Germany

Prussia (Floericke, 1898), and Wuestnei (1902) reports that a flock was met with at Neubrandenburg in Mecklenburg. Palmén (1876) is authority for an old, and it seems to me, probably mistaken record for Lake Ladoga, Russia. It has never been included in the list of birds of the St. Petersburg Government. Nevertheless a specimen was taken in 1871 in Esthonia (Loudon-Lisden, 1909).

In the Netherlands the species has been twice recorded from Holland, one specimen dating from October 6, 1869, and the other from December 5, 1910 (van Oort, 1911). There are Netherno records for Belgium, and very few for France, these being an old one for Camargue, lands Rhone Delta (Müller, Journ. f. Ornith., vol. 4, p. 232, 1856), one for Toulouse, Jan- Belgium uary, 1876 (Lacroix, 1876), an old one for Normandy, 1838, and a more recent one for France Calvados, December, 1912. Furthermore the species has occurred once at Crotoy and is known to appear rarely about Perpignan and in the eastern Pyrenees (Brasil, Bull. Soc. Linn. de Normandie, Caen, ser. 6, vol. 6, p. 31, 1913). In Switzerland specimens have occasionally been taken, one on Lake Constance and two on Lake Geneva (Fatio, 1904). Its status in Austria and Hungary is vague. Fritsch (1872) claims that it has occurred near Frauenberg, Bohemia, and Austria Mojsisovics (1887) records it for east Slavonia and Dalmatia. Kolombatovič (1903) Hungary also reports its occurrence on the Narenta River. In Hungary it has very naturally occurred from time to time, coming from the east side of the Transylvanian Alps and consequently being most frequently met with in Transylvania. From there it has been reported by Danford and HarvieBrown (1875), Wagner (fide Dresser, 1871-81), Stetter (ibid.), Csato (1895), Frivaldski (1891). From Budapest it has been recorded by Petényi (1884), and from the Sajo and Maros Rivers by Mojsvar (1897). Szabo even claims that occasionally large flocks, as on April 10, 1830, fly over, but $I$ think this record is a mistaken one. At best the species is rare in Hungary.

I find a few records for Italy. Four specimens were taken in Tuscany: two in the Romana, one near Naples, and one in Apulia (Arrigoni degli Oddi, 1904). In Sicily it has been taken at Lentini (Döderlein, 1869) and at Syracuse (Arrigoni degli Oddi, 1904), and Italy three were taken on Malta (C. A. Wright, 1864; Adams, 1870). Despott (1917) adds a recent record for Malta.

The species has been recorded for Guadiana, Portugal (Oliveira, 1896), and is of regular occurrence in parts of Spain. At Gerona it is found in cold winters, though rare (Vayreda y Vila, Portugal 1883), but in the marismas about the mouth of the Guadalquivir it breeds regularly Spain in small numbers (Saunders, 1871; Irby, 1875; A. Chapman and Buck, 1910).

Passing over to Africa it appears that the Ruddy Sheldrake is resident from Morocco to Tunis, in the mountainous districts. Rochebrune's (1883-85) statement that the species is resident on the Upper Senegal and Gambia has never been verified, and, like most of that writer's state- Northern ments, must be regarded with suspicion until proved. It is also reported as resident Africa from Morocco (Favier, fide Dresser, 1871-81; Lynes, Ibis, ser. 11, vol. 2, p. 300, 1920), Tangiers (Carstensen, 1852; Irby, 1875; Favier, fide Dresser, 1871-81), Algeria (Loche, 1867; Sclater and Salvin, 1859; Taczanowski, 1870; Buvry, 1857; Tristram, 1860) and Tunis (Talamon, 1904; Whitaker, 1905; Matschie, 1894). It seems that the birds are met with on the very edge of the Sahara, 
(Tristram, 1860) in elevated plains, and in the Atlas (Sclater and Salvin, 1859) as well as on the seacoast (Whitaker, 1905). Farther east the species occurs in Egypt, primarily in winter (Nicoll, 1919), though very likely it breeds in the Nile Delta and the Fayum as von Heuglin (1873) conjectured.

There is considerable question as to its breeding in Greece. Powys (1860) says it is rare in Corfu, but von der Muihle (1844) says it is seen late in the spring. According to Lindermayer

Greece (1860) it is to be found only in severe winters. At any rate it breeds in Macedonia Balkan (Krüper, 1862; Sladen, 1918) and in the eastern Balkans (Elwes and Buckley, 1870). States It is an especially common bird on the Lower Danube, below Nicopolis, and throughout the Dobrudja (Reiser, 1894; Petényi, 1884; Sintenis, 1877; von Almásy, 1898). Lintia (1909) reports it for Rumania and Radakoff (1879) says it is common in Bessarabia and the Pruth region. It no doubt breeds commonly on the Lower Dnieper and Don. Such is the testimony of Pallas (1831), von Nordmann (1840) and Möschler (1853). Radde (1854) says it is abundant on the Sea of Azov, and states that it is of common occurrence in the Crimea. Czernay (1852) has reported it for Charkow and Ekaterinoslaw. According to Valkh (1911) it breeds rarely in the eastern, but commonly in the southern parts of the latter government.

The species breeds also in Palestine (Tristram, 1884), in Cyprus (Lilford, 1889), in Asia Minor (Danford, 1878; Selous, Ibis, ser. 7, vol. 6, pp. 410, 419, 1900), in northern Mesopotamia (Neumann, 1915), at Babylon and Bagdad (Jones and Loftus, Journ. f. Ornith., vol. 63, p. 119, 1915), at Erzerum Asia (Radde, 1854; P. McGregor, 1917) and commonly in Armenia (Nesterov, 1911). In Minor the Caucasus it breeds regularly in suitable places (Seebohm, 1883), especially on the Kura River and Gotschai Lake (Radde, 1854). North of the Caspian it is evidently a very common breeding bird. Becker (1853) reports it so on the Volga up to Sarepta, while Sabanaëff (HarvieBrown, 1878), an authority, gives Samara as its northern limit in this region. At any rate it is abundant in Astracan (Cornelius, 1865; Seebohm, 1882) and likewise throughout the entire steppe region north of the Aral Sea (Suschkin, 1914; Nazarow, 1887). In Transcaspia, too, it has been repeatedly reported as breeding: on the Murghab and Teshen Rivers (Zarudny, 1889-90), at Merv (Radde and Walter, 1889) and on the southeastern Caspian (Zarudny, 1889-90). Molcanov (1912) took young birds at the mouth of the Amu Daria.

It breeds in suitable localities throughout the entire Persian region. According to Zarudny (1911) it is found there in the Atrek, north and south Chorassan, Parapamis, Seistan, Kuhistan-Kirman and Persia Zagross regions. It is also recorded for northwest Persia by Radde (1886) and Stanchinsky (1914); for the southwest, and for the south, by St. John (fide Dresser, 1871-81).

Zarudny (1911) says it breeds in the north but not in the south of Baluchistan. Baker (1908) states that it is found in Afghanistan in summer, and there can be no doubt as to the correctness of the statement.

In the western Himalayas, the North Iranian Chain, Kashmir, Pamir, Buchara, Kashgaria, and the Tyan-shan, it is exceptionally common, and is found breeding at heights varying from 10,000 to Western 18,000 feet. Loudon (1910) records it for Merv and Buchara, and Henderson and Himalayas Hume (1873), as well as Sharpe (1891) and Scully (1876), for Yarkand (16,000 feet). Sharpe (1889) gives it for Hari-Rud River, Afghanistan. Its abundance in Pamir and Turkestan is attested by Walton (1906), Severtzoff (1883), Alcock (1897), Lansdell (1885) and Schalow (1908). Koslow (1899) gives it for Kashgaria. In the Tyan-shan it is everywhere abundant (Smallbones, 1906; Schalow, 1908; Lönnberg, 1905; Koslow, 1899). But its breeding range extends even farther north, covering not only the great steppe region of central Asia, but also the Altai, Sajan, and other ranges Central eastward and north to far beyond Lake Baikal. Hesse (1913) reports it for Lake TelzAsia ker and the eastern Altai, while Finsch (1879) found it about Arkatberg, Chinchili, Saissan, Semipalatinsk and everywhere on the steppes; on the Ala-Kul, though not on the SaissanNor, nor in the southern Altai. It was found on the Marka-Kul and was common in the northern Altai to Siranowsk (Finsch, 1879). Suschkin (1913) states that it breeds about Minussinsk, in southern 


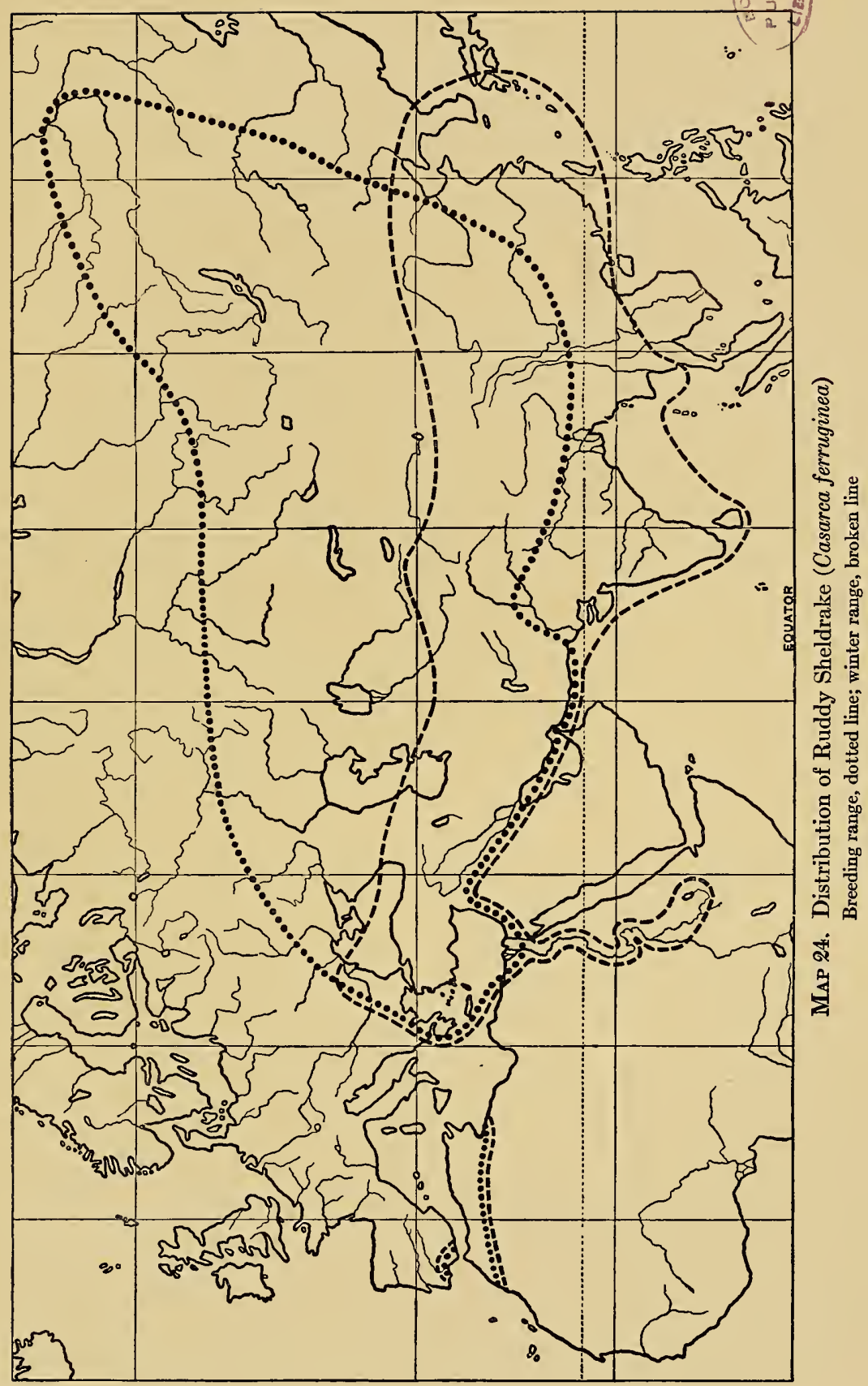



West Siberia, on the Saissan-Nor, etc., while Poliakov (1916) has recorded it for the basin of the Upper Irtysh.

Farther eastward it appears to breed throughout the mountains of the Baikal region. It was found about the southwest end of Lake Baikal (Radde, 1863) and not uncommonly in the southern Transbaikalia (Radde, 1863; Lönnberg (1909). Taczanowski (1874) states that it breeds in Lake Dauria, and the same is said for the source of the Amur (von Homeyer, 1870). Suschkin Baikal (1913) also records it for the Baikal region, while according to Maak (1859), it is com- Transmon on the Lena as far north as Olekminsk. Buturlin (1908) gives $58^{\circ}$ or $59^{\circ}$ north baikalia latitude as its limit on the Lena, but Maak (1859) found it even on the Wiljui near Wiljuisk, July 1. This, I believe, is its northernmost breeding record.

In the Chinese Empire the species occurs as a breeding bird in most areas. In Tibet it is exceedingly common and nests at very high altitudes, varying from 10,000 to 18,000 feet (Schalow, 1908). It has been repeatedly recorded for this region, having been found in northwestern Kashmir by Biddulph (1881), in Tibet by von Pelzeln (Journ. f. Ornith., vol. 16, p. 37, 1868),

Tibet Schalow (1908), Parrot (1909) (west), Landon (1905), Koslow (1899) (Lob-Nor region), Baker (1908) (Ladakh), Hume (1873) (high Himalayas), Walton (1906) (Tuna to Gyangtse), Desgodins (1873), Waddell (1906) (central), and Bonvalot (1892). Prjevalski (Deditius, 1886) found it in the country about $44^{\circ}$ north latitude and $92^{\circ}$ east longitude. It probably breeds throughout most of the western and northern sections of China proper, having been found in Kan-su (Prjevalski, 1878), at Tachienlu Lake, west China (E.H. Wilson, 1913), in the Shen-Kan region (Sowerby, 1912), at Chagan-Nor and in the Ordos (Berezowski and Bianchi, 1891), and at

China Peking (David and Oustalet, 1877), while in Mongolia it seems to be a very abundant breeding bird (Prjevalski, 1878; David and Oustalet, 1877). I find no record of its nesting in southern or southeastern China, but the species breeds in Manchuria (Kuroda, 1918). It appears that its breeding areas are only the colder mountain districts. There seems to be no foundation for the statements, variously made, that it nests in southern Japan. From all authorities it appears to be a very rare bird there, and even in winter it is only very occasionally met with about

Japan Nagasaki (Seebohm, 1890; Ogawa, 1908).

\section{Winter Area}

BEING essentially a resident bird the Ruddy Sheldrake winters in practically the same regions in which it breeds, though in Asia there seems to be considerable migration. As regards Europe we may say that it occurs in the marismas about the mouth of the Guadalquivir, though not in large numbers (Saunders, 1871; Irby, 1875; A. Chapman and Buck, 1910). Vayreda y Spain Vila (1883) states that it occurs even at Gerona in severe winters. Across the Straits at Tangier and Morocco (Favier, fide Dresser, 1871-81), in Algeria (Loche, 1867, etc.) and in Tunis (Talamon, 1904; Whitaker, 1905; Matschie, 1894) it is resident and found as far south as the Sahara Northern (Loche, 1867; Tristram, 1860). It winters in the Nile Delta (von Heuglin, 1873; Nicoll, Africa 1919) and at Lake Menzaleh, while it occurs much farther south in winter. Nicoll (1909) found it near the Pyramids and both Koenig (1911) and A. L. Butler (1905) say that it is common on the White Nile south of Khartum. Brehm and Vierthaler ( $f$ ide Dresser, 1871-81) report it for the Blue Nile, but Reichenow (1900) thinks its occurrence there as well as in Shoa must be regarded as questionable. I did not see it on the Blue Nile in the winter of 1912-13. Taken all in all its status in northeastern Africa is very vague. Its occurrence in Shoa has been determined by Salvadori (1888), who reported a flock seen there on November 14. Ogilvie-Grant (1900) also has recorded Shoa a specimen from southern Abyssinia. Reichenow (1900) states that it goes south as far as Aden, but I cannot say on what authority his statement is made. It seems likely that though uncommon along the middle Nile, Egypt and Nubia (Adams, 1864) a considerable number must Egypt winter in the high country of Abyssinia and Shoa.

Nubia 
In eastern Europe the species is found in winter in Greece (Krüper, 1862; von der Mühle, 1844; Greece

Balkan States Lindermayer, 1860), in Macedonia (Harrison, 1918), and apparently throughout the eastern Balkans. The authorities for this region are uniformly negligent in specifying the time of its occurrence in winter, all of them being more interested in describing its nesting there. But Elwes and Buckley (1870) report that it is common in the Dobrudja and Finsch (1859) says the same for Bulgaria. The same laxity in reporting applies to the investigators of the north shore of the Black Sea. Radde (1854), however, states that it is common in late summer on the Sea of Azov, and I think possibly it may winter along the entire coast. At any rate it is a common winter bird in Asia Minor, at Constantinople (Braun, 1908), at Smyrna (StrickAsia land, Proc. Zool. Soc. London, 1836, p. 102), on the west coast (Krüper, 1862; Reiser, Minor 1894), and in Lydia (Hamilton, fide Keller, 1913), and it is found in Cyprus (Bucknill, 1911) and in Palestine (Tristram, 1884) as well. Both Meinertzhagen (1914) and Stoneham (1919) found the species plentiful in Mesopotamia during the winter. It is resident in the Caucasus (Seebohm, 1883; Radde, 1884), but there is no evidence to show that it winters in the northern part, or along the Caspian north of the Caspian and Aral Seas. I question very much whether it would be found Region in Transcaspia north of the rivers (Teshen, Murghab, etc.), though it is resident in that section (Radde and Walter, 1889; Stolzmann, 1893). In Persia it is very common in the cold season, and its occurrence there is given by the authority, Zarudny (1911), for the south Caspian, Atrek, Parapamis, Seistan, Kuhistan-Kirman, Zagross, Mesopotamian and Persian Gulf littoral sections. Radde (1886) also reports it for the southwest Caspian and Araxes region, while Hohenacker (1837) found it at Lenkoran and Blanford (1876) about Shiraz Lake. Zarudny (1911) goes on to state that it winters in Baluchistan and along the littoral of the Arabian Sea. Scully (1887) and C. Swinhoe (1882) found it in Afghanistan and Yarkand, while Koslow (1899) is authority for its wintering in southern Kashgaria.

As far as I am able to determine, its winter range does not extend farther north than the Pamir region, and there the species must be rare in the cold weather. Still it winters in Kashmir and in India Tibet (Walton, 1906; Baker, 1908). Its great wintering area in this region is, however, the Indian Empire. Numerous writers testify to its abundance in suitable places throughout the peninsula. Hume and Marshall (1879) state that it is very common in Sind and the Punjab; Ball (1874) says the same for Bengal, though Scully (1879) observes that it is uncommon in Nepal. Baker (1908) states that it has been recorded from every district of the peninsula excepting Ceylon the waterless tracts. It is found even in Ceylon (Legge, 1880; Wait, 1917). Eastward from the Ganges its status is more doubtful. Baker (1908) found it rare in Cachar and not common in East Sylhet, though it was more abundant in South and West Sylhet, and he thinks Burma it is only a straggler to southern Burma. Yet E. W. Oates (1883) says it is abundant in Pegu, and both Blyth (1875) and Hopwood (1912) state that it is common in Arakan. Hume (1875) says it is plentiful in Upper Pegu, but though found between Thatone and Sittang and even on the Mergui Archipelago, it is very rare in Tenasserim (Hume and Davison, 1878). In the interior it seems to be more abundant, being fairly common in the South Shan States (Rippon, 1901) and very common in Burma at Bhamo (Baker, 1908; Blyth, 1875). It may possibly occur in Lower Siam (Robinson and Kloss, 1921).

In China it is apparently a winter bird everywhere south of the Hoang-Ho. Swinhoe (von Heuglin, China 1874a) says it is common in the interior, and in general it may be said that it is less abundant on the coasts. The species seems to be especially common in southwestern China, particularly in Yunnan, whence it has been recorded by H. R. Davies (1909), R. C. and Y. B. Andrews (1918), J. Anderson (1878) and by Menegaux and Didier (1913). I find further records for its occurrence at Amoy and Hongkong (R. Swinhoe, 1860, 1861), at Foochow (La Touche, 1892; R. Swinhoe, 1862), on Formosa (R. Swinhoe, 1863; Uchida, 1912), at Shanghai (Wade, 1895), at Kiauchow (Kleinschmidt, 1913) and in Shantung (R. Swinhoe, 1875; Blackwelder, 1907). It has also been 
recorded from the vicinity of Peking (David and Oustalet, 1877; Walton, 1903; R. Swinhoe, 1861). In the interior it has been found common on the Lower Yangtse (Styan, 1891; Seebohm, 1884) and in western China about Kiating (E. H. Wilson, 1913). In the north there are records for the Provinces of Shen-si (Sharpe, 1901) and Kan-su with the Ordos (Deditius, 1897). Prjevalski (1878) says a limited number winter on the Hoang-Ho. This seems to be its northernmost winter limit in this region.

The species is evidently common in cold weather in south Manchuria and Korea (Kuroda, 1918). Campbell (1892) found it about Seoul and Chemulpo. As I remarked above, the bird has been taken in Japan. Temminck and Schlegel (Fauna Japonica, Aves, p. 128, 1847-49) obtained specimens, presumably from about Nagasaki, and

Manchuria

Korea Japan Seebohm (1890) thinks it must be confined to that region although very rare there. Ogawa (1908), in his recent list of Japanese birds, gives it for Nagasaki without comment.

\section{Migration}

There is very little that needs to be said of the migration of this species. Favier (fide Dresser, 187181) tells us that a few of the Moroccan birds are migratory, but their journey is probably limited to passage across the Straits to Spain. In northwest Africa the birds appear to be resident. As I have pointed out there seems to be some movement up the Nile to Abyssinia in winter, though there are no data at hand. There must be considerable migration in western Siberia, however, where the birds leave the Kirgis steppes for Persia in the winter. We have a few dates concerning their movements in India and northward. According to Hume and Marshall (1879) and Baker (1908) the birds arrive in northern India in late September or early October. There the flocks break up and the separate couples very slowly work their way south, reaching the Central Provinces in late October or early November, and arriving in the Deccan in late November. In the spring they start from the Deccan by the end of February or early March, from the Central Provinces by the middle of March, and from northern India by April. Some few stay until later, however, and there are instances of a few in northern India even in late May. Prjevalski (1878) says that they arrive at Tsaidam as early as February 10, and in southeast Mongolia by early March. These are probably not Indian birds.

\section{GENERAL HABITS}

Haunts. Owing to its intelligence and adaptability, the Ruddy Sheldrake is able to exist in a great variety of climates and environments. It is essentially a fresh-water species, in this respect being the exact opposite of the Common Sheldrake. In its general habits it very closely approaches the Nile Goose; in fact the Nile Goose is one of the few birds with which it ever associates. In the regions about the Black Sea, which is its great center of abundance in Europe, it not only frequents the lagoons, but is often seen far inland on tributaries of the Danube. Here it is found grazing on young grass and corn near the water's edge and sometimes visiting inland pastures in the company of geese (Seebohm, 1885). In certain places they resort to the seacoast for protection, returning inland to feed (Radde, 1854). Speaking of the Caucasus, Radde (1884) says they go far inland to breed, flocking to the sea in August in great numbers. In the valleys of the Kura and Araxes they seem unconcerned as to the nature of their abode, frequenting artificial oases, deserted barren wildernesses and fertile meadows near streams; or again the hot regions of the lower Araxes. They do not care particularly for large bodies of fresh water, 
but like the vicinity of small streams where there are bare rocks or exposed sandbars (Finsch, 1879). Throughout central Asia the spring migration takes them from the lowlands to great altitudes, even to the snow-line, where they breed. Parrot (1909) says that in western Tibet they have been found nesting as high as 5700 meters. In the western end of its range the winter and summer areas are practically co-extensive, but farther east, in the Caucasus and in the ranges of central Asia there is a marked vertical migration, besides the north and south one. Their haunts in India are the clean sand-banks which break the broad beds of rivers into many channels. Soon after arriving in these winter quarters they separate into pairs, each of which keeps to its own section of the river front (Hume and Marshall, 1879). They prefer clean, clear waters devoid of vegetation, and with open banks. Small dirty ponds or weedy tanks are resorted to only in distress (Baker, 1908).

Wariness. The Ruddy Sheldrake is unquestionably one of the most intelligent of water-fowl, ranking in this respect, rather with the geese and swans than with the ducks. So well acquainted are they with man and his ways, that in many regions they will not take the trouble to rise until approached almost within range of a gun. Where persecuted, they resort to many devices to safeguard themselves. Scully (1876) speaks of their posting sentinels at some distance from the feeding flock, who sounded the approach of danger, first by a warning cry, and later by a loud scream. On the Sivash Sea, where great numbers assemble in autumn, three scouts were sent out at sunrise to reconnoiter the feeding grounds. These would return and bring back the flock (Radde, 1854). In India they are the bette noire of all sportsmen, who compare them in intelligence to the crow. It is, in fact, almost impossible to approach a flock of ducks when any Ruddy Sheldrakes are at hand. Such a situation is vividly described by Hume and Marshall (1879) in the following words: "You are working down on a lump of fowl-a few minutes more and you will be within range. Suddenly the loud call of the Brahminy sounds, and rising out of a hollow in the sand where they have been squatting, you see a pair waddling to the water's edge. Again and again the pair call and answer (side by side as they are one would think that save out of sheer spite they need not shout at each other thus), then, with a rapid chuckle off they go, their wings clattering as they rise, like a train on an iron culvert, and with them of course go all the fowl." Other ducks, he says, may shun the haunts of men, but these birds calculate the danger so closely that they seem oblivious of the presence of man and merely choose the places which suit their convenience, "thoroughly confident in their own ceaseless watchfulness." At a great fair on the banks of the Ganges Hume saw two pairs calmly standing on the shore near a place where 200,000 people were bathing, the roar of this multitude sounding a mile away, while scores of boats were plying back and forth ceaselessly. Hundreds of gaudy flags were fluttering from the gigantic bamboos planted on the water's 
edge - yet these old Brahminies dawdled about barely three hundred yards away, "as though these vagaries were no concern of theirs, and signified no more than a convocation of ants."

In regions where it is not persecuted this intelligent bird, so wary elsewhere, becomes surprisingly tame. In southern Tibet, where it is held sacred to Buddha, and called the Duck of Lama, it is remarkably tame (Landon, 1905), "indeed almost ludicrously so" (Walton, 1906), merely waddling away a few yards, and showing itself very reluctant to take flight until shot at. On the coast of Shantung they were noted as being wild, while in the interior, where they were probably seldom molested, they were so tame that they followed the farmer as he plowed the fields (Blackwelder, 1907). According to David and Oustalet (1877), in Mongolia, where they are also held in religious reverence, they will not even budge at the approach of a man.

In Yunnan, where they were seen feeding in the opium fields, they were so tame that writers have even suggested that they were stupefied by eating the poppy (H. R. Davies, 1909), but this explanation is inadequate for the simple reason that opium has no effect upon birds, judging from experiments which I have made myself.

Daily Movements. Every one who has kept these birds must have noted their activity at night, if their continual calls may be any indication. Whether they are really more nocturnal than other geese or ducks it is hard to say. In the Crimea they were found in August and September flying to the millet-fields in the interior to feed until about eight o'clock in the morning, and then returning to the coast to rest. At two o'clock in the afternoon they returned to the fields, where they stayed till sundown, returning again to the sea and making a great racket during the twilight hours (Radde, 1854). Their wakefulness at night is indicated by the fact that in the Dobrudja they are kept by the natives in place of watch-dogs, because like the Tree Ducks, they call at the approach of any intruder.

Gart. The Ruddy Sheldrake walks as well as do the true geese, and is slow and deliberate in its movements, carrying itself more erect than the true ducks. Its general appearance, too, is much more dignified, but in a case of necessity it can show remarkable speed. Demidorff (von Nordmann, 1840), who saw them in south Russia, says that when wounded they run so quickly one can hardly catch them.

Swimmrng AND Drving. This is essentially a grazing species, spending comparatively little time on the water. The swimming position is gooselike, with the stern high and the breast deeply submerged. When feeding it dips, but it does not dive unless wounded. Hume and Marshall (1879) say that the birds can turn under water with great ease, but are unable to stay under a long time. On the White Nile 
Abel Chapman (1921) often noticed them squatting flat on the russet-colored sand, and when in this position they were very hard to see because the brilliant speculum and white wing-patches were quite covered by the body feathers.

Perching. There are very few notes about its perching habits, but it must of necessity perch during the breeding season, for the nest is often on almost inaccessible cliffs, banks or trees. In Asia Minor they were observed perching on the ruined walls among which the nests were located (Selous, Ibis, ser. 7, vol. 6, p. 410, 1900). In captivity free-winged specimens like to perch on roofs of buildings, and even on the narrow T-irons on the wiring of enclosures (Heinroth, 1911).

Fuight. Heinroth (1911) says that when about to fly they hold their heads high and wag them to and fro quickly, uttering their call-notes. When in flight the wingbeats are slow and gooselike, but this appearance is deceptive, for in reality Sheldrakes travel very fast, and are often missed by sportsmen (Hume and Marshall, 1879). The Casarcas are able, when on the wing, to drop or dive like a bird of prey, a habit which may enable them to escape large, rapacious birds. This proclivity was noted by Heinroth (1911), who says he never saw Peregrines attack them, though they did annoy Gray Geese. These Sheldrakes are strikingly handsome in flight, the slow wing-beats showing off the white wing-patches against the cinnamon body to the greatest advantage. Before alighting they usually circle about for a time, gliding and scaling, and indulging in very graceful movements (A. E. Brehm, 1879).

So far as is known, individual pairs remain together throughout the year and the large flocks which assemble for migration are composed exclusively of paired birds. After the breeding season they are quite gregarious, but in the winter quarters the pairs again become isolated (Seebohm, 1885; Hume and Marshall, 1879). Flocks consisting of over one hundred have been described by Prjevalski (1878), and Radde (1854) saw aggregations of thousands in south Russia in late summer. Flocks of thousands are to be found in India too, just before the spring migration (Jerdon, 1864).

Association with other Species. Ruddy Sheldrakes are very independent in their habits, and as a rule their presence among other water-fowl is accidental. In Africa, however, they do appear in company with Egyptian Geese, to which species, of course, they are quite closely related (A. L. Butler, 1905; Koenig, 1911; A. Chapman, 1921; etc.). It has been suggested that the similarity of the white wingpatch in both species may in part explain this association (Heinroth, 1911), but their very similar habits may just as easily account for it. In India they have been seen with flocks of Comb Ducks (Ball, Stray Feathers, vol. 2, p. 437, 1874). During the breeding season their practice of resorting to rocks brings them in contact with 
kites, vultures and ravens, but this too is explained rather by similarity of habits, and ability to protect themselves, than by any predilection for other species.

VoIce. The notes of these birds are loud, incessantly uttered, and, while easily imitated, are exceedingly difficult to suggest in writing. The trachea of the male has a very small bony-walled bulb, about the size of a pea (Finn, 1900). In general the note of both sexes has been described by such a variety of syllables, that it seems almost useless to repeat them all. The note is bisyllabic, and sounds to me like a crow's, but more nasal, - in other words a harsh nasal kaa-a. Pallas described its voice when on the wing as being like a clarionet, and at other times, especially in captivity, like that of a peacock, while other writers have symbolized it by the syllables a-oung or ung. Almost all observers have failed to distinguish the notes of the two sexes, but A. E. Brehm (1879) noticed that the male's notes are pitched higher than those of the female, while Heinroth (1911) has given a full account of the differences. According to him the notes of the male are based on the sound $O$, while those of the female are based on the sound $A$. The male's most characteristic note is a drawn-out, howling, rolling chorr, the warning note being a drawn-out ho while ho-ho expresses anger. The alarm note of the female is $h a$, while anger is expressed by a sound resembling rärr, short and oft-repeated. The call-note of this sex is $h a-a$, very nasal and loud, and varying greatly. He adds that the male does not attain the characteristic chorr note until at least two years of age.

FooD. This species is omnivorous, and is not dependent on any particular class of food. It grazes where young grass is available and where crops are accessible, but it is able to subsist on animal diet of a varied kind. In India it has been found gleaning fallen rice in the settlements at night (Ball, Stray Feathers, vol. 2, p. 437, 1874), and in general feeds on young grass and corn, various kinds of water-weeds and seeds, but predominantly on tiny fish-fry, shrimps, and all kinds of small landand water-shells (Hume and Marshall, 1879). In northeast Africa it feeds on grasssprouts and water-plants, fishes, frogs, worms and snails (von Heuglin, 1873). The diet in Tunis and in southeastern Europe does not seem to be essentially different, judging from the information available from Whitaker (1905) and Seebohm (1885). Specimens shot in the Crimea as they were returning inland from the sea had empty crops, indicating that the birds do not obtain nourishment on the coasts. Its habit of feeding in the opium fields in Yunnan has already been mentioned (H. R. Davies, 1909). In Shensi it was also found frequenting the opium fields (Sharpe, Compt.

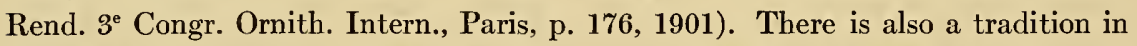
India that it occasionally takes offal, or may even feed on corpses, which, though perhaps only rarely true, has left an impression on European minds which is not easily overcome. My friend Captain E. H. Penticost, who was many years ago in 
the Irrawaddy flotilla, once saw four of these birds feeding on, or at least close to, a corpse at a place called Thayetmyo on the Irrawaddy River, Burma, some two bundred miles above its mouth. He has actually seen them feeding on the intestines of a putrid buffalo in that country.

Courtship AND Nesting. The Ruddy Sheldrake may be classed as a distinctly early breeder. In the regions about the mouth of the Danube young birds were seen on May 30 (Seebohm, 1885), while in Asia Minor, near Smyrna, all clutches were hatched and the young birds taken to the salt lakes by early May (Danford, 1878; Selous, Ibis, ser. 7, vol. 6, p. 410, 1900). Young have been found as early as the second half of March in the warm desert regions about Merv, in Transcaspia (Loudon, 1910), while on the Marka Kul, in Russian Turkestan, young in down were taken on June 7 (Finsch, 1879). Perhaps the greatest breeding area is in the highlands of Tibet. They hatch there by the end of May (Walton, 1906), but in the higher altitudes the season may be delayed till much later, at least till the end of June (Hume and Marshall, 1879). In Transbaikalia they breed in the middle of May (Taczanowski, 1873), but in Mongolia the first young were seen on June 16 (Prjevalski, 1878).

The sexes remain together exactly in the manner of geese, and exhibit the utmost attachment for each other. That they pair for life seems highly probable, considering the fact that they remain in pairs during the winter, and that even the migrating flocks are composed of paired birds. Many stories of their devotion to each other fill the volumes of ornithological literature, and need not be repeated in detail here. Radde (1884) says that if one of a pair is shot in the breeding season the other will follow the hunter for hours, trumpeting and flying at him incessantly. The classical example, however, is to be found in the Indian legend that in a pair of these birds were embodied the "souls of erring lovers, who have loved not wisely but too well," and were condemned "thenceforth to pass the night, the season of their transgressions, apart, on opposite banks of some stream, each ever praying the other for permission to cross, and each compelled sternly to refuse." The lovers' appeal to each other- "Ahna sukta, Chackwa" (May I come, Chackwa) and "Nai, Chackwi" (No, Chackwi), - is said to resemble closely the call-notes of the mates. Hume and Marshall (1879) cynically remark, that in these degenerate days, either the world is more virtuous, or celestial vigilance less keen, for it is certain that except in the case of very narrow rivers, alike by day and night, Chackwa and Chackwi are to be found on the same side of the water. He denies having ever heard the legend except through Europeans, but Baker (1908) insists that he has heard it repeatedly from natives.

During the mating period the male is particularly chivalric and pugnacious, so that in confinement he becomes a menace to other animals and even to small children. 
The display is gooselike, consisting of the dipping of the head, as seen in true geese and swans. The mating act takes place on land, or at times perhaps in shallow water, and is followed by a postlude, also strictly anserine, the male standing beside his mate with high-lifted wings, while the female swims about in a low crouching position (Heinroth). Aviculturalists find that they do not breed the first year.

The nest itself is always covered, like that of the Common Sheldrake, being usually placed in crevices or holes in rocks, or steep cliffs, more rarely in burrows, or among rocks on the ground, and even in holes in trees. A few of the more unusual nesting sites are worthy of special mention. Holes among the ruins of the old city of Merv are mentioned by Radde and Walter (1889), while Prjevalski (1878) speaks of nests found in the fireplaces of deserted Mongol villages. In eastern Siberia they are said to make use ordinarily of the abandoned nests of birds of prey on a tree, or the hollow of a tree (Taczanowski, 1873). Walton (1906) says that in southern Tibet, where they are so tame, they nest even in the ditches between fields. The nest may in certain cases be a long distance from the water, and even on high sandy clay-hills in the deserts, as in Transcaspia (Radde and Walter, 1889). In Chinese Turkestan a nest was found eight miles from the water (Betham, Journ. Bombay Nat. Hist. Soc. vol. 19, p. 751, 1909).

Their cliff-nesting habits bring them into contact with Griffon Vultures, Egyptian Vultures, Ravens and Black Kites (Tristram, 1884). Though usually nesting in high places, they may imitate their relatives, the Common Sheldrakes, in choosing burrows of various mammals, such as foxes, marmots, and badgers (Taczanowski, 1873). Radde (1884) says that they like fox-holes, but will frequently make their own burrows, probably enlarging these from the holes of small birds or rodents.

The nest is nothing but a mass of down and feathers, sometimes with a few twigs. Hume and Marshall (1879) were told by natives that the feathers of the Bar-headed Goose were sometimes utilized. The normal clutch probably numbers eight eggs, sometimes perhaps as many as twelve, but everything beyond this number is, no doubt, the work of two birds. The eggs themselves are not to be distinguished from those of the Common Sheldrake, being a creamy, or ivory white, and very smooth. They measure from 62 to 70.2 by 46 to $50 \mathrm{~mm}$. The incubation period is twentynine days (Heinroth, 1908), during which time the male stays closely by the nest, warning the female of the approach of danger and actually protecting the nest by attacking or distracting predatory animals and birds (A. E. Brehm, 1879; Heinroth, 1911). The young leave the elevated nesting-sites by jumping out, as do other water-fowl, and both parents take part in bringing up the offspring. The young develop very quickly, full plumage being attained by the end of the second month (Rogeron, 1903). It is not known how long the young stay with the old pair.

Food VALUE. The flesh is universally regarded as worthless, although some 
natives in India are said to eat it (Jesse, 1903). The Tartars of Russia even considered it as dangerous food (Latham, 1785). According to Hume and Marshall (1879) these ducks are edible only when skinned, which renders them less fishy, though even then they are dry or tasteless. Their occasional practice of feeding on carrion has already been referred to.

Status. There is no indication of any general decrease in the numbers of this species, though in the European regions it may very well be diminishing. Its intelligence, however, removes it from all immediate danger of extermination.

Enemies. So far as is known, man is its only serious enemy, since it is apparently well able to protect itself against birds of prey, and probably also against foxes and other vermin.

Damage. In the Crimea these birds were once reported as doing incredible damage to the millet-fields. Five thousand birds were feeding in one district twice a day, and the crop of one specimen, killed after feeding, was found to contain from one and a half to two and a half ounces of this grain (Radde, 1854).

Hunt. In few parts of its range is the Ruddy Sheldrake hunted as an object of food, while in Tibet, Mongolia, and perhaps in Burma it receives protection on account of its religious significance. In other places stories of its eating carrion have made it an object of suspicion. Nevertheless it is seen in the markets of India (Hume and Marshall, 1879) and in the poultry-shops of Smyrna (Yarrell, 1856). In Bulgaria the adult birds are caught in nets, or the young captured, to be raised for the purpose mentioned under the paragraph on Daily Movements. Hume and Marshall (1879) and Baker (1908) have much to say of the difficulty of shooting them in India, and the former recommend a small-bore rifle, as about the only method of bringing them to bag.

Behavior in Captivity. The Ruddy Sheldrake has probably always been kept in zoölogical collections. Indeed, the Chenalopex or Fox-goose of the ancient Greeks may well have been this species, and not the Nile Goose. In modern times it was kept by Catherine the Great of Russia in her gardens at Tsarkoë Selo, but since the "divine Catherine" would not permit the wings of her exotic birds to be mutilated, they would ordinarily disappear at the approach of cold weather (Pallas, 1831). In the Balkans, in Turkey, and among the Bedouins, they are kept in confinement for ornament, and because of their vigilance (Reiser, 1894; Petényi, Zeitschr. f. Ornith., vol 1, p. 33, 1884; von Heuglin, 1873). The London Gardens, however, do not seem to have had specimens before 1850 (Sclater, 1880). 
When confined they are hardy birds, and very easy to keep, though they are quarrelsome, which necessitates the separation of the males in the breeding season. A pair which I kept for five or six years, and which I finally disposed of in as good a condition as when I received them, used to inhabit a pasture where many species of the larger cranes and geese were confined, but they never came to any harm. In the Berlin Gardens they have frequently bred, and free-flying specimens are successfully kept. They have also bred repeatedly in the London Gardens, and may be classed as one of the more ready breeders in captivity, perhaps ranking close to the Egyptian Goose in this respect.

During the mating period the most noteworthy characteristic of the bird's psychology is seen in the female urging the male to pick fights with other males, and even with strange species, while she selects her own mate. What she really does is to hound on and worry the male by rushing at strangers and pretending to attack them. The stranger runs away if he is weaker, but if he is stronger he stands his ground and the female returns to her prospective mate. The male still stands with head high, but the female goads him on until at last he is induced to fight. If he shows no inclination to fight she will even pluck at his breast. She seems to show a real preference for the most pugnacious males, and therefore is partial to the males of the Black Sheldrake (Casarca variegata). The males seem to have nothing to do with the choice of mates, and are quiet and peaceful, so that if the females are removed they make no effort to fight. Once paired, the females cannot bear the sight of any other swimming bird, and in captivity they will attack all other ducks, geese, swans, dogs, and even children (Heinroth, 1911; Floericke, 1898). Heinroth (1911) tells a very amusing story of a full-winged female who conceived such a dislike for him that she would fly at him, screaming and almost brushing his face as she circled around him.

In the Paris Gardens this Sheldrake bred regularly. A wooden box was placed on the bank of a stream, and about the beginning of April a little pile of reeds or hay was placed inside. During the latter part of April the female laid her clutch and pulled the down from her breast. When she began to sit, the male, who up to that time had not paid much attention to her, began to keep a strict guard, and drove away all intruders. The hatching took place in thirty-two to thirty-four days, according to the temperature (Huet, Le Naturaliste, vol. 12, p. 107, 1890).

In confinement the Ruddy Sheldrake crosses readily with other species. Leverkuihn (1890) enumerates the following hybrids, with the proper authorities:

$$
\begin{aligned}
& \text { o Tadorna tadorna } \times \text { o Casarca ferruginea } \\
& \text { o Casarca ferruginea } \times \text { o Alopochen ægyptiacus } \\
& \text { o Casarca ferruginea } \times \text { o Anas boschas. }
\end{aligned}
$$

In the British Museum there is a hybrid between Casarca ferruginea and Casarca cana, raised in the London Gardens. Heinroth (1911) thinks that hybrids of Casarca ferruginea and Casarca variegata, which were raised at Berlin, are fertile. 
The species, if well cared for, will live for many years. In 1883 the London Gardens possessed a pair which had been bred there twenty-four years before, in 1859 (Sclater, 1883). Radde $(1854,1884)$, who kept many for at least twelve years, says that they gradually became more brown-black, some having pale black backs, and others a wide black belt on the upper breast. The heads of both sexes became lighter, and in old age were nearly white. White feathers also appeared on the wings.

In both Europe and America these birds were easily obtained, the price being about $\$ 25.00$ the pair in the United States and, according to Hubbard (1907), at 40 shillings to $£ 4$ in England. They are of course more expensive and more difficult to obtain since the War, which is the case with nearly all desirable species.

Historical Note. As has been noted above, this species is held sacred by the Mongols and Kalmucks, possibly on account of its clarionet-like whistle, and priestlike plumage. Keller (1913) thinks it may be identified with the Duck of Pontus of the ancients, which was said to be poisonous, and to have medicinal value. In Tibet it is called the Duck of Lama (Lama Shubu) and is held to be sacred by the followers of the Lamaistic religion. It is not held sacred in India, but it is the national bird of the Burmese, and is considered deserving of especial honor. 


\title{
SOUTH AFRICAN SHELDRAKE
}

\author{
CASARCA CANA (GMELIN)
}

(Plate 17)

SYNONYMY

Anas cana Gmelin, Linné's Systema Naturæ, ed. 13, vol. 1, pt. 2, p. 510, 1788.

Casarca cana Blyth, Journ. Asiatic Soc. Bengal, vol. 17, p. 254, 1848.

Tadorna cana Sclater, Proc. Zool. Soc. London, 1864, p. 190.

\section{English: \\ South African Shelduck or Sheldrake \\ Gray-headed Duck \\ White-fronted Sheldrake
Oie sauvage à tête grise
Casarka du Cap de Bonne
Espérance \\ French:}

Vernacular Names

\section{German:}

Grauköpfige Fuchsgans

Boers:

Berg-eend

\section{DESCRIPTION}

AddLt MaLE: Head and neck ash-colored; a dark rufous collar around neck; lower part of the neck and breast fulvous, changing into cinnamon-color on the upper back, scapulars, and underparts; the lower abdomen almost chestnut; under tail-coverts bright fulvous; back and scapulars vermiculated with black; lower back blackish, with pale vermiculations; upper tail-coverts and tail, black; lower flanks blackish, with fulvous vermiculations; upper and under wing-coverts white; primaries, bastard wing, and primary coverts, black; secondaries glossy green on the outer web, forming a speculum; inner secondaries cinnamon on the outer web, dark gray on the inner; greater under wing-coverts blackish.

Iris pale yellow (Stark and Sclater, 1906); beak and feet black (Salvadori, 1895).

Wing $381 \mathrm{~mm}$.; bill 51; tarsus 61 .

Note: The adult male closely resembles the male of Casarca ferruginea except for the light ashyblue color of the head.

Adult Female: Similar to the male, from which, however, it differs in having the anterior part of the head, sides of the head above the ear-coverts, and the throat white. Size somewhat smaller (Salvadori). A specimen in the New York Zoölogical Park has the iris black, culmen blue-black, the legs and feet dirty gray.

Wing $330 \mathrm{~mm}$; bill 44; tarsus 47 .

Young MALE: Paler and duller than the adult bird; the head and upper part of the neck dull grayish brown. 
Young IN Down: Figured by Horsbrugh (1912); apparently very much like the young of the Ruddy Sheldrake.

REMarks: Holub and von Pelzeln (1882) say that some females lack totally the white on the head and neck, while others have it only on cheeks or head. In general this color is to be found in all shades from yellowish white, or brownish white to a snow-white.

\section{DISTRIBUTION}

VERY little is known of this species of Sheldrake, which has a restricted range in South Africa and appears to be common in only a few localities. In Cape Colony it seems to be most common on the Cape high plateau, and about the Orange River (Stark and Sclater, 1906). For this region it Colony has been reported as very common throughout the year at Deelfontein (Sharpe, 1904), and as a breeder at Carnarvon (Littledale, Journ. South African Ornith. Union, vol. 4, p. 44, 1908). Holub and von Pelzeln (1882) found it common in the Eastern Province, and the South African Pondoland Museum has specimens from Beaufort West, the Berg River and the Cape Flats. On Griqualand the east coast it is said to occur, but not commonly, in Pondoland (Shortridge, 1904), while at Matatiele, East Griqualand, it is scarce (C. G. Davies, 1908).

As yet the species has not been seen in Natal, but there are various records for the Orange River Colony. Holub and von Pelzeln (1882) speak of it as common in the Colony as a whole, and C. H. T. Orange Whitehead (1903) states that it is common in autumn on the Orange River near River Aliwal North. According to Horsbrugh (1912) it may be seen not uncommonly throughout the year in the vicinity of Bloemfontein. In Basutoland, also, it is a fairly common bird (Murray, fide Stark and Sclater, 1906). But farther north, at Kroonstad, it is not a plentiful species (Symonds, Ibis, ser. 5, vol. 5, p. 335, 1887), while for the Transvaal there appears to be only one record - that for Potchefstroom (T. Ayres, 1871).

\section{GENERAL HABITS}

This rare duck is an inland species, and exceedingly little is known of its life history. Its chief habitat seems to be the high plateau of Cape Colony and the region about the Orange River (Stark and Sclater, 1906). It is a very local species, and is rare both in zoölogical gardens and in museums. The most recently taken museum specimen which I have seen came from Nabies, Bushmanland, Cape Colony, in 1911.

Horsbrugh (1912) invariably found them wild and suspicious, and the first to leave when the shooting began; but earlier writers (Holub and von Pelzeln, 1882) describe them as not shy, though cautious, this referring, however, chiefly to the birds seen in the vicinity of Boer farms, where they were well treated and protected.

The birds usually are to be found in pairs, but occasionally companies of five or six are seen, presumably one family (Sharpe, 1904).

The voice of this species is very much like that of the Ruddy Sheldrake, being a loud nasal how, in addition to the usual variety of specialized notes (Horsbrugh, 1912). A female which I watched in the New York Gardens gave a regular Sheldrake call like caak-caak rather nasal in quality and uttered slowly.

Nothing appears to be known of the diet.

We know almost nothing of the breeding habits of the South African Sheldrake 


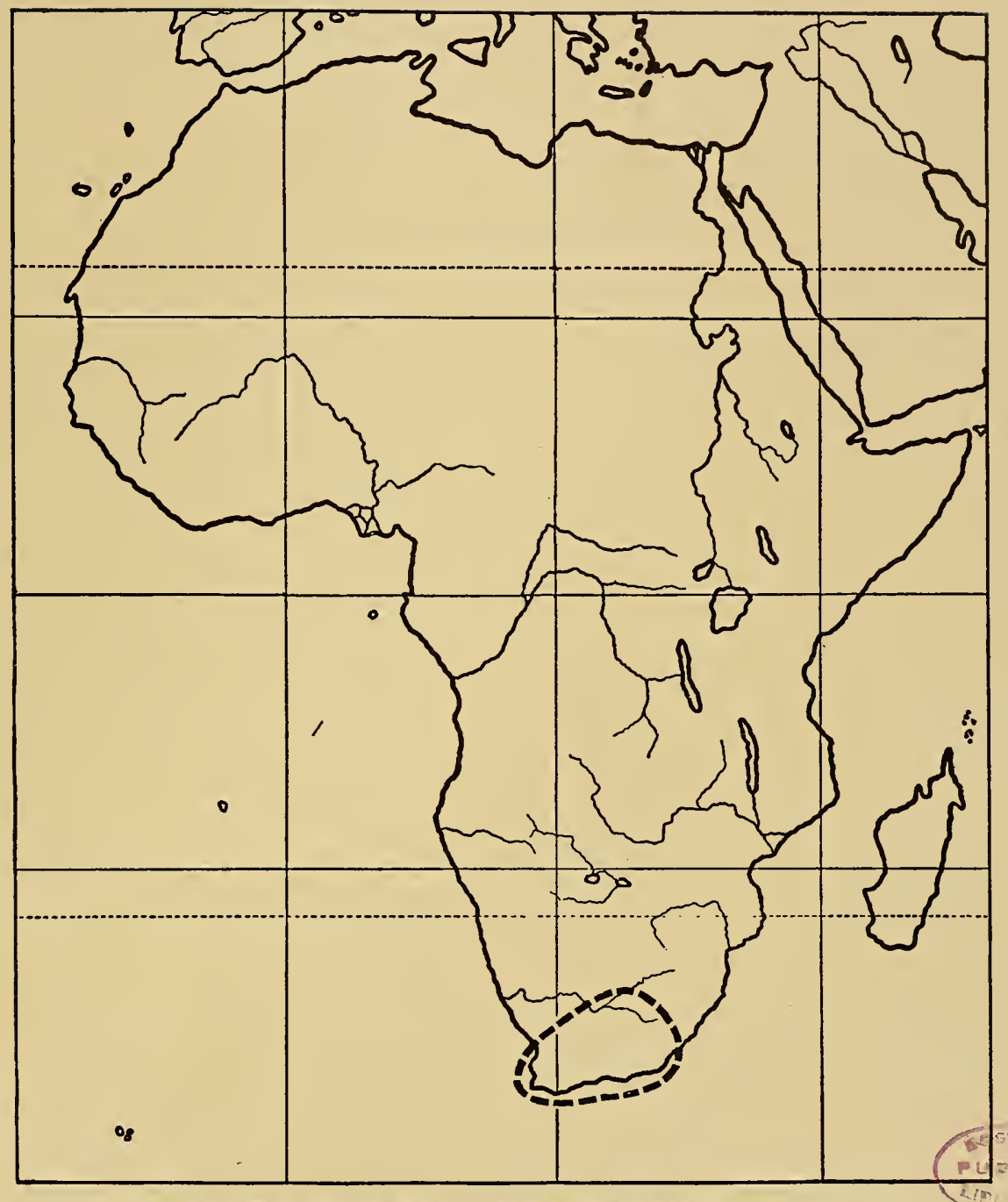

MAP 25. Distribution of South African Sheldrake (Casarca cana) 

excepting what is contained in a few isolated notes. Grant and Seimund found them nesting in the hole of an ant-bear or porcupine, and it took them from five to six hours to dig one out. The clutch numbers eight to ten eggs of a creamy-white color, measuring 65 to $71 \mathrm{~mm}$. by 46 to $59 \mathrm{~mm}$. (Sharpe, 1904). Other nests have been found among rocks above the Orange River (C. H. T. Whitehead, 1903).

In September, broods three and four weeks old were seen (Holub and von Pelzeln, 1882), so that it is probably an early-spring breeder, like the Ruddy Sheldrake.

It is said that these birds are most indifferent eating, being both rank and tough (Horsbrugh, 1912), but the Boer farmers, who are not hypercritical in their tastes, consider them a delicacy (Sharpe, 1904).

Thomas Eyton (1838) mentions the introduction of this Sheldrake into England in a live state by Lord Derby. I find reference to another specimen imported into Europe in 1849. This bird was also owned by Lord Derby, and, when Knowsley was sold in 1851, it was purchased by the London Zoological Society. It died in 1862. In 1855 and 1856 this bird, which was a female, mated with a Ruddy Sheldrake, and in the two following years with one of her own offspring of this cross. Finally, in 1859, she mated with a Common Sheldrake (Sclater, Proc. Zool. Soc. London, 1864, p. 190).

In South Africa these birds were kept half-tamed in the farmyards of the Boer settlers. Holub and von Pelzeln (1882) describe them as feeding partly in swamps, and partly on bits of corn or vegetable matter thrown to the barnyard poultry. Such a handsome bird was a great ornament to these lonely farms. In more recent times it is evidently less commonly kept, for Horsbrugh (1912) states that most of his journeys to see the specimens reported to him, ended in disappointment at the sight of Egyptian Geese. Only once did he find a pair which a Boer had caught while still young, as the mother was leading them over the veldt.

A pair was received by the New York Zoölogical Society in 1920 but the male was in poor condition and soon died. The female, a fine bird, is still alive and was studied by Mr. Fuertes in making his plate. I saw a single live specimen at Woburn Park, England, in 1922, and Mr. F. E. Blaauw writes me that they have been kept there before.

Mr. A. K. Haagner, Director of the National Zoological Gardens at Pretoria, writes me that this fine bird is not in any immediate danger of becoming extinct, and is still rather common near Richmond in the Cape Province. He adds that the species has never been bred in confinement there. 


\title{
NEW ZEALAND or PARADISE SHELDRAKE
}

\author{
CASARCA VARIEGATA (GMELIN)
}

(Plate 18)

SYNONYMY

Anas variegata Gmelin, Linné's Systema Naturæ, ed. 13, vol. 1, pt. 2, p. 505, 1788.

Casarca variegata G. R. Gray in Dieffenbach's Travels in New Zealand, vol. 2, app., p. 198, 1843.

Tadorna variegata Sclater, Proc. Zool. Soc. London, 1864, p. 191, pl. 19.

English:

Variegated Sheldrake

Paradise Duck

New Zealand Sheldrake

Black Sheldrake

French:

Casarka de Paradis

\section{Vernacular Names}

German:

Schwarze Kasarka

Schwarze Fuchsgans

Maoris:

Putangitangi

- Putakitaki

Putangi (wail of death)

\section{DESCRIPTION}

AdULT MALE: Head and neck black with a metallic gloss, mantle and breast dark brown, very finely vermiculated with buff. Back, scapulars, and flanks black, with fine, wavy irregular lines and points of a light gray. Upper tail-coverts and tail black, middle of abdomen chestnut brown, under tailcoverts chestnut. Wing-coverts white, secondaries metallic green on outer web, primaries black. Tertials chestnut on outer web, gray on inner web.

Bill lead black; legs grayish black; iris black (Buller).

Wing 365-370 mm.; bill 42-45; tarsus 65-70

Adult Female: Head and upper neck pure white; lower neck, mantle, scapulars, back, breast and under parts chestnut, freckled and barred with black and gray lines. Wing and tail as in male. Wing 325-330 mm.; bill 40; tarsus 58-62.

ImMATurE: As Sclater noted in 1866 both sexes pass through a plumage more nearly resembling the male's than the female's, a fact of great interest and rarity in the bird world. The head and upper portion of the neck are sooty black, varied with light brown; lower portion of neck dark brown, with narrow transverse lines of rufous; the whole of the under surface blackish brown, mottled and barred with rufous, each feather narrowly margined with white; shoulders, back and lower parts of the body black, with white freckles and vermiculations; wings as in the adult; rump and tail black; under tailcoverts pale ferruginous (Buller).

Young males have a tinge of brown about the head and the shoulders more or less margined with dull fulvous brown, presenting on the surface, wavy lines (Buller). Young females show irregular white feathers on the head and neck, which rapidly increase in number, till the plumage of these parts becomes entirely white (Buller). 



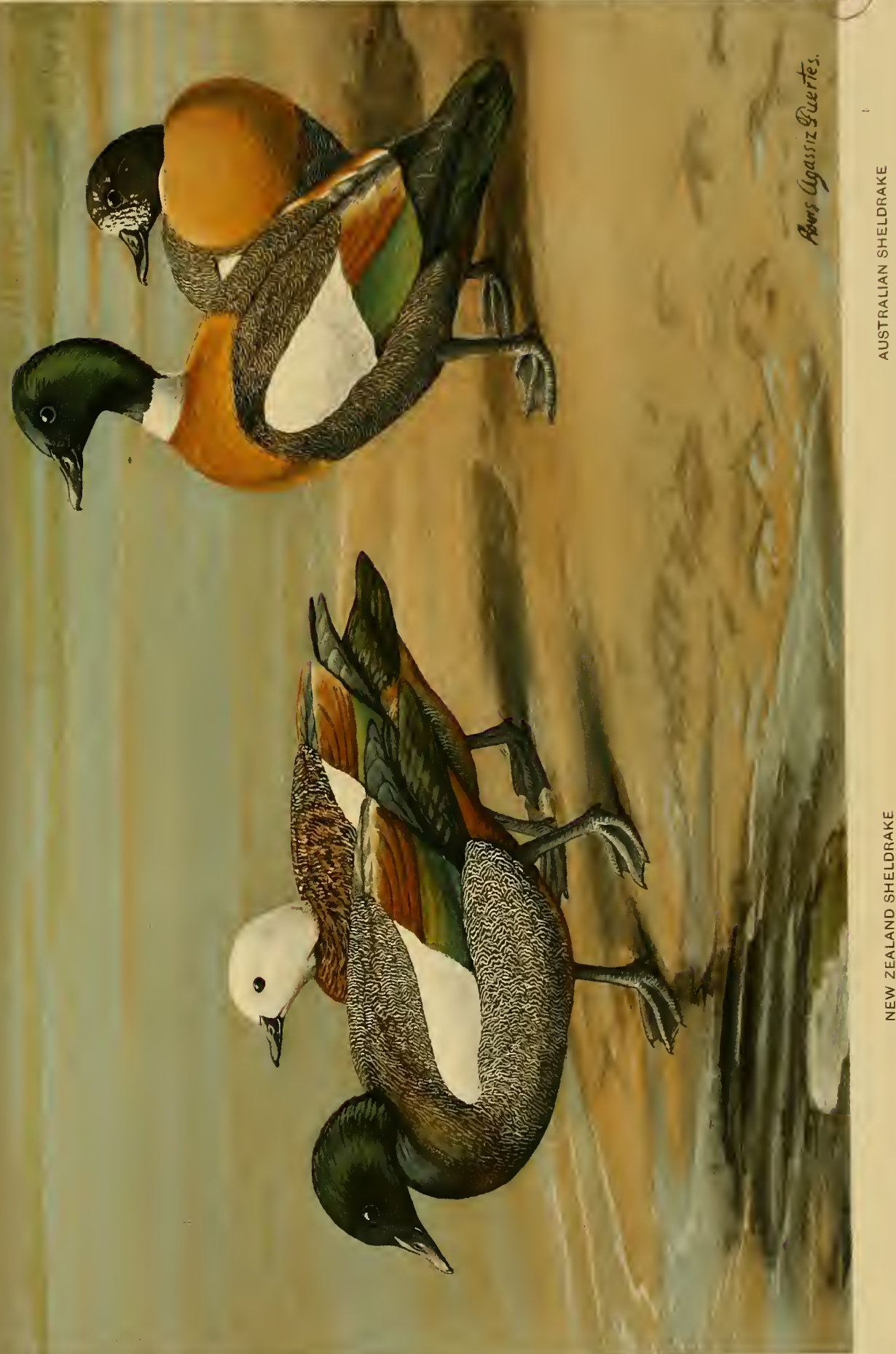

Young IN Down: Specimens which I saw in the Leyden Museum seemed to me indistinguishable from young of the Common Sheldrake. Buller's description follows: "Covered with soft down, for the most part pure white, but largely varied on the upper surface with brown; the cheeks, throat, fore neck, and all the under surface entirely white; the top and upper sides of the head, in a line with the eyes, the hind neck and shoulders, a broad mark down the back spreading on the tail, the anterior portion and tips of wings, and a broad patch on each flank, continued in a line over the thighs, dull umber-brown; bill and feet pale brown."

Remarks: It is probable that all the Sheldrakes have at least a partial double moult. This has been referred to in connection with the Common Sheldrake. In the present species the female has been noticed to assume colors somewhat like those of the male, on the mantle, flanks, scapulars and belly, after the breeding season (Jones, Avicult. Mag., ser. 3, vol. 1, p. 61, 1910). This is interesting in connection with the presence of a more highly specialized plumage in the female sex.

\section{DISTRIBUTION}

The Paradise Duck is a localized species, being confined to New Zealand. A specimen in the British Museum, reputed to have been taken near Brisbane, Australia, could at best have been but a straggler. In New Zealand the species is far more common in the South than in the North Island, Australia being generally distributed in the former, but apparently more common in the lower South country of the eastern than in the mountainous regions of the western part. Though Island not yet recorded from Stewart Island, it has been found on Resolution Island (Henry, Emu, vol. 6 , p. 171, 1907), and in the same vicinity at Dusky Bay (Gray, 1862). It has been Resolution found in Milford Sound (Buller, 1905), and Green (High Alps of New Zealand, Island p. 157, 1883) met with it fairly commonly on the Hooke River; and it is evidently a rather plentiful bird in the Canterbury District, where it has been found on the Upper Waiko (Harvie-Brown, Ibis, ser. 3, vol. 4, p. 96, 1874), on the Canterbury Plains (Finsch, 1870a), on the Rakaia River, Malvern Hills, Potts River, Rangitata River (Potts, 1870), Waimakariri River (Buller, 1888) and in the valley of the Tasman (Finsch, Ibis, ser. 4, vol. 6, p. 401, 1882). In the Marlboro District it was formerly plentiful, though it is now becoming rare (Buller, 1905), and in earlier times it was abundant in the Nelson District also (Haast, Tbis, ser. 1, vol. 4, p. 101, 1862). W. W. Smith (1889) says that it is not rare in the Lake Brunner region, and Travers (1872) found it at Guyon.

In the North Island the species was never common excepting in the southern parts. Buller (1888) states that in his day it was abundant in the Wairarapa and Ruataniwha plains (Wellington District) and it seems to be common still in parts of that province (Handly, Trans. and North Proc. New Zealand Inst., vol. 28, p. 365, 1896) as in the Maruia Forest (Fulton, ibid., Island vol. 40, p. 499, 1908). Buller (1888) fixes its northern limit on the east side, as the Petane District, $39^{\circ}$ south latitude, but according to Layard (Ibis, ser. 1, vol. 5, p. 245, 1863) it was common there about Napier. On the west coast of the North Island, it is very rare, a few having been met with near the mouth of the Ohau, and specimens having been taken on the Wanganui race-course. The most northern records are those for Lakes Taupo and Rotomahana, and the unusual record for the Kaipara region, north of Auckland (Buller, 1888). Hutton (Ibis, ser. 2, vol. 6, p. 398, 1870), however, states that it is occasionally seen in the southern parts of the Auckland District.

\section{GENERAL HABITS}

Hadnts. This species is closely related to the Ruddy Sheldrake, which it resembles in its habits. It is essentially a fresh-water species, and "delights to live in the open country, near broad river beds composed of shingle and sand, or on grassy flats near 
lakes or pools of clear water" (W. W. Smith, 1889). There is an instance of a pair having stayed in one locality for one or even two years (Henry, fide Buller, 1905), though ordinarily the birds seem to flock together after the breeding season and resort to river-mouths or salt-marshes near the coast (Buller, 1888). The periodical flooding of the rivers seems to compel them to seek new feeding grounds, and short migrations result, such as that described for the Lake Brunner District (W. W. Smith, 1889).

Wariness. Like all other Sheldrakes, the Paradise Duck is not only extremely wary, but very intelligent, taking advantage of protection when offered it and knowing how to guard against surprise in places where persecuted. Like its relatives, it is in the habit of posting a sentinel while feeding (Buller, 1888; Green, High Alps of New Zealand, p. 157, 1883). During the seasonal moult it is exceptionally wary, assembling near broad sheets of water, and making for the middle of the lake at the least sign of danger (Travers, 1872).

GaIT. In its gait, the Paradise Duck also resembles its relative, the Ruddy Sheldrake. Its walk is "distinguished and elegant, no other duck excelling it in this respect" (Rogeron, 1903).

Swimming and Diving. These birds dive when young, but when adult, only if wounded or in full moult. Even at such times they are said to be indifferent divers, using their wings to propel themselves under water (Buller, 1888; Travers, 1872). In swimming, the stern is carried high, as in other Sheldrakes. The species seems to be quite at home on the mountain torrents of the New Zealand Alps.

Furght. The pairs remain together for at least most of the year, but Buller (1888) states that in the winter a partial separation of the sexes takes place, for he not infrequently saw companies of ten or more drakes with one duck, or vice versa. Large flocks are not seen, but groups of six or seven are not uncommon. When about to rise, the members of this species execute the same head-wagging movements that are characteristic of the Egyptian Goose (Heinroth, 1911). They move their heads up and down, not sideways as in the Ruddy Sheldrake, acting in this respect like the Australian species.

Association with other Species. The mere fact that there are no records of any association of these birds with other species indicates that their quarrelsome and intolerant disposition makes it impossible for them to live peacefully with other birds. 


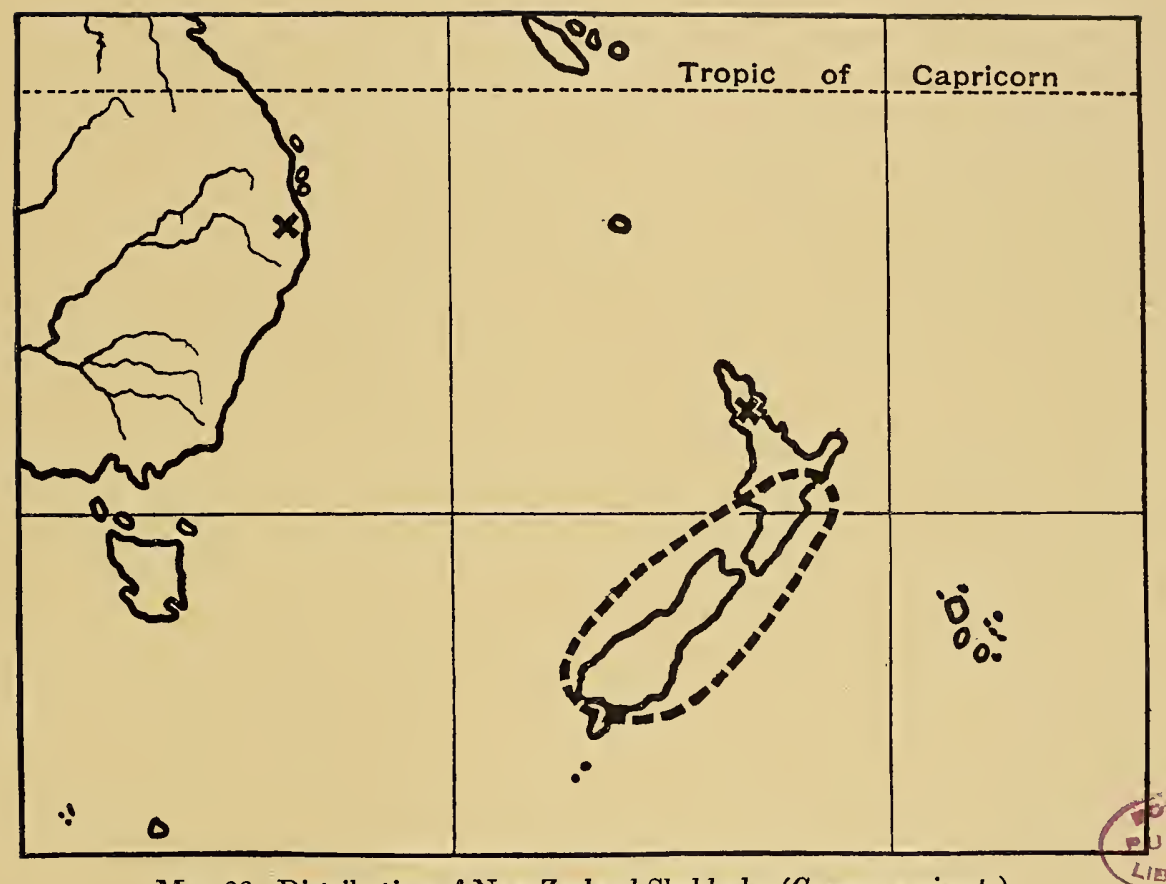

MaP 26. Distribution of New Zealand Sheldrake (Casarca variegata) Sporadic records indicated by a cross $(X)$ 

Vorce. The note is widely different from that of the Ruddy Sheldrake, and is even more dissimilar in the two sexes than in the case of the latter species. The male's voice is low and grunting, which may be due to the existence of a modification in the trachea. The plumage of the two sexes is so highly differentiated that a large tracheal bulb may be looked for in the male. Unfortunately there is no available information on this point. Buller (1888) speaks of the male's note as a prolonged guttural utterance, represented by the syllables tuk-o-o-o, with head bent down. The call-note, according to Heinroth (1911), is a nasal $s n$, which though not loud, is audible during flight, for as great, or greater distance than the call of the Ruddy Sheldrake. The call of the male when provoked has been described as a hiss, like that of the gander (Buller, 1905), or as a deep nasal sruck (Heinroth, 1911).

The notes of the female have in general a complaining sound. When excited she utters a very long, nasal, complaining $j a$, repeated to the point of irritation. The call-note is very similar, and when uttered loudly sounds more snappy, like cha. In addition there is a complicated note employed by the female when hounding the male against an opponent. This and other modifications of the voice in both sexes have been admirably described by Heinroth (1911).

Foon. The diet is probably more vegetable than animal, at least during certain seasons of the year, but no information is available beyond the remarks of Travers (1872) and Buller (1888) that it feeds on grass and herbage, rather than on fish or other animal food. The young are said to eat only a little grass and to depend on animal food such as mysis, sand-hoppers, shrimps and other animals which they pick up at low tide on the shore (Henry, Emu, vol. 6, p. 171, 1907).

Courtship and Nesting. The nesting season, as is usual in south temperate regions, varies more widely than in the north, where the seasons are more sharply defined. According to Travers (1872) the Paradise Ducks breed from October to January, but there is at least one record of earlier breeding, namely, the last week in September (Henry, Emu, vol. 6, p. 171, 1907). The former writer mentions having seen two broods of different ages with the same parents, but $I$ think it hardly likely that this is at all a common occurrence. The display is apparently like that of the Ruddy Sheldrake, consisting of the dipping movements characteristic of the geese. The postlude also resembles that of the latter.

It is an interesting fact that the female is very forward, very active and very amatory, while the male assumes a rather passive rôle. Taken in connection with the fact that the young resemble the male, and that the female plumage is so different and perhaps the result of more recent specialization, the relation of the sexes would well repay further investigation. The mating takes place on land, or occasionally in shallow water (Heinroth, 1911). All Sheldrakes are prodigious fighters, at 
least during the breeding season, but this species leads them all in strength and combativeness. All aviculturalists have dilated on this characteristic. Here again the female takes the initiative, egging her mate on with loud calls and excited movements.

The nest is probably always in a covered situation, though Buller (1888), in contrast to most observers, says the nest is generally placed among reeds and tussocks near the water's edge. This seems very unlikely for a bird of this genus, especially as there is ample evidence from other writers that they nest on cliffs or in holes of trees. One described by Potts (1870) was fifteen feet from the ground in a black birch. Others were in the shelter of huge tussocks or in holes in rocks (Potts, 1870). Harvie-Brown (Ibis, ser. 3, vol. 4, p. 96, 1874) speaks of a nearly inaccessible nest in a horizontal fissure, fifty feet from the ground and fifty miles inland on the Waiko River. Buller (1888) himself found one breeding in a cavern in the face of a sandstone cliff overhanging a river.

Clutches have been described as containing five, eight, nine, and even eleven eggs, but the average seems to be seven or eight. A brood of thirteen young mentioned by Buller (1905) may easily have been the work of two females, or the association of two broods after hatching. The eggs are yellowish cream-color, measuring 65 by $47 \mathrm{~mm}$. The incubation period is thirty to thirty-one days. A not very viable clutch hatched under a hen in thirty days (Rogeron, Bull. Soc. d'Acclimat. Paris, ser. 4, vol. 2, p. 151, 1885). Instances of the supposed carrying of the young by the female are given by Buller (1888).

A minute account of the behavior of a partially tame pair on the seacoast during the laying period is given by Henry (Emu, vol. 6, p. 171, 1907), a brief résumé of which must suffice here. On September 20 the female began examining holes in banks and old stumps. About a week later she was missed, and the first egg was probably deposited at that time. During her absence the male called continually for her. He stayed close to the spot where he was fed, and would meet the female when he heard her coming from the nesting place. The pair had a joyous greeting in the cove, and the male would then conduct his mate to the food-box, standing by without eating a grain, until she had finished her meal. On each day she stayed away a little longer and the male continued to guard the food, chasing away Teal, Cormorants, Gulls and Wood-hens (Giant Rails). Henry was sure the female was nesting in a hole, as her white head was soiled with earth. About thirty-one days after the female started to sit she called in a great hurry and took the male away with her. Nothing was seen of them the two following days, which were stormy and wet. Then the pair reappeared with four newly hatched young, which the male guarded with extreme solicitude, for the notorious Wood-hens were ever ready to snatch the young. They spent that night on the open beach, apparently afraid to enter the scrub, though the weather was cold and stormy. The next morning the pair mustered up sufficient courage to bring the young to the observer's yard. The 
young would take only a little grass besides the wild food which they picked up on the shore. They would not eat wheat until they were two weeks old. One day Mr. Henry saw the male bird killing a Blue Penguin on the beach. During all this period the young were exposed to constant danger from all sorts of predaceous birds, particularly Skua Gulls, but only one of them disappeared.

Other writers have enlarged on the affection shown by the parents for their young, and the complex devices employed by them to distract the attention of intruders, both men and beasts, from their brood. One remarkable instance of the persistence of parental instinct is quoted by Buller (1905). A Mr. Shalders captured three young and placed them in a box on his wagon, taking them six miles to his camp. Next morning not far from his wagon he was surprised to see both parents, and on releasing the young they were immediately taken in charge by the drake, who led them back toward the river.

Another pair was surprised with ten young, and immediately took to a near-by mountain torrent and sailed diagonally across, beak to tail, the young resting safe against their parents on the upstream side.

In the Emu for 1913 (vol. 13, p. 215) there is quoted a newspaper article by Mr. James Drummond which is of great interest. The nests here described were in rabbitburrows, and both the duck and the drake assisted in incubation. The burrows were not deep, and the observer could see the birds from outside. He continues, quoting a Mr. Murdock, who says, "The drake takes his turn at sitting on the eggs. It is a solemn business with him. Perhaps it is his coloring that makes him so serious, so different from the gay and light-hearted duck. But for all that I do not think he is trusted to turn the eggs, the duck attends to that work."

Status. The Paradise Duck is rapidly becoming a rare bird. Its disappearance in the Nelson District was generally attributed to the laying of poisoned wheat to eradicate rabbits, but Buller (1905) is inclined to ascribe it to ravages of introduced stoats and weasels. The same thing is true of the Marlboro District, where it is now counted by tens and twenties, where formerly the Maoris would capture them in great numbers (Buller, 1905). Handly (Trans. and Proc. New Zealand Inst., vol. 27, p. 365, 1896), writing of the Wellington District, says that the Warian lagoons used to be alive with them, and that they were slaughtered by thousands for the Wellington market. This continued till the Governor was persuaded to proclaim a protected area. In the Maruia they were reported still to exist in immense numbers as late as 1907 (Fulton, Trans. and Proc. New Zealand Inst., vol. 40, p. 499, 1908). The bird was certainly very plentiful when Lieut.-Col. Montagu Cradock wrote his book Sport in New Zealand (1904) but he tells of the great persecution which was then taking place and the numbers which were killed by phosphorized oats intended for killing rabbits. 
ENEmiEs. Some of the enemies of the young birds have already been mentioned, and the various exotic animals which have been introduced with mistaken intention are certainly having a disastrous effect on this, as well as on other native New Zealand birds.

DAMAGE. The birds are said to have been destructive to young pasture (Travers, 1872), but it is very doubtful if they exist in large enough numbers to do any damage now.

FOOD VALUE. Young birds are said to be good eating, but the old individuals have a "degree of toughness which only the sharpest appetite can overcome" (Potts, 1870).

HoNT. In earlier times these birds were slaughtered in thousands, as mentioned above, and the Maoris used to take thousands in the flapper stage, or during the moult. Buller (1905) also tells how thin flax rope with running loops was suspended across the narrow part of Lake Papaitonga, into which flocks of ducks were driven during the gloom of evening. Lieut.-Col. Cradock (1904) speaks of a bag of seventy-eight taken in one day by shooting from bush shelters on Lake Teanau. They were also shot successfully over decoys in oat stubble, and he gives a long account of this form of sport. It is indeed a sad thing to see so fine a species in danger of eradication without even the excuse of well-flavored flesh.

Habits in Confinement. ' Much has been written about this wonderful bird, whose very name is poetical enough to ensure an active demand for live specimens. It has been very rarely imported into America, and did not reach the London Gardens until 1863 (P. L. Sclater, 1880), where it bred in 1865 and for many years following. The female of the first pair laid five eggs, all of which were hatched (Sclater, 1866). They were breeding in the Berlin Gardens in 1914 (Journ. f. Ornith., vol. 63, p. 302, 1915) and a brood of seven males was reared. They were bred by Mr. T. A. Havermeyer at Mahwah, New Jersey, not many years ago.

These birds have always been expensive, and at the time they were first introduced into England cost as much as $£ 20$ a pair. Later on they were bred freely on the continent, and the price fell to $£ 6$ or $£ 8$ per pair.

They are easily tamed, and are hardy under conditions of restraint, but like all other Sheldrakes become very destructive during the mating season to any birds that they imagine might be rivals. Thus they have been known to kill six gulls in the Jardin des Plantes in one morning (Rogeron, 1903), and the same writer relates how they worsted his Red Sheldrakes and a Bewick's Swan. A pair which Miss I. D. Smith tells about in the Avicultural Magazine (ser. 3, vol. 2, p. 157, 1911) kept 
all others, Sheldrakes, White-fronted, Barnacle, Chinese and Magellanic Geese in "great order." Hubbard's pair attacked and almost succeeded in drowning a fullgrown Canada Goose, both male and female jumping on his back and forcing him under water. Curiously enough, they are usually quite harmless among Teal and smaller ducks, and treat them with utter indifference and disdain.

In their native island they are said to be easily reared and tamed, and they stay about the poultry-yard until the following spring, when they fly away, unless pinioned (Potts, 1870).

Any one who is particularly interested in the psychology of the sexes in this species should refer to the long and detailed account which that veteran aviculturalist Rogeron has left us (Bull. Soc. d'Acclimat., Paris, ser. 4, vol. 2, p. 151-173, 1885). It is impossible to much more than mention it here. The first pair which he obtained never mated. They were kept at night in a small house with thirty small ducks and never did them any harm. They made intimate friends with a Bewick's Swan, following this unfortunate bird around all the time. During the second spring the female devoted all her attention to the swan and tried in every way to induce him to mate. This behavior finally aroused the male, who became furious and worried and chased the swan continually, though he did not actually fight with him. This little incident is interesting as showing the roundabout methods employed by the female to arouse the jealousy of the male, but in this case it did not result in any actual mating of the pair. The next pair that Rogeron obtained was tame and easily handled, like the first. The two birds were not quarrelsome excepting toward such as were regarded as rivals. When spring came they began to fight with a pair of Ruddy Sheldrakes, who were utterly powerless against them. Several times Rogeron saved the lives of the Ruddy Sheldrakes in the nick of time. The female of this second pair laid the first egg on March 24 in a thicket of a hedge under an earthen dish. She laid two more eggs there, a fourth in a different place and then four more in the original nest. These eggs were set under hens, but only one egg which hatched in twenty-nine days produced a viable duckling. This single young one was raised almost entirely on bread crumbled into milk, water lentils and a little corn. It did not care for worms or ant larvæ, and the taste for milk continued until the bird was almost full grown. After the pairing season the Paradise Ducks lived in perfect harmony with the Ruddy Sheldrakes.

A remarkable example of the homing instinct, and comparable to the sort of thing that is sometimes seen in dogs, was quoted by Buller. A tame, pinioned bird was kept at a certain farm. After a time its mistress moved away and carried the bird with her in a basket. The journey was ninety-five miles by rail and about ten more by coach. By and by the duck disappeared from its new home and was looked upon as lost. Some time later its mistress returned to her old home and found to her astonishment that the pet Sheldrake had returned before her and settled down in its 
old home. It was thought that this bird had actually walked across country a distance of one hundred and twenty miles!

This species does not seem to have been bred on the Continent before 1875, at which time M. Courtois had exceptional success with two pairs. From the first pair he obtained in two years forty-six eggs, and from them was able to rear thirty young. From the second pair he raised twenty-eight young in two years (Courtois, Bull. Soc. d'Acclimat., Paris, ser. 3, vol. 7, p. 169, 1880). It was afterward related that this gentleman, who invested 400 francs in his original stock, received 5,470 francs for the young between 1876 and 1884. In the Paris Gardens the species first bred in 1882.

Like its relatives of the Sheldrake group, the Paradise Ducks live long in confinement. In 1883 the London Gardens apparently had a pair which had been received in 1863, but according to Mitchell (1911) forty-one specimens averaged forty-seven months each, the maximum being one hundred and seventy-two months.

No hybrids have been described in the wild state, but in confinement it has mated with the Ruddy Sheldrake and the Ashy-headed Goose (Chloëphaga poliocephala), as recorded by Heinroth (1911). 


\section{AUSTRALIAN SHELDRAKE \\ CASARCA TADORNOIDES (JaRDINE ANd Selby)}

(Plate 18)

\section{SYNONYMY}

Anas tadornoides Jardine and Selby, Illustrations of Ornith., vol, 2, pl. 62, 1828.

Casarca tadornoides Gould, Birds of Australia, vol. 7, pl. 7, 1844.

Tadorna tadornoides Hartlaub, Syst. Verz. Ges. Mus., p. 118, 1844.

Tadorna tadornoides westralis Mathews, Austral Avian Record, vol. 1, p. 118, 1912.

\section{Vernacular Names}

English:

Mountain Duck

Chestnut-collared Sheldrake

Australian Sheldrake

French:

Casarka d'Australie

\section{German:}

Australische Brandente or Kasarka

Schwarzrote Kasarka

Zimmetgans

Aborigines of Australia:

Goo-ra-ga

Gnarcoondull

Perna

\section{DESCRIPTION}

AdUlt MaLE: Head and upper neck black with metallic reflections; around the lower neck a broad white collar. This separates a broad fox-red belt, comprising the mantle and breast. Back, scapulars and rest of lower parts black, finely vermiculated with brown dots and lines. Wing like that of Casarca variegata; lower back, rump and tail black. Under tail-coverts black.

Bill black; legs and feet grayish brown to black. Iris brown.

Wing 373-380 mm.; bill 41-48; tarsus 56-64.

Adult Female: Similar but duller and smaller according to Mathews (1914-15). The feathers encircling the base of the bill are white and there is also a white ring around the eye, which broadens out posteriorly. The white collar is narrower and the chestnut is not so uniform in color. Abdomen brown instead of black.

Immature Male: Differs from female in having less white at base of bill and around the eye, the head brown instead of black and the chestnut collar much paler. Abdomen much paler (Mathews).

Immature Female: Differs from adult female in having the crown of the head more freckled with brown.

Young IN Down (specimens at Tring Museum): Apparently the same as the young of the New Zealand Sheldrake, except for being somewhat lighter colored on the occiput, which may not be constant. The pattern is the same as in other members of this group. 
REMARKS on ModLT: In this species also there is good evidence of a double moult, which probably occurs in all species of this genus, but the eclipse or summer dress is so little different from the breeding dress that it has largely escaped notice. Fortunately Mr. Blaauw (Ibis, ser. 6, vol. 6, p. 317, 1894) has made very full observations on captive specimens, which I extract at length.

"In May the first moult takes place of all feathers, primaries and tail-feathers included. The rich shining chestnut feathers of the breast are then replaced by dull yellowish-brown feathers, and the white neck-collar is replaced by another collar, also white, but not so clearly defined, and not nearly so pure in colour. This is the winter dress. At the end of August generally, the second moult (of the small feathers only) begins and produces the breeding dress. The dull yellowish breast-feathers are then shed and replaced by the bright chestnut-coloured ones, whilst the shiny white neck-collar is also regained. These bright feathers also seem to have a different structure from those of the winter dress, being much more silky and hairy in appearance.

“... ducks of the genus Tadorna are generally supposed to moult only once a year ... [but] $\mathrm{I}$ have had my pair now for three years, and the double moult ... has occurred quite regularly each year."

\section{DISTRIBUTION}

THE Mountain Duck belongs to the southern half of Australia and to Tasmania. The northernmost record seems to be that for the Fitzroy River, in northwestern Australia, where Keartland (North, 1898) saw a few. In the southern parts of Wést Australia the species is tolerably plentiful and is genWest erally distributed throughout the western, central and southwestern divisions (OgilvieAustralia Grant, 1910), having been recorded for Lake Way (North, 1898), Lake Violet and for East Murchison (Whitlock, Emu, vol. 9, p. 190, 1910), Wongan Hills (Milligan, Emu, vol. 4, p. 11, 1904), Moora (Orton and Sandland, 1913), Cumminin Station (Crossman, Emu, vol. 9, p. 86, 1909), and Cape Mentelle, on the southwest coast (Milligan, Emu, vol. 2, p. 76, 1902). Mathews (191415) quotes Carter who states that he saw these birds in thousands and that he found them breeding on Lake Muir, and in a recent article Carter and Mathews (1920) make similar statements, recording the species also for a lake one hundred and forty miles east of Perth, where large flocks were seen. (See also W. B. Alexander, Emu, vol. 20, p. 160, 1921.)

In South Australia the Mountain Duck was seen on the Palmer River (North, 1898), but its chief center of distribution is southeastern South Australia and western Victoria. It has been found South at Kellidie Bay, Eyre Peninsula (R. Hall, 1910), but most records are for the region east Australia of Spencer's Gulf and along the lower Murray River. Eylmann (1911) says it occurs in large flocks in this region. White (1914) has recorded it for the Dalhousie region. It is said to be very rare at Balah, but fairly common in Burra (Sandland, fide Mathews, 1914-15), while it breeds about Gawler (Gould, 1865). About the mouth of the Murray River, on Lakes Albert and Alexandrina, it is a fairly common breeder (Mellor, fide Mathews, 1914-15). White (fide Mathews, 1914-15) found it in enormous numbers on Lake Albert.

The species is perhaps commonest in western Victoria. The correspondents of North (1913) and Victoria Mathews (1914-15) give ample proof of this, and it would be useless to quote all available records for this region. Suffice it to say that it has been found breeding at Hamilton

(Macgillivray, fide North, 1913), Ararat (Hill, Emu, vol. 7, p. 23, 1907), Lake Boga (A. C. Stone, 1912), Caramut (Mann, fide North, 1913), Winchelsea (Austin, fide North, 1913), and South Gippsland (ibid.).

Tasmania In Tasmania the Mountain Duck appears to be generally distributed but not common. It has been found breeding on the Macquarie River (Brent, fide North, 1913).

So far as known this duck has never been taken in the northern parts of New South Wales. Ramsay (1876a) says they were for sale in the Sydney market in his day. These specimens probably came from Lakes George and Bathurst, the species being confined to the southeast part of this State (North, 1913). 


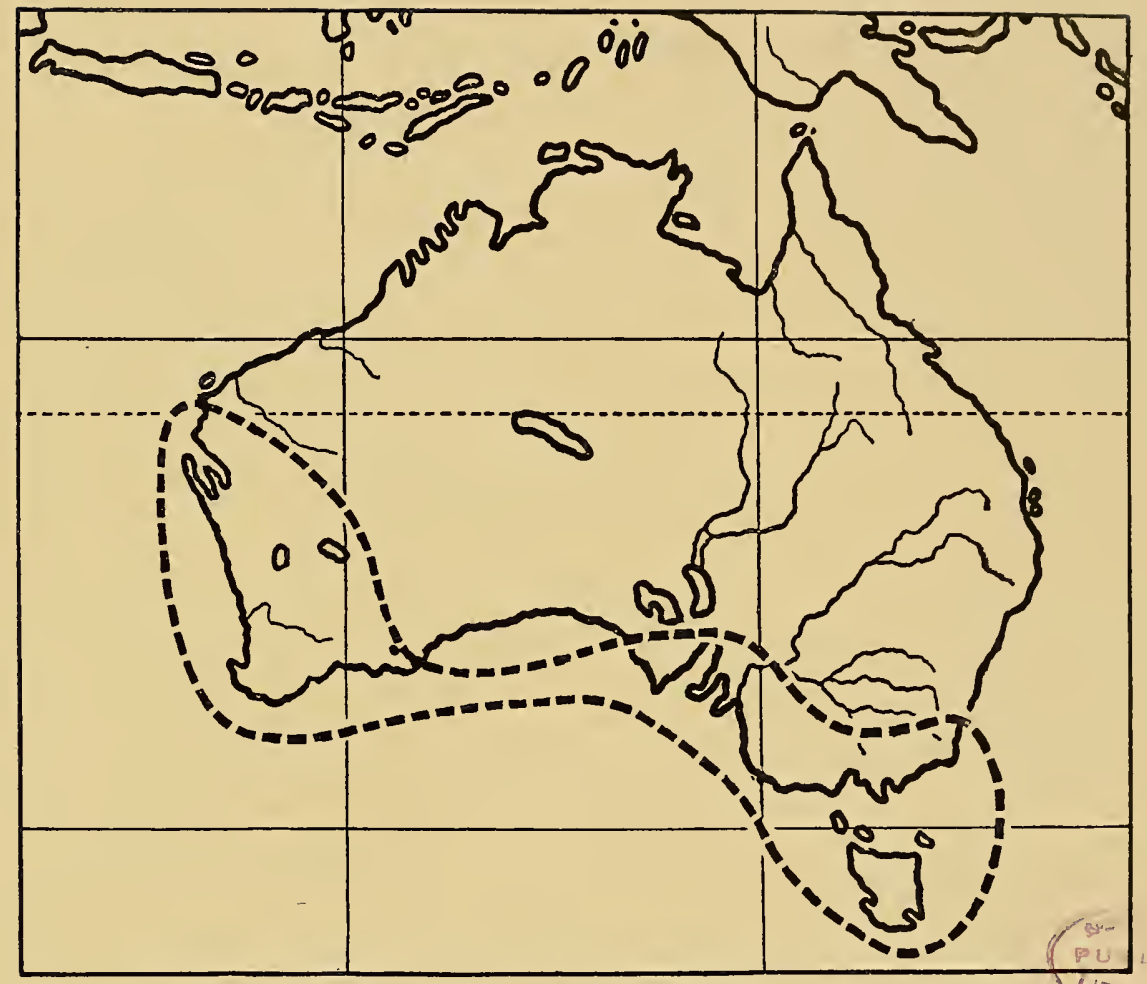

MaP 27. Distribution of Australian Sheldrake (Casarca tadornoides) 



\section{GENERAL HABITS}

Haunts. The Mountain Duck seems to be especially fond of salt lakes. Thus they are rare on Lake Muir when it is high and fresh, while when it is low and salty they abound there (Carter and Mathews, 1920). In Victoria they are to be seen on the brackish and salt lakes throughout the year (Austin, fide North, 1913). During the breeding season they in part shift their habitat to more inland and more elevated districts. Few writers have made remarks as to their status on tidal waters, but Gould (1865) speaks of their frequenting heads of bays and inlets of the sea in Tasmania, and we must conclude that they do so, at least during certain seasons of the year. According to Austin (North, 1913) it is a most unusual thing to see them on fresh water.

WARINess. Like all Sheldrakes this species is exceedingly wild, and has been described by one observer as the wildest of Australian ducks (Austin, fide North, 1913). Macgillivray (North, 1913) says that, unlike most ducks, they will leave a swamp or lagoon at the very first shot, and will not return again. Like their relatives they appear to post sentinels when feeding (White, Emu, vol. 12, p. 183, 1913).

Darly Movements. Mellor (Mathews, 1914-15) speaks of them as being constantly on the watch night and day, being nocturnal as much as diurnal; and one wonders when they take their rest.

Gart, Swrmming, Drving, and Perching. In these points the present species, so far as I know, does not differ from other Sheldrakes.

FuIGHT. In alighting the Mountain Duck has been described as making violent rocking movements, during which the points of the wings describe ares of ninety degrees (Eylmann, 1914). To my knowledge this habit has not been remarked in other species of the Sheldrake group, but it is not unlikely that it occurs in the Sheldrakes for it is not uncommon in the duck family. Before rising, this species jerks the head up and down, not sideways, as in the Ruddy Sheldrake (Heinroth, 1911).

They go about in pairs during most of the year. Nevertheless enormous flocks have been noticed after the breeding season in various parts of Australia. On Lake Albert, Captain White approached within thirty yards of a flock which he estimated to contain between three and four thousand birds (Mathews, 1914-15). The congregations are naturally made up of family parties. Carter (Mathews, 1914-15) also noted them in thousands on Lake Muir in April and December.

Association wrth other Species. Association with other birds is probably 
purely accidental. On Lake Albert they were seen feeding in the company of various kinds of ducks as well as Pelicans, Spoonbills, Cranes, etc. (White, fide Mathews, 1914-15).

Vorce. The call-note has been described as a deep honck or chank, uttered twice, and resembling the call of a goose; there is a second note often uttered by the male while on the ground, sounding like the syllables chick-hunke or chickooke, the o's being sounded softly and the note being made with outstretched neck, and with the head near the ground (Mellor, fide Mathews, 1914-15; W. H. D. Le Souef, 1907). The notes of the sexes are very different, the female uttering loud gooselike cries while the male has a low short grunting note. Heinroth (1911) describes the male's note as resembling closely that of the Paradise Duck, but as even more grunting and without the characteristic $s$ sound. The female's voice he describes as less striking than that of the female Paradise Duck.

Food. No detailed analyses have been made of the stomach-contents in this species, but it feeds on both animal and vegetable matter. Hall (Emu, vol. 9, p. 79, 1909) found them feeding on short mossy grasses, and White (Mathews, 1914-15) saw them eating weeds in the shallows of Lake Albert. Christian (Mathews, 191415) adds an interesting note as to their service in the counteracting of the caterpillar pest, and says that one year (1907), when grasshoppers were bad, they were out on the plains "eating them as fast as they could." Gould (1865) describes their diet as consisting of small fish, crustaceans and mollusks, which abound in the flats and swampy places.

Courtship and Nesting. This species seems to be by far the earliest of the Australian ducks to breed, its eggs being obtainable in July and August. In southeastern Australia and in Tasmania, July to October are the months constituting the regular breeding season (North, 1913).

The only remarks on the courtship of the Mountain Duck are contained in Heinroth's (1911) long article on the psychology of the Anatido. The display may consist of a submerging act characteristic of the Common Sheldrake and described under that species. But this is not the rule. The mating prelude is more often a mere bowing of the head and neck. After pairing the male usually held his closed wings over his back.

The usual nesting site is undoubtedly in decayed portions of large trees, but open marsh land has been mentioned (Hood, fide North, 1913). Rabbit-burrows have been spoken of as occasional resorts (Mellor, fide Mathews, 1914-15; Sandland, fide Mathews, 1914-15). Ramsay ( fide North, 1913) speaks of a nest on the ground beneath a mass of Polygonum bushes. When placed in a tree-trunk the nest is some- 
times as much as six feet below the entrance (Carter, fide Mathews, 1914-15). The nest is lined with down, and may be composed of grass and débris, with a few sticks (Ramsay, fide North, 1913). A rather different nesting site is described by Mellor (Mathews, 1914-15). In the Lake Albert region, he says, they place the nest on the rising sandy soil, beneath the long overhanging spinelike leaves of the grass-tree (Xanthorrhoea) which reach right to the ground and so make a closed-in hollow.

The normal clutch numbers eight to fourteen eggs of a pale cream color, measuring 68 to 70 by 49 to $50 \mathrm{~mm}$. Much larger clutches have been reported (seventeen, nineteen, twenty-two), but these were undoubtedly the work of two females. The incubation period is probably about thirty days, as in other Sheldrakes. When hatched the young in most cases drop from the nest into the water, as described by Keartland (North, 1913), but observers have even described the male (!) as carrying them down in his bill, a procedure which certainly requires verification.

Status. Still seen in large flocks, and no reduction in numbers is noted in the literature. The intelligence of the bird, coupled with the fact that it is generally regarded as inedible, should serve to perpetuate it, unless the introduction of some noxious mammal or bird interfere with its existence.

\section{Enemies and Damage. No information.}

Food Value. Captain White (Mathews, 1914-15) regards the flesh as edible, and says he was glad to get it at times during his travels. Other observers invariably describe the flesh as coarse and unpalatable.

Hunt. Though seldom hunted for its flesh, the bird was, at least in earlier times, exposed for sale in the Sydney market (Ramsay, 1876a).

Behavior in Captrvity. The Mountain Duck has been bred in the Melbourne Gardens, so Mr. Le Souef writes me, but in Europe all attempts to breed it have thus far failed. Even Mr. Blaauw has not succeeded and he writes me that they want to breed during the winter when the cold prevents. The first were received in London in 1862 (Sclater, 1880). In 1902 a trapper arrived from Australia with about one hundred pairs. The first specimens sold for as high as $£ 40$ a pair, but the price gradually declined to forty shillings. The birds are not usually obtainable, and ordinarily bring from $£ 6$ to $£ 8$ a couple (Hubbard, 1907). I believe that they have never been exhibited in American Gardens.

Like other Sheldrakes this species does well in captivity. The average longevity of fifteen specimens in the London Gardens was fifty-two months, the maximum being one hundred and eighty-six months (Mitchell, 1911). As to their behavior there are 
very few notes, but from what Heinroth (1911) says, it is evident that in habits the Mountain Ducks do not differ radically from other members of the genus. The female, like the female of the Paradise Duck, is very excitable and quarrelsome. They pay little attention to smaller birds, but, especially during the breeding season, they become the bane of larger species. Heinroth tells of a female who repeatedly hounded her mate against a free-flying Nile Goose, which of course soon made off. At such times, being unable to reach the opponent, the enraged mates in their excitement would often transfer the attack to themselves, belaboring each other with their wings. The stronger male was, very naturally, the victor. This point of behavior is characteristic of the Paradise Ducks also.

The Australian Sheldrake has been crossed with the Ashy-headed Goose (Chloëphaga poliocephala) (Poll, 1921). 
<smiles>CCC</smiles> 


